\title{
SELF-IMPROVEMENT BOOKS: \\ A GENRE ANALYSIS
}

\author{
by \\ Koay Dong Liang
}

\begin{abstract}
A thesis
submitted to the Victoria University of Wellington in fulfilment of the requirements for the degree of Doctor of Philosophy in Applied Linguistics
\end{abstract}

Victoria University of Wellington 
To the memory of my late grandmother, Lim Chai Siew, for your sacrificial love To my mother, Tan Yeap Wah, who taught me how to hold a pencil And to my sister, Ruby Koay, for all the wonderful childhood memories 


\section{Abstract}

The aim of the thesis is to explore the characteristics of self-improvement books as a genre. Although self-improvement books are a widely read genre, particularly in the Western world, none to my knowledge has examined the linguistic features of this genre in detail.

The thesis draws on the three main schools of genre theory: English for Specific Purposes, Systemic Functional Linguistics, and the New Rhetoric, and begins by investigating the sections (e.g., acknowledgement, introduction chapter) in selfimprovement books and the typicality of the sections. Focusing on three sections: introduction chapters, body chapters, and about the author sections, the thesis examines how authors structure the sections by analysing the moves and steps. This study also examines the stories in self-improvement books by analysing the purpose of the stories and their structure. Stories were chosen because they seemed to be a feature of selfimprovement books based on my observation and as suggested by interview data. To analyse self-improvement books at a register level, the thesis examines the most unambiguous aspects of engagement: personal pronouns focusing on you, imperative clauses, and questions. It also examines the lexicogrammatical features of selfimprovement book titles and compares them to the titles of historical biographies, showing that imperative clauses and ing-clause are found only in self-improvement book titles. Drawing on interview data and literature on the American Dream, American individualism, Neoliberalism, and New Age beliefs, the thesis explains how the linguistic characteristics of the genre of self-improvement books reflect these ideologies.

The dataset for the study is 40 self-improvement books, selected on the basis of a set of criteria that I developed. Subsets were selected from the main dataset for specific analyses. The text analysis part of the study is supplemented by interview data from specialist informants, who come from three categories: readers of the genre, non-readers of the genre, and authors of the genre.

Move analysis identifies obligatory rhetorical moves and indicates that the main purposes of introduction chapters and about the author sections are persuading readers to read the book, and establishing credibility, respectively. Authors always persuade readers to read their books by listing reasons to read them. To demonstrate authors' credibility, they refer 
to their areas of expertise. Unlike the introduction chapters and about the author sections, the body chapters have more than one obligatory rhetorical move. The body chapters present the problem that readers potentially experience, present the authors' message, recommend practical applications, and encourage readers to apply them. From a genre perspective, the purpose of all the stories in my analysis is to illustrate the authors' message.

Register analysis, and drawing on interview data, suggests that authors use the personal pronoun you, imperative clauses, and questions to engage readers. The abundance of the personal pronoun you suggests that self-improvement books are a reader-oriented genre. The analysis of the imperative clauses using Halliday's process types suggests that the main way to improve our lives, the authors recommend, is to change how we think.

Finally, my thesis shows that the social purpose of self-improvement books is to help potential readers improve their lives, and the approach of improving one's life has an individualistic orientation. 


\title{
Acknowledgements
}

\author{
"Whenever I am afraid, I will trust in You." \\ Psalm 56:3 NKJV
}

Firstly, I would like to thank the Lord for His faithfulness and providence in this $\mathrm{PhD}$ journey.

I am deeply grateful to have Dr Jean Parkinson and Dr Elaine Vine as my supervisors. I would like to thank them for the time they spent on reading and commenting on the drafts of this thesis, and the fortnightly meetings we had for the past three and a half years. They have taught me valuable lessons of life: the importance of reflection, the value of humility, and "this is not a perfect world." They reminded me that writing up the thesis is ideally not the "ultimate" goal of a $\mathrm{PhD}$, rather it is what I have learned in the process.

I would like to acknowledge my research participants for their time and insights. I would like to particularly thank the self-improvement authors in America who willingly participated in the Skype interview despite the time zone difference.

I would like to thank Victoria University of Wellington who generously funded my studies with the Victoria Doctoral Scholarship. I would also like to thank the School of Linguistics and Applied Language Studies for providing a supportive environment. My thanks go to Associate Professor Meredith Marra for bouncing ideas with me. Thanks to my officemate, Jay Woodhams, for the engaging discussions we had, both academic and non-academic, and for the weekly squash sessions at the court. I would like to thank Dr Kieran File for discussing the concept of genre with me at the initial stage of my study, and Dr Jackie Yeoh for encouraging me when I am doubtful of my ability. I would also like to thank Kirsten Reid from Student Learning for being a sounding board.

I would not have pursued this degree without the encouragement of my Master's research supervisor, Associate Professor Mohamad Hassan Zakaria. 
I would also like to acknowledge and thank my examiners - Professor John Swales, Dr Ian Bruce and Dr Keith Comer - for reading my thesis and providing insightful comments.

Thanks also to Nick Field for your prayers and friendship. I would especially thank a very special friend, Mark Moore, for being a father figure to me. I would also like to thank George and Irene Ross for being my New Zealand family, and to Jude Murdoch for taking interest in my study and providing an outsider's perspective. I would like to thank Rev. Allister Lane for accepting me as I am and praying for me when my world seems confusing. I would also like to thank my friends who were with me through the ups and downs of my PhD journey: Stephen Caughley, Benjamin Ching, David Jones, Pakjira Leelertphan, Douglas Meyer, Alvin Ngai, Alyssa Ong, Will Quinn, Allen Xu, and those whose names are not mentioned here.

I would like to thank my students, particularly my choir students in Malaysia, for enriching my life; to Tan Seoah Chee and Wan Nor Maizan Wan Ismail for being very supportive colleagues in Malaysia; and to Lee Ai Leng for supporting my decision to further my studies.

Finally, I would like to specially thank my mother, Tan Yeap Wah, for believing in my dreams and constantly praying for me; to my sister, Ruby Koay, for keeping me updated with mum's health; and Aunty Lian Choo for keeping mum company while I was away. I am grateful to my away-from-home family, Ooi Yew Chai, Loh Bee Gek, Ooi Shaw Yang, Ooi Lih Yang and Ooi Kaylene for their Facebook messages that kept me going. 


\section{Contents}

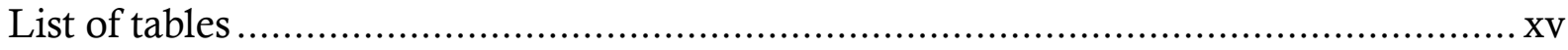

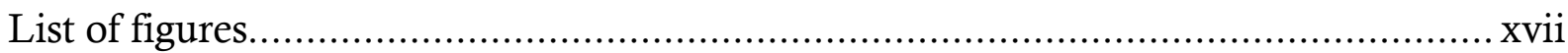

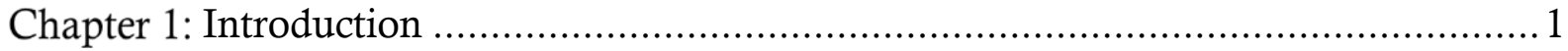

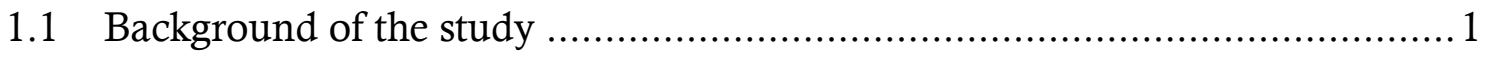

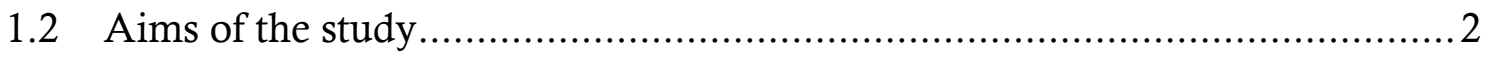

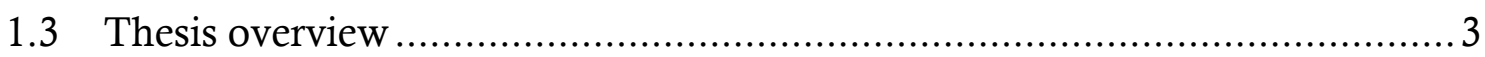

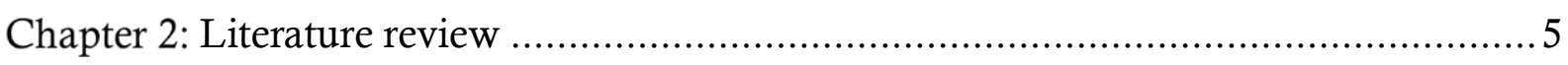

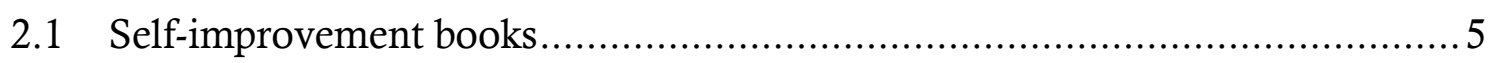

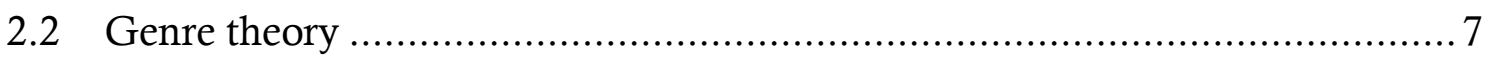

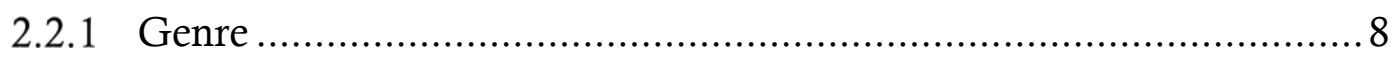

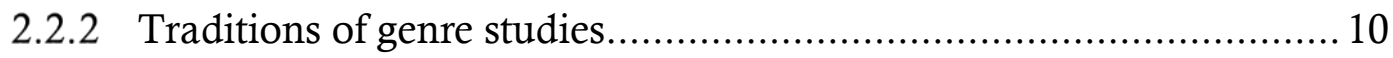

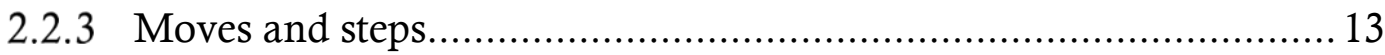

2.2.4 Obligatory, typical and optional moves.......................................... 16

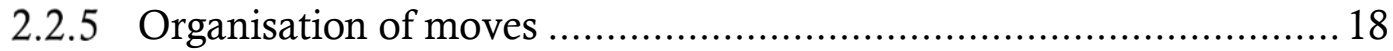

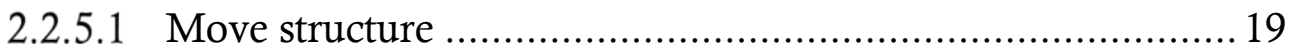

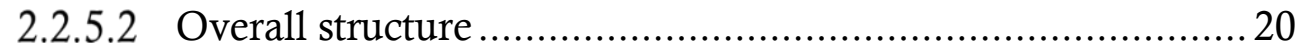

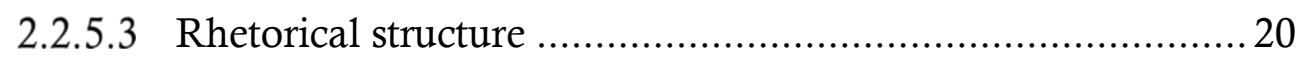

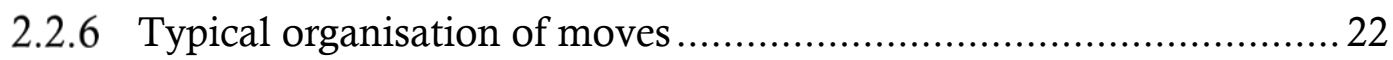

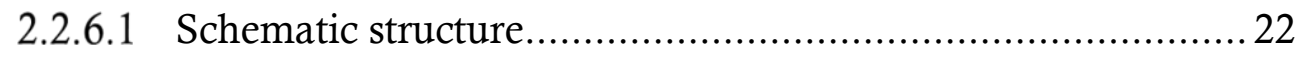

2.2.6.2 Distinctive structural pattern ............................................. 23

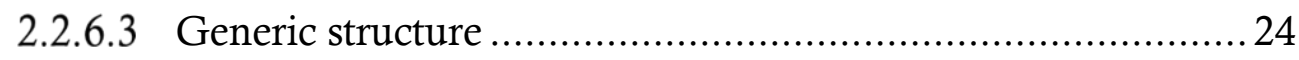

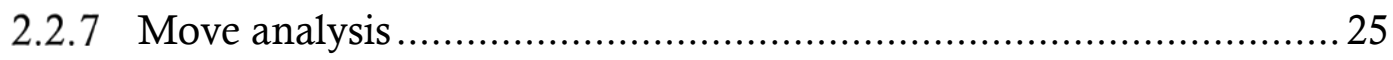

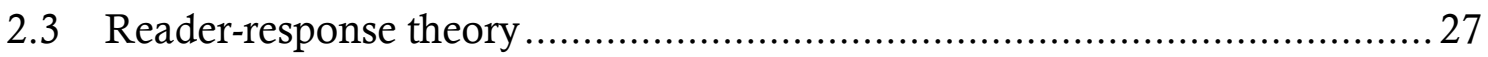

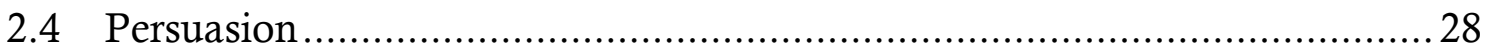




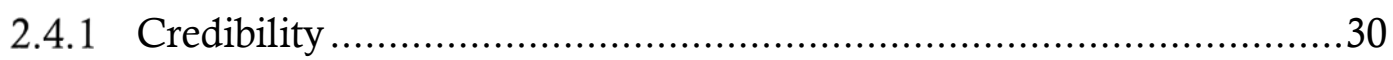

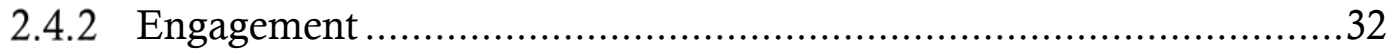

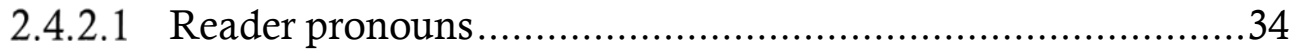

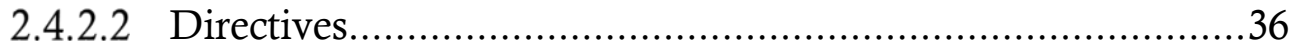

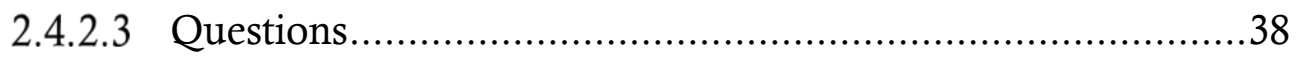

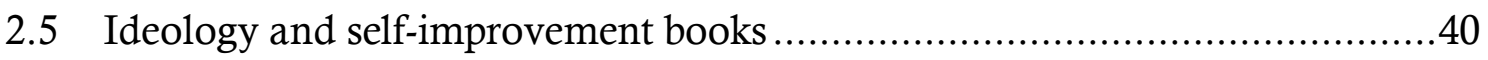

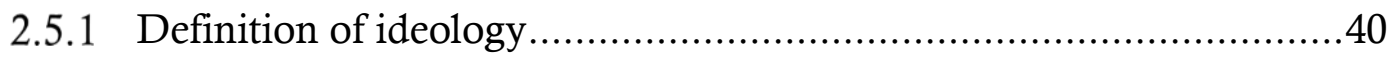

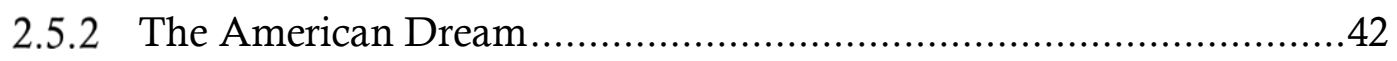

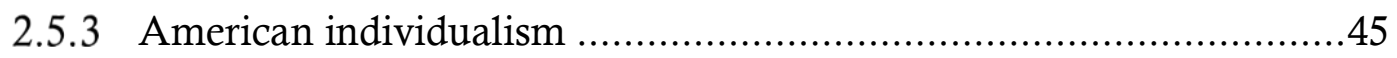

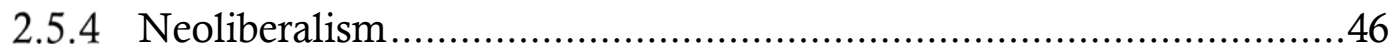

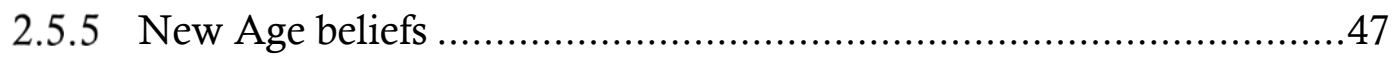

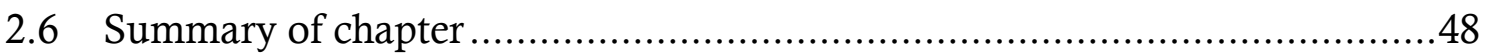

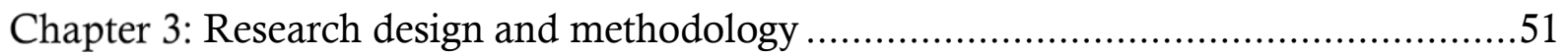

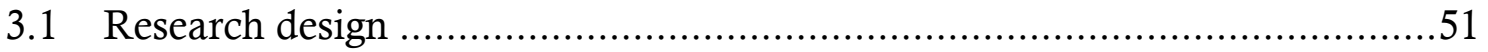

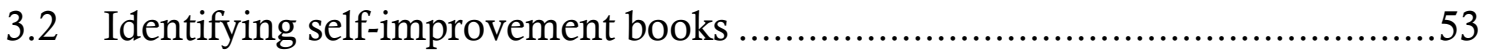

3.3 Analysing the sections in self-improvement books ....................................57

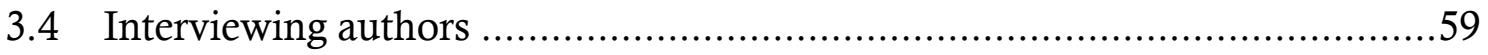

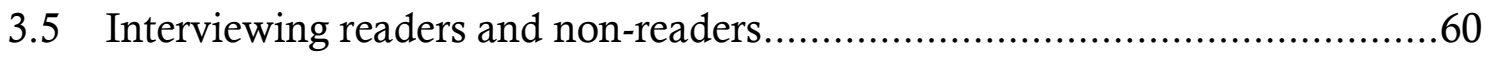

3.6 Ethical considerations and copyright issues ...............................................62

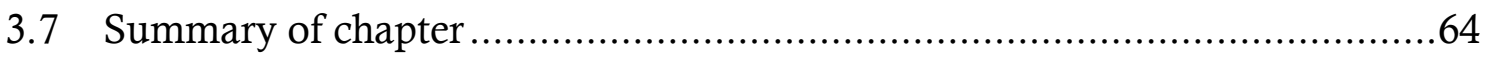

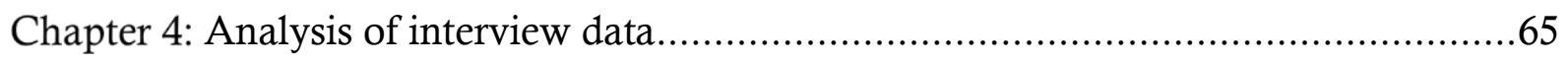

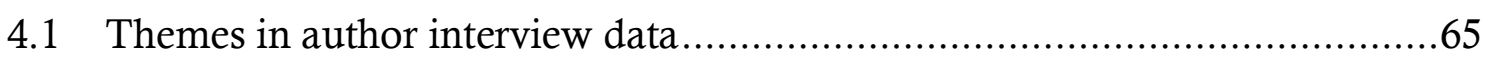

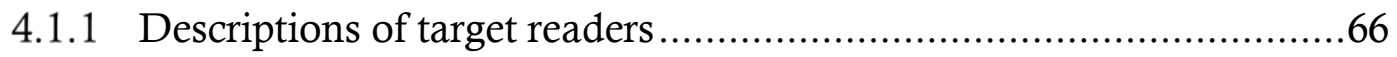

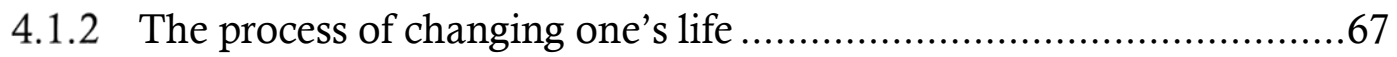

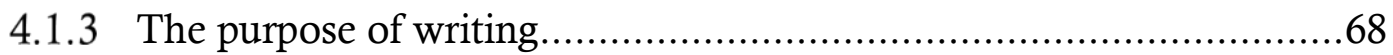

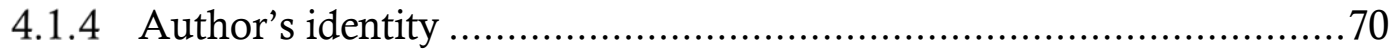

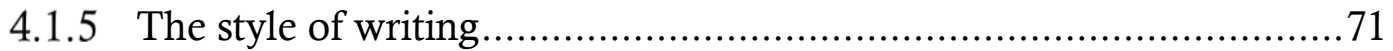


4.2 Themes in reader and non-reader interview data................................. 72

4.2.1 Common labelling of the genre ............................................... 72

4.2.2 Changing and improving reader's life ................................... 73

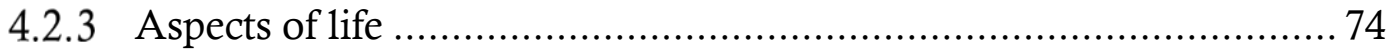

4.2.4 Repetitive character of the message..................................... 75

4.2.5 Individualistic approach ..................................................... 76

4.2.6 Accessible style of language ............................................... 76

4.2.7 How readers read self-improvement books ................................ 77

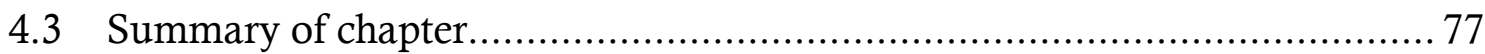

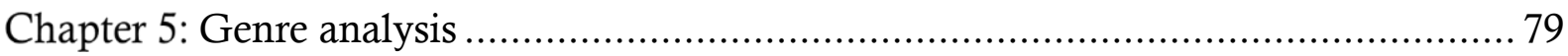

5.1 Sections in self-improvement books ............................................ 79

5.2 Moves in introduction chapters ..................................................... 100

5.3 Moves in body chapters ........................................................... 128

5.4 Moves in about the author section .............................................. 156

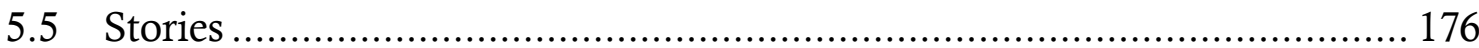

5.5.1 Stories and storytelling ................................................ 176

5.5.1.1 Recount................................................................. 179

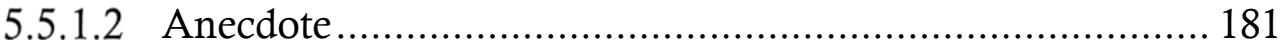

5.5.1.3 Exemplum.......................................................... 182

5.5.1.4 Observation ......................................................... 183

5.5.1.5 Narrative ............................................................. 184

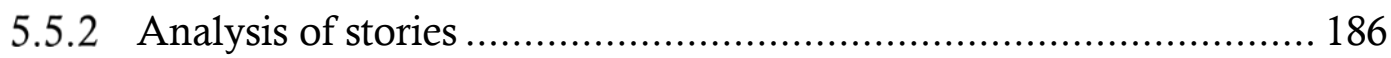

5.5.2.1 Analysis of exemplums .......................................... 188

5.5.2.2 Analysis of narrative structure ................................... 191

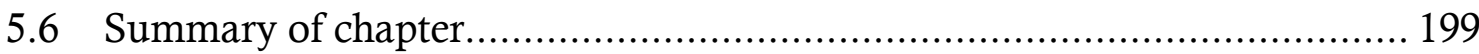

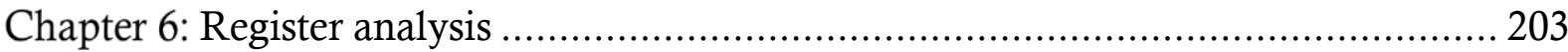

6.1 Personal pronouns ............................................................................ 203 
6.1.1 Comparing frequencies of you across genres ..........................205

6.1.2 Grammatical positions of you...........................................208

6.1.3 Collocates of your ........................................................209

6.1.4 Verbs that connect with your life ...........................................2213

6.1.4.1 Your life in the subject position ..................................215

6.1.4.2 Your life in the object position.......................................216

6.2 Directives in the imperative form ..................................................219

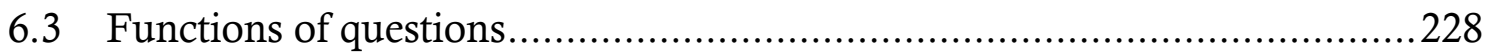

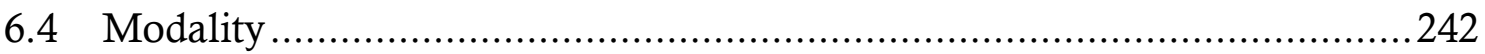

6.5 Lexicogrammar of self-improvement book titles ...............................252

6.5.1 Lengths of titles, head titles and subtitles ..................................254

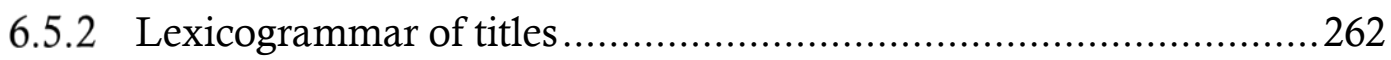

6.5.2.1 The field of titles ..................................................... 262

6.5.2.2 Your life in titles ........................................................263

6.5.2.3 Grammatical structure of head titles .............................266

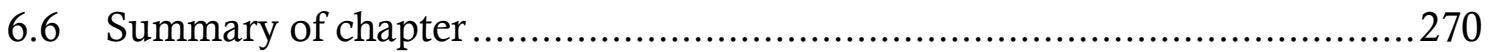

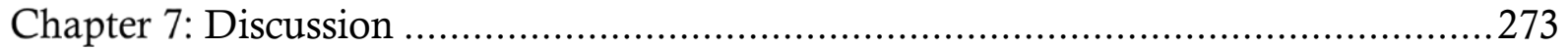

7.1 The purpose of self-improvement books ........................................2 274

7.2 Areas of improvement in self-improvement books ............................2278

7.3 The self in self-improvement books .............................................2 279

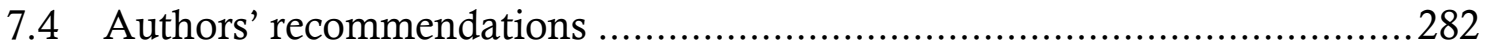

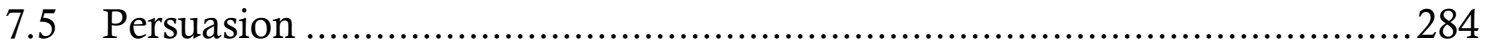

7.5.1 Constructing a credible persona .........................................28 284

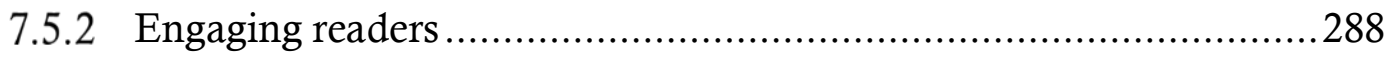

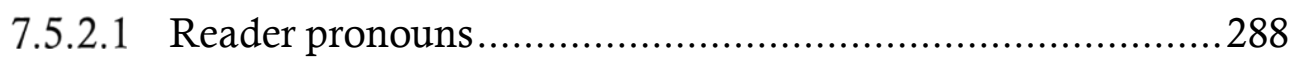

7.5.2.2 Directives in the imperative form ................................289

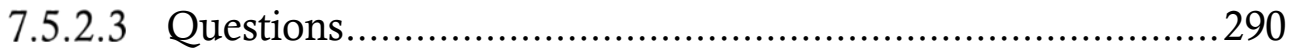




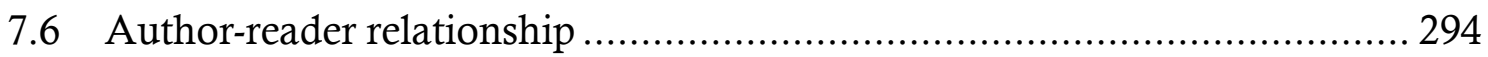

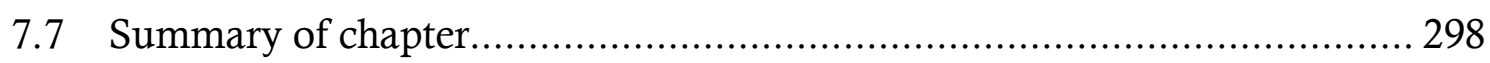

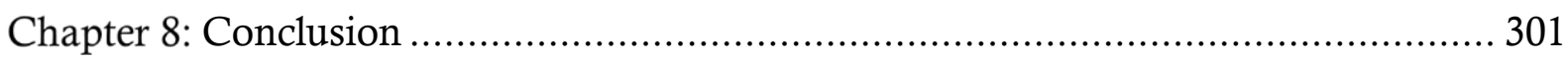

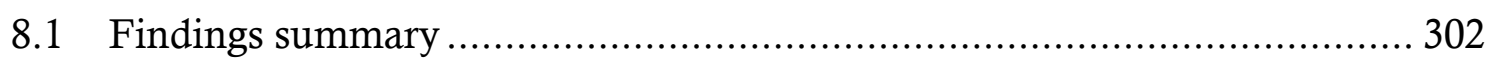

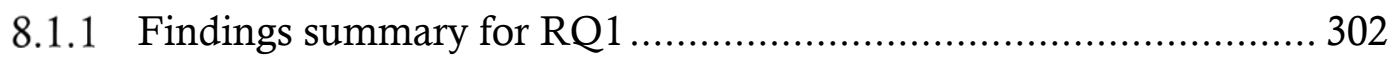

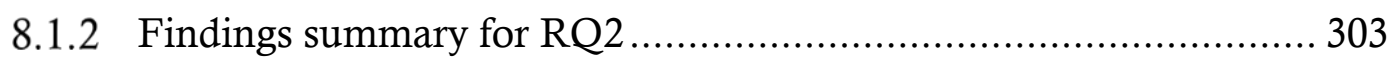

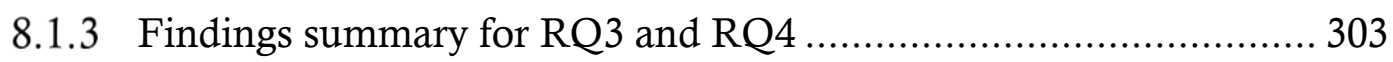

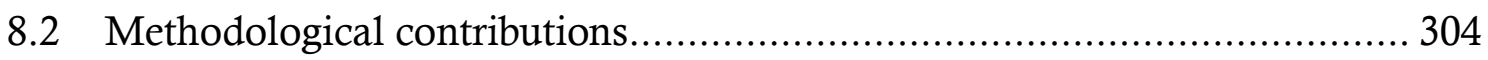

8.2.1 Non-readers of self-improvement books as informants.................... 304

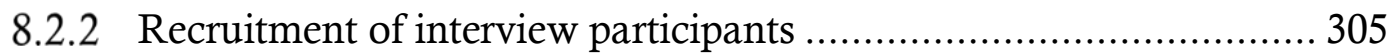

8.2.3 Identifying readers/non-readers of self-improvement books............ 307

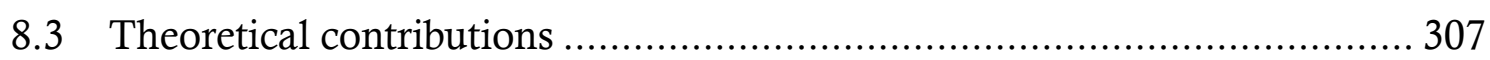

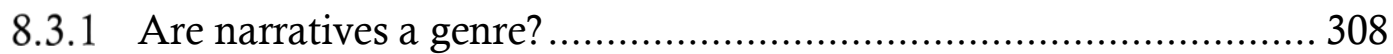

8.3.2 Extending Hyland's system of engagement - stories ....................... 309

8.3.3 Analysing steps to understand a culture ……….............................. 310

8.3.4 Behavioural process and existential process .................................. 311

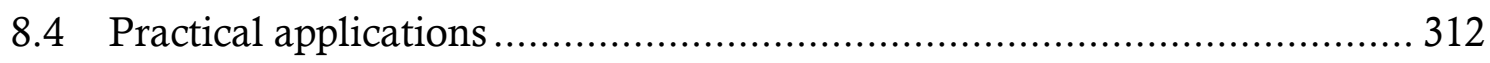

8.4.1 A resource for new self-improvement book authors ........................ 312

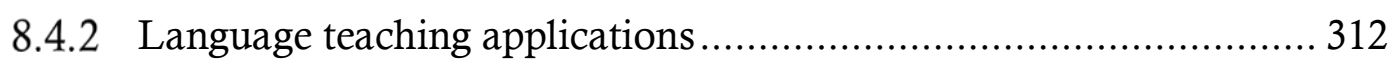

8.4.2.1 Engaging and reader-oriented........................................... 313

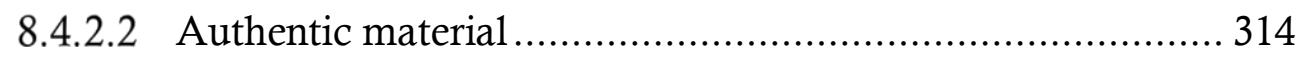

8.4.2.3 Opportunities for critical reflection .................................... 314

8.4.2.4 Teaching material evaluation ................................................. 315

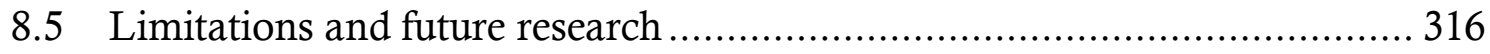

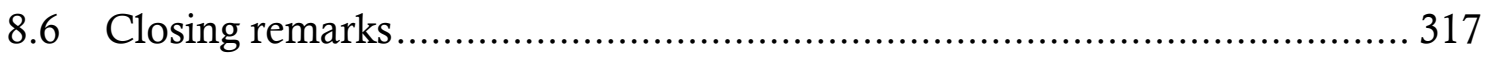


Appendix 1: List of books in the main dataset................................................319

Appendix 2: Examples of interview questions (author) ................................ 321

Appendix 3: Examples of interview questions (reader/non-reader) ...................322

Appendix 4: Reader/non-reader interviewee recruitment advertisement............323

Appendix 5: Ethics approval memorandum.............................................. 324

Appendix 6: Information sheets and letter of consent ............................... 325

Appendix 7: Copyright permissions letter ........................................ 328

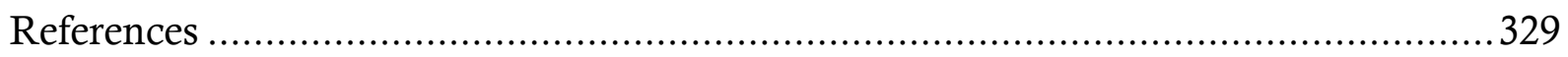

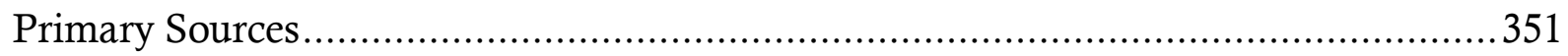




\section{List of tables}

Table 1: A move and related steps in research articles ............................................ 15

Table 2: Characteristics of self-improvement books .............................................. 54

Table 3: Characteristics of eliminated books ....................................................... 56

Table 4: Prototypical arrangement of sections in self-improvement books ................... 80

Table 5: Sections in self-improvement books according to frequency ........................ 98

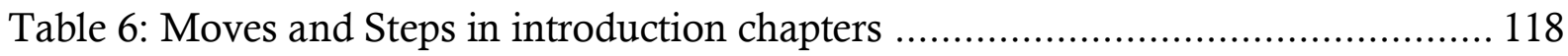

Table 7: Example of full introduction chapter ...................................................... 121

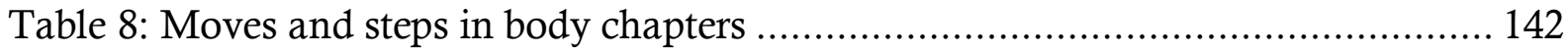

Table 9: Example of full body chapter .............................................................. 144

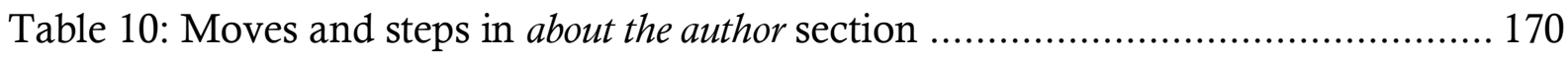

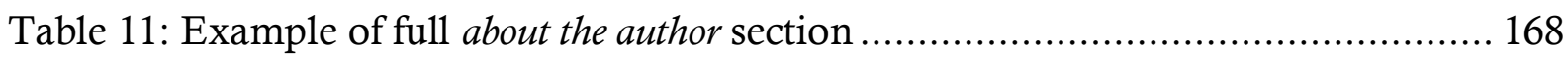

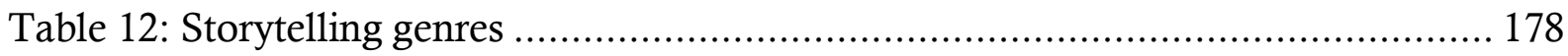

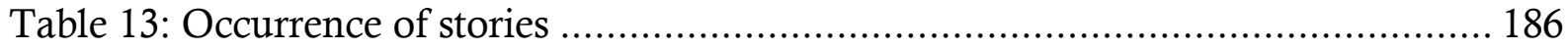

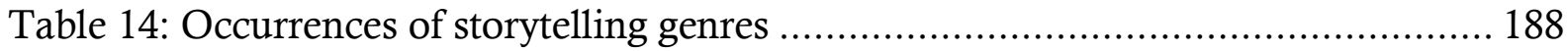

Table 15: Complete example of exemplum ............................................... 189

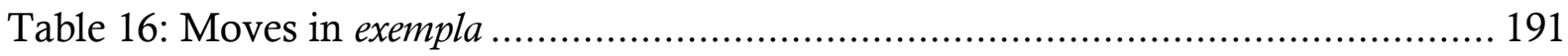

Table 17: Occurrence of stories with complication-resolution structure.................... 192

Table 18: Complete example of story with complication-resolution structure ............. 192

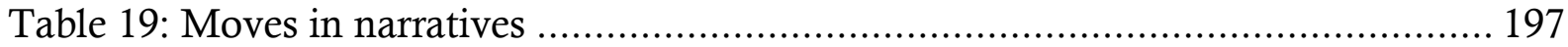

Table 20: Most frequent words in 20 self-improvement books (1,327,500 word tokens) 205

Table 21: Comparison of you frequencies............................................................ 206

Table 22: Comparison of grammatical positions of you in self-improvement books and job

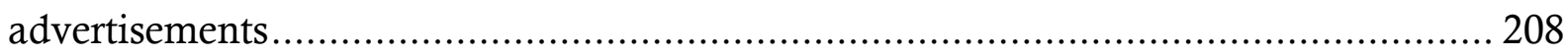

Table 23: Collocates of your in 20 self-improvement books (1,327,500 word tokens) ... 210

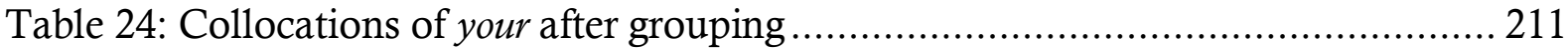

Table 25: Comparing grammatical positions of your life and you ............................. 214

Table 26: Verbs that frequently govern your life ................................................ 216

Table 27: Frequency of directive in the imperative form ...................................... 220

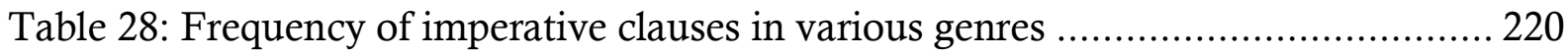

Table 29: Distribution of process types in six self-improvement books ..................... 225

Table 30: Number of questions per 10,000 words in five self-improvement books ....... 230 
Table 31: Number of questions per 10,000 words in various genres 231

Table 32: Distribution of question functions in five self-improvement books 240

Table 33: Frequency of questions with reader pronoun. 241

Table 34: Modality according to Biber et al. (1999) ..............................................243

Table 35: Number of high and low modality elements per 180 turns .........................246

Table 36: Collective frequency of modal verbs................................................... 248

Table 37: Frequency of modal verbs in individual chapters.....................................249

Table 38: Frequencies of occurrence of lengths of titles, head titles and subtitles of self-

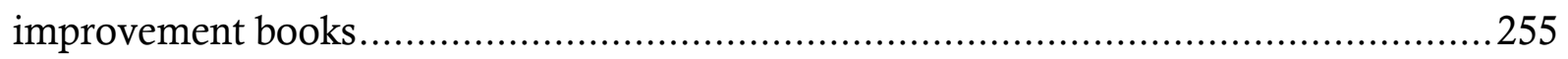

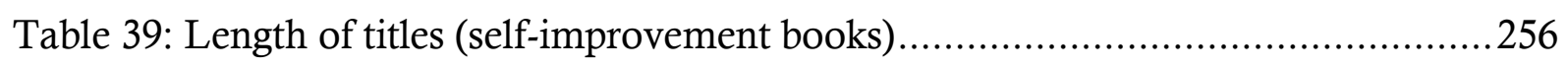

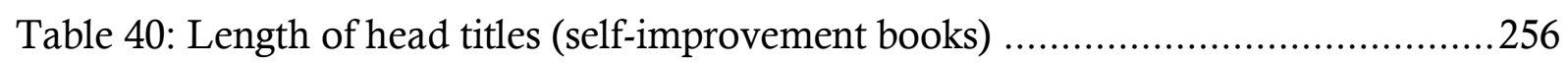

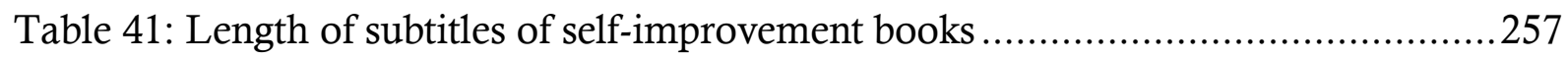

Table 42: Frequencies of occurrence of lengths of titles, head titles and subtitles of

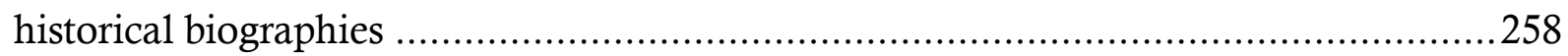

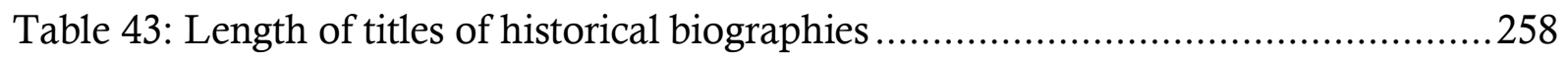

Table 44: Length of head titles of historical biographies.......................................2259

Table 45: Length of subtitles of historical biographies.........................................259

Table 46: Comparing self-improvement books and historical biographies..................260

Table 47: Mean lengths of complex titles of self-improvement books and journal articles

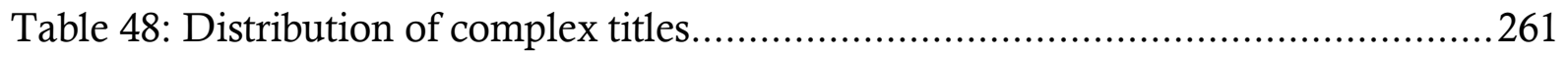

Table 49: Word frequency list of self-improvement book titles ................................263

Table 50: Grammatical structures of self-improvement book head titles ....................268

Table 51: Grammatical structure of historical biography head titles .........................268

Table 52: Grammatical comparison of head titles of self-improvement book and historical biography .269 


\section{List of figures}

Figure 1: Example of title page with quote....................................................... 81

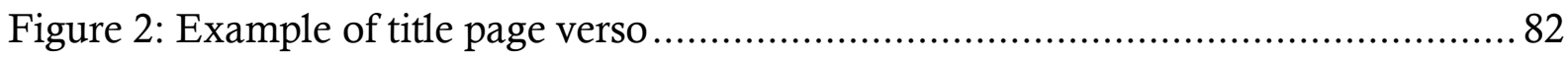

Figure 3: Example of praise from others ........................................................ 84

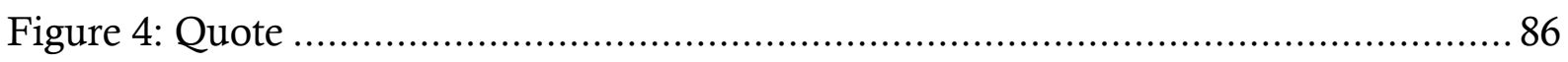

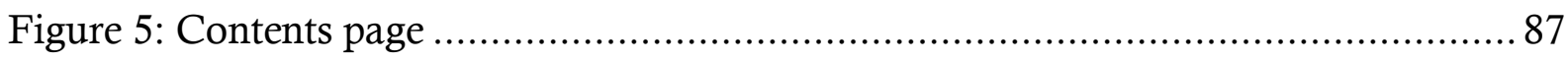

Figure 6: Affirmative statements ................................................................. 88

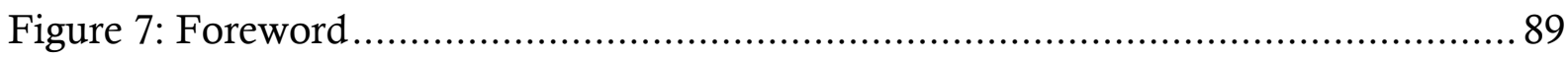

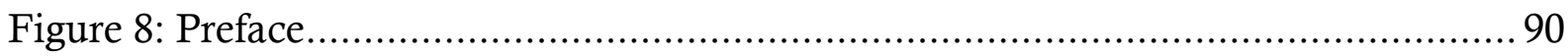

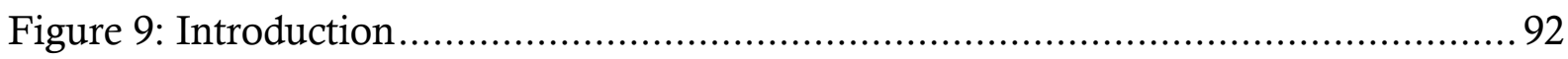

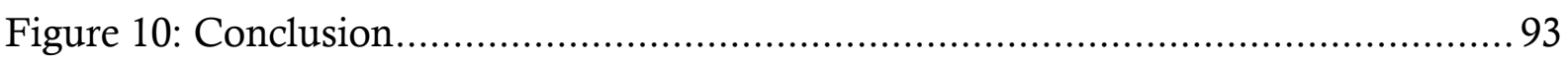

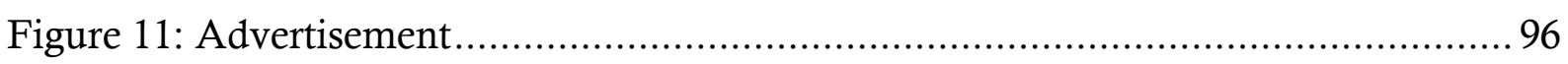

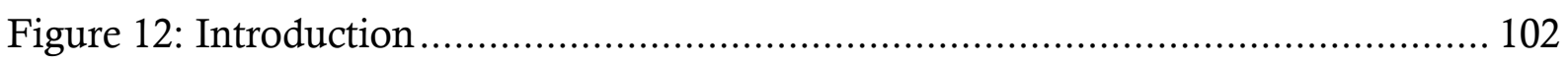

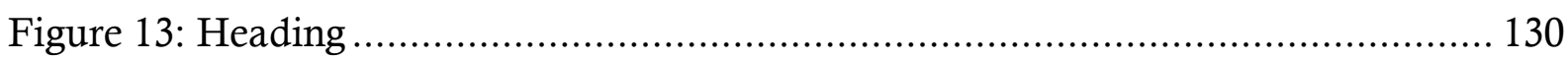

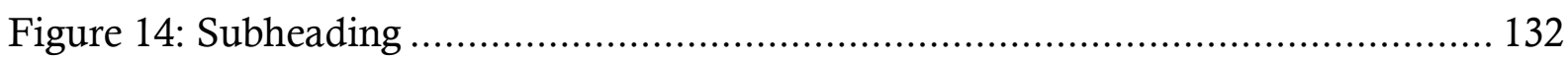

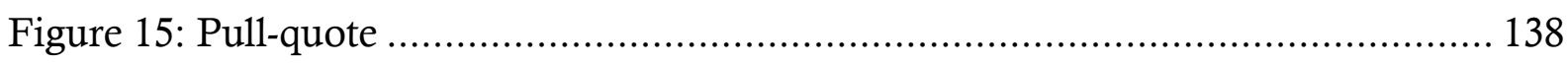

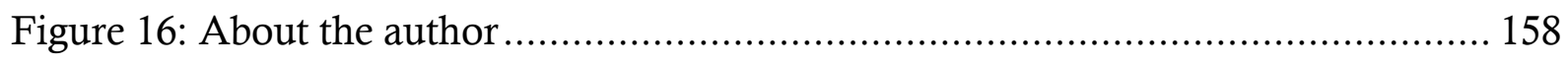

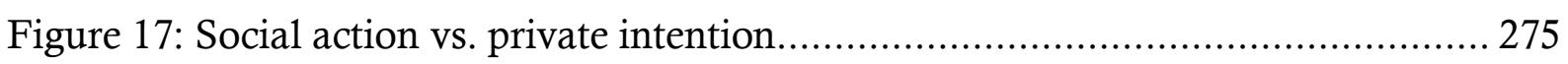





\section{Chapter 1: Introduction}

This chapter presents the background of the study through a brief account of my teaching experience in a Malaysian secondary school, and how that teaching experience led me to study self-improvement books as a genre. It then introduces the aims of this thesis, and the research questions that this thesis addresses. It concludes with an overview of the thesis.

\subsection{Background of the study}

Teaching has always been my passion and I am most satisfied when I see adolescents growing up to discover their potential and when I can contribute to their individual journey of discovery. During my seven years of teaching a wide range of secondary school students in Malaysia, from highly reluctant to highly motivated ones and from a lower English proficiency group to a higher English proficiency group, self-improvement books (commonly known as self-help books) were a staple in my teaching programmes.

I read these books for my personal growth: both as a teacher and as an individual, and selected interesting texts and quotes from such books for classroom activities. I observed that reluctant learners seemed to be slightly more engaged in such discussions compared to motivated learners who had higher English proficiency and were more concerned about their grades in an exam-oriented education system. Even though they were keener on exam-oriented worksheets and model test papers, "inspirational" texts seemed to have a "magical" engaging effect on these learners during discussions and writing activities. Such discussions seemed to promote reflective thinking and some parents gave positive feedback about the approach. I also observed that such topics were more engaging compared to those such as pollution, drug abuse and health. The engaging effect contributed to my interest and aroused my curiosity to explore this genre in detail. 
Rather than focusing on self-improvement books directly as ESL teaching material, I wanted to investigate how this genre functions in a larger context. In studying the characteristics of these texts as a genre, I wanted to look at the micro level of how writers construct themselves and the readers, how persuasion is achieved, and how engagement is achieved. In taking a closer look at the social context of self-improvement books, in this study I focused mainly on the social participants, namely the authors, the readers and the non-readers of this genre. To understand the social context better, I was eager to know why authors write such books and why readers of this genre read these books. Furthermore, I included non-readers of this genre in the belief that they can help us to view it from the other side of the coin.

\subsection{Aims of the study}

My study addresses the following research questions:

RQ1: What are the characteristics of self-improvement books as a genre?

RQ2: Why do authors write self-improvement books?

RQ3: Why do readers of self-improvement books read this genre?

RQ4: Why do non-readers of self-improvement books not read this genre?

This thesis aims to understand the linguistic characteristics of self-improvement books by analysing these texts as a genre. At a genre level, it focuses on the structure of selfimprovement books, and at a register level, the linguistic resources that authors use in their attempt to engage readers. As texts do not exist in isolation, this thesis aims to understand the context in which this genre is situated by answering RQs 2,3 , and 4 . To answer these questions, the study draws on author, reader, and non-reader interview data. 


\subsection{Thesis overview}

This thesis investigates self-improvement books as a genre focusing on how social purpose is instantiated in texts. Following this introductory chapter, Chapter 2 outlines the relevant theories and terms that I used in this study such as genre, self-improvement books, storytelling genres, persuasion, and the American Dream. I situate the concept of genre that I use within the three main schools: English for Specific Purposes, Systemic Functional Linguistics and New Rhetoric, and review problematic terms (e.g., obligatory) in the literature. Chapter 3 outlines the research design and methodology, presenting how I developed the selection criteria for identifying self-improvement books, how I developed the dataset, the recruitment process of interview participants, and how I analysed the data.

Chapters 4 to 6 are the analysis chapters of the thesis. I present the analysis of interview data in Chapter 4. The analysis of interview data is crucial in my study because it sheds light on text analyses in this thesis. Author interview data, in particular, is useful for understanding authors' intentions for writing the genre. In Chapters 5 and 6 , the focus shifts to text analysis. Chapter 5 focuses on move analysis and presents the analysis of sections in self-improvement books and then the typicality of the sections, followed by the analysis of moves and steps in the introduction chapters, the body chapters, the about the author sections, and stories. Chapter 6 analyses the register of self-improvement books focusing on personal pronouns, collocations of your, directives in the imperative form, lexicogrammar of self-improvement book titles, functions of questions and modality.

A summary of findings and a discussion of underlying ideologies in the genre are presented in Chapter 7. This chapter discusses how self-improvement books reflect the American Dream, American individualism, neoliberalism and New Age ideology. Finally, the thesis presents methodological and theoretical contributions, and practical applications of my research in Chapter 8. 


\section{Chapter 2: Literature review}

The main purpose of this literature review is to position this thesis within the broader existing literature. The chapter reviews research studies related to self-improvement books, then the theories and terms that I draw on in this research. They include genre theory, reader-response theory, stories and storytelling, and persuasion. Finally, I review literature on ideologies that are related to self-improvement books.

\subsection{Self-improvement books}

Self-improvement is an important genre in American popular literature and this phenomenon is closely related to the history, culture and ideology of the United States (Coyle \& Grodin, 1993; Dolby, 2005; Grodin, 1991; Hight, 2011; McGee, 2005). The online Oxford Dictionaries define self-improvement as "the improvement of one's knowledge, status, or character by one's own efforts" (Self-improvement, 2015). I describe self-improvement books as books that contain discussions related to personal growth.

Wilson and Cash (2000, p. 120) report that millions of Americans look to psychology self-improvement books as a source of "advice, insights and inspiration in solving personal and interpersonal problems." Dolby (2005) proposes that many Americans read self-improvement books as a resource to grow in wisdom and lead a satisfying life. This genre is becoming more prominent in Western Europe and Australia (Bergsma, 2008; Philip, 2009) and some American self-improvement authors are also popular in China (Bergsma, 2008, p. 342). Stine (1997, p. 7) suggests that human beings are always in search of ways to resolve personal problems or expand their mental, physical, social, and professional skills, resulting in the constant demand for self-improvement/how-to books, and Bergsma (2008, p. 342) describes this industry as a goldmine, that is a profitable one. 
Although Dolby (2005) argues that the main reason for the shift from the term self-help books to self-improvement books is the idea that self-help denotes readers as helpless and in need of help, while the idea of self-improvement implies proactive readers. In my study, I use self-help books as the umbrella term to include self-improvement books and how-to books as Stine (1997) does. Following Stine (1997, p. 10), the main difference between self-improvement books and how-to books lies in their focus: self-improvement books provide readers with the means to overcome critical problems or to achieve personal growth; and how-to books guide readers through the acquisition of specific mechanical skills. Taking this into consideration, DIY (Do-It-Yourself)/how-to books and (auto)biographies are not included as self-improvement books. However, personal narratives that come with explicit instructions/advice and commentaries are considered self-improvement books. Some self-improvement books have titles that are similar to a how-to book, such as How to win friends and influence people (Carnegie, 1936), How to live on 24 hours a day (Bennett, 2009), and How to do everything and be happy (Jones, 2011). Even though these books come with a how-to title, they are personal growth oriented. In this thesis, I use these terms according to my definitions above to ease reading. To be consistent, where the literature uses the term self-help to mean self-improvement, the latter will be used.

The literature identifies various categories of self-help books such as DIY books/self-help manual/advice books (Kamler \& Thomson, 2008), psychology self-help books (Wilson \& Cash, 2000), psycho-religious self-help books (Woodstock, 2006) and how-to books (Stine, 1997). These books offer prescriptive advice in areas including anxiety, stress, depression, diet, physical health, self-esteem, body image, addictions, spirituality and relationships (Bergsma, 2008; Philip, 2009; Wilson \& Cash, 2000), and the underlying purpose across the subgenres is improving the quality of life (Bergsma, 2008) and is therapeutic in nature (Coyle \& Grodin, 1993).

The common themes of self-improvement books include self-discovery, finding inner strength, overcoming adversity and living fulfilling lives (McKay \& Bonner, 2002; Woodstock, 2005); and a common message that is shared by virtually all selfimprovement books is that you can improve yourself (Bergsma, 2008). Philip (2009) identifies that a distinctive issue addressed within self-help literature on depression is living a happier, healthier and more productive life. The underlying ideology of these themes seems to be Progressivism (Rodgers, 1982), an ideology that promotes 
reformation rather than revolution, believes in common good and is proactive in nature (Nugent, 2010). As Dolby (2005) and Grodin (1991) observe, this genre typically attempts to empower the lay public to cope with problems, live more effective lives, and build personal philosophy, and professes that individuals are able to do something to improve themselves to fit in better with the status quo.

To date, studies in the area of self-help have focused on a range of issues: politics and government (Erjavec \& Volćić, 2009; Rimke, 2000), religious studies (Woodstock, 2005), discourse studies (Askehave, 2004), diachronics of self-help articles (McKay \& Bonner, 2002), self-help books in psychological clinical practice (Philip, 2009), the effectiveness of self-help books (Bergsma, 2008), readership/attitude towards self-help books (Grodin, 1991; Wilson \& Cash, 2000), content analysis of self-help books (McGee, 2005), and engagement in reading self-help books (Lichterman, 1992). However, to my knowledge, no study has involved conducting a detailed linguistic analysis of inspirational selfimprovement books. To understand these books as a genre, my study draws eclectically on various traditions of genre theory. The next section reviews concepts in genre theory that are relevant to my study.

\subsection{Genre theory}

A genre is a class of texts that can be described as having similar characteristics in terms of, for example, structure, style, content, intended audience, social purpose, and communicative purpose. These characteristics can be observed at a text level (structure, style, content) and context level (intended audience, social purpose, communicative purpose). Although genre analysis may appear to be primarily classification oriented, Swales (1990, p. 58) explains that the objective of this analysis is primarily clarification oriented. This implies that analysing a genre is predominantly describing the characteristics of a particular genre rather than analysing whether an item fits a particular genre.

While genre analysts examine texts, following Swales (2009), rather than viewing genre solely as a text, I view genre as predominantly a performance, or what Miller (1984) calls 
social action. This view implies that the aim of genre analysis, as Tardy $(2011$, p. 54) summarises, is to describe features of socially recognisable forms and actions.

\subsubsection{Genre}

Genres are recognised primarily by their communicative purpose(s) (Askehave \& Swales, 2001; Bhatia, 1993), social action(s) (Miller, 1984; Rauen, 2009), and social purpose(s) (Martin \& Rose, 2008; Tardy, 2011). Swales (1990) states that:

The principal criterial feature that turns a collection of communicative events into a genre is some shared set of communicative purpose. Placing the primary determinant of genre-membership on shared [communicative] purpose rather than on similarities of form or some other criterion is to take a position that accords with that of Miller (1984) or Martin (1985) (p. 46).

This implies that Swales views Miller's social action and Martin's social purpose to be the same as communicative purpose. He also explains that "genres are communicative vehicles for the achievement of goals" (p. 46), implying that the shared purpose is communication driven. Bhatia (1990) explains that "within the framework of socially recognised purpose(s)," text producers often use conventions of a genre "to achieve private intentions" (p. 13). This explanation seems to raise a private vs. social issue. As genres are socially recognised, private intentions cannot be a criterion for genre identification. However, this is not to discount the idea of private intention. Askehave and Swales (2001) explain that while a socially recognised purpose of a shopping list is to remind the shopper the items he/she needs to buy, the private intentions could be "to prevent impulsive purchases," thus "to impose discipline on" the buyers, or using the list as "an instrument of romantic hope," to convince a potential partner that he/she is "a domestic partner" (p. 201). Although these intentions are not prototypical purposes of the genre, as opposed to Bhatia (1990), they do not seem to be constrained by socially recognised purposes. In my study, private intentions are non-typical purposes and they are not constrained by socially recognised purposes.

Another issue that Askehave and Swales' examples raise is their definition of communicative purpose. They refer to the various purposes of shopping list as "variation in communicative purpose" (p. 201). It seems to me that using a shopping list to prevent 
impulsive purchase or to impose discipline does not have a clear communicative driven purpose.

Social action, Miller (1984, p. 152) explains, refers to "rhetorical action" that language performs. Consistent with speech act theory, this idea views language as a mediation of social actions. Miller explains that social action is "a rhetorical response" motivated by a particular "situational demand" as perceived by the speaker/writer (p. 152) and this action is "recurrent" and represents "typified rhetorical action" (p. 151). Although text producers may have private intentions (those that are not typical), as Bhatia (2008) argues, Miller's idea of genre does not consider such intentions to be an aspect of genre identification because they are not socially recognised. As Freedman and Medway (1994) explain, recurring rhetorical actions are results from "shared social interpretation" rather than individual perception (p. 10). Because genres are socially interpreted, Rauen (2009, p. 63) explains that they are more or less "standardised, typical, and intelligible."

The third term that I will discuss is social purpose. Eggins and Martin (1997, p. 236), Martin (2009, p. 12), and Rose and Martin (2012, p. 22) explain that genres are recognised by the social purposes they perform. Social purpose is related to achieving "goals" (Martin, 2009, p. 12) and "culturally established tasks" (Eggins \& Martin, 1997, p. 236), but they are not restricted to communicative goals. A diary, for example, does not strictly speaking have a communicative purpose but has a social purpose.

Socially recognisable, Hasan (1994) explains, does not mean a genre is recognisable by "each and every normal human being" (p. 143) but through "participation in everyday life in socially defined environments" (p. 144). It seems that social purpose and social action are very similar concepts. For example, Eggins and Martin (1997) state that "texts which are doing different jobs [emphasis added] in the culture will unfold in different ways" (p. 236). It seems reasonable to view doing a particular job as similar to an action.

As mentioned earlier, Askehave and Swales' example of using a shopping list as a reminder seems to fit the idea of social action and social purpose rather than communicative purpose. It seems Askehave and Swales use the term communicative purpose in a broader sense, more than being communication driven, in other words, social purpose. My study views communicative purpose as what writers/speakers intend to convey, and social action/purpose as, not being limited to text producer's communication-oriented 
intention, actions/goals that are socially recognisable within a particular (or a wider) community.

Holmes (1997, p. 322) claims that similarity in terms of communicative purpose among a group of texts results in "distinctive structural patterns." However, following the notion of prototypes (Bawarshi \& Reiff, 2010; Hyland, 2002b; Paltridge, 1997; Swales, 1990), I view texts of a same genre have similar structural characteristics, for example, which may not be distinctive. Prototypes are exemplars of a genre which have clear characteristics which fit the typical features of a particular genre (Bax, 2011; Swales, 1990), an idea that originates from Wittgenstein's (1958) idea of family resemblances or what Rosch (1973, p. 140) later calls "the focal examples." Based on the notion of prototypicality, members of a genre are identified by how closely they are related to the genre prototype (Bawarshi \& Reiff, 2010).

Coutinho and Miranda (2009) use the terms centripetal (principle of identity) and centrifugal (principle of difference) in their discussion of genre. Centripetal refers to the family nature of a particular genre and centrifugal refers to the innovation and variation within a particular genre that make a text unique. The idea of centripetal is similar to Swales' (1990) idea of family resemblance approach to identifying members of a genre. Bhatia (1997) explains that variations happen because expert members of the discourse community innovatively exploit what is common within a genre to create a particular effect on the reader.

\subsubsection{Traditions of genre studies}

In her influential paper, Hyon (1996) conceptualised genre studies as three distinct traditions: English for Specific Purposes (ESP), Rhetorical Genre Studies (RGS), and Systemic Functional Linguistics (SFL). Rather than discussing each school as a distinct tradition, I discuss the contribution of each to genre studies as a whole.

In SFL, the notion of genre relates to the context of culture while the notion of register relates to the context of situation (Paltridge, 1997). Genres, Martin (1984, p. 28) explains, are used to "accomplish things, on a day to day basis, in a culturally specific way." Register, in SFL, is seen as a configuration of field (the experiential content and nature of the social activity), tenor (the relationship between participants in the activity) and mode 
(the role of language in the communication and the medium or channel of communication) (Paltridge, 1997, p. 23). Within SFL, genre analyses have mainly examined the schematic structure and the generic structure potential of particular genres (Paltridge, 1997). Schematic structure refers to the prototypical organisation of a genre and generic structure potential refers to a system that has all possible organisations of a particular genre. Nunan (2008) states that a well-informed genre analysis should include register analysis because genre and register are dialectically related. This implies that a register analysis of self-improvement books is necessary to complement genre analysis.

Rhetorical Genre Studies focus on studying the social context where a genre is situated (Paltridge, 1997) and on the action a genre accomplishes (Miller, 1984). Bazerman (1997, p. 19), an influential genre theorist from RGS, explains that:

Genres are not just forms. Genres are forms of life, ways of being. They are frames for social action. They are environments for learning. They are locations within which meaning is constructed. Genres shape the thoughts we form and the communications by which we interact. Genres are the familiar places we go to create intelligible communicative action with each other and the guideposts we use to explore the unfamiliar.

Bazerman's explanation that genres are more than forms (i.e., texts) implies that genre analysis should be more than text analysis and that genres are recognisable because they are reasonably stable. The idea that genres shape the thoughts we form indicates that genres and their users have a dialectical relationship.

"Methodologies in this school [Rhetorical Genre Studies] tend to be ethnographic, aiming to uncover something of the attitudes, values, and beliefs of the communities of text users that genres imply and construct" (Hyland, 2002b, p. 114). Similar to RGS, ESP genre studies draw on ethnographic perspectives extended to the idea of discourse community where the community shares its common goals and employs one or more genres in the furtherance of its communicative aims (Bhatia, 1997; Paltridge, 1997; Swales, 1990). However, the idea of discourse community has been challenged for various reasons. Borg (2003, p. 399), for example, suggests that it seems unclear as to whether a discourse community is defined in relation to shared purpose among the community members or whether oral communication is necessary to maintain a discourse community. In reconsidering this problematic term, Swales (1998) introduces 
the term place discourse community to refer to groups of people who work together on a regular basis and communicate in a range of modes (i.e., not limited to written communication).

Within ESP, Bhatia (1997, p. 34) stresses that a genre analyst should include a "specialist informant" in a study, to double-check the findings or guide the investigation. Swales (1990, p. 56), an influential genre theorist from the ESP tradition, explains that:

a genre comprises a class of communicative events, the members of which share some set of communicative purposes. These purposes are recognised by the expert members of the parent discourse community, and thereby constitute the rationale for the genre. This rationale shapes the schematic structure of the discourse and influences and constrains choice of content and style. Communicative purpose is both a privileged criterion and one that operates to keep the scope of the genre as here conceived focused on comparable rhetorical action. In addition to purpose, exemplars of a genre exhibit various patterns of similarity in terms of structure, style, content and intended audience.

Swales' definition considers communicative purpose as a unifying component of a particular genre and acknowledges the active role of users of a particular genre, both speaker/writer and intended audience, in shaping the genre. His definition also considers the relationship between communicative purpose and textual features.

Research within genre studies has analysed a number of genres such as service encounters (Ventola, 2005), writing in academic settings (Flowerdew \& Dudley-Evans, 2002; Maingueneau, 2002; Samraj, 2008), scientific writing (Li \& Ge, 2009), business letters (Bhatia, 2008; dos Santos, 2002; Flowerdew \& Wan, 2006), cooking classes (Mayes, 2003), application letters (Ding, 2007), and press releases (Lassen, 2006). However, prior to this thesis, no study to my knowledge has examined self-improvement books as a genre.

Although current mainstream research, as Hyland (2002b, p. 116) observes, has an interest in examining clusters of register, style, lexis, and other rhetorical features which might distinguish particular genres, Flowerdew and Wan (2006), and Muntigl and Gruber (2005) report that genre analysts, as well as having an interest in the traditional 
move analysis (see Section 2.2.8) and linguistic features, are becoming increasingly interested in investigating the interpersonal aspects of genre.

As Hyland (2002b) notes, what unites the three traditions is their common attempt to identify regularities of purpose, form, and situated social action. All three traditions rely on the idea of prototype although each tradition may emphasise different aspects of prototypicality. Drawing eclectically on the three traditions, my study analyses the linguistic features, focusing on moves and steps and the interpersonal aspects of selfimprovement books.

\subsubsection{Moves and steps}

As the focus of the thesis is partly to analyse how self-improvement books are structured, moves and steps are relevant concepts. Although these terms are widely used within the ESP tradition, scholars do not always explain these terms in their writing and the terms they use vary. This section reviews the concepts of moves and steps in the literature, and provides definitions for the two concepts in this study.

Swales (2004, p. 228) defines a move as "a discoursal or rhetorical unit that performs a coherent communicative function in a written or spoken discourse." For example, a move in a research article introduction is establishing a territory (Swales, 1990, 141). In this example, the mentioned move introduces a research article by positioning how the article fits in a broader body of research. Other definitions of moves include those of Bhatia (1993) and Upton and Cohen (2009). Bhatia (1993, p. 30) refers to moves as segments of a text where each move aims to accomplish a particular intention while contributing to the overall communicative purpose of the genre. Upton and Cohen (2009, p. 585) refer to moves as "functional or communicative structures that typically make up texts in a genre." Similar to Swales' (2004) definition, both Bhatia (1993), and Upton and Cohen's definitions relate a particular move to the function it performs.

Within SFL, stages are a concept that refers to these rhetorical units that is often associated with the idea of the beginning-middle-end of a particular genre (Eggins, 2004, p. 59). These stages, Rose and Martin (2012) explain, are steps that we use to accomplish particular goals as "more than one step" are needed to achieve these goals (p. 54). They explain that "each stage and phase of a genre has a specialised function that contributes 
to the social purpose of the genre as a whole" and each "has characteristic language features" (p. 54). Within this tradition, genre analysts identify the stages in a particular genre and analyse the lexicogrammatical features that realise them. It seems that researchers who analyse stages tend to emphasise the order of the rhetorical units they analyse. However, I would avoid claiming that this emphasis is unique to the SFL tradition because such interest is not uncommon among ESP theorists. However, at a practical level, a stage is similar to a move, in my view, because both are rhetorical units that realise a particular genre.

Moves can be categorised as rhetorical moves (Halleck \& Connor, 2006; Samraj, 2005) and structural moves (Sadeghi \& Samuel, 2013; Zhu, 2000). While the former have rhetorically oriented purposes, the latter perform a more indicative function. Examples of rhetorical moves in TESOL conference proposals are reporting previous research, establishing research territory, and stating the research objective (Halleck \& Connor, 2006, pp. 77-78) and examples of structural moves in letters of appeal include salutations, date, recipient address, and signature (Sadeghi \& Samuel, 2013, p. 233).

Drawing on the ESP and SFL traditions, moves are characterised by their functions that serve to achieve the overall social purpose of the genre, and these moves are often organised, though not always, as a series of typical sequences specific to a particular genre (Flowerdew \& Dudley-Evans, 2002, p. 469; Halleck \& Connor, 2006, p. 72; Martín \& León Pérez, 2014, p. 4; Taboada, 2011, p. 249). Swales (2004, pp. 228-229) defines a move as a functional unit rather than a formal one and mentions that a move "is better seen as flexible in terms of its linguistic realisation." While it is common for ESP genre analysts to analyse the steps or strategies that realise a particular move, SFL genre analysts typically analyse the lexicogrammatical features that realise the stages.

The second concept that this section discusses is steps. A familiar concept in ESP, a step is also known as a strategy (Bhatia, 1983, p. 19), sub-move (Zhou, 2012, p. 328) and sub-unit of move (Chang \& Kuo, 2011, p. 224). Although Bhatia (1993, p. 30) does not define steps explicitly, he implies that they are "rhetorical strategies" that "realise a particular communicative intention at the level of a move." Similar to Bhatia's explanation, Kanoksilapatham (2007, p. 24) states that the primary purpose of a step is "to achieve the purpose of the move to which it belongs." To elaborate Kanoksilapatham's explanation of 
step, Basturkmen (1999, p. 23) states that a step provides options or resources that writers use to achieve the purpose of a particular move.

Both Basturkmen (1999, p. 23) and Zhu (2000, p. 476) define a step as a lower unit under a move. Although their definition is not very descriptive in terms of conceptualising the idea of step, this definition indicates that steps are the building blocks of moves. This idea is consistent with Ozturk's (2007, p. 28) explanation that a move "can be realised in a number of ways, called steps [emphasis added]." Bhatia (1993, p. 31) states that minimally one step is necessary to realise a move.

Perhaps the clearest explanation of moves and steps is provided by Martín and León Pérez (2014), who explain that "the concept of move captures the function of a segment of text at a more general level, whereas step refers to the more specific rhetorical choices available to authors to realise the function of a particular move" (p. 4). In brief, a move aims to accomplish a particular intention which contributes to the overall communicative purpose of the genre, and steps refer to choices that realise a particular move. To illustrate the concepts of moves and steps, I include an example from Martín and León Pérez (2014, p. 4) in Table 1.

Table 1: A move and related steps in research articles

\begin{tabular}{|l|l|}
\hline Move 3: Presenting the present work & Step 1: Announcing present research \\
\cline { 2 - 2 } & Step 2: Presenting hypotheses \\
\cline { 2 - 2 } & Step 3: Announcing principal outcomes \\
\cline { 2 - 2 } & Step 4: Stating the value of the present research \\
\cline { 2 - 2 } & Step 5: Outlining the structure of the paper \\
\hline
\end{tabular}

The communicative function of Move 3 is to present the researcher's present work. According to Martín and León Pérez, this function can be realised by five steps. They are resources that researchers can use, in the context of introductions in research articles, to present their present research.

In Move 3, we can ask the following questions:
a) Why is the author announcing the present research?
b) Why is the author presenting the hypotheses?
c) Why is the author announcing principal outcomes?
d) Why is the author stating the value of the research? 
e) Why is the author outlining the structure of the paper?

The answer to these questions is "to present the present work." In other words, moves are related to intentions authors attempt to achieve, and steps are related to the resources that authors use to realise the intentions. In the introduction of research articles, authors can choose from the five steps or resources to achieve the intention of this move (i.e., one that presents research).

In summary, moves have communicative functions while steps are resources available to achieve the said functions. Steps are related to a system of choices, in a Hallidayan sense, that writers or speakers can use to realise a particular move. Even though the term steps may give the impression that they are sequential, they are not. In my study, a step does not relate to the idea of "step-by-step" but is an option or way of realising the function of a move.

\subsubsection{Obligatory, typical and optional moves}

Besides identifying the moves and steps in a particular genre, genre analysts are often interested in analysing the moves and steps in terms of their typicality. However, the terms obligatory, optional and typical are used somewhat ambiguously in the literature.

Most studies use the term obligatory in a non-literal sense. They either state explicitly how they operationalise the term or leave the readers of their articles to derive the meaning of obligatory from their frequency tables. For example, Sadeghi and Samuel (2013) conducted a genre analysis on letters of appeal written by international students at University of Malaya. Their corpus consists of 1161 letters of appeal. They discuss the three most important moves in their data based on frequency and label them as obligatory. Based on their frequency table, obligatory ranges from $92 \%$ to $73 \%$. However, Sadeghi and Samuel are careful to use inverted commas to indicate that obligatory is not used in a literal sense.

Henry and Roseberry (1998, p. 147) state that obligatory moves are necessary to achieve the communicative purpose of a genre. They identify four obligatory moves in their data of brief tourist information texts. However, because Henry and Roseberry do not provide the frequency of the moves in their data, readers are unable to determine if necessary in 
their article means $100 \%$ or some smaller proportion. Thus the term obligatory in Henry and Roseberry is ambiguous.

To further demonstrate that literature does not always use obligatory in a literal sense, consider the following examples. Xiao and Cao (2013) are among the few authors who operationalise their terms clearly. They compare moves in research article abstracts written in English by native and non-native writers of English, focusing on the biology discipline. They define obligatory moves as those that occur in more than $90 \%$ of the texts. Cheung (2008) studies sales letters and regards a move that occurs in 153 out of 160 sales texts or $95.6 \%$ as obligatory (p. 176). Even though Cheung (2008) has a stricter criterion for obligatory moves than Xiao and Cao (2013), she does not use obligatory in a literal sense.

Tessuto (2015) is the only study, to my knowledge, that uses the term obligatory in a literal sense. Like Tessuto, I argue that the term obligatory should be reserved to describe moves that are present in all the texts in a particular dataset. In my study, I use obligatory in that literal sense.

Typical moves are sometimes called quasi-obligatory (Cheung, 2008, p. 174; Tessuto, 2015, p. 20). Zhu (2000) compares the moves in English and Chinese sales letters (20 from each category). She uses the term typical moves descriptively but does not define what is meant by typical. Zhu (2000) states that headline $(13 / 20)$ and postscript $(11 / 20)$ are typical moves in English sales letters, but surprisingly, establishing credentials $(16 / 20)$ is not mentioned as a typical move even though it appears more frequently than headline and postscript. Salutation, offering incentives, soliciting a response and closing move are present in all of Zhu's English sales letters data but these moves are not described as obligatory. In search of the meaning of obligatory and typical, Zhu does not appear to be very useful.

Cheung (2008, p. 174) uses the term quasi-obligatory to refer to a move that occurs "in more than half of the 160 sales texts (95/160)," or $59.3 \%$, that she analysed, and it is implied in Tessuto $(2015$, p. 16) data that she uses the same term to refer to moves that occur between $83 \%$ and $88 \%$ of the cases. Note that the definitions of the term quasiobligatory vary considerably in the two studies. Some studies do not even have a typical or quasi-obligatory category in describing moves. Yang (2015), for example, combines the obligatory and quasi-obligatory categories into one category and calls it obligatory - having "over $60 \%$ occurrence in the corpus" (p. 46). In my study, a typical move is one that is 
highly common, and I operationalize that as having over $70 \%$ occurrence in my dataset but less than 100\%. This implies that Sadeghi and Samuel's (2013) obligatory moves and Xiao and Cao's (2013) obligatory moves are considered as typical moves in my study.

Henry and Roseberry (1998) explain that optional moves are often added by speakers and writers to add to the effectiveness of the communicative purpose. However, the way optional is operationalised in the literature is often inconsistent. For example, Shi and Wannaruk $(2014$, p. 2) consider moves that occur below $60 \%$ to be optional, and Cheung (2008, p. 174) uses the term quasi-obligatory to refer to a move that occurs "in more than half of the 160 sales texts $(95 / 160)$." Although Cheung considers a move that occurs in more than half of her dataset to be quasi-obligatory, she does not discuss those that occur in less than half. Also the boundary between obligatory and quasi-obligatory in her study seems unclear. Optional moves in my study refers to those that occur below $70 \%$ but occur at least once in my dataset. This implies that in my study a typical move is an optional move that has a higher occurrence. In my study, Cheung's quasi-obligatory move (i.e., more than half or 59.3\%), for example, would be considered an optional move because it occurs less than $70 \%$.

The terms obligatory, typical and optional are used variably in the literature. In my study I have chosen to use obligatory in a literal sense of occurring in $100 \%$ of cases. Typical moves refer to moves that occur in more than $70 \%$ but less than $100 \%$ of texts, while optional moves are moves that occur in less than $70 \%$ of texts. Besides analysing the typicality of moves, genre analysts from the ESP and SFL traditions pay attention to how the moves and stages are organised in a text. The next section explores concepts related to the organisation of moves.

\subsubsection{Organisation of moves}

Although the organisation of moves and stages are common concepts in genre theory particularly within the ESP and SFL traditions, the terms the traditions use seemed varied. The goal of this section is to report and discuss various terms (i.e., move structure, overall structure, rhetorical structure, rhetorical move structure) that genre scholars use to describe the organisation of moves in a particular text. 


\subsubsection{Move structure}

The term move structure is usually used to mean the organisation of moves in individual texts. Bhatia (1993, p. 56) states that "there is a certain degree of freedom in the sequencing of moves" which he refers to as "flexibility of move-structure." This implies that move structure refers to how moves are organised in individual texts. Flowerdew and Wan (2006, p. 142) also use the term to refer to the organisation of moves in an individual text.

Holmes (1997) compares the organisation of moves in research article discussion sections across disciplines (history, political science, and sociology). He presents a table, which consists of the organisation of moves in individual texts from each discipline, and labels the table "move structure of RA (research article) discussion sections" (p. 329). Even though the term move structure is not explicitly defined, the table shows that Holmes uses move structure to refer the organisation of moves in individual texts. This is an example of move structure of a discussion section in history in Holmes' (1997, p. 329) analysis: Move 1: Background information - Move 2: Statement of result - Move 8: Outlining parallel or subsequent developments - Move 6: Generalisation.

Kwan (2006, p. 35) studies the literature review chapters in doctoral theses and states that one of her research objectives is to find out whether the literature review chapters in her corpus "share the same move structure" (p. 35). Even though Kwan does not explicitly define move structure, her usage implies that move structure refers to the organisation of moves in a particular text.

Ozturk (2007) studies the difference of textual organisation of research article introductions within a single discipline, applied linguistics. His findings show that there are "five different patterns of move structure," and he points out that there is "one predominant pattern" (p. 30). He uses the term move structure to refer to the organisation of moves in particular texts and does not attach the idea of typicality.

The review of the term move structure shows consistency in which it is used to refer to the way moves are organised in a particular text without attaching the idea of prototype. This term is used in that way in this thesis. 


\subsubsection{Overall structure}

Besides the term move structure a review of literature shows that scholars use the term overall structure. Ozturk (2007, p.28) explicitly states that the purpose of his study is "to investigate the overall structure of RA introductions" and that "the analysis was restricted to the organisation of moves." Ozturk's statement, "the analysis [referring to the overall structure] was restricted to the organisation of moves," implies that he uses the terms overall structure and the organisation of moves in a parallel fashion. He also states that "the overall organisation (i.e. rhetorical structure) of an article may vary in accordance to its type" (p. 28), indicating that the term overall organisation is used at individual text level. It is reasonable to conclude that Ozturk uses the terms overall structure and overall organisation interchangeably to mean the organisation of moves in individual texts.

Holmes (1997) observes "the similarity of overall RA structure in that the conventional four sections are usually present in social science RAs and that the structure of the introductions is broadly similar" (p. 331). Holmes' statement can be paraphrased as individual RA overall structure is similar in social science RA. This implies that Holmes uses the term overall structure to refer to the organisation of moves in individual text rather than a typical pattern within a particular discipline.

A review of the term overall structure shows that it is used in the literature to mean organisation of moves in individual text without attaching the concept of typicality.

\subsubsection{Rhetorical structure}

Kwan (2006) mentions that the purpose of her study is "to identify rhetorical structure" (p. 30), and in her findings she presents the structure as "Introduction-Body-Conclusion structure" (p. 50). In the same article, Kwan (2006, p. 35) seems to imply that "a common rhetorical move structure" of a genre refers to "the prototypical structure" of the genre. Because Kwan uses common and prototypical in a parallel, this implies that Kwan uses the term rhetorical move structure without attaching the meaning of prototype. The following is an example of how Kwan uses rhetorical structure and move structure interchangeably. Kwan (2006, p. 32) states that one of the purposes of her study is: 
"to compare the rhetorical structure [emphasis added] of LRs [literature reviews] with the established CARS model (Swales, 1990) that has been posited for research writing introductions, and to investigate the extent to which the three-move model can be applied to describe the move structure [emphasis added] of LRs."

In the above statement, rhetorical structure and move structure refer to the same thing, and CARS model and the three-move model are used in a parallel fashion. A review of Kwan's article reveals that she uses "rhetorical structure" (p. 32), "move structure" (p. 30) and "rhetorical move structure" (p. 35) interchangeably to mean organisation of moves in individual texts.

Ozturk (2007) also uses the term rhetorical structure but in a different way, namely to mean prototypical move structure of a particular genre (p. 28). In his study of RA introductions, he states that his corpus does not include theoretical articles and articles published in special issues because they vary in terms of "overall organisation (i.e. rhetorical structure)" (p. 28). This implies that investigating rhetorical structure is the same as investigating the overall organisation of a genre.

Contributing to the ambiguity of terms, Ding (2007, p. 389) uses rhetorical structure, rhetorical move structure and move structure interchangeably. Like Ozturk (2007), Ding (2007, p. 389) attaches the concept of prototype in her usage of rhetorical move structure, stating that:

The rhetorical move structure [italics added] delineated in this study helps to demystify the writing of personal statements and other related promotional genres and facilitate the creation of persuasive documents. The rhetorical structure [italics added] revealed by move analysis can be presented in writing classrooms to enhance students' understanding of the genre of personal statements. The move structure [italics added] can be used to explicitly teach the disciplinary contexts, audience expectations, and communicative purposes surrounding the graduate school application processes and to demystify the writing process.

This statement shows that Ding uses the terms rhetorical structure, rhetorical move structure and move structure interchangeably to mean the typical organisation of moves in a particular genre. Also, the word rhetorical, in rhetorical structure, gives the impression that it does not include structural moves. See Section 2.2.3 for a discussion of structural moves. 


\subsubsection{Typical organisation of moves}

Moving on from move structure in individual texts, this section reviews three terms (schematic structure, distinctive structural patterns, generic structure) that scholars use to refer to prototypical organisation of moves in a particular genre.

\subsubsection{Schematic structure}

Swales (1990, p. 58) relates the concept of genre with a shared set of communicative purposes which "shapes the schematic structure [emphasis added] of the discourse." Even though Swales does not explicitly explain what he means by schematic structure, the way he uses the term implies that he associates schematic structure with the idea of prototypical organisation of moves.

Similarly, Flowerdew and Dudley-Evans (2002) use the term schematic structure to refer to the prototypical organisation of moves of a particular genre. They explain explicitly that "schematic structures are prototypes" which can vary according "to the degree to which the genre is conventionalised" (p. 470). Flowerdew and Dudley-Evans (2002, p. 469) state that "the notion of schematic structure [emphasis added]" refers to the idea of "mapping of the macro-structure of texts." This explanation shows that Flowerdew and Dudley-Evans use schematic structure to refer to the prototypical organisation of moves in a particular genre. However, later in the same article, Flowerdew and Dudley-Evans (2002, p. 479) present two complete editorial letters as examples of the genre they study and comment that the two letters were selected because they were "quite close to the prototypical schematic structure" of the genre. The use of prototypical schematic structure is somewhat ambiguous because if they use schematic structure to refer to the prototypical organisation of moves, the word prototypical is redundant in the term. Also, the use of the term prototypical schematic structure suggests that schematic structure is not prototypical. One way to reconcile this seeming conflict in terms is to view Flowerdew and Dudley-Evans as using the two terms interchangeably. However, this is perhaps not the case because in presenting the two examples Flowerdew and Dudley-Evans (2002, p. 480) state that "The schematic structure [emphasis added] of letter \#6 (Text 1) can be analysed as follows..." This example suggests that Flowerdew and Dudley-Evans use schematic structure to refer to the organisation of moves in a specific text with no indications of prototypicality. This 
usage of the term schematic structure seems to be in conflict with the earlier explanation of schematic structure.

Besides schematic structure and prototypical schematic structure, a review of literature shows that recurrent schematic structure is also used to refer to the typical organisation of moves in a particular genre. Flowerdew and Wan (2006, p. 141) use the term "recurrent schematic structure" to label a figure that represents the typical organisation of moves in tax computation letters in their article. This implies that "recurrent [emphasis added] schematic structure" indicates the concept of prototype, and it seems reasonable to read schematic structure as move organisation of a particular text. Another term that is used to refer to the typical organisation of moves in a particular genre is "recursive move structure" (Kwan, 2006, p. 30). Although Kwan does not explain this term, it seems she uses the term to refer to typical organisation of moves in a same way as Flowerdew and Wan's recurrent schematic structure.

Eggins (2004, p. 59) uses the term schematic structure to refer to "the staged, step-by-step organisation of the genre" and explains that this structure is established as "we habitualise our joint negotiation of communicative tasks." Eggins' explanation indicates that schematic structure means the typical organisation of moves of a particular genre, and this structure is somewhat established.

The above review shows that the term schematic structure is used to describe typical organisations of moves, implied by the recurring pattern of moves. The review also shows that this term is used in both the ESP and SFL.

\subsubsection{Distinctive structural pattern}

Distinctive structural patterns is also used to refer to the typical organisation of moves in a particular genre. For example, Holmes (1997, p. 322) concisely defines a genre as "a class of texts characterised by a specific communicative function that tends to produce distinctive structural patterns [emphasis added]." Holmes (1997, p. 328) explains that the distinctive structural patterns are "a standard pattern of organisation" referring to the typical organisation of moves in a particular genre. Consider this statement from Holmes (1997, p. 328): 
It seems safe to say that there is a standard pattern of organisation [italics added] for RAs in political science and sociology and perhaps for other social science disciplines consisting of Introduction-Background-Methods-Results-Discussion, with a number including a Hypotheses section between the Background and the Methods section.

The above example shows that the typical organisation of moves or the standard pattern of organisation can be referred to as distinctive structural patterns.

\subsubsection{Generic structure}

Paltridge (1996, p. 240) uses the term "generic structure" to refer to the typical organisation of moves of a particular genre. Paltridge (1996, p. 239) explains that generic structure accounts for the conventions of a particular genre such as "where the sender's and receiver's address should be placed" in the case of a formal letter.

Hyland (2004b, p. 303) examines the organisation of moves of dissertation acknowledgements as a genre and he calls it "the generic structure of dissertation acknowledgements." Even though Hyland does not explicitly explain the term, he uses generic structure to refer to the typical move structure of a particular genre.

More explicitly, Martin (1997, p. 13) states that as "most genres take more than a single phase to unfold," a genre is recognisable by its generic structure which consists of a set of stages. Martin's explanation implies that he uses generic structure to refer to the organisation of stages in a particular genre.

The above review shows that the terms schematic structure, distinctive structural patterns, and generic structure are used in the literature to refer to the typical organisation of moves in a particular genre, and the term generic structure in particular is used in both the ESP and SFL traditions. In my study, I use the term schematic structure because it is well-explained. 


\subsubsection{Move analysis}

Move analysis is primarily a methodology that genre analysts, particularly from the ESP tradition, use to analyse genres. The analysis involves analysing the moves and steps, and identifying the moves which are obligatory, typical or optional. However, it is not uncommon to analyse the moves without analysing the steps (Halleck \& Connor, 2006; Hopkins \& Dudley-Evans, 1988; Sadeghi \& Samuel, 2013). There are also studies (Labrador et al., 2014; Martín \& León Pérez, 2014; Yang, 2015) that analyse the lexicogrammatical features of particular moves and steps. Move analysis can also involve identifying the schematic structure of a particular genre.

A review of literature shows that analysing genres by paying attention to moves is wellestablished. A number of scholars have paid attention to moves in academic related genres such as theses (Hopkins \& Dudley-Evans, 1988; Samraj, 2008; Soler-Monreal et al., 2011), research articles (Kanoksilapatham, 2005; Posteguillo, 1999; Ruiying \& Allison, 2003; Samraj, 2002; Samraj, 2005; Xiao \& Cao, 2013), conference proposals (Halleck \& Connor, 2006), grant proposals (Connor \& Mauranen, 1999), and engineering lecture introductions (Shamsudin \& Ebrahimi, 2013), application letters to medical and dental schools (Ding, 2007), letters of appeal (Sadeghi \& Samuel, 2013); business and promotional genres such as business letters of negotiation (dos Santos, 2002), and sales letters (Zhu, 2000); and other genres such as birthmother letters (Upton \& Cohen, 2009) and sermons (Cheong, 1999).

Martín and León Pérez (2014) is an example of move analysis that analyses both moves and steps, identifies the schematic structure and analyses the lexicogrammatical features of the steps. Martín and León Pérez (2014) analyse 160 introductions of research articles in English (80 articles) and Spanish (80 articles), and compare how English and Spanish writers promote their research in their writing. Martín and León Pérez focus specifically on how writers present their research in Swales' Move 3: Presenting the present work and the steps that realise this move. I describe their methodology at some length here because it is an exemplary move analysis in my opinion. They use two corpora that include four subdisciplines each: health sciences (clinical and health psychology, dermatology) and humanities/social sciences (political philosophy and political science). The English journals were selected from highly-rated journals and all the texts were selected randomly. The Spanish journals were selected from leading national journals. Twenty 
texts were selected for each category. After collecting the texts, the authors conducted the move analysis independently and they achieved 98\% inter-rater reliability after discussion between the researchers. They identified the moves based mainly on semantic and functional criteria rather than on formal criteria. Within Swales' Move 3, which is presenting the present work, they concluded that there are five steps:

Step 1: Announcing present research

Step 2: Presenting hypotheses

Step 3: Announcing principal outcomes

Step 4: Stating value of the present research

Step 5: Outlining the structure of the paper

Martín and León Pérez (2014) found that announcing present research is the most common step in both the English and Spanish corpora and this step occurs in almost all the texts in the corpora. They also found that Step 5 did not occur in the health sciences corpus. Besides paying attention to the function of the move and steps, this study presents a balanced analysis of both macro and micro linguistic features. Martín and León Pérez (2014) identified lexicogrammatical features that are typical of each step. For example, in the health science corpus, they identified that lexical items such as important, importance, novel or original are typically used to explicitly emphasise the value of the research in Step 4. In the humanities/social sciences corpus, they identified that the use of first person pronoun followed by assertive verbs in the present or future tense (e.g. I argue, I shall demonstrate) is common in Step 5.

Genre analysts have also identified a phenomenon in which a genre (micro-genre) is embedded in another genre (macro-genre). For example, Woodward-Kron (2005, p. 28) analyses tertiary student assignments and explains that macro-genre is the "dominant genre of a student's text," and micro-genre refers to "genres that are embedded in the macro-genre." She found that students embed "empirical accounts" or "records of an experiment as evidence for a point within an argument" in the macro-genres of their assignments (i.e., exposition and discussion) (p. 29). Woodward-Kron (2005, p. 36) reports that "in many instances the micro-genres functioned implicitly as part of the argument stage of a discussion or exposition." This implies that a move in a particular genre (i.e., macro-genre) can be realised by other genres (i.e., micro-genres). 
As genres are social processes (i.e., processes that involve human interactions and human perceptions), a sound understanding of genre theory implies the necessity of analysing both texts and contexts. To understand the relationship between texts and contexts, for example, how readers of self-improvement books interact with the genre, I draw on Rosenblatt's reader-response theory, sometimes referred to as transactional theory.

\subsection{Reader-response theory}

Asselin (2000) states that a significant argument of reader-response theory is that there is no authoritative "correct" interpretation of a text. Although this theory rejects the existence of an authoritative "correct" interpretation of a text, drawing on genre theory, a prototypical interpretation is likely to exist. That is to say texts that belong to a particular genre are likely to have a typical structural organisation or generic structure (see Section 2.2.6.3) and linguistic features. Even though Rosenblatt (1982) rejects the Structuralist view where meaning is situated solely in a text, she does not advocate pure subjectivity in interpretation. In other words, reader-response theory avoids concentration solely on the reader's contribution or on feeling for its own sake, but centres on the reciprocal interplay of reader and text (Rosenblatt, 1982, p. 276). As Hirvela (1996) also notes, Rosenblatt views readers and texts as having approximately equal roles.

Similar to Asselin (2000), I conclude that the main objective of reader-response theory is to explain how readers negotiate meaning. Rosenblatt views a reader's response to a text as both individually and socially constructed. This implies that the purpose of a reader is crucial in determining the nature of a reading experience and the interpretation of a text. She views reading as a transaction involving a reader and a text at a particular time under particular circumstances (Rosenblatt, 1982, p. 268). This explains how individual feelings, experiences and knowledge contribute to a diverse response to a common reading.

One of the main contributions of reader-response theory is viewing reading as an efferentaesthetic continuum. In a predominantly efferent stance, readers focus on what is to be carried away at the end of the reading (Rosenblatt, 1982) in order to learn something (Asselin, 2000). Asselin (2000) suggests that in a predominantly aesthetic stance, the 
reading experience itself is a "lived-through experience," which Allen (1991, p. 20) describes as a rich experience of thought and feeling during the reading itself. In short, Carlisle (2000, p. 13) describes the aesthetic transaction as paying attention to the experience of reading itself. To make a distinction between the efferent and aesthetic stance, Pradl (1991, p. 40) suggests that someone else can read a text efferently for us, and acceptably paraphrase it but no one can read aesthetically for us.

In this study, I view genre theory and reader-response theory as complementary because genres are viewed in relation to social contexts, and in the case of self-improvement books, the readers' role in meaning making is a social one. A primary tenet of readerresponse theory is that meaning making happens when a reader transacts with a text, hence recognising equal roles of both the text and the reader. This is parallel to the main precept of genre theory where a class of texts cannot be analysed in isolation of social context.

\subsection{Persuasion}

As the literature suggests, the social purpose of self-improvement books is to offer advice and insights (see Section 2.1). This implies that authors need to persuade their potential readers that their advice and insights are worth "buying." Consistent with Rosenblatt's (1982) reader-response theory, this thesis views persuasions as a transactional process and persuasions as attempts. To understand how self-improvement authors persuade their potential readers, this section reviews the concept of persuasion.

Following this approach to persuasion, Virtanen and Halmari (2005, p. 3) explain that persuasion is:

all linguistic behaviour that attempts to either change the thinking or behaviour of an audience or to strengthen its beliefs, should the audience already agree.

Virtanen and Halmari's definition is useful to my study because it considers persuasion as a linguistic phenomenon and takes the role of the audience into consideration. Also, their definition has a functional orientation where speakers/writers attempt to modify, be it to change or strengthen, the audience's belief or behaviour. The success of these attempts, 
Hyland (2008, p. 3) says, is related to how effective speakers/writers "anticipate possible negative reaction to their claims," or what Roitman (2014, p. 742) calls "counterargumentation" in political debates.

To explore the aspects of these attempts, I draw on Connor and Lauer's (1988) work on persuasion in persuasive student writing. According to Connor and Lauer's (1988, p. 146) model, persuasion has three components: rational appeals, credibility appeals and affective appeals. Rational appeals refer to logical reasoning and can be realised grammatically by coherence markers such as conjunctions (e.g., and, but). Credibility appeals refer, Dafouz-Milne (2008, p. 101) explains, to "writer's personal experience, knowledge of the subject, and awareness of the audience's values." Similarly, Hyland (1998b) also states the importance of speakers/writers presenting themselves as credible personas in the attempt to persuade an audience. Finally, affective appeals refer to the use of language to "evoke emotion and sentiment in the audience" (Dafouz-Milne, 2008, p. 101). Consistent with sociocultural theory's idea that cognition and affect are "interrelated" (Swain et al., 2011, p. 76), rather than having rational appeals (cognitive) and affective appeals (affective), I combine the two appeals and discuss them as engagement. Drawing on sociocultural theory and Connor and Lauer's (1988) system of persuasion, for the purpose of my study, the two components of persuasion are credibility and engagement.

To illustrate the relationship between authors' attempts to persuade (i.e., linguistic realisations) and readers' perception of persuasion, a view consistent with readerresponse theory, I provide a review of Dafouz-Milne (2008). She studies how metadiscourse markers function as a persuasive device in British and Spanish newspapers. She defines metadiscourse as "features which writers include to help readers decode the message, share the writer's views and reflect the particular conventions that are followed in a given culture" (p. 97). She identifies textual metadiscourse markers and interpersonal metadiscourse markers, and compares the occurrence of these markers with readers' perspective of the persuasiveness of the text. It is worth noting that the terms and definitional approach to metadiscourse in Dafouz-Milne are based on Hyland (2005a). It seems to me that Hyland's idea of metadiscourse originates from the Hallidayan idea of register that looks at discourse as carrying ideational, interpersonal and textual meanings. 
In Dafouz-Milne's (2008, pp. 98-99) study, textual metadiscourse markers include logical markers (e.g., furthermore, but), sequencers (e.g., first, on the other hand), and reminders (e.g., let us return to, as was mentioned before), and interpersonal metadiscourse markers include certainty markers (e.g., undoubtedly, clearly), attributors (e.g., $x$ claims that, as the prime minister remarked) and attitude markers (e.g., unfortunately, I believe). The participants in her studies are native speakers of English and Spanish, and each group was given six opinion columns from either the English or Spanish newspapers. The six texts that each participant reads comprise two columns with a high proportion of metadiscourse markers, two with a medium proportion and two with a low proportion. After reading the texts, readers were given a questionnaire to rate the texts in terms of their persuasiveness. Dafouz-Milne (2008) concludes that participants in her study view texts with a balanced number of textual and interpersonal metadiscourse items to be the most persuasive followed by those that have a high occurrence of the markers. Even though coherence and engagement are rather different concepts, I view them as having a dialectical relationship. For instance, readers are unlikely to be persuaded by an incoherent text because it is incomprehensible. On the other hand, readers are unlikely to read an author's advice carefully when they do not perceive the author to be credible.

My discussion of the persuasion literature has shown that writers use a variety of linguistic resources in their attempt to persuade their audience, and that the main components of persuasion are credibility and engagement. The following sections discuss the concepts of credibility and engagement. I attempt to illustrate how perception of credibility differs across cultures and I will discuss the linguistic realisations of engagement.

\subsubsection{Credibility}

Hyland (1998a, p. 233) explains that credibility relates to the readers' perception of the speaker's/writer's "authority and competence." Hyland (1998b, p. 437) also states that, in academic writing, writers seek to persuade their readers by displaying "an appropriate professional persona." By "appropriate," Hyland implies that persuasion, in the form of ways to construct a credible persona, is genre specific. As Hyland (2005a, p. 64) notes, although a writer may construct a credible persona in his/her writing, readers may perceive a particular writer as credible before reading the text. This might be the case for 
authors who have built a positive reputation in their areas of expertise. Because a person's reputation is dynamic, the discussion of credibility in my study focuses on the resources that speakers/writers use in their attempt to construct a credible persona.

As mentioned in the previous paragraph, the ways speakers/writers construct credibility vary across genres. For example, in postgraduate writing, Hyland (2004a, pp. 141-142) states that citation is crucial because it justifies an argument and demonstrates the writers' familiarity with the literature. The crucial role of citation in postgraduate writing implies that justifying an argument and demonstrating familiarity with the literature by means of citation is viewed as credible within this particular culture. Very similar to citation, Hyland's (2010b, p. 122) analysis shows that popular science articles use direct quotes from experts to construct credibility. In research articles, Hyland (2010b, p. 116) states that researchers construct credibility by "claiming solidarity with readers, appraising ideas and acknowledging alternative views." To create a credible persona in research articles, authors align themselves with fellow experts in the field, and simultaneously compete with other members of the expert community to present their work as a unique contribution (Abdollahzadeh, 2011; Hyland, 2003, 2010a).

To explore how self-improvement authors construct credibility, Woodstock (2006) states that authors of this genre construct a credible persona by presenting themselves as being sympathetic to the problems that readers are experiencing, having genuine intentions to help the readers, and claiming solidarity with readers by presenting authors' life experiences as shared experiences (p. 322). Perhaps the most important way to construct an authoritative and credible persona in this genre, Woodstock (2006, p. 322) states, is to construct the authors as having "lay knowledge drawn from personal experience." Woodstock (2006, p. 324) also states that self-improvement authors construct an authoritative persona by presenting their "self-transformation" stories. While simultaneously using these resources to establish credibility, unlike authors of research articles who construct themselves as belonging to the community of experts, Woodstock (2006, p. 330) observes that self-improvement authors often present themselves as "average people like the constructed reader" and avoid associating themselves with the expert community.

A review of the literature shows that credibility is genre specific in that the resources that authors of different genres use to construct a credible and authoritative persona differ 
according to the genres. Moving on to the other aspect of persuasion, the next section discusses the idea of engagement.

\subsubsection{Engagement}

Hyland (2005b, p. 176) defines engagement as a "dimension where writers acknowledge and connect to others, recognising the presence of their readers, pulling them along with their argument, focusing their attention, acknowledging their uncertainties, including them as discourse participants, and guiding them to interpretations." Hyland's definition of engagement focuses on what writers "do" in the attempt to engage their readers, and is consistent with Rosenblatt's (1982, p. 268) reader-response theory where readers are not viewed as passive recipients but as active participants in a particular "transaction." Similarly, Fu (2012, p. 401) states that "engagement resources deal with reader-oriented features and their major function is to address the reader directly." Drawing on the above studies, this thesis focuses on the strategies that authors use in their attempts to engage readers while acknowledging that engagement is a negotiation or a transaction in Rosenblatt's terms.

The idea that engagement is related to persuasion is not a foreign one within linguistics and traces of this idea can be found in Virtanen and Halmari's (2005, p. 21) statement: "while the linguistic manifestation of explicit persuasion (such as imperatives) are easy to detect, markers of implicit persuasion are, by definition, less transparent." This statement includes imperatives as a persuasion resource. Following Hyland (2005b), I view imperatives, a subset of directives, to be predominantly performing an engagement function that is part of persuasion because I view engagement as a component of persuasion.

Studies on engagement have focused on cross-disciplinary comparison, such as comparing typical engagement strategies in academic journal articles across disciplines (Hyland, 2005b; McGrath \& Kuteeva, 2012), and cross-cultural differences, such as comparing Iranian and Anglo-American academic writers (Abdollahzadeh, 2011). Within the field of applied linguistics, most research that analyses engagement combines a functional (e.g., directives, shared knowledge) approach with a grammatical (e.g., pronouns, adverbs, modal verbs) approach. 
Hyland's (2005b, p. 177) engagement system, within academic writing, consists of five elements: reader pronouns, directives, questions, shared knowledge, and personal asides. My study draws on Hyland's system of engagement because it provides a practical and comprehensive framework for analysing elements of engagement. In this thesis, I focus on reader pronouns, directives (in the imperative form) and questions because they are the most unambiguous realisations of engagement in Hyland's system. I will briefly outline the five elements of engagement in Hyland's system and elaborate on the three aspects that I focus on.

Hyland (2005b, p. 182) proposes that reader pronouns (e.g., you, your, inclusive-we) are "the most explicit way" to bring readers into the text and "the clearest way" to acknowledge reader's presence, and writers can use them "to guide readers through an argument." This is an example of reader pronouns that Hyland (2005b, p. 183) provides from a philosophy journal article:

1. Suppose we say that static images can depict movement. This brings us into conflict with Currie's account,...

In Example 1, the writer uses inclusive-we to draw readers into the discourse and align them with an interpretation that this particular view of static images may result in conflict with Currie's account.

Hyland (2005b, p. 184) states that directives "instruct the reader to perform an action or to see things in a way determined by the writer."

Hyland (2005b, p. 185) states that questions arouse interest and encourage the reader to explore an unresolved issue with the writer as an equal, a conversational partner, sharing his or her curiosity and following where the argument leads. Hyland (2005b, p. 186) identifies questions that are followed up by an immediate answer from the writer in his data. This is Hyland's (2005b, p. 186) example:

2. What do these two have in common, one might ask? The answer is that they share the same politics.

Hyland (2005b, p. 183) states that writers use personal asides "to address readers directly by briefly interrupting the argument to offer a comment on what has been said" and he explains that this is a way writers use to construct readers as "an active audience." This is 
an example that Hyland (2005b, p. 183) provides from an applied linguistics journal article:

3. And - as I believe many TESOL professionals will readily acknowledge - critical thinking has now begun to make its mark, particularly in the area of L2 composition.

Example 3 illustrates how the writer interrupted his/her argument about critical thinking by inserting a comment on how many TESOL professionals would agree on his/her argument.

Hyland (2005b, p. 184) explains that appeals to shared knowledge seek to construct solidarity with readers, and writers can use it "smuggle contested ideas into their argument." Consider this example from Hyland (2005b, p. 184):

4. Of course, we know [emphasis added] that the indigenous communities of today have been reorganized by the catholic church in colonial times and after,...

Example 4 shows how the writer constructs the statement as common information that readers may share.

As can be seen in Examples 3 and 4, personal asides and shared knowledge can somewhat be ambiguous compared to reader pronouns, directives and questions. Because the main aspect of my study is not about how authors attempt to engage their potential readers, I have focused on the unambiguous realisations of engagement in Hyland's system (i.e., reader pronoun, directive (imperative form), and question) to get a sense of engagement in selfimprovement books. The central focus of this study is to analyse how authors structure the organisation of texts in self-improvement books and examine the social purpose of this genre.

\subsubsection{Reader pronouns}

Studies have examined second person pronoun in a number of contexts such as internet advice giving forum (Morrow, 2006), job postings ( $\mathrm{Fu}, 2012)$, lecture introductions (Yeo \& Ting, 2014), and pure mathematics research articles (McGrath \& Kuteeva, 2012). 
Although reader pronouns, Hyland (2005b) says, are the most explicit way to address readers, it is not always easy to identify the difference between you referring to a specific reader or to people in general, like the indefinite pronoun one. However, the differences, in my view, do not pose a problem for the purpose of my study because using you to refer to people in general would have included the specific reader. The purpose of analysing the pronouns in my study is to analyse how authors use pronouns as a resource to engage the readers. $\mathrm{Li}$ (2009, p. 132), for example, explains that you can be used to attract attention. This is an example from her data:

5. Hey you, you just scratched my car with your Frisbee.

Some studies examine the frequency of pronouns and analyse their discourse functions. Yeo and Ting (2014), for example, compared how you functions in lecture introductions across fields of study: arts and science. In their study, they make a distinction between you that refers to a specific audience and you that refers to people in general. Their analysis shows that about $80 \%$ of you in their dataset is used to refer to the audience. In comparing the arts and science lecture introductions, Yeo and Ting (2014, p. 30) find that you-audience is more frequent in the science ( 31 per 1000 word tokens) than the arts (20 per 1000 word tokens).

Because personal pronouns are not the focus of my study, I did not make this distinction in this thesis. The most common discourse function of you in both fields of study is activating students' prior knowledge followed by giving instructions or making announcements (Yeo \& Ting, 2014, p. 31).

Even though you is unspoken in an imperative clause (Kuo, 1999, p. 127), this thesis does not include such instances in my counting because I would not be able to compare the frequency of you in my dataset with other genres in the literature as such instances are not typically included. Because the prototypical function of imperative clauses is to perform a directive speech act, I will discuss these clauses with reference to directives rather than reader pronouns, although I agree with Kuo (1999) that you is unspoken in imperative clauses. 


\subsubsection{Directives}

Goodwin (2006, p. 517) defines directives as "utterances designed to get someone to do something," and Vine (2009, p. 1396) explicitly states that these utterances should be viewed as "attempts" to get someone do something. Researchers have studied directives in various contexts such as physiotherapist-patient discourse (Parry, 2013), parentchildren mealtime interactions (Craven \& Potter, 2010), teacher mentoring conversation (Strong \& Baron, 2004), academic writing (Hyland, 2002a) advice giving in a radio callin programme (Hudson, 1990), doctor-patient discourse (West, 1990), and spoken American English (Ervin-Tripp, 1976).

Swales et al. (1998) investigate how imperatives in 50 research articles from ten disciplines, five from each discipline. In categorising the imperatives they identified, they included hortative imperatives or imperatives with let. An example from their data is the let us + verb pattern. Swales et al. (1998, p. 107) explain that let us + verb pattern can be interpreted as an invitation. Similarly, Neiderhiser et al. (2014) examine imperatives in upper-level A-graded student papers from 16 disciplines and they also included let us + verb pattern in their analysis. Because the pronoun us in let us includes the author, I excluded this pattern from my analysis because I am interested in imperatives that are directed solely to readers. Although not all hortative imperatives have the pronoun us, I have consistently excluded all hortative imperatives in my study. Also, as the purpose of studying imperatives in my research is to investigate the types of advice (see Section 6.2) that self-improvement authors give, hortative imperatives seem to perform a more illocutionary force related function rather than a field related function in a Hallidayan sense.

Ervin-Tripp (1976) investigates spoken American English and she suggests that different syntactic forms of directives carry different social meaning. She notes that syntactic forms of directives occur systematically in various settings and different social relationships. She concludes that syntactic forms of directives can reflect the type of power relationship between the addresser and the addressee. Ervin-Tripp (1976, p. 31) includes attentiongetters such as "please" or "excuse me" as imperatives. These are her examples: 
6. [A child yelling in the vicinity of a group of adults talking]:

[Father to child]: Please!

7. [A student enters lecture hall, starts to sit on chair and finds a pile of books]:

[To person seated in next chair]: Excuse me!

Ervin-Tripp (1976, p. 30) seems to categorise imperatives both syntactically and functionally, which I find problematic. In other words, Ervin-Tripp (1976) sees attentiongetters as a subset of imperatives. I view attention-getters as a subset of directives (as they perform acts of giving instructions) rather than a subset of imperatives.

Similarly, Parry (2013) focuses on spoken discourse. She analyses physiotherapist-patient communication in physiotherapy sessions which focuses on directives, requests and recommendations. Following Craven and Potter (2010), Parry (2013, p. 109) describes directives as instructions where the addressee's willingness is not taken into consideration, and requests as asking rather than telling. Parry (2013, p. 109) argues that try-clauses, such as "try and come forwards and up lifting..." are requests. She claims that such clauses require patients to try rather than to perform a movement. Parry (2013, p. 112) notices that recommendations for future actions are often in the declarative form and they are often accompanied by modals such as "I think you would need somebody with you" and they are often followed up with reasons such as "...because the gap between the pavement and the bus is quite big". In her study, directives, requests and recommendations are seen as three different categories of giving instructions. In my study, directives are not a subcategory. Drawing on Vine (2009) and Goodwin (2006), I view directives as utterances that writers use to attempt to get someone to do something. In that sense, making a request and making recommendations are subsets of directives because they are attempts to get someone do something regardless of whether the addressee's willingness is taken into consideration or whether the instruction is for the future.

To explore the relationship between directives and advice giving, Strong and Baron (2004) studied mentoring conversations between veteran teacher mentors and beginning teachers in a new teacher induction programme. Strong and Baron found that the strategies that veteran teacher mentors use to present their advice can be categorised as direct and indirect. The direct category refers to instances where imperative clauses are used and this category is the least common strategy in their data. The indirect category consists of four subcategories: possibility, question, anecdote, and reformulation. Strong 
and Baron explain that words such as perhaps, maybe, might, and could are present when veteran teachers present their advice as possibilities. This is the most common strategy in their data. Questions are the second most common subcategory and anecdotes are the third. Note that Strong and Baron use the term anecdote to refer to ideas or accounts of teaching methodology that beginning teachers "had seen elsewhere, read or heard about" (p. 51). The fourth most common strategy is reformulation, which refers to how veteran teachers paraphrase beginning teachers' ideas. Strong and Baron's study shows that veteran teachers most commonly present their advice as possibilities and avoid giving direct advice. They explain that veteran teachers avoid using imperative clauses because they want to promote thinking and elicit ideas from beginning teachers (p. 53). This study shows that directives or more specifically suggestions are realised in various ways motivated by various reasons.

\subsubsection{Questions}

Biber and Conrad (2009, p. 7) note that questions are a common feature in conversation. Studies have shown that questions are used as a resource to engage readers in academic writing (Hyland, 2005b), to construct membership in a doctor-patient interaction (Ainsworth-Vaughn, 1994), to build rapport with students in lectures (Flowerdew \& Miller, 1997), to introduce new a new topic in academic setting (Flowerdew \& Miller, 1997; Hyland, 2002c), to solicit agreement (Brown, 2010b) and convey information (Freed, 1994) in casual conversation, and to challenge opposing ideas at workplace (Manning, 2012). In written discourse, research has investigated a number of contexts including dating advertisements (Marley, 2002), direct sales letters (Frank, 1989), business textbooks and online learning resources (Crawford Camiciottoli, 2008), and research articles and undergraduate project reports (Hyland, 2002c).

Flowerdew and Miller (1997) compare questions in commercial academic listening textbooks and authentic first year undergraduate lectures offered by the Department of Economics and Finance at City University of Hong Kong. Their study includes analysing the recorded lecture and conducting semi-structured interviews with the lecturer and students. The lecturer was given a log book to record his reflection on the lectures of that course. Two researchers were present in five of the lectures given by this lecturer to observe the presentation style and students' behaviour. Flowerdew and Miller (1997) 
discover that the questions found in lectures are not well represented in academic listening textbooks. A lecture was selected from a larger dataset of lectures collected from the same university. The lecture was selected because it has typical characteristics of the larger dataset and it does not contain any feature that is unusual to the pool of data. Their analysis shows that questions are used to establish the theme of the lecture, to check student's comprehension, to create an impression of a joint effort between lecturer and students, to introduce a new topic, to create rapport with students, and to signal the structure of the lecture.

Ainsworth-Vaughn (1994) observes that physicians usually use rhetorical questions to mitigate their commands. Occasionally, patients in her study use rhetorical questions to criticise physicians and to engage in potentially face-threatening behaviour such as challenging the physician's competence. She observes that physicians, at times, take over patients' question-asking role and later provide an explanation for the patients as if responding to the patients' question. Ainsworth-Vaughn's (1994) includes recordings of 40 patient-physician encounters in a private-practice setting. The recordings were done without the presence of the researcher. The analysis of the recordings is supplemented with on-site observations and interviews with two physicians and ten patients.

Holmes and Chiles (2010) examine questions within New Zealand workplace interactions, and analyse their data both grammatically and pragmatically. Grammatically, they categorise the questions into four question types: a) yes/no, b) wh, c) declarative and d) tags. Pragmatically, the questions are categorised as a) requests for information, b) requests for confirmation and c) others. Holmes and Chiles discover that yes/no questions are the most common form of question in New Zealand workplace interactions. Their data shows that, pragmatically, $44 \%$ of the total questions are used to request information and $45 \%$ of the total questions are used to request confirmation. Their study suggests that the distribution of question functions is similar in one-on-one interactions and large meetings.

The studies that I reviewed above demonstrate that questions do not always seek information. The review also shows that questions can be analysed in terms of function and question types (e.g., yes/no question, wh-question). Also, these studies use observation and interview data to supplement their text analyses. Drawing on these 
studies, my thesis focuses on the purpose that self-improvement authors have for using questions in their books.

\subsection{Ideology and self-improvement books}

Ideology, Martin (1992, p. 296) states, relates to "discourses manifested across a range of texts." This implies that a set of ideologies holds a range of self-improvement books together as a genre, and motivates genre analysts to "excavate" these latent ideologies. This section reviews the definition of ideology and discusses four ideologies that relate to self-improvement books: the American Dream, American individualism, neoliberalism, and New Age beliefs.

\subsubsection{Definition of ideology}

Hamilton (1987) reviews definitions of ideology from 85 sources. Based on his review of the elements in various definitions, he formulates his own definition. Hamilton (1987, p. 38) defines ideology as:

"...a system of collectively held normative and reputedly factual ideas and beliefs and attitudes advocating a particular pattern of social relationships and arrangements, and/or aimed at justifying a particular pattern of conduct, which its proponents seek to promote, realise, pursue or maintain".

Hamilton's definition includes the various realisations of ideology including the social aspects of ideology. These aspects are relevant to my study because like any genre, selfimprovement books are a realisation of a particular ideology. This implies that the way authors write self-improvement books indicates that a particular ideology is being promoted, realised and maintained.

Gerring (1997, p. 961) observes that some scholars view the word ideology to be problematic, and that some of them have opted for words such as worldview, attitude, philosophy, and culture. Gerring (1997, p. 961) criticises such alternatives as not always capturing the "full" meaning of ideology, and he proposes that having a core definition is 
a potential solution. He summarises his literature review into a list of seven attributes of the concept ideology. Because my study examines self-improvement books as a genre and explores how linguistic features relate to the social purpose of the genre, the most relevant attribute in Gerring's (1997, p. 967) framework is the "location" attribute of ideology:

a) Thought - ideology as a set of beliefs

b) Behaviour - ideology as a set of practices

c) Language - ideology derived from linguistic norms

The location aspect of Gerring's framework includes the dialectical relationship between the three components: beliefs, practices and language norms. Consistent with social theories, I view the three components as dynamic, each supporting the other components. In other words, I do not view linguistic norms, for example, as a result of a set of beliefs. I reason that linguistic norms "reinforce" beliefs, and beliefs "affect" how language is used. They have a complex inter-relationship.

Within the field of discourse analysis, similar to Gerring (1997), van Dijk (2009, p. 65) includes the component of shared beliefs among members of a particular community in his definition of ideology, and states that ideologies are "the shared, fundamental and axiomatic beliefs of specific social groups (socialism, neoliberalism, feminism, (anti)racism, pacifism, etc.)."

These shared beliefs, van Dijk (2011) explains, have a dialectical relationship with how members of a particular community construct reality and use language:

General systems of basic ideas shared by the members of a social group, ideas that will influence their interpretation of social events and situations and control their discourse and other social practices as group members (p. 380).

This system of shared beliefs, van Dijk (2011, p. 388) explains, tells members of an ideological community, for example, what is desirable/undesirable, what is valid/invalid, and what is moral/immoral. From this perspective, my study explores what self-improvement authors construct as desirable, valid, and moral.

Drawing on various definitions of ideology, I view ideology as a dynamic set of beliefs and practices (Gerring, 1997; Hamilton, 1987; van Dijk, 2011) that are socially developed 
among specific social groups over a period of time (van Dijk, 2011). This shared system (e.g., desirable/undesirable) is linguistically observable (Gerring, 1997; van Dijk, 2011). Gerring's (1997) and van Dijk's (2011) idea that ideologies are linguistically observable implies that it is reasonable to use text analysis to identify the ideologies underlying selfimprovement books.

\subsubsection{The American Dream}

As discussed in Section 2.1, literature indicates that self-improvement books are closely related to the ideology of the United States. To explore this ideology, this section reviews American Dream literature. The American Dream is the view that America is the land of opportunity and with hard work and perseverance, individuals can be successful (Spence, 1985). Self-reliance, self-determination, and self-made men and women are the main values within the American Dream (Cullen, 2003; Miller, 1967; Spence, 1985), and Cullen (2003, p. 6) claims that these values remain major elements in America's identity in the twenty-first century. Cullen (2003) states that the American Dream advocates a better, richer and fuller life, and he explains that this is often defined in terms of money. Cullen explains that this can be extended to religious transformation, political reform, educational attainment and sexual expression, to name a few areas. In short, the American Dream is about individual Americans finding personal fulfilment in their lives.

Cullen (2003, p. 8) states that an aspect of the American Dream is upward mobility, an aspect that is often associated with economic and/or social advancement. This aspect relates to the goal of becoming successful in terms of career advancement, for example. Slightly different from Cullen's explanation, James Truslow Adams, the historian who coined the term American Dream, emphasises that the American Dream is more than material success. Adams (1931) states that the American Dream is about a dream of:

a land in which life should be better and richer and fuller for every man, with opportunity for each according to his ability or achievement.... It is not a dream of motor cars and high wages merely, but a dream of a social order in which each man and each woman shall be able to attain to the fullest stature of which they are innately capable, and be recognised by others for what they are, regardless of the fortuitous circumstances of birth or position (p. 317). 
Writing in the 1930's, Adams uses the masculine forms man and his in an apparently sexist way, but then refers to each man and each woman. This shows that his message is not intended to be sexist, and reflecting on the time, it is not surprising that his use of language does not conform to current non-sexist usage guidelines.

Adams' (1931) definition of the American Dream includes emphasis on a better life, which implies the necessity of constant self-improvement, along with an ideal government, social reputation and equality. His definition implies that regardless of social class, both men and women should have equal opportunity. This aspect is evident in the American Declaration of Independence (US, 1776) that Martin Luther King Jr. (1963) called a creed in his speech:

I still have a dream. It is a dream deeply rooted in the American dream that one day this nation will rise up and live out the true meaning of its creed - we hold these truths to be self-evident, that all men are created equal.

Another aspect of the American Dream, Cullen (2003, p. 10) states, is freedom, and that includes "freedom to commit" and "freedom from commitment." Cullen (2003, p. 10) explains that all notions of freedom rest on the idea that an individual should be free to pursue his/her dreams. Cullen (2003, p. 16) adds that the American Dream is the notion of improvement and that "one's children might have a better life." The last aspect of the American Dream that Cullen (2003, p. 133) identifies is the dream of home ownership. This implies the necessity of career advancement in order to afford a house.

Because ideologies evolve historically (van Dijk, 2011, p. 386), I briefly summarise Cullen's (2003) historical account of the American Dream to demonstrate how the ideology evolved over time. The beginning of the American Dream can be traced to the time when the Puritans left England for America in search of a land that was free of "contamination." This is because the Puritans viewed the Church of England to be as corrupt as they viewed the Catholic Church as being. The Puritans were known for their self-righteousness, but they were also known for their hard work, which Cullen argues has an influence in shaping the American Dream. The Puritans believed that destiny is predetermined by God and human effort is unable to change divine predetermination. Ironically, Cullen notices that the effort and determination in search for the "promised land" may contradict the very idea of predetermined destiny. From the migration, the Declaration of Independence marks another milestone of the American Dream. Cullen 
suggests that the declaration of independence indicates that people are embracing the idea of the possibility of human effort in shaping one's destiny. Later in American history, Cullen argues that the emergence of self-improvement books indicates that advocates of the American Dream believe that humans, by individual effort, could determine their future.

Within folklore and communication studies, scholars such as Grodin (1991) and Dolby (2005) state that self-improvement books are often associated with American values and cultures. To discuss self-improvement books in light of the American Dream, Cullen (2003) discusses the genre within this ideology and provides an overview of how the American Dream evolved over time:

The American Dream narrative begins with people who denied their efforts could affect their fates, moves through successors who later declared independence to get that chance, to heirs who elaborated a gospel of self-help promising they could shape their fates with effort (p. 10).

Cullen's statement illustrates how the American Dream has evolved from the view that human beings could not change their destiny to the view that human beings could have control over their destiny.

Dolby (2005, p. 157) proposes that readers and writers of self-improvement books alike are participants in the American "pursuit of happiness" (US, 1776) that is also a tenet of the Declaration of Independence. Bergsma (2008, p. 347) explains that self-improvement books became a source of guidance when Americans noticed that obstacles to upward social mobility were removed and they felt that they could now participate in the American Dream.

The main idea of the American Dream as presented in this section is that individuals through hard work and perseverance should have freedom and equal opportunity to pursue happiness and success regardless of their social background and gender. This section has also presented a brief historical account of the American Dream to explain how the idea evolved. 


\subsubsection{American individualism}

To explore another ideology that is closely related to the American Dream is American individualism. The concept of American individualism was originally associated with "equal rights, freedom and dignity" (Becker \& Marecek, 2008, p. 1768), and these pursuits are often related to, as Jones et al. (2011, p. 319) explain, the freedom to pursue individual "talents and ambitions." Historically, Miller (1967, p. 102) writes that, by about 1820, the ideals of American individualism were "self-reliance, self-determination, and self-made men." Although these elements are similar to the American Dream, the word self in the three elements signals the individualistic aspects of the elements. Again, reflective of the time of writing, Miller uses the expression self-made men in an apparently sexist way but later refers to these self-made men as "“self-made" individuals" (Miller, 1967, p. 115). This implies that though Miller's use of language sometimes appears to be sexist for readers today, his message is not intended in that way.

Individualism within American context, Miller $(1967$, p. 8) states, advocates that the primary goal of an individual is "to achieve a better image" of himself/herself in his/her own eyes and in the eyes of society through "continual efforts." This achievement, Miller (1967, p. 103) explains, is often associated with "performing a respectable role in society." In more recent literature, Becker and Marecek (2008, p. 1770) state that selfimprovement has always been "the mantra of American individualism," and explain that the need for constant improvement is motivated by the hope to increase happiness and self-fulfilment. Other goals for self-improvement include the pursuit of "self-interest" (Jones et al., 2011, p. 318).

Miller (1967, p. 7) refers to the process of utilising one's potential to the maximum and constantly putting effort in improving oneself as self-actualisation. This concept, Becker and Marecek (2008, p. 1768) report from their literature survey, is at the centre of contemporary American concept of self-actualisation and is about the search for satisfaction and personal gratification by the expression of individual uniqueness. In other words, contemporary American individualism expects individuals to continually strive for self-improvement by focusing on and enhancing their own strengths in order to find fulfilment and happiness in their own lives, and also places responsibility for doing so on the individual. 
The artefacts of American individualism are self-improvement books (McGee, 2005). Bergsma (2008, p. 347) reasons that individuals reading self-improvement books fit the individualistic approach to pursuing self-improvement and happiness. However, the idea of self-fulfilment and happiness that this genre presents, Becker and Marecek (2008, p. 1772) note, is mainly the "ideal" of middle-class Americans, and Bergsma (2008, p. 350) criticises the "one-size-fit-all" approach and the lack of consideration for the diverse background of potential readers in self-improvement books. This implies that American individualism, as realised in self-improvement books, does not consider sociocultural aspects that are integral to an individual's development.

In summary, similar to the American Dream, American individualism has a focus on hard work, perseverance and the idea of self-made men and women. The main idea of American individualism is that individuals are able to pursue their goals and they should have the rights to achieve these goals. This implies that individuals should constantly strive to improve themselves to maximise their potential.

\subsubsection{Neoliberalism}

A review of literature in Section 2.1 shows that self-help discourse is evident in political speeches in Slovenia, a government that was moving from post-socialism to neoliberalism. This section provides a review of neoliberalism. Young (2008, p. 5) defines neoliberalism as:

a policy strategy that aims to achieve specific political and economic goals through the partial transfer of authority and/or responsibility from the public sphere (where it is subject to collective political contestation) to private domains (be they corporate, group, and/or individual).

Young's (2008) definition illustrates how neoliberal governments transfer the responsibility of the government to individuals or individual corporates, and expect the individuals or individual corporates to be responsible for their own survival with minimal or no aid from the government. Jessop (2002, p. 461) reasons that by reducing the role of the government, this ideology results in free competition. Choi et al. (2012, p. 55) define neoliberalism as "a philosophical framework that supports competition, standardisation, efficiency, top-down hierarchy, and individualism." According to this definition, 
advocates of neoliberalism consider that individuals are ultimately responsible for constantly improving themselves to be more efficient in order to be competitive. Jessop (2002, p. 465) states that this competition results in "the key" role of "education and informal self-help" for survival.

This ideology can be promoted through language, as illustrated by Erjavec and Volćićs (2009) account of how an ex-president of Slovenia used self-help discourse in his speeches and blogs to transfer responsibility from the government to the citizens of Slovenia. At the beginning of the twenty-first century, Erjavec and Volćić (2009, p. 100) state, the government of Slovenia was moving from post-socialism to neoliberalism, and this move resulted in the reduction of welfare programmes (e.g., public health) and transferred such responsibilities to citizens. Erjavec and Volćić (2009, p. 101) explain that President Drnovsek, the then president of Slovenia, achieved this responsibility transfer by using self-help discourse to promote the idea of personal empowerment and selfgovernance in his political speeches. Jessop (2002, p. 465) adds that citizens, in such selfhelp discourse, are constructed as "active and productive" and described as citizens "who will not burden the government."

In short, a neoliberal government transfers the responsibility of public welfare from the government to the citizen, and this ideology can be promoted, as in the case of Slovenia, through the use of self-help discourse by its head of state in public speech. This ideology results in a constant need for citizens to strive to survive, which implies the necessity of constant self-improvement. The ideology seems relevant to self-improvement books, a genre that promotes the idea that readers are responsible themselves to improve their lives.

\subsubsection{New Age beliefs}

Spiritual self-help books, a genre that Askehave $(2004$, p. 8) says originates from and promotes the New Age ideology, seems to be a genre closely related to self-improvement books. This section provides a concise review of the New Age ideology. Askehave (2004, p. 8) argues that, similar to most ideologies, the New Age movement is not a unified movement, but that it varies slightly in different parts of the world. Askehave (2004, p. 11) states that a shared belief among New Agers is that human beings have two types of 
self: the personality self (ego) and the Higher Self. Askehave (2004, p. 11) explains that this Higher Self, New Agers believe, is a God-like entity within human beings that provides them with "unlimited power, love and wisdom." Askehave (2004) states that the Higher Self is regarded as the source to turn to when trying to improve one's life, and she points out that this ideology is evident in spiritual self-help books.

Since New Agers believe that human beings are divine and are the source of selfimprovement, human beings are viewed as both helpers and opponents in their lives. Askehave (2004, p. 12) states that New Age ideology assumes that human beings (being divine) are responsible for creating their own reality and improving their lives, unlike Christians who call upon "an Almighty God" for the same purpose. In other words, human beings are to be blamed or praised for the "bad" things or "good" things that take place in their lives. This ideology is evident in the stories in the spiritual self-help book that Askehave (2004, p. 27) examines in which the main character is constructed both as a person who needs to improve, who initiates the improvement, and who assists the improvement process, but also as the person who hinders the process. These characteristics of the stories imply that authors of spiritual self-help books construct their potential readers as individuals who should be responsible for their lives.

In the broadest sense, New Agers believe that as divine beings, human beings have the power to determine their destiny, which implies that they are responsible for improving themselves. The idea that individuals are responsible for improving their lives seems to be at the core of spiritual self-help books, and self-improvement books in general share this idea.

\subsection{Summary of chapter}

The goals of this chapter were to position the study within existing studies of selfimprovement books, and to outline the theoretical approach I use in this thesis. Because the main purpose of this thesis is to explore the characteristics of self-improvement books, my study draws on the three main traditions of genre theory eclectically: English for Specific Purposes, Systemic Functional Linguistics, and the New Rhetoric. This study uses the terms move structure and schematic structure to refer to the organisation of moves in 
a particular text and the prototypical organisation of moves in a particular genre.

Following reader-response theory, this study views readers as active participants in a reading process rather than passive recipients of information. This implies that both text analysis and interview data are crucial in this study. To explore how self-improvement authors attempt to persuade their readers, my study draws on the idea of credibility and engagement. Because a genre is situated within particular ideologies, my study draws on relevant ideologies to explain linguistic characteristics of self-improvement books. This chapter has discussed studies and theories that are relevant for analysing selfimprovement books as a genre, and the next chapter will present the methodology used for exploring the genre. 


\section{Chapter 3: Research design and methodology}

To understand self-improvement books from a genre analysis perspective, paying close attention to linguistic features of the genre, Paltridge (1997) explains, is insufficient as genres are situated in context of culture. As a systemic functional linguistics concept, context of culture relates to the "interpretation of genre as the cultural purpose of texts" (Eggins, 2004, p. 54). Any text, Christie (1984, p. 24) explains, can only be fully understood in relation to "the purposes of constructing the language text" and "the relationships between the participants involved." Hence, it is incumbent on the study to explore beyond written texts by studying the context where the genre is situated: the authors, the readers, and, I would argue, the necessity of studying the non-readers as well to provide insights from the other side of the coin. This study approached text from context and context from text. The text analysis (move analysis and register analysis) and the ethnographic approach (Flowerdew \& Wan, 2006) informed each other (see Section 2.2.2).

\subsection{Research design}

The methodology is presented with reference to the research questions. The questions can be organised as text oriented and context oriented. RQ1 is text oriented and the others are context oriented.

RQ1: What are the characteristics of self-improvement books as a genre?

To study the characteristics of this genre, I rely on the notion of prototypes (Bawarshi \& Reiff, 2010; Hyland, 2002b; Mayes, 2003; Paltridge, 1997; Swales, 1990). The notion of prototypes in this study includes linguistic features that are typical of this genre (see Section 2.2.1) and social purposes (i.e., purposes that are typical and socially recognisable). The text analysis of self-improvement books consisted of two phases. The 
first phase involved the selection of self-improvement books. The second phase involved analysing the moves and lexicogrammatical features of the genre. I will describe the phases in the following paragraphs.

To identify self-improvement books, a set of descriptive criteria of the genre was developed. I selected 40 books based on the description. This process will be described in detail in the next section. See Appendix 1 for the list of books. To describe the sections in the genre, I selected 20 books from the 40-book dataset. A detailed description of this process is in Section 3.4. This analysis then informed my decision in terms of selecting prominent sections in the genre that required closer examinations. The methodology of these sections is reported in Chapter 5. At a register level, I examined personal pronouns, directives in the imperative form, and questions. As book titles are arguably the first component that potential readers encounter, I examined the characteristics of selfimprovement book titles in terms of length and lexicogrammatical features, and compared them to another genre. To explore the interpersonal meaning in selfimprovement books, I analysed modal verbs. The methodologies of analyses at a register level are presented in Chapter 6.

RQ2: Why do authors write self-improvement books?

To answer the second research question, I used semi-structured interviews (Flowerdew \& Wan, 2006). My main purpose for interviews, following Grodin (1991), is to summarize the common experiences of participants rather than suggesting that the group is a coherent entity. Following the semi-structured interviews conducted by Flowerdew and Wan (2006) with three tax accountants and Samraj (2008) with three professors, I conducted semi-structured interviews with seven self-improvement book authors. By a semi-structured, I mean an open-ended interview with minimal directions from the interviewer. I approached 10 authors by email and seven agreed to participate, two declined the invitation, and I did not receive a reply from the other one. Five interviews were conducted via Skype, one via email, and one face-to-face. I will describe the interview process in some detail in Section 3.4. 
RQ3 and RQ4: Why do readers/non-readers of self-improvement books read/not read this genre?

To answer RQ3 and RQ4, I used semi-structured interview and recruited 12 readers of this genre and 15 non-readers of this genre. The interview questions were mainly about the purpose of reading self-improvement books. See Appendix 3 for the interview questions.

To recruit the interviewees, I designed an advertisement (see Appendix 4) and asked a Wellington City Library librarian for permission to have a notice advertising my proposed research in the library. The librarian suggested I give three copies for each public library in Wellington and she would distribute them to all the public libraries in Wellington. The advertisement included my contact details and a brief description of the interviews.

The advertisement sought people who read and did not mind talking about their reading experience. This was to make sure I had interviewees who read something. The nonreaders of self-improvement books in my study had to be people who read other genres beside self-improvement books. If a participant did not read anything, it would be inevitable that he/she was not a reader of self-improvement books. I did not advertise the research as a self-improvement books related project because the label of the genre is arguably ambiguous (see Section 2.1). Also, because a participant from my preliminary interview reported that reading self-improvement books is a sign of weakness, I did not want the advertisement to keep readers from being potential participants. I also approached bookshops regarding posting the advertisement there and received three positive responses. When I received an e-mail from people who volunteered to be interviewed, we arranged to meet at a mutually agreed time and venue. The interview process is described in Section 3.5.

\subsection{Identifying self-improvement books}

In the process of building a dataset of self-improvement books, I developed a set of characteristics for the selection of self-improvement books. Not only did the 
characteristics enable me to include books in the dataset in a consistent manner, but they also allow other researchers to replicate the dataset.

To develop the list of criteria, I browsed the books at the self-help section at the Wellington City Library, looking at the title and contents pages of each book and eliminating those that I thought were not self-improvement books. In the process of elimination, I made notes and kept a reflective record of why a particular book was not included. I also recorded characteristics of books that I considered to be selfimprovement books. I have summarised the characteristics of self-improvement books in Table 2 and the characteristics of the books that were eliminated in Table 3. Based on these characteristics, I selected the books to build the dataset for my study.

Table 2: Characteristics of self-improvement books

\begin{tabular}{|l|l|}
\hline Self-development topics & $\begin{array}{l}\text { 1. Appreciation of unique talent and } \\
\text { personality/loving yourself }\end{array}$ \\
2. Being confident and comfortable with oneself \\
3. Being effective individuals \\
4. Believing in your dream/following your heart \\
5. Coping with emotional crisis \\
6. Coping with misunderstanding \\
7. Courage to move on in love, work and life \\
8. Dealing with bad news \\
9. Dealing with self-doubts \\
10. Discovering purpose in life \\
11. Discovering the key to happiness \\
12. Discovering your destiny \\
13. Embracing risk rather than giving into the fear of \\
setbacks \\
14. Emotional balance \\
15. Expanding horizon/perspective \\
16. Family interaction \\
17. Forgiveness \\
18. Friendship \\
19. General career development \\
\end{tabular}




\begin{tabular}{|c|c|}
\hline & $\begin{array}{l}\text { 20. Happiness } \\
\text { 21. Having a positive attitude } \\
\text { 22. Individual maturity } \\
\text { 23. Learning from the past } \\
\text { 24. Leaving a legacy } \\
\text { 25. Life should be more memorable rather than average } \\
\text { 26. Overcoming adversity/anxiety } \\
\text { 27. Peace of mind } \\
\text { 28. Positive thinking/Optimism } \\
\text { 29. Preparing for the "real world" } \\
\text { 30. Relationship } \\
\text { 31. Self-discovery } \\
\text { 32. Self-esteem } \\
\text { 33. Self-fulfillment/sense of achievement } \\
\text { 34. Self-realization (open up to the truth about their own } \\
\text { inner being) } \\
\text { 35. Street-smart wisdom } \\
\text { 36. Taking responsibility } \\
\text { 37. Trust your ability } \\
\text { 38. Wisdom }\end{array}$ \\
\hline Nature/style of writing & $\begin{array}{l}\text { 1. Author includes his/her personal experiences } \\
\text { 2. Directs/advises/suggests and inspires } \\
\text { 3. Elements of inspirational short stories } \\
\text { 4. Engaging/insightful } \\
\text { 5. Informs and inspires } \\
\text { 6. Interactive - gives room for reflection } \\
\text { 7. Personal } \\
\text { 8. Touches the heart }\end{array}$ \\
\hline General approach & $\begin{array}{l}\text { 1. Caters to the general needs (not a specific need e.g., } \\
\text { pregnancy, how to quit smoking, financial } \\
\text { management) } \\
\text { 2. Counseling approach } \\
\text { 3. Life changing elements/transforming }\end{array}$ \\
\hline
\end{tabular}




\begin{tabular}{|l|l|}
\hline 4. Makes your spirit soar \\
5. Mere mention of religion/ universal concept of \\
religion is acceptable (e.g., personal belief in God, \\
call on a higher power) \\
6. Motivational \\
7. Practical help (e.g., stop whining and start living) \\
8. Simple truth (not heavy philosophy e.g., Socratic)
\end{tabular}

Table 3: Characteristics of eliminated books

\begin{tabular}{|c|c|}
\hline $\begin{array}{l}\text { New age } \\
\text { beliefs/practices }\end{array}$ & $\begin{array}{l}\text { 1. Awakening senses, body and brain } \\
\text { 2. Metaphysical philosophy } \\
\text { 3. Promotes meditation } \\
\text { 4. Promotes yoga }\end{array}$ \\
\hline $\begin{array}{l}\text { Excessive religious } \\
\text { elements }\end{array}$ & $\begin{array}{l}\text { 1. Heavy religious discussion e.g., heaven/hell topic } \\
\text { 2. How to pray/pray in a particular way } \\
\text { 3. Promoting a particular religion } \\
\text { 4. Spiritual/religious devotional elements }\end{array}$ \\
\hline Ancient beliefs & $\begin{array}{l}\text { 1. Astrology } \\
\text { 2. Feng Shui } \\
\text { 3. Horoscope } \\
\text { 4. Numerology }\end{array}$ \\
\hline Scientific approach & $\begin{array}{l}\text { 1. Hypnotic elements } \\
\text { 2. Mental health } \\
\text { 3. Neuroscience approach } \\
\text { 4. Psychiatric approach } \\
\text { 5. Psychotherapy } \\
\text { 6. Dietary approach to stress management } \\
\text { 7. Specific method (e.g., how to breathe) }\end{array}$ \\
\hline $\begin{array}{l}\text { Very specific topics } \\
{ }^{*} \text { Accepted if the specific } \\
\text { topics are mentioned as } \\
\text { examples of a point or }\end{array}$ & $\begin{array}{l}\text { 1. Financial management/planning/investment } \\
\text { 2. Parenting } \\
\text { 3. Pregnancy loss }\end{array}$ \\
\hline
\end{tabular}




\begin{tabular}{|l|l|}
\hline $\begin{array}{l}\text { presented as part of a } \\
\text { bigger picture. }\end{array}$ & \\
\hline Nature/style of writing & $\begin{array}{l}\text { 1. Informs rather than inspires } \\
\text { 2. Not personal }\end{array}$ \\
& 3. Solely inspirational narratives/stories \\
\hline
\end{tabular}

\subsection{Analysing the sections in self-improvement books}

This section presents how I built the main dataset of self-improvement books and describes the process of identifying the sections (e.g., dedication, conclusion chapter, about the author) in self-improvement books. This study uses chapter for three sections: introduction chapter, body chapter, and conclusion chapter. Based on the criteria that I developed (see Section 3.3), I built a dataset of 40 self-improvement books. Some of the books were hardcopy and some were electronic version. Although gender was not a selection criteria, an informal check showed that most of the authors are male. See Appendix 1 for the list of books. I used the bestseller chart on amazon.com as a guide in the selection process to ensure the books that I selected were reasonably popular, assuming that books that were popular were likely to be prototypical for the genre.

To analyse the sections in self-improvement books, I selected a subset of 20 selfimprovement books from the main dataset. Because the analysis involved looking at different sections of the books, I chose the hardcopy books to ease page-turning. The 20 books were:

1. A Few Keys to All Success (Muncy, 2002)

2. A Kick in the Attitudes! (Glenn, 2008)

3. Building Your Legacy (Fritz, 2003)

4. Fuel (Beavis, 2009)

5. Here's to Your Success (Keller, 2007)

6. How to Have a Beautiful Mind (de Bono, 2004)

7. How Will You Measure Your Life? (Christensen et al., 2012)

8. Leadership and Self-Deception (The Arbinger Institute, 2000)

9. Life Lifters (Ziglar, 2003) 
10. Talent is Never Enough (Maxwell, 2007)

11. Tapping Potential (Lodi, 2000)

12. The Difference Maker (Maxwell, 2006)

13. The Eight Facets of a Fulfilling Life (Pearson, 2012)

14. The Magic is in the Extra Mile (DiAngi, 2002)

15. The Power of Focus (Canfield et al., 2001)

16. The Wisdom of Sam (Gottlieb, 2011)

17. The 7 Habits of Highly Effective People (Covey, 1989)

18. You Can be Happy No Matter What (Carlson, 1997)

19. 5 Tools to Change Your World (Oldham, 2012)

20. 7 Secrets of a Phenomenal L.I.F.E. (Partridge, 2012)

I identified all the sections in the dataset from the front book cover to the back cover of the book and listed the sections according to their sequence in the individual book using Microsoft Excel. I identified the sections based on their functions rather than how they were labelled. For example, a section towards the end of a book in this dataset is labelled as final thoughts and it summarises the contents in the body chapters. Based on the content of this section, I included it in my counting of conclusion chapter. I totalled up the occurrence of each section in this dataset to examine the obligatory, typical, and optional sections of self-improvement books. I consider a particular section to be obligatory if it occurs in all the 20 books. I consider typical sections to be those that occur more than 70 percent or at least 14 out of the 20 books. For a more detailed discussion of obligatory, typical and optional, see Section 2.2.3.

Besides presenting the typicality of the sections in terms of occurrence, the analysis aimed to account for the typical arrangement of the sections. Based on the list of sections that I created in the Excel spreadsheet, I paid attention to the obligatory sections and manually merged them to form the frame of the prototypical arrangement. Then I inserted the typical and optional sections into the main frame based on regularity. In instances where the regularity of two arrangements is the same, I considered the section sequence in the book written by a more experienced author (written more books) to be the typical sequence. For example, there are two forewords in my dataset. One occurs before the contents page and one occurs after the contents page. In such situations, I relied on the number of books that an author has written as a criterion to decide the typical sequence. 
This analysis allowed me to identify the obligatory sections in the genre. Because the move and step analyses in this thesis focus on obligatory sections, the findings of the above analysis informed me of the sections that required examination. The investigations of these sections involved analysing the moves and steps. I describe the methodology of these analyses in Chapter 5 as the subsequent analyses rely on the findings of the above analysis. At a register level, because the methodology of the analyses involves discussions related to the register findings, I describe the methodology in Chapter 6.

\subsection{Interviewing authors}

Due to geographical distance and availability of authors, the ways I collected data from authors were synchronous: face-to-face interview (one author), Skype interview (five authors), and asynchronous: sending questions to and receiving responses from author by email (one author). This section describes the three interview modes.

The only face-to-face interview was with a New Zealand author. I got to know about him from a local magazine. I contacted him and we arranged to meet at a mutually agreed time and place. The interview was conducted at his house. I used a digital voice recorder to audio record the interview and saved it in MP3 format. The author was interested to know more about my study but I did not explain anything beyond what was on the information sheet (see Appendix 6). Then I asked him to describe his experience writing self-improvement books. The interview questions revolved around his purposes for writing such books and his perceptions of his roles and identities. See Appendix 2 for the list of questions. Because I used a semi-structured interview, I did not restrict the interview to the questions I prepared. Immediately after the one hour interview, I described and made notes regarding the context of the interviews in a journal. The context includes venue, how the interviewees came to know about the research, and a general description and reflection on the interview process. I also recorded in my journal emerging themes that I noticed during the interviews.

For the Skype interviews, because all the authors who agreed to be interviewed via Skype were in America, I took the time zone difference into account in the process of arranging the Skype interviews. I used video recording software, Messenger Plus!, to record Skype 
interviews and save them in AVI format. I labelled the files according to the pseudonyms that I assigned to the interviewees. After thanking the participants for their participation, I asked them whether they were comfortable with the volume. The procedures from this point forward were the same as the face-to-face interview.

One author from America volunteered to participate in the study but he specified that he did not have time for a Skype interview. However, he proposed using email instead of Skype. I sent the questions (see Appendix 2) to him by email and he sent his answers by email. All our communication was facilitated through his personal assistant. After receiving his responses to the interview questions, I thanked the author by email through his personal assistant.

The entire interview period covered took about three months (June 24, 2013 - October 1, 2013), and the interviews were spread more or less evenly across that period. Questions were added to the list throughout the interview period as issues were raised from text analysis. For example, questions about the purpose of about the author section were added to the list when I analysed the section.

\subsection{Interviewing readers and non-readers}

The interviews with readers and non-readers of self-improvement books were semistructured and were between 40 minutes to an hour long. The interviews were conducted at public libraries, cafes and interviewees' houses.

I started the interview by thanking the interviewee for his/her participation. Then I went through the letter of consent and information sheet with the interviewee (see Appendix 6). The interviewees were given the opportunity to ask questions or clarify any points in the letter of consent before they signed it. The interviewee kept the information sheet and I kept the signed the letter of consent. After this, I asked the interviewees to talk about a book that they were currently reading. The purpose of this was to make sure they read something. As mentioned earlier, I did not want to include participants who did not read at all. For the non-readers of self-improvement books, I was interested in those who read a genre other than self-improvement books. Then, I had a procedure that helped me to 
identify readers of the genre from non-readers of the genre. I showed the interviewees four books, each from a different genre:
a) The Kite Runner (Hosseini, 2003) - Novel
b) Hot Topic: Global warming and the future of New Zealand (Renowden, 2007) - Non-fiction
c) Live Longer, Look Younger (Brewer, 2012) - How-to book
d) The Choice is Yours (Maxwell, 2008) - Self-improvement book

I did not ask the interviewees whether they were readers or non-readers of the genre because they might have had various interpretation of what a self-improvement book is. In my study, I make a distinction between self-improvement books and how-to books but both genres come under the umbrella category, self-help books. In my research, The Choice is Yours is a self-improvement book and Live Longer, Look Younger is a how-to book. After showing them these books, I asked the interviewees to arrange the books according to their preference. Then I asked them to name the genre of each book. An interviewee's labelling of the genre (e.g., self-help book, motivational book) was then used throughout her/his interview.

Then I asked the interviewees to talk about what they thought about each book and their encounter or reading experience with similar books. Some readers would point to The Choice is Yours and comment that they were currently reading a similar type of book. This process helped me to identify whether the interviewees were readers or non-readers of self-improvement books. After that I removed The Kite Runner and Hot Topic from the table and asked the interviewees to compare Live Longer, Look Younger and The Choice is Yours. The purpose of doing this was to understand the similarities and differences between self-improvement books and how-to books. If they were readers of selfimprovement books, they compared the books based on their experience. If they were non-readers of self-improvement books, they compared them based on their assumptions.

Then I asked the interviewees the possible reasons for reading and not reading selfimprovement books. These questions were framed in the third person. Rather than asking the readers of the genre the reason they read self-improvement books, I asked them why people read self-improvement books. This was to avoid the possibility of interviewees feeling uncomfortable talking about their personal experience. I think some people may feel uneasy or embarrassed when talking about why they read self-improvement books. 
Dolby (2005, p. 56) mentions that some Americans are embarrassed about the popularity of the genre. Moreover, I had little interest in linking the reasons with the interviewees because that is not related to the objective of the interview, which was to investigate the reasons people read or do not read self-improvement books. Then I asked the interviewees to talk about what they thought the reasons for self-improvement authors to write such books were. Viewing genres as having a recognisable social purpose, a nonauthor's perspective (reader and non-reader) is valuable in informing the study. In other words, the purpose of the genre should be recognisable beyond the authors.

After this I asked the readers and non-readers of self-improvement books what they would associate the genre with. As it was a semi-structured interview, I let the interviewees talk freely. Then I asked them if they could describe a person they know who reads self-improvement books. After they described this person, I carried on to ask them if they could think of a person who strongly dislikes the genre and describe him/her. These two questions were meant to help me understand the reasons people read or do not read self-improvement books. For interviewees who did not identify selfimprovement books as an American genre, I asked them whether they had any thoughts about it.

The entire interview period was about ten months (February 5, 2013 - November 27, 2013). Most of the interviews were conducted in February and March. The main questions were the same in all the interviews but as my ongoing text analysis of selfimprovement books raised issues, I added more questions to the interview schedule. For example, at the stage when I was analysing self-improvement book titles, I asked the participants what they thought about the titles and book covers to guide the analysis. This implies that the questions that I added were driven by my text analyses.

\subsection{Ethical considerations and copyright issues}

Before the interviews were conducted, I received the human ethics approval from Victoria University of Wellington's human ethics committee (see Appendix 5). Information about this approval was included in the reader/non-reader interviewee recruitment advertisement. This was to ensure that potential participants were made 
aware that this study had obtained human ethics approval before they decided whether or not to participate. On the interview day, participants were given the information sheet and letter of consent (see Appendix 6), and I explained each point on the information sheet. At this point, I explicitly drew participants' attention to their rights to withdraw from the study without providing any reasons within a period of two months.

Participants were also made aware that the interview data may contribute to conference presentations, research publications, and a thesis which will be publicly available. I also informed the participants that pseudonyms were used to ensure their identities remain confidential. Participants were given the opportunity to ask questions regarding the study if they had ethical concerns.

One participant expressed her concerns about whether the information she provided would feed into marketing strategies and whether this study was funded by an institution that would benefit from the study financially. I informed her that the study was not commercially commissioned or funded but the findings of the study will be reported in a form of a thesis that is publicly accessible. After I explained the points in the information sheet and answered questions that participants asked, they signed the letter of consent.

For the author participants, electronic copies of the letter of consent and information sheet were attached to the invitation e-mails I sent them. In the e-mails, I requested the authors to send me by e-mail prior to the interviews a scanned copy of the signed the letter of consent if they wanted to participate in the study. For the only face-to-face author interview that I conducted, the letter of consent was signed at the beginning of the interviews rather than before the meeting. Although all the author participants expressed that they were not concerned about the confidentiality of their identities, I informed them that pseudonyms were used. The reason for using pseudonyms for authors was to avoid the possibilities of authors using the interviews as a platform for advertising or promotional purposes which may influence their response in the interviews. All participants (i.e., readers, non-readers, and authors) were offered a summary of the thesis, and those who wanted a copy of the summary could indicate that in the letter of consent by providing their e-mail or postal addresses.

As a substantial amount of materials is presented in this thesis for illustrative purposes and because the thesis is publicly accessible, copyright of the materials became an issue. To seek copyright permissions from publishers, I filled in online forms that were usually 
available on their websites. For publishers that did not have such forms, I sent by e-mail a copy of copyright permissions letter (see Appendix 7) to the publishers and requested they sign and return the letter to me. Two publishers requested for more information about my study and in response I sent them a copy of my thesis abstract.

\subsection{Summary of chapter}

This chapter has outlined the methodology that I used to answer the research questions. I have described how I built the dataset of self-improvement books and how I went about analysing them to understand the characteristics of self-improvement books as a genre. As noted in Section 3.3, I provide further methodological detail with respect to genre in Chapter 5 and with respect to register in Chapter 6.

To understand the context of self-improvement books, the thesis draws on interviews with authors, readers, and non-readers of the genre. In this chapter, I have explained how the participants were recruited, described the interview process, and how I analysed the interview data. The next chapter presents the analysis of interview data. 


\section{Chapter 4: Analysis of interview data}

This thesis draws on interview data and the literature to understand the context of selfimprovement books. This chapter presents themes that I identified in interview data from seven authors of self-improvement books, 12 readers and 15 non-readers of the genre. The analysis of interview data is organised into two main sections: author interview data and reader/non-reader interview data. The themes from author interview data are the imagined readership, the process of self-improvement, the purpose of writing the genre, author's identity, and style of writing. The second section reports the themes from reader/non-reader interview data. The themes include readers' and non-readers' perception of the purpose of self-improvement books and their characteristics.

The themes were identified from semi-structured interviews. Based on the interview recordings, I made interview summaries in separate Word documents and coded them using NVivo 10. The initial themes that I coded were informed by the notes I made after each interview. The coding system developed as I coded more data, and the data that was coded earlier was re-coded based on the updated codes. Although my study does not view interview data as objective "truth" such data serve as "displays of perspectives" and "potentially true reports" (Silverman, 2001, p. 113) which can provide insights to the research. In other words, this study does not view interview data as a source that confirms text analysis, it can only be consistent or inconsistent.

\subsection{Themes in author interview data}

This section presents the analysis of interview data from seven self-improvement authors. I identified five main themes from the interview responses: descriptions of target readers, the process of changing one's life, the purpose of writing self-improvement books, the authors' identity, and the style of writing. The questions for these interviews are found in Appendix 2. 


\subsubsection{Descriptions of target readers}

This section reports how self-improvement authors describe their potential readers. When I asked Matt, a family psychologist and self-improvement book author, to describe his potential readers, he said:

Searchers. People who are introspective. People who like to explore the internal world. People who like to hear a story. People who have distress in their lives. Looking for something. (September 12, 2013; Skype interview)

Matt described his target readers as people who are searching for something. The fact that Matt was able to describe the characteristics of his potential readers suggests that authors write for a specific group of readers. Matt's comments suggest that his imagined potential readers are people who reflect on their current conditions and problems, and seek ways to improve them. Matt's comments also suggest that "stories" are a feature of self-improvement books.

Another author, Peter, stated that his potential readers are mainly business people:

My target audience was primarily people in business but anybody who saw themselves as a leader. (June 24, 2013; Face-to-face interview)

Peter's comments suggest that as well as writing for a specific category of target readers, he also attempted to make his books as relevant as possible to a wider readership of leaders.

When I asked Allen how he viewed his potential readers, he said:

I guess there are two categories. One certainly, people who have tried all these positive thinking books but found it to be like banging their head against the wall and they are for something else. The other category, I suppose, is people who came from where I was which is sort of a bit cynical about the whole idea of a book, technique or philosophy that lead you to cultivate happiness...It's good to be sceptical but you don't need to be so cynical. There are actually philosophies and techniques that exist that are not so cheesy. (September 13, 2013; Skype interview)

Similar to Matt and Peter, Allen's comments indicate that he was quite clear about who his imagined target readers were. His comments suggest that potential readers were 
people who have tried various techniques and principles to live happier lives but they did not seem to be effective. As a result of their ineffectiveness, potential readers are seeking new techniques and principles. This suggests that self-improvement authors would have to constantly present their advice as unique and different from other existing selfimprovement books.

John is one of the two authors who responded to the set of interview questions by email. Responding to my question on how he viewed his potential readers, John wrote:

A lot of my readers are fans who have seen me speak. Some saw me in junior high and are adults now and still reference my books. I hear a lot from people who are going through challenging times, picked up my book, found some inspiration and wanted to share their stories with me. (July 13, 2013; Email)

John's comments suggest that some readers of self-improvement books read a particular author because they already know about him/her. Similar to Matt, it seems that potential readers are people who are looking for a solution or encouragement when they encounter problems.

\subsubsection{The process of changing one's life}

All seven authors interviewed mentioned in various different ways during the interviews that changing one's life starts with changing how one thinks followed by the individual determination and commitment to act on advice from authors. Barry stated that the primary purpose of self-improvement books was to help readers change their lives. Asked where he thought this change took place he said:

I think improvement starts with intention. You will have to want to do something.

You have to care enough about it to make the changes. (July 30, 2013; Skype interview)

Barry's response suggests that changing one's life starts with mental processes such as having an intention or a desire to change. Also, his comments on readers' intention and willingness to change seem to imply that readers are the primary agents of change. 
When I asked Tim what he thought the crucial elements of a self-improvement book were, he said:

To me, it's making the decision to feed your mind with the right thing. A self-help book would convince you that's what you need to do. And then it will give you the right things to put in your mind. Because once you change your thinking, you change your actions. They will need to have the right inspiration to help you. People need to know the right thing to think and how to live it out. (October 1, 2013; Skype interview)

Similar to Barry, Tim's comments suggest that improving one's life starts with changing how one thinks. It seems that self-improvement authors attempt to persuade readers to change their worldview and adopt those of the authors. Tim's comments also suggest that some self-improvement authors perceive having the "wrong" worldview to be the cause of readers' problems. Like Barry, Tim's comments on readers' way of thinking and action suggest that readers are primarily responsible for improving their own lives.

\subsubsection{The purpose of writing}

All seven authors interviewed implied that their purpose in writing self-improvement books was to share their experience. Matt commented that:

Some people who write self-help books believe they know the secret that other people don't know and it's never the truth. And some people write self-help books because they just care about people and they care about their audience and that's their goal. (September 12, 2013; Skype interview)

Matt's comments suggest that, more than sharing authors' experience, some authors claim to have the ultimate solution and want to share them with their potential readers. Barry and Matt explicitly mentioned that they had experienced depressing moments in their lives and they wanted to share how they overcame them. When I asked Barry what his reasons were for writing a self-improvement book, he said: 
I've gone through a time of intense depression. I was finding ways to deal with that. I was trying to find a book a book that says it all but I couldn't find any. (July 30, 2013; Skype interview)

Barry's comments suggest that some self-improvement books are a result of authors' reflection and research related to problems they faced. It seems some authors write to fill in the gap because they perceive existing advice, from their past experience, to be inefficient in addressing their problems.

Peter is a self-improvement speaker at professional development seminars that he organises for corporate companies. When I asked him what his purpose in writing a selfimprovement book was, he said:

That's really easy. I was with a colleague and we were running workshops and we were trying to think how we could grow the business. He said the one thing that would validate the work we do is by publishing a book. (June 24, 2013; Face-to-face interview)

Later in the interview, Peter explained that he had to write a self-improvement book to boost his business. I asked him to explain the relationship between writing a book and boosting his business, and he explained:

I have this feeling that I want to do another book which captures the things that I'm apparently doing. It is a good marketing tool. It gives me great credibility. You got a book and it validates what you are doing. (June 24, 2013; Face-to-face interview)

Peter perceived writing self-improvement books to be a way to construct credibility as a self-improvement speaker. His comments suggest that having written a few selfimprovement books adds to his credibility as a speaker.

Three of the seven authors mentioned money as a motivation for some authors. When I asked Barry what he thought were crucial elements in a self-improvement book, he said:

For me a good self-help book is specific. It has a reason for existing. It has something that it wants to help you achieve. It has a systematic approach to doing that. That's what self-help books are for...But there are self-help books that are basically like unconnected essays that are strung together to make money. It's a 
business and they really designed to lock people into the system or coaching or buying more books. (July 30, 2013; Skype interview)

Barry's comments suggest that for some authors, a primary purpose of writing selfimprovement books is financial gain. He claims that authors with this intention can be identified by the poor quality of the books they write.

\subsubsection{Author's identity}

Four of the seven authors interviewed viewed their identity as peers to readers. Peter and Barry explicitly stated that they did not want to appear to be authoritative figures. When I asked Peter to describe himself as a self-improvement author, he said:

I viewed myself not as a self-help author in a normal sense. My basic approach is to treat people as fully functioning adults. I just like to think of it as giving you some tools and say here they are. You may find it useful but it's not telling you what to do, when to do...I think a peer, a friend or a confidant in some ways. (June 24, 2013; Face-to-face interview)

Peter seems to distance himself from self-improvement authors who prescribe advice to their readers. Peter's comments suggest that there is a constant tension between authors as friendly peers and authors as authoritative advice givers. It seems that while some authors construct their message as prescriptive advice, some construct their message as potential ideas.

Matt and Tim mentioned that they saw themselves as teachers. When I asked Matt what his roles are as a self-improvement author, he said:

Everything I do is caring for the universe. How do I do that? I teach about kindness. I teach about humanity. I teach how people can be vulnerable and safe at the same time. About how people can open their heart and getting hurt is not the end of the world. What I want from my readers is when they finish the book they feel more understood. Feel OK. And their hearts are open a little bit more. (September 12, 2013; Skype interview) 
Matt constructs himself as an expert having something to teach, while Peter constructs himself as friend and confidant. We see variation in how authors see themselves.

\subsubsection{The style of writing}

Five of the seven authors interviewed stated that they kept their style of writing accessible. As Peter was commenting on his second book that was recently published, comparing the two books he said:

This one I tried to keep it in a colloquial style. (June 24, 2013; Face-to-face interview)

Peter's comments suggest that his first book was not written in an accessible style and to improve, he has deliberately written it in an accessible style. It seems authors are aware that an accessible style of writing is a characteristic of self-improvement books.

When I asked Peter how he decided on his book title, he said:

Initially it was ... change the world... But everybody rang me and said no it's got to be your world so people can connect with it. (June 24, 2013; Face-to-face interview)

Peter's comments suggest that readers are able to recognise that addressing readers explicitly using personal pronouns is a linguistic feature of self-improvement book titles.

Barry and John also mentioned keeping their message concise. For example, after Barry stated that it is important to engage readers by having concise messages in selfimprovement books, he commented on his style of writing in his book:

That is part of the reason the book that I wrote was very short and very to the point. There is no extra crap in it. It's just like do these 10 things. (July 30, 2013; Skype interview)

Barry's comments suggest that authors perceive keeping chapters concise as a way to engage readers. His comments show that it is unnecessary for authors to explain an idea extensively. Also, his comments indicate that one of the ways to be concise is to organise the message like a series of bullet-points. 
When I asked John what he thought were crucial elements of self-improvement books, he said:

I like how some books summarise this [message] at the end of each chapter. Also, shorter chapters keep people more engaged in reading. (July 13, 2013; Email)

John's comments suggest that having shorter chapters and concise messages are ways to help readers stay focused.

\subsection{Themes in reader and non-reader interview data}

The analysis of reader and non-reader data is organised according to themes followed by illustrative examples and comments. I identified seven themes in the interview data and present them in the following sections. They include the common labelling of the genre, how the genre is related to changing and improving reader's life, the aspects of life that self-improvement authors write about, the repetitive character of the message across selfimprovement books, the individualistic approach of the genre, the style of language that authors use, and how readers interact with the genre.

\subsubsection{Common labelling of the genre}

From the interview data, self-improvement books are commonly referred to as self-help books. Two-thirds of participants (8/12 readers and 10/15 non-readers) called this genre self-help books. Others called them motivational books, inspirational books, personal development books and positive thinking books. For example, when I asked Katrina, a reader of self-improvement books, to comment on The Choice is Yours (a self-improvement book), she said:

I love self-help books. I like reading books that inspire me... They are uplifting for me. I just find them inspirational and helpful in my journey... They often talk about looking after yourself emotionally, mentally, and spiritually. (February 22, 2013; Face-to-face interview) 
Katrina described self-improvement books as inspiring and "uplifting" and mentioned that this genre has helped her in her journey which she, later in the interview, referred to as the process of understanding herself emotionally. She was able to identify the characteristics of the genre such as giving advice related to emotional, mental and spiritual health. While commenting on The Choice is Yours, Katrina used the plural form they to refer to a group of books that belong to the same genre as The Choice is Yours. This gives us an indication that Katrina was able to recognise that The Choice is Yours belongs to a genre that she called self-help books.

When I asked Christina, a non-reader, pointing to The Choice is Yours, what sort of books do you call these and to comment on it, she said it is a:

self-help book. It can be about the way you think and the way you can change your thinking. They sometimes have a lot of quotes from a lot of people. They say you can better your life if you choose to do this and that. (March 25, 2013; Face-to-face interview)

Note that Christina shifted from the singular pronoun it to the plural form they. This indicates that Christina was able to recognise The Choice is Yours as belonging to a genre that she called self-help books, as we saw above in the case of Katrina. Like readers, nonreaders were able to identify the genre and list its common characteristics. Christina, for example, labelled The Choice is Yours as a self-help book and stated that such books sometimes have a lot of quotes. She also identified that the purpose of the genre is to help potential readers improve their lives. This gives us an indication that Christina was able to recognise the genre by identifying the social purpose (e.g., giving advice related to improving one's life) and the content (e.g., anecdotes, quotes) of the genre.

\subsubsection{Changing and improving reader's life}

All 12 readers and all 15 non-readers stated and/or implied, at some point in their interviews, that the purpose of self-improvement books is to help readers change or improve their lives. For example, Lynn, a reader of self-improvement books, pointing at The Choice is Yours (a self-improvement book) commented that it: 
...is about how applying the principles he [author] live by can improve your life.

(February 21, 2013; Face-to-face interview)

When I asked Hazel, a non-reader participant, what she thought was the reason people read self-improvement books, she said that:

They feel depressed, stressed in their lives and want some answers, some things or tools to help them in making progress in their lives. (March 5, 2013; Face-to-face interview)

Lynn explicitly mentioned that the purpose of the genre is to help readers improve their lives. I consider Hazel's response as an implicit way of indicating the similar purpose of the genre because she was not directly commenting on the book. Instead, she was listing the reasons people read this genre.

\subsubsection{Aspects of life}

Because life is the most frequent "lexical word" (Biber et al., 1999, p. 55) in my 1,360,000-word token dataset of self-improvement books (see Section 6.1.1), and because all reader and non-reader participants mentioned life at some point in their interviews, I examined how readers and non-readers construct life in the interview data. Both groups constructed life as mainly related to happiness and success in terms of business and career. For example, when I asked Joanne, a reader, what she thought was a common message across self-improvement books if she thought there was one, she stated:

One common message is that if you do this, your life will be better. You will be richer, you will be happier, you will be more fulfilled if you read this book and do what I suggest. (June 6, 2013; Face-to-face interview)

Joanne's association between a better life, and being richer and happier is consistent with the idea of an ideal life in the American Dream (see Section 2.5.2).

When I asked Robert, a non-reader participant, who he thought were the potential target readers of self-improvement books, he said:

Middle age business people who are not happy with their career. Get some motivation. Get their full potential out. (February 28, 2013; Face-to-face interview) 
Besides happiness and success in terms of career, other aspects of life that interview participants identified were related to emotion, mental state, spiritual wellbeing, and human relationships. Confidence is one aspect of life that appears only in the non-reader data. Seven out of 15 non-reader interviewees mentioned that people who did not read self-improvement books are those who were confident with themselves. Unlike the reader data, the non-reader data gives us an impression that being more confident is part of improving one's life. For example, when I asked Pamela what she thought was the reason why some people did not read the genre, she reasoned that they are:

Probably confident and happy with their life and self-assured people...Some people won't even think about that [reading self-improvement books]. These are people who are confident. (February 25, 2013; Face-to-face interview)

Paying attention to how interviewees construct life shows that both readers and nonreaders of the self-improvement books identified happiness and success in terms of career as the main aspects of life that self-improvement authors address. It seems also from the interview data that both readers and non-readers were able to identify self-improvement books by the domain of advice they give.

\subsubsection{Repetitive character of the message}

Three readers and two non-readers of self-improvement books stated explicitly that the similarity and predictability of the message across these books made this genre recognisable. When I asked Gladys, a reader of self-improvement books, to comment on The Choice is Yours (a self-improvement book), she stated that these books:

...say something in a hundred different ways or have a hundred different people saying the same thing. (February 19, 2013; Face-to-face interview)

From the interview data, Joanne, a reader of the genre, commented that because of the repetitive nature of the message across self-improvement books, she decided to stop reading them. 


\subsubsection{Individualistic approach}

In the interview data, five readers and six non-readers of self-improvement books mentioned that the approach to improving one's life in this genre has an individualistic orientation. From the interview data, self-improvement books often place the responsibility of improving oneself on the reader. Joanne used to read self-improvement books on a regular basis, and when I asked her to comment on The Choice is Yours (a selfimprovement book), she commented that:

This is about self-determination and you will determine your life and it's all about you. You can decide to and you can decide not to... They are very individualistic and their approach to these books is, I feel, to place a lot of responsibility back onto the individual for creating the perfect life and the perfect world... I do have a bit of concern for that sort of books and their individualistic approach to life. I guess it's part of the way society has become more individualistic and less socially focused. (June 6, 2013; Face-to-face interview)

Joanne pointed out that self-improvement books are about how readers can improve their lives and how readers' decisions and determination are central in that process. In other words, interviewees who had a similar view to Joanne thought that self-improvement books often hold the individual responsible for his/her success or failure. One of the nonreader participants, Brenda, pointed out that these books did not take social economic and sociocultural background into consideration. She concluded that not everything is within one's control. As a whole, interview data reveals that the advice in selfimprovement books is mainly to benefit the individual and the individual is constructed as primarily responsible for improving her/his life.

\subsubsection{Accessible style of language}

Six reader participants and four non-reader participants commented on the register of self-improvement books. They stated that the language in self-improvement books is accessible and/or conversational. When I asked Jane, a reader, to comment on four book at the beginning of the interview, pointing to The Choice is Yours, she said it is: 
...more chatty... and the language in self-help books is very accessible. (March 19, 2013; Face-to-face interview)

Grace, a reader participant, reasoned that the purpose of self-improvement authors using accessible language is to reach a general readership. Stine (1997), an editor of selfimprovement books, in her book Writing successful self-help and how-to books, advises selfimprovement authors to write in a conversational style, "avoid stodgy words and phrases" (p. 94) and keep their writing style simple in order to reach "the vast audience that makes a book a bestseller" (p. 97). Information from Stine, an insider, seems to agree with some participants' comments regarding the register of self-improvement books.

\subsubsection{How readers read self-improvement books}

Two readers mentioned that they usually do not read self-improvement books from cover to cover and they would usually select a chapter that interests them by referring to the contents page. I showed Joanne, a reader, The Choice is Yours and asked her to name and describe the genre that this book belongs to. She stated that:

Maybe it's a book that you won't read from cover to cover. If I have this book on my shelf, I might dip into it every now and then but I wouldn't be reading from cover to cover. (June 6, 2013; Face-to-face interview)

Joanne thinks that readers do not usually read this genre from cover to cover and it is not necessary to finish reading the whole book. Readers can select and read chapters that are useful and interesting to them and leave the rest out. Some interviewees commented that readers may select a chapter based on their current needs. This may imply that chapters in self-improvement books can be a collection of loosely related, independent units. That is why readers can make sense of a chapter without reading the previous chapter.

\subsection{Summary of chapter}

In this chapter, I have presented the themes that emerged from my interview data. From the interview data, it seems both readers and non-readers of the genre were able to 
recognise self-improvement books present a common message, and as a genre, they share similar social purposes.

Some self-improvement authors claimed that while trying to make their books as relevant as possible to as wide a readership as possible, their target readers were people who were seeking solutions to their problems, principles to improve their lives, or encouragement when going through a difficult time. Authors also perceived improvement to start with changing the way people think, followed by taking actions. Also, readers are perceived as the primary agent of improvement. Some authors claimed to write for financial gain, while others expressed that they wanted to help their readers by sharing their experiences. Also, some authors construct themselves as experts in helping readers to improve their lives, others construct themselves as having equal power relationship with their readers. In terms of characteristics of self-improvement books, authors write the genre in an accessible style and use personal pronouns to address readers. Authors also perceive having short chapters and concise messages to be ways to engage readers.

Both readers and non-readers of the genre were also able to identify whether a book is a self-improvement book by looking at its cover and contents page. There seem to be a consensus among readers and non-readers that the social purpose of the genre is to provide potential readers with principles and solutions to improve their lives. Readers and non-readers perceived this genre to provide advice related to happiness, success in terms of career advancement, and relationships. Both groups saw self-improvement books as a genre that has an individualistic approach. At a text level, both readers and non-readers seem to comment that this genre has a conversational and accessible style of language. It is likely that, reader interview data suggests, readers do not read the genre from cover to cover but the chapters selectively according to their needs.

Although I do not regard interview data as objective "truth," my study draws on author, reader, and non-reader interview data as a means to understand the social purpose of selfimprovement books. I drew on this understanding in the process of identifying the moves in the genre. 


\section{Chapter 5: Genre analysis}

This chapter begins by presenting the analysis of sections in self-improvement books. The purpose of this analysis is to understand the purpose of self-improvement books by identifying the obligatory sections. Then, I analyse the moves and steps of three obligatory sections (i.e., the introduction chapters, the body chapters, and the about the author sections) in self-improvement books. After that, I review studies that analyse stories to motivate my analysis of stories in self-improvement books. The analysis of stories focuses on the examination of their purpose and structure. Throughout this chapter and the next, I draw on the interview data presented in Chapter 4 to guide and elucidate my analyses.

\subsection{Sections in self-improvement books}

The analysis of sections in self-improvement books includes 20 books (see Section 3.3) from the dataset of 40 self-improvement books (see Appendix 1). I included as sections parts of the text of a book that are signalled by headings and formatting. Using NVivo 10, I coded the sections according to their functions rather than how the headings of the section are labelled. For example, an author labelled a section towards the end of his book as final thoughts. I coded that section as conclusion based on its content and function. In my discussion of each section, I included the numbers of occurrences. For example, $(14 / 20)$ indicates that a particular section can be found in 14 out of the 20 selfimprovement books. In this study, a section is considered obligatory if it occurs in all the books in this dataset. A typical section is one that occurs in more than 70 percent of the books (at least 14). I identified 21 sections, each of which is described with examples. Table 4 shows sections in self-improvement books in their prototypical order. 
Table 4: Prototypical arrangement of sections in self-improvement books

\begin{tabular}{|l|c|}
\hline Sections & Occurrence (Total = 20) \\
\hline Front book cover & 17 \\
\hline Praise from others & 19 \\
\hline Title page & 20 \\
\hline Title page verso & 17 \\
\hline Dedication & 16 \\
\hline Acknowledgement & 4 \\
\hline Aphorism & 20 \\
\hline Contents page & 2 \\
\hline List of self-affirmation statements & 2 \\
\hline Foreword & 20 \\
\hline Preface & 20 \\
\hline Introduction chapter & 12 \\
\hline Body chapters & 1 \\
\hline Conclusion chapter & 8 \\
\hline Appendix & 2 \\
\hline References & 19 \\
\hline Index & 14 \\
\hline About the author & 20 \\
\hline Space for notes & 2 \\
\hline Advertisement & 2 \\
\hline Back book cover & 2 \\
\hline & \\
\hline
\end{tabular}

\section{Section 1: Front book cover $(20 / 20)$}

Front book cover is an obligatory section in self-improvement books. It is the first section of the book. Information that is obligatory in this section is author's/authors' name(s) and book title. This section typically displays the subtitle of the book $(18 / 20)$ and author promoting statements $(17 / 20)$. These are examples of author promoting statements: 
a) New York Times Best-selling author of The 21 Irrefutable Laws of Leadership. (Maxwell, 2006)

b) The international bestselling author of Lateral Thinking [emphasis in original] and Six Thinking Hats. (de Bono, 2004)

Such statements construct self-improvement authors as being popular and highly sought after. These statements also construct authors as credible and reliable advice givers.

\section{Section 2: Title page $(19 / 20)$}

This is a typical section in my dataset. A title page has a book title and the author's/authors' name(s). These elements are obligatory in the title pages in this dataset. The publisher's name is typically found at the bottom of the page. There are two instances where the author includes a quote on the title page. All the title pages in my data are one-page long. There is one book in my dataset that does not have a title page. This may have been the result of the function of this section being replaced by the front cover of the book because they are very similar. The following examples are from The Seven Habits of Highly Effective People (Covey, 1989) and Tapping Potential (Lodi, 2000).

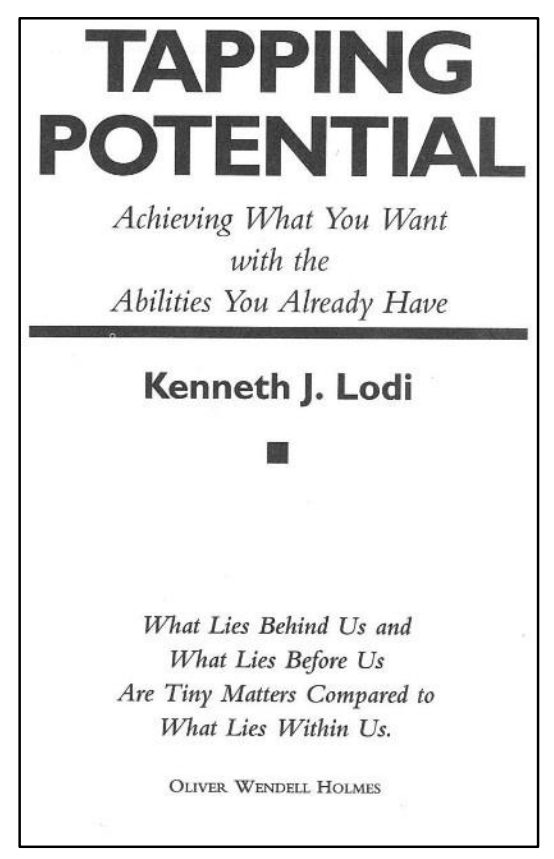

Figure 1: Example of title page with quote

From the book Tapping Potential. Copyright (C) 2000 by Kenneth J. Lodi. Reprinted with permission from Ken Lodi Communications, Los Angeles CA. http://kenlodi.com/ 
Figure 1 illustrates a title page that has the obligatory elements (title and author's name) along with a quote that is related to the book title. This example does not have the usual publisher's name at the bottom of the page.

\section{Section 3: Title page verso $(20 / 20)$}

The title page verso is a one-page long section where copyright information can be found. It also has information about the publisher, ISBN code, the place where the book is printed and library cataloguing information. It is an obligatory section based on my dataset. This is an example from 7 Secrets of a Phenomenal L.I.F.E. (Partridge, 2012).

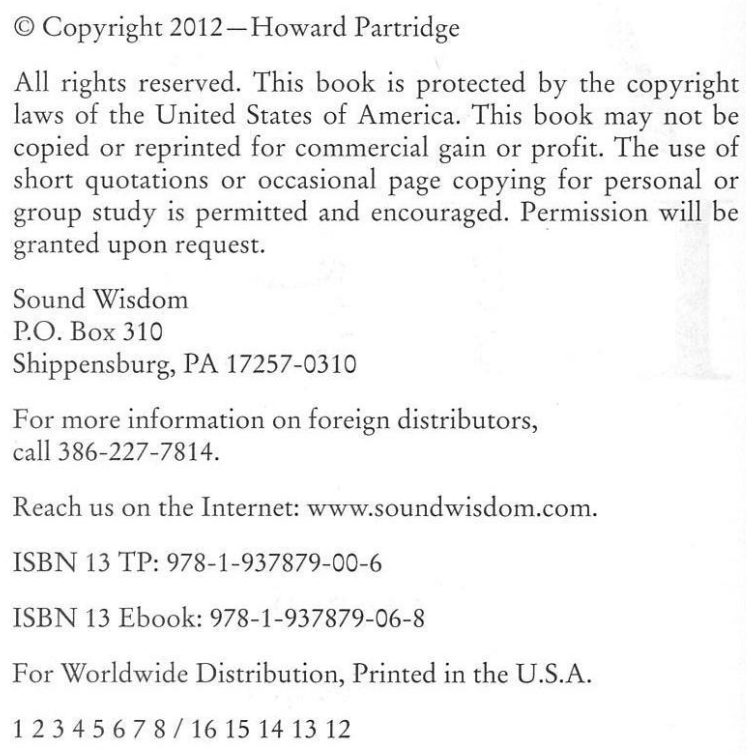

Figure 2: Example of title page verso

From the book 7 Secrets of a Phenomenal L.I.F.E.. Copyright $(\mathcal{C} 2012$ by Howard Partridge. Reprinted with permission from Sound Wisdom, Shippensburg PA. www.soundwisdom.com

\section{Section 4: Praise from others $(17 / 20)$}

Praise from others is typically found in the books as a section before (9 instances) or after (4 instances) the title page verso. This section can also be found on the front cover ( 8 instances) or the back cover ( 7 instances) of the book. This study includes praise from others regardless of location in the counting. In cases where the sections appeared in the 
book and on the book cover, they were counted as one occurrence. The positions of the commenters are included below their names (see Figure 3 ) in 14 out of 17 books and such positions are not mentioned in three books.

As well as establishing credibility, these comments also indicate how authors construct their potential readers. Consider these examples:

c) Tapping Potential offers unique insights to important life principles and a dynamic, practical approach for making a positive difference in your life.- Hyrum W. Smith, CEO, Franklin Covey. (Lodi, 2000)

d) "...a profoundly simple, hopeful, and human book about what's available to us all - happiness." - Josephs Bailey, author of The Serenity Principle. (Carlson, 1997)

The collection of praise from others seem to construct readers as people who are seeking life improving principles or strategies that are unique, profound and accessible.

Interview data suggests a similar interpretation. For example, when I asked Jane, a regular reader of self-improvement books, what she thought were the reasons people read self-improvement books, she said:

To perhaps have a better life, live a better life, feel better about yourself. Some of them [self-improvement books] might be about self-esteem, being happy, or about thinking smarter but all of that can be seen as improving the status quo. (March 19, 2013; Face-to-face interview)

When I asked Christina, a non-reader of the genre, the same question, she said:

They feel they need help. They feel they are not fulfilled. Some people feel they need a deep knowledge of something. Some people think reading books like this is a fix. It can give you ideas. (March 25, 2013; Face-to-face interview)

Interview data suggests that readers of self-improvement books are seeking "deep" or profound principles that will help them improve their lives. Figure 3 shows a section that is devoted specifically to praise from others from Building Your Legacy (Fritz, 2003). 


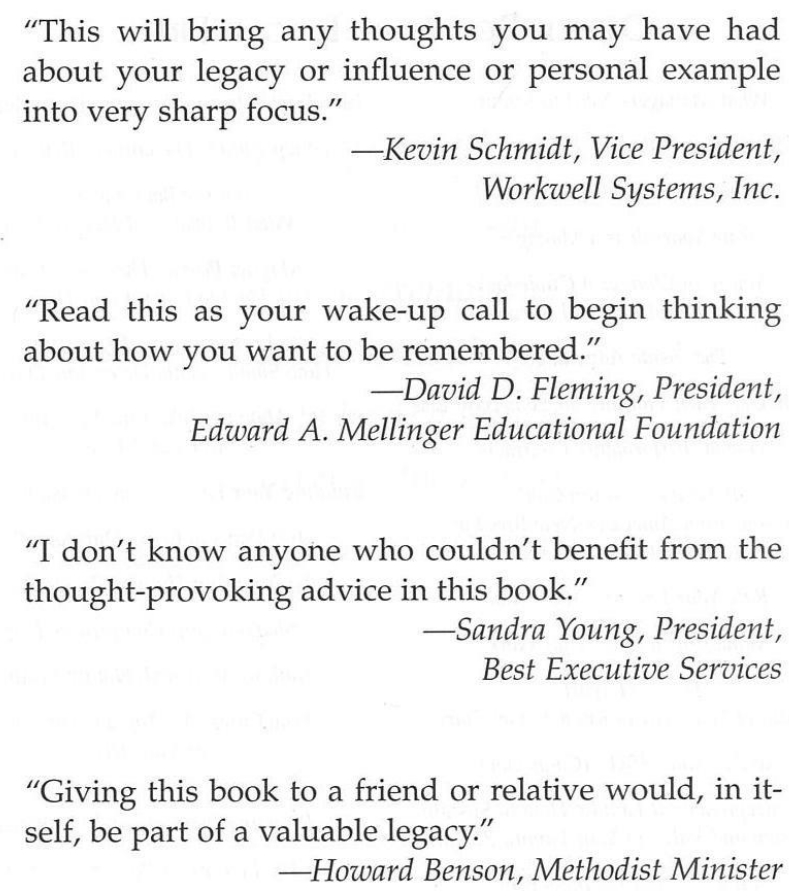

"I don't know anyone who couldn't benefit from the thought-provoking advice in this book."

-Sandra Young, President, Best Executive Services

"Giving this book to a friend or relative would, in itself, be part of a valuable legacy."

-Howard Benson, Methodist Minister

Figure 3: Example of praise from others

\section{Section 5: Dedication $(17 / 20)$}

Dedication sections are typical in the books in this dataset. They are not usually indicated by headings. There is only one dedication section in this dataset that has a heading that reads Dedication. In multiple-author books, each author writes his/her own dedication within the section. The length of individual dedications in my dataset ranges from six to 67 words. The longer ones are due to the long list of names that authors include. The text in the dedication sections does not necessarily end with a full stop. Authors commonly dedicate their books to their spouses, children, and/or teachers. They can include people who are no longer alive. The people referred to in this section are not named in 14 out of 17 dedication sections in my dataset. Dedication sections are often realised by the preposition to $(11 / 17)$ or dedicated to $(6 / 17)$. Consider these examples:

e) To my colleagues, empowered and empowering (Covey, 1989)

f) Dedicated to the brave men and women - past, present, and future in our military forces - who have committed their lives to protect our faith, freedom, and families. (Ziglar, 2003) 
Interpersonal meaning, in Halliday's terms, is foregrounded in the dedication sections. They give readers a sense of who the authors are. They construct self-improvement authors as thankful and sincere people.

\section{Section 6: Acknowledgement (16/20)}

Acknowledgement sections involve thanking people who have contributed in one way or another. They are family members and people who are involved in the process of writing the book in a technical way (e.g., editing, proof-reading). This implies that these sections are relatively less personal compared to dedication sections. Unlike dedication sections, all acknowledgement sections are indicated by headings and have a separate page.

\section{Section 7: Aphorism (4/20)}

This section is an optional section and is located before the contents page. Aphorisms include quotes and "wise" sayings. A quote is signalled by the name of the person being quoted and a "wise" saying is a statement that does not have the name of the person quoted. Authors use the aphorism section to draw reader's attention to the main message of the book. Figure 4 is an example of a quote. 


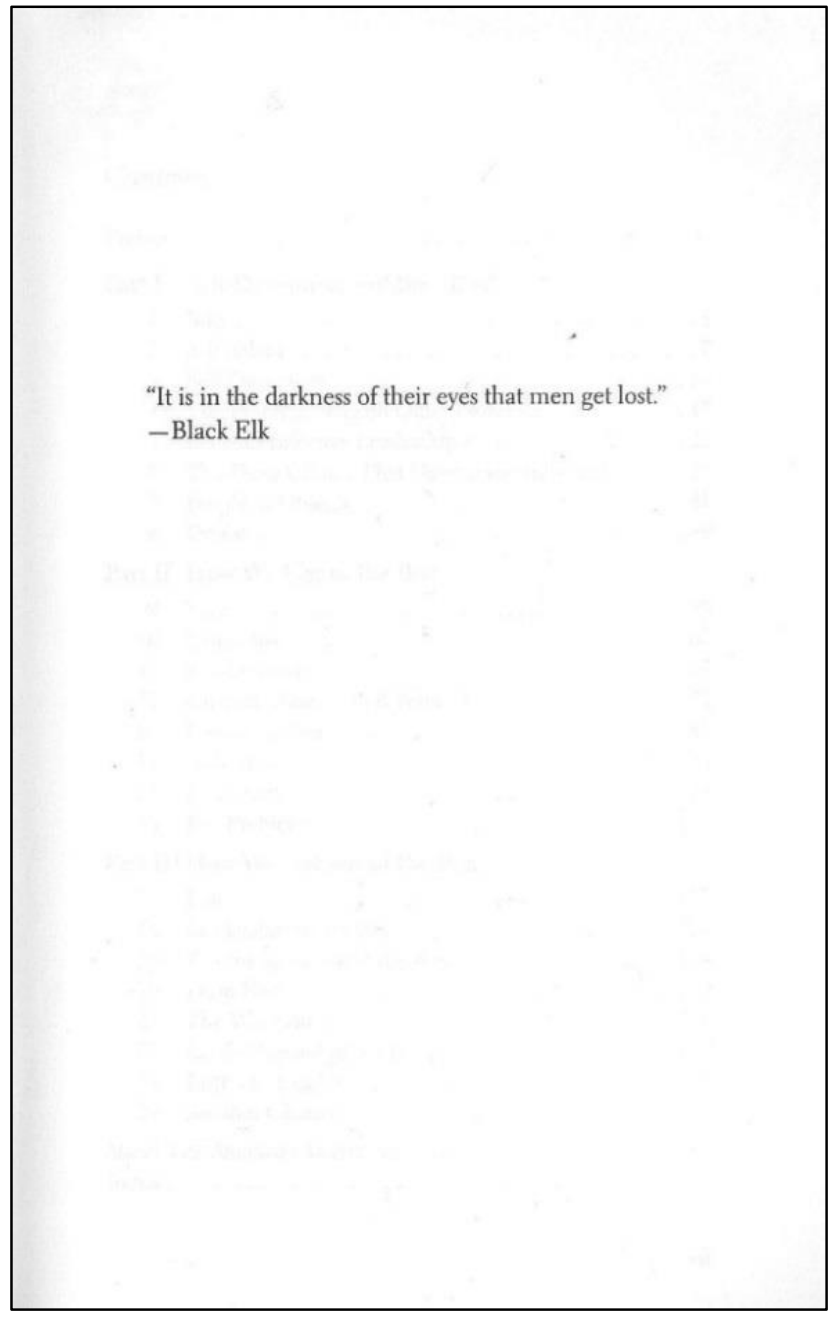

Figure 4: Quote

From the book Leadership and Self-Deception. Copyright () 2000 by The Arbinger Institute. Reprinted with permission from The Arbinger Institute, Farmington UT. http://arbinger.com/

Section 8: Contents page (20/20)

Contents page is an obligatory section in self-improvement books in my dataset. It is always indicated by a heading. A contents page presents sections in the book chronologically with page numbers. Performing mainly an ideational function, this section informs readers about the location of the chapters. As discussed in Section 4.2.7, reader and non-reader interview data suggests that readers do not always read selfimprovement books cover-to-cover, and they rely on the contents page to enable them to turn directly to the chapter that they are interested to read. For example, in an interview with Christina (non-reader), I showed her a how-to book and a self-improvement book 
and asked her to describe the similarities and/or differences between them. Part of her response was:

Also, both books, you might not want to read from cover to cover. You take out what you want. (March 25, 2013; Face-to-face interview)

Both the reader and non-reader interview data suggests that readers who read selfimprovement books do not necessarily read the chapters in a particular self-improvement book in a chronological order. This implies that the contents page is particularly useful when readers decide to select and read the chapters that they think are relevant to their need or interest.

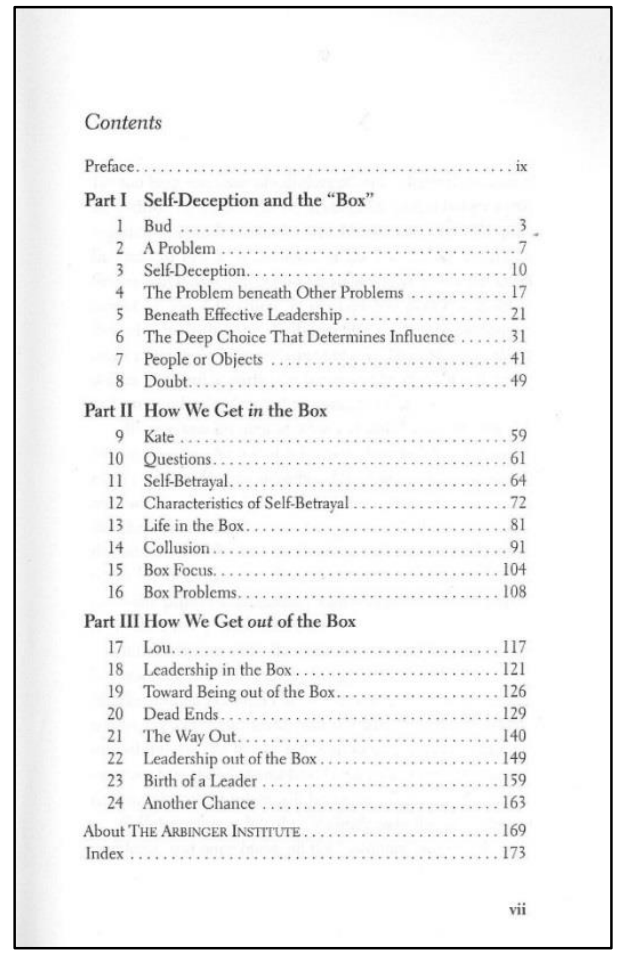

Figure 5: Contents page

From the book Leadership and Self-Deception. Copyright ( 2000 by The Arbinger Institute. Reprinted with permission from The Arbinger Institute, Farmington UT. http://arbinger.com/

\section{Section 9: List of affirmative statements $(1 / 20)$}

This section is an optional section and is found in only one book in my dataset. It is located after the contents page. These statements may look similar to aphorisms but they have a different purpose. The author deliberately instructs readers to read the affirmative 
statements to themselves (see Figure 6). It is likely that authors intend such statements to be read by the readers on a regular basis. Singular first person pronouns (I, me, my, myself) are abundant in these statements. The sole occurrence of this section is in $A$ Kick in the Attitude! (Glenn, 2008).

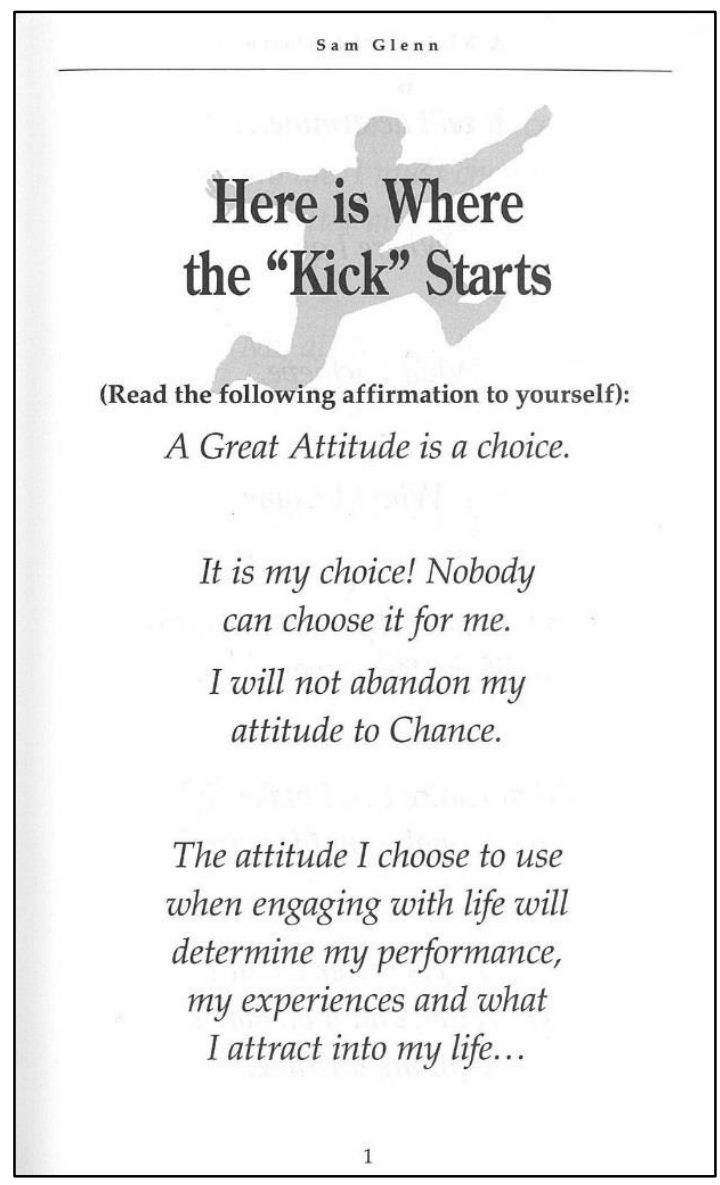

Figure 6: Affirmative statements

From the book $A$ Kick in the Attitude. Copyright $(\odot) 2008$ by Sam Glenn. Reprinted with permission from Sam Glenn Inc., Carmel IN. http://samglenn.com/

\section{Section 10: Foreword $(2 / 20)$}

The online Oxford Dictionaries defines foreword as "a short introduction to a book, typically by a person other than the author" (Foreword, 2015). The forewords in my dataset are written by experienced and prominent self-improvement authors other than the author of the book. The main purpose of forewords in self-improvement books is similar to that of praise from others in the way they construct authors' credibility. While praise from others are usually statements, forewords are more extensive in terms of length 
and they provide an introduction to the book. Forewords are optional sections and are relatively rare (two books). They are located after the contents page and are signalled by a heading in both instances. The names of people who wrote the forewords are presented below the heading (see Figure 7). The length of forewords in my dataset is about two and a half pages.

There are two instances in my dataset where a section is labelled as foreword but its content resembles that of an introduction chapter, and they are written by the author of the book rather than a person other than the author. I have counted these two instances as introduction chapters based on their content and the fact that there are no sections that are labelled as introduction in the two instances.

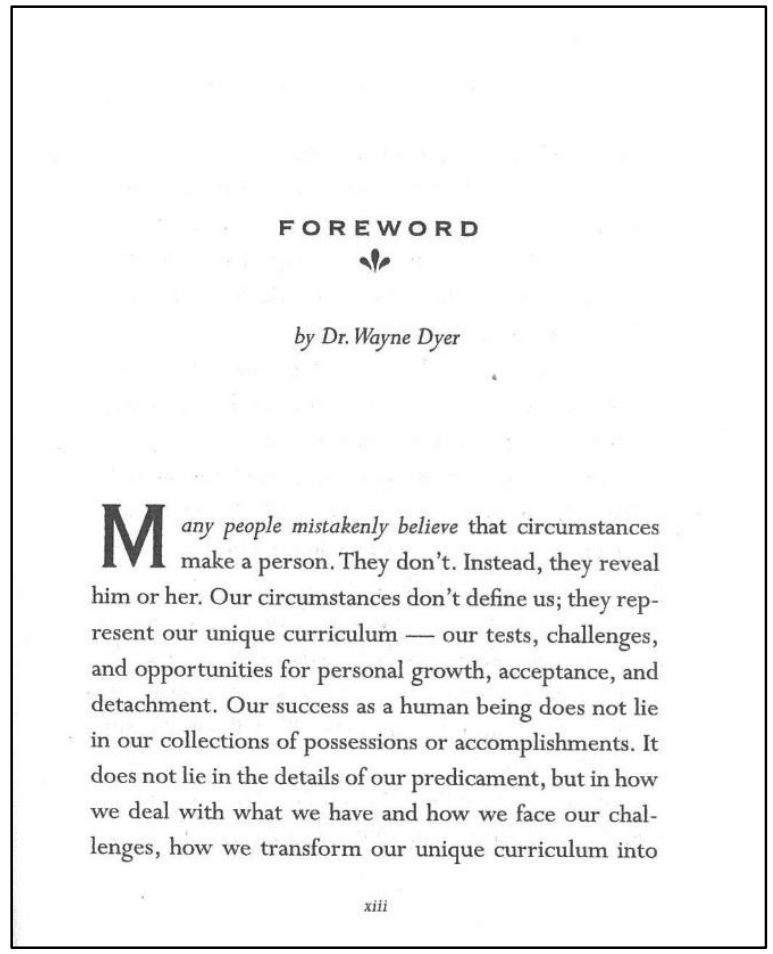

Figure 7: Foreword

From the book You Can Be Happy No Matter Work. Copyright (C) 1992 by Richard Carlson, PhD. Reprinted with permission from New World Library, Novato CA. www.newworldlibrary.com 
The online Oxford Dictionaries defines preface as "an introduction to a book, especially one that explains the author's aims" (Preface, 2015). This section occurs in only one book, thus an optional section. It is very similar to an introduction chapter. However, I have categorised this section as a preface rather than an introduction chapter because the book has both sections. It seems to me that, unlike the purpose of introduction chapters, that is to introduce the content or message of the book, the main purpose of a preface is to explain the author's aims for writing the book or the purpose of the book. It appears to me that the author attempts to persuade readers to read the book by listing reasons to read the book in this section. It is located in between an aphorism section and an introduction chapter. Figure 8 shows a complete preface section from Building Your Legacy (Fritz, 2003).

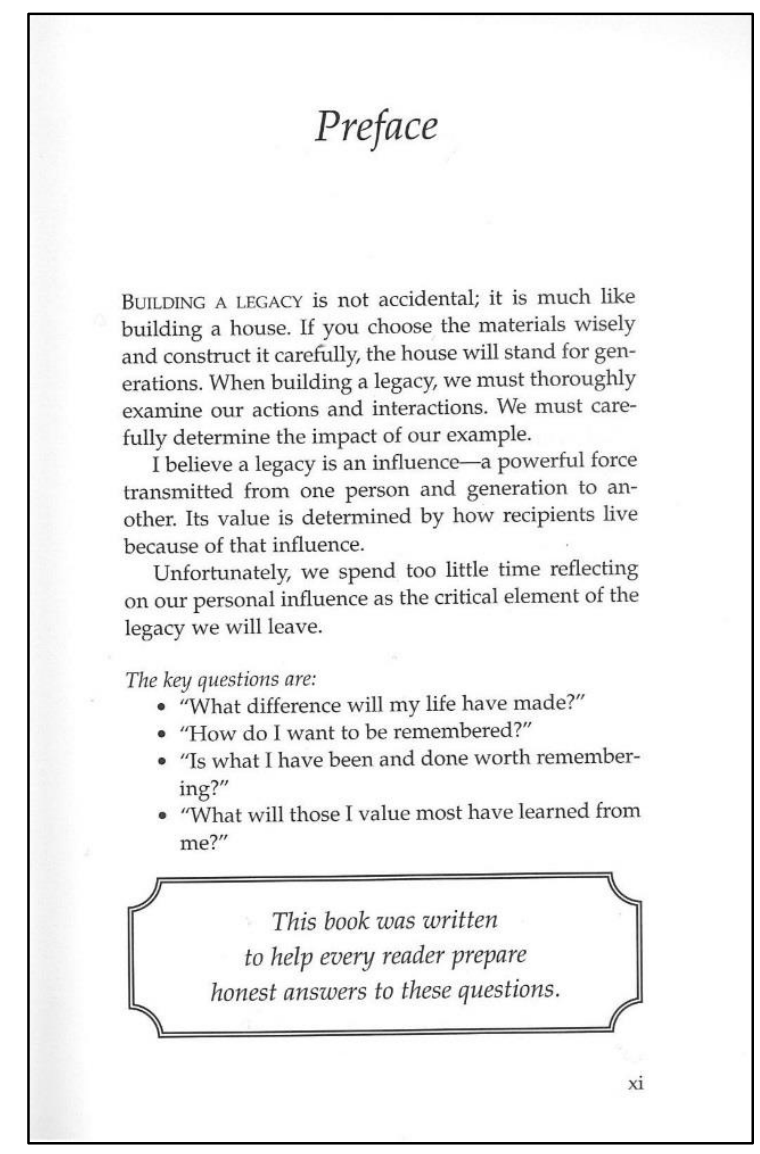

Figure 8: Preface

As can be seen in Figure 8, the author emphasises the aim of the book by putting "This book was written to..." in a box. There is one instance in my dataset where I categorised 
a section that is labelled as preface as an introduction chapter because the content of the section serves the purpose of an introduction chapter. Moreover, there is no section labelled as introduction in that book.

\section{Section 12: Introduction chapter (20/20)}

The purpose of the introduction chapter is to introduce the content or message of the book. This section is an obligatory section in my dataset and a more detailed analysis will be provided in Section 5.2. All introduction chapters in this dataset are located just before body chapters. This section is typically $(16 / 20)$ labelled as introduction and the remaining four are labelled as:

g) Personal message from Jeff Keller [the author] (Keller, 2007)

h) Introduction: Another book on attitude? (Glenn, 2008)

i) The Seven Habits - An Overview (Covey, 1989)

j) IS ATTITUDE EVERYTHING OR NOTHING? THE TRUTH MAY SURPRISE YOU [emphasis in original]. (Maxwell, 2006)

As discussed earlier, there is one instance in this dataset where the section was labelled as foreword but its purpose resembles that of an introduction chapter, so I included that section here. Figure 9 is an example of the first page of an introduction chapter from Building Your Legacy (Fritz, 2003). 


\section{Introduction}

WE WILL ALL LEAVE A LEGACY. We will make decisions and engage in actions or interactions that permanently impact our family, our friends, our co-workers. Even a single encounter with an absolute stranger can leave an imprint changing the course of that person's life. Whether it is a legacy of integrity or indifference, an impression will be left on those whose lives touch ours. The question is, "What do we want that legacy to be?"

The most familiar definition of legacy refers to money or property left to someone by a will. Another calls a legacy anything passed down, as from an ancestor. The first is very specific. The second is larger in scope, and allows for legacies to be broader than material possessions. Our definition will encompass and stress the exemplary qualities and characteristics one person passes to another as a powerful influence shaping their lives.

As I see it, leaving a legacy does not require dying. Each of us is creating our legacy every day. It does not require greatness or fame. It does not require a higher education or unique talent. All it requires is the understanding that as we move from one moment in our lives to another, we leave something of ourselves behind. With each step we take we are creating our legacy, one choice at a time.

Wrapped within that understanding is the fact that not all legacies are positive. Just as we have the poten-

Figure 9: Introduction

\section{Section 13: Body chapter (20/20)}

Self-improvement authors present and elaborate their message and advice in the body chapters. Because of their function, I propose that this section is the most crucial section in self-improvement books. All the body chapters in this dataset are located between the introduction chapter and the conclusion chapter. The body chapter is an obligatory section in my dataset and it is indicated by headings such as strategies, tools, steps, and keys. For a more detailed analysis of this section, see Section 5.3.

\section{Section 14: Conclusion chapter (12/20)}

The main purpose of this section is to encourage readers to apply the message of the book. Conclusion chapters are often reflective in that they include questions that prompt readers to reflect on the message of the book. Despite the function of this section, it is 
optional in this dataset (12/20). All conclusion chapters in this dataset are located after the last body chapters. As illustrated in Figure 10, conclusion chapters are indicated by headings. They are usually (9/12) labelled as conclusion and the remaining three are labelled as closing thoughts, final thoughts and final words.

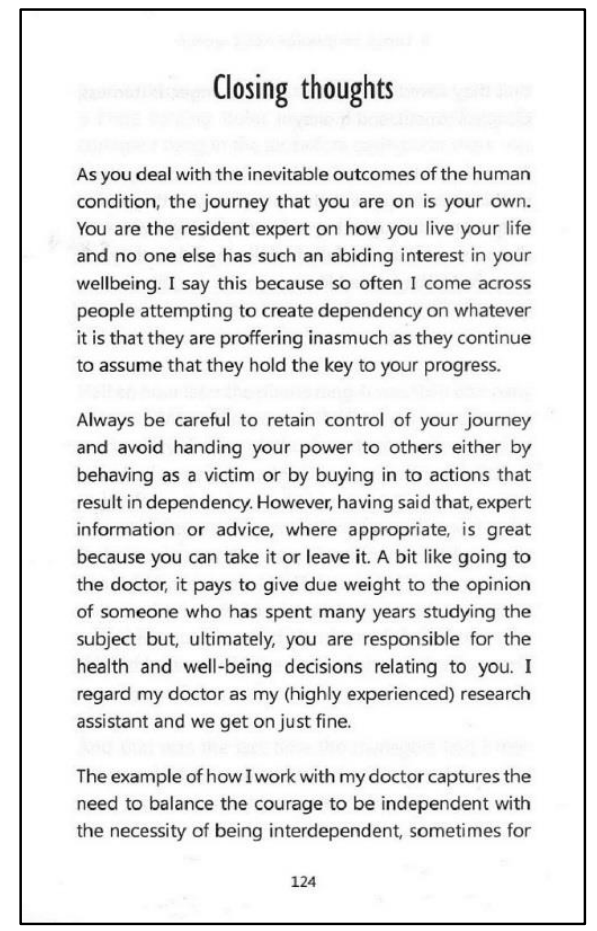

Figure 10: Conclusion

From the book 5 Tools to Change Your World. Copyright (C) 2012 by Ian Oldham. Reprinted with permission from Ian Oldham, Wellington, New Zealand. www.shiftinggears.co.nz

\section{Section 15: Appendix (1/20)}

The items in the appendix are tables and charts that illustrate the main points of the message. This section is optional as there is only one book that has an appendix section in my dataset. It is located between the last body chapter and the about the author section of this book. The example is not included because copyright permission was not granted.

\section{Section 16: References $(8 / 20)$}

References consist of a list of books that authors refer to. They are optional in my dataset. This section is signalled by a heading in all eight instances. They are labelled as 
References, Notes, or Bibliography. The number of items in the list can vary considerably (two to 13 references).

\section{Section 17: Index $(2 / 20)$}

The index section consists of a list of words arranged in alphabetical order to help readers find the specific page that relates to a particular topic. There are only two books in my dataset that have an index section. It is one of the final sections in the two selfimprovement books. In the first instance, the index is located between the conclusion chapter and the references. In another instance, it is located in between the about the author section and the back cover of the book. Interview data suggests that the index section is one of the least important sections in a self-improvement book. In an interview with Peter (self-improvement author), I asked him to describe his experience writing the genre. Peter described the differences between his first book and his second book, and he stated that his first book did not have the index section for technical reasons:

The previous one [book] doesn't have the index. I sacrificed the index page because when you send your work for printing, the number of pages has to be in multiples of eight. (June 24, 2013; Face-to-face interview)

Peter was the only participant who mentioned the index section. None of my reader and non-reader participants mentioned anything about the section. Even though interview data suggests that the index section is the least important section, its purpose to direct readers to a more specific topic (compared to the contents page) is valuable. This is probably why Peter would have to "sacrifice" this section.

\section{Section 18: About the author (19/20)}

More than merely introducing the authors in a general sense, authors use the about the author sections to construct credibility by, for example, listing relevant experiences, listing areas of expertise, and academic achievement. There are five instances where the section appears on the back cover of the book. In those five instances, a more extensive or the same version of the section can be found within the respective books. In terms of counting, I did not include those on the back covers because counting them would result 
in the total occurrences to be over 20 . The sections that occur within the book are located either after the conclusion chapter or after the last body chapter (for books that do not have conclusion chapters).

Among the 13 about the author sections that have headings, 11 are labelled as About the Author. There is one instance where the section is labelled as About the Arbinger Institute. This is the only instance in my dataset where the author is an institution. The other has a more elaborated heading About Jim Rohn-One of America's most sought-after success counselors. There is one book in my dataset that has two about the author sections; one in the beginning of the book and one at the end of the book, and they are slightly different in terms of content. I counted them as one to account for the typicality of the about the author section in my dataset.

There is one book in my dataset that does not have an about the author section. Because this section is almost obligatory (19/20), I contacted William, the author of the book, by email and asked him if he had a particular reason for not including the section in this book. His reply was:

I always like to put some bio in the back of the book. Not sure why this one did not have it. I wonder what was going on in my mind at that point as to why I didn't. (July 31, 2014; E mail communication)

William's comments suggest that an about the author section could be regarded as obligatory. A more detailed analysis of this section is provided in Section 5.4.

\section{Section 19: Space for notes $(1 / 20)$}

This is a page with lines that allows readers to write their notes. There is only one occurrence in my dataset, thus it is an optional section. This one occurrence has eight pages and is located between the about the author section and the back cover of the book. Interview data suggests that book printing process requires the number of pages of a book to be in multiples of eight. Since there are eight pages in this section, it is likely that this section was inserted deliberately, not designed to fill up empty pages. 
Advertisements publicise books that are:

a) written by the author

b) recommended by the author

c) published by the same publisher.

Advertisements are a typical section in my dataset and they are usually (12/14) found in between the about the author section and the back book cover. Two of these sections are located between the conclusion chapter and the back book cover.

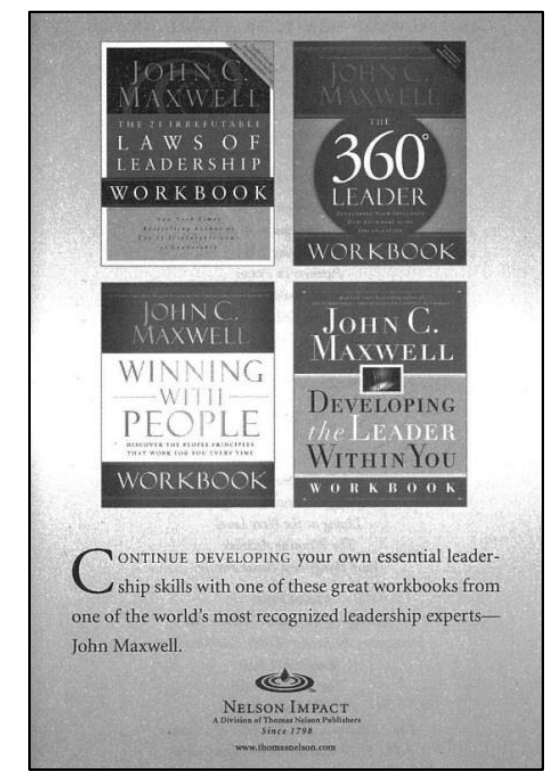

Figure 11: Advertisement

From the book Talent is Never Enough. Copyright (C) 2007 by John C. Maxwell. Reprinted with permission from Thomas Nelson, Nashville TN. http://www.thomasnelson.com/

\section{Section 21: Back book cover (20/20)}

The back book cover is the last section of the self-improvement books in my dataset and it consists of a brief summary and commentary of the book. This section is an obligatory section in my dataset. It can have promotional elements such as praise from others and about the author. Barcode is a typical (19/20) element on the back book cover in my dataset. 
To sum up, there are 21 sections in this dataset of 20 self-improvement books, of which seven are obligatory, five are typical and nine are optional. Table 5 summarises the sections that I identified, arranged according to frequency. 
Table 5: Sections in self-improvement books according to frequency

\begin{tabular}{|c|c|c|}
\hline Sections & Occurrence $($ Total $=20)$ & Typicality \\
\hline Front book cover & 20 & Obligatory \\
\hline Back book cover & 20 & Obligatory \\
\hline Title page verso & 20 & Obligatory \\
\hline Contents page & 20 & Obligatory \\
\hline Body chapters & 20 & Obligatory \\
\hline Introduction chapter & 20 & Obligatory \\
\hline About the author & $19^{*}$ & Obligatory \\
\hline Title page & 19 & Typical \\
\hline Dedication & 17 & Typical \\
\hline Praise from other & 17 & Typical \\
\hline Acknowledgement & 16 & Typical \\
\hline Advertisement & 14 & Typical \\
\hline Conclusion chapter & 12 & Optional \\
\hline References & 8 & Optional \\
\hline Aphorism & 4 & Optional \\
\hline Foreword & 2 & Optional \\
\hline Index & 2 & Optional \\
\hline Preface & 2 & Optional \\
\hline Appendix & 1 & Optional \\
\hline List of self-affirmation statements & 1 & Optional \\
\hline Space for notes & 1 & Optional \\
\hline
\end{tabular}

${ }^{*}$ Considered obligatory based on earlier argument in Section 18: About the author.

A minimal self-improvement book would have just the following obligatory sections:

1. Front book cover

2. Title page verso

3. Contents page

4. Introduction chapter

5. Body chapters

6. About the author

7. Back book cover 
The book structure in the dataset for this analysis that is the closest to the minimal structure is The Magic is in the Extra Mile (DiAngi, 2002). Other than the obligatory sections, this book has a title page and dedication.

The obligatory sections which present substantive content in a self-improvement book are the introduction chapter, body chapter, and about the author section. Identifying the obligatory sections is important because it is part of describing the characteristics of a particular genre which contributes to the understanding of the genre. The introduction chapters (obligatory) introduce the problems that authors discuss and the solutions they recommend in the body chapters (obligatory). These two obligatory chapters imply that the main purpose of self-improvement books is to provide advice for problems that authors perceive readers to have. The other obligatory section that presents substantive content in the genre is the about the author section. This shows that introducing the author is crucial in this genre.

While introduction chapters in self-improvement books are obligatory, conclusion chapters are not. An informal check shows that academic textbooks usually have a conclusion chapter or an epilogue that presents "take home" messages or how theories discussed these textbooks can be applied. Presenting what a particular author perceives to be important and useful for his/her potential readers in the conclusion chapter seems to construct the author as an expert or teacher who prescribes what his/her students need. That a conclusion chapter is optional in a self-improvement book indicates that not all authors view themselves as experts or teachers or want to be seen by their readers to be presenting themselves as such.

My analysis shows that self-improvement books minimally have three obligatory sections: an introduction chapter that introduces the message, body chapters that present the message, and about the author section that introduces the author(s). These obligatory sections contribute to the recognisability of the genre. For further exploration, I analysed the moves and steps in the respective sections. These analyses will be presented in Sections 5.2, 5.3, and 5.4, respectively. Similar to how research articles and research article abstracts are both viewed as genres, this thesis views the various sections of selfimprovement books as genres. 


\subsection{Moves in introduction chapters}

This section analyses the moves and steps in eight introduction chapters. Books that were popular were selected based on Amazon's bestselling charts and the recency of the book. This analysis involved eight introduction chapters from the following books:

1. How to have a beautiful mind (de Bono, 2004)

2. Life code (McGraw, 2012)

3. Tapping potential (Lodi, 2000)

4. The five major pieces to the life puzzle (Rohn, 2002)

5. The power of negative thinking (Knight, 2013)

6. The power of positive thinking (Peale, 1952)

7. The 18 rules of happiness (Moore, 2013)

8. 100 ways to boost your self-confidence (Goldsmith, 2010)

Note that all the authors of the eight books are male. Gender of authors was not taken into account in the selection process, but an informal check indicates that most authors of self-improvement books are male.

The size of this dataset was informed by the analysis. I chose one book at a time, analysed it, and continued adding one book at a time until I arrived at a stable system of moves. I did not identify any new moves when I analysed the sixth book and then added two more introduction chapters to confirm that no new moves appeared.

The electronic version books in this dataset were imported directly into NVivo 10, while the hardcopy books were scanned and saved in PDF format before I imported them into the same software. To identify the moves, I paid attention to segments of the text that serve a particular function and I coded the tentative moves using NVivo 10.

To guide the identification process, I paid attention to formatting such as headings and paragraphing. This process resulted in a system of moves. I proceeded to analyse more introduction chapters based on the existing system, and added new moves and adjusted existing moves in the system to account for segments of text that did not fit the existing system. After identifying the moves, I identified the steps that authors use to realise the moves. To identify the steps, my guiding criterion was what strategies authors used to achieve a particular move. I used NVivo 10 to display all instances of a particular move and read them to have a general idea of how the move was achieved. Similar to the move 
identification process, I identified tentative steps and modified them when necessary throughout the analysis. The process of developing the system also involved discussing problematic examples with my supervisors.

Because I did not notice a clear prototypical sequence of moves, I decided to focus on the typicality (obligatory or optional) of the moves and steps in terms of occurrence rather than sequence. I did not have a typical moves category in this analysis because a relatively small dataset does not allow me to make a convincing case for one. In the examples, underlining is added for emphasis. The moves and steps are as follows:

\section{Move 1: Indicating the chapter $(8 / 8)$}

The structural function or, in Halliday's terms, textual meaning, is predominant in this move. The purpose of this move is to signal the introduction chapter. It signals the location of the chapter in relation to the book.

\section{Step 1: Using a heading $(8 / 8)$}

Seven out of eight headings that indicate the introduction chapters are realised by the noun phrase, introduction. Example 1 is the only instance in my dataset that has a complex noun phrase heading where introduction is the head noun.

Example:

1) A Behind-the-Scenes Introduction to the New "Life Code" [emphasis in original] (McGraw, 2012) 


\section{Step 2: Using bigger font size $(8 / 8)$}

All the headings that indicate the introduction chapters have a bigger font size compared to that of the body paragraphs. Figure 12 illustrates how authors use bigger font size to indicate the chapter.

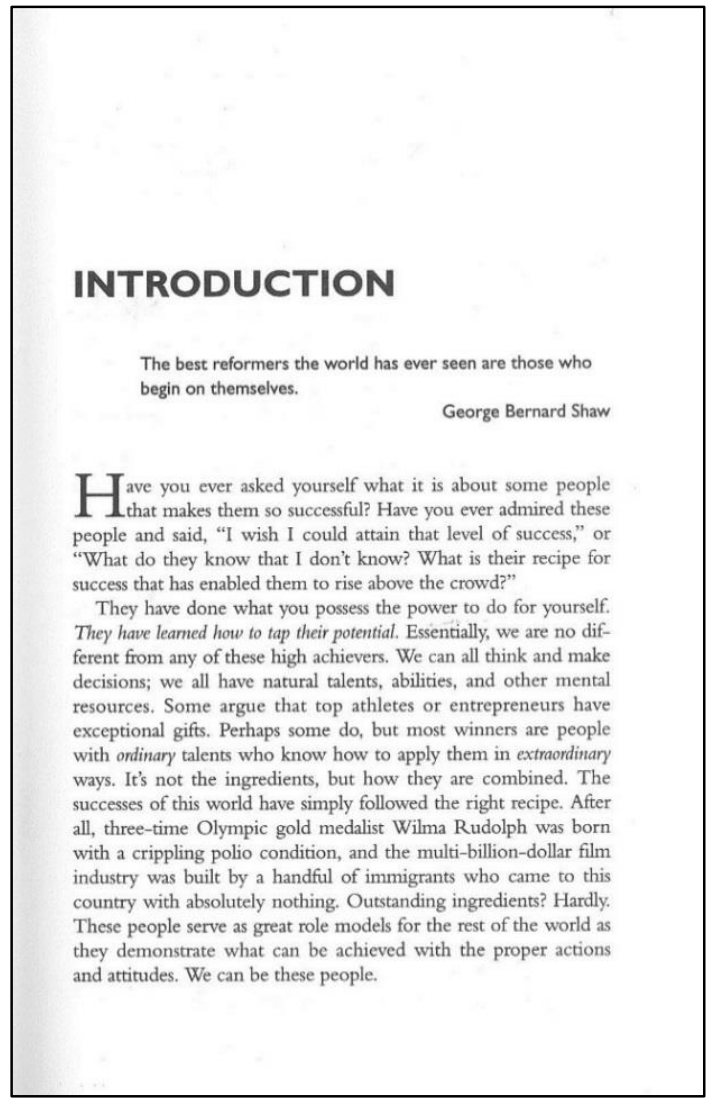

Figure 12: Introduction

From the book Tapping Potential. Copyright (C) 2000 by Kenneth J. Lodi. Reprinted with permission from Ken Lodi Communications, Los Angeles CA. http://kenlodi.com/

Step 3: Using boldface (6/8)

In Figure 12, the heading, INTRODUCTION, is in boldface.

Step 4: Using capital letters for every letter (4/8)

Example:

2) Each letter in the heading is in capital letter. See Figure 12. 
Such headings are often formatted with font style that is different from that of the body paragraphs. In Figure 12 the heading uses sans-serif font while the body text uses serifed font.

\section{Step 6: Using centred formatting (4/8)}

Centred formatting helps readers to identify the headings more easily because they are different from the formatting of the body paragraphs that is typically aligned to the left of the page.

Step 7: Using capital letters for the first letter of every lexical word (1/8)

There is only one instance where the first letter of every word in the heading is a capital letter. Taking a conservative approach, only headings with more than one word are considered for this step. This is the only example from my dataset.

Example:

3) A Behind-the-Scenes Introduction to the New "Life Code" [emphasis in original] (McGraw, 2012)

Step 8: Using underlining (1/8)

Underlining occurs only once in my dataset to signal the heading.

Example:

4) Introduction [emphasis in original] (Goldsmith, 2010) 
Move 2: Indicating the content of the section (5/8)

Move 2 is a structural move that indicates the content of the section within the chapter. Unlike Move 1, it does not signal the location of the text. The main purpose of Move 2 is to give readers a sense of the content of the coming section.

\section{Step 1: Using a sub-heading (5/5)}

Sub-headings indicate the content of the section and they usually highlight information that might be of interest to potential readers. Although a sub-heading can be found immediately below a heading, it is not restricted to that location and can be found between body paragraphs to indicate the content of the coming paragraph(s).

\section{Step 2: Using bigger font size (5/5)}

In my dataset, the font size of all (obligatory) the subheadings in Move 2 are bigger than that of the body paragraphs (see Figure 12).

\section{Step 3: Using boldface (4/5)}

Four out of five instances of Move 2 are realised by this step.

Step 4: Using capital letters for first letter of every word (4/5)

Step 4 is a typical step in Move 2.

Examples:

5) How The Process Of Change Begins [emphasis in original] (Rohn, 2002)

6) Our Objective [emphasis in original] (Lodi, 2000) 


\section{Step 5: Using centred formatting (3/5)}

This step occurs only three times in the dataset and is considered to be an optional step. The three instances of centred formatting occur immediately after the introduction chapter heading. This suggests that sub-headings that are realised by centred formatting indicate the overall content of introduction chapters rather than sections within the chapters.

\section{Step 6: Using different font style (3/5)}

The font style of these subheadings is different from that of the body paragraphs, and is an optional step.

\section{Step 7: Using capital letters for every letter (1/5)}

This is an optional step.

\section{Move 3: Persuading readers to read the book $(8 / 8)$}

One purpose of the introduction chapter is to persuade readers to buy the book, or to read or continue reading the book, and that purpose is realised in this move, which has promotional elements.

\section{Step 1: Listing potential problems $(8 / 8)$}

This is an obligatory step which occurs in Move 3. Authors list potential problems that readers may encounter or want to know more about. This step is an attempt to match readers' problems with those that the book addresses. Authors also use potential problems as a resource to convince readers to read the book. In other words, the authors are saying you should read this book if you have this problem, or if you want to know about this problem. This step is similar to Swales' (1990, p. 
141) indicating a gap in a thesis or research article. Authors also construct a lack of information, such as Example 8, to be a reason to read the books.

Examples:

7) For many who live with doubt, or are in challenging situations, believing that they are even capable of feeling confident can be difficult. (Goldsmith, 2010)

8) Did they teach you how to be happy at school or college? Have you ever attended a seminar on the topic? In fact, when was the last time you even consciously THOUGHT [emphasis in original] about your own happiness? (Moore, 2013)

\section{Step 2: Stating the purpose of the book (8/8)}

This is another obligatory step. One purpose of a self-improvement book is to recommend strategies or solutions to help readers live a more fulfilled life. This purpose can be expressed explicitly by clauses such as the purpose of this book is..., this book tells you what to do to..., I intend to..., and this book is written to suggest....

Examples:

9) This book tells you what to do to make your mind more beautiful. (de Bono, 2004)

10) In this book, I intend to help you understand how the world really works and who you really are as you go about dealing with this real world. (McGraw, 2012)

\section{Step 3: Summarising/Presenting parts of the message of the book $(8 / 8)$}

This is an obligatory step in Move 3 in this dataset. It presents a brief overview of parts of the message from the book, for example, solutions to a problem or topics that authors discuss in their books. It allows readers to have a glimpse of the content of the book. 
Examples:

11) Confidence isn't about taking over the world; it is about enjoying your world as much as possible. It doesn't take much, and you do have it inside your heart and soul, so take a little time and look for it. (Goldsmith, 2010)

12) The beauty of your mind shows in your conversation. That is what this book is about. The beauty of your mind should show in your conversation. Just as people can look at your physical beauty they can listen to the beauty of your mind. (de Bono, 2004)

\section{Step 4: Making claims about outcome of reading the book (4/8)}

Authors list specific positive outcomes of applying the strategies in this optional step. It is often signalled grammatically by the modal, will, indicating a future event that authors foresee. Such outcomes are often the improvement or changes that readers desire to see in their lives. Authors make such claims to persuade readers to read their books. This step can occur before or after Step 5: Placing responsibility on readers. In a Step 4 - Step 5 sequence (five instances), Step 4 functions as a conditional promise where the authors make claims about the outcomes of applying the principles but then in Step 5 explicitly place the responsibility of applying the principles on readers as a condition. In cases where Step 5 occurs before Step 4 (three instances), Step 4 functions as a reward for practising the author's advice.

\section{Examples:}

13) The principles in this book will help you make the leap from the potential to the actual, changing where you are to where you would prefer to be. (Lodi, 2000)

14) Those little pieces of success, pride, and assurance are like seeds: If you plant them, give them a little sunlight and water (or in this case some time and thought), you will begin to feel better about yourself and what you are doing. (Goldsmith, 2010) 


\section{Step 5: Placing responsibility on readers (5/8)}

This is an optional step and occurs in five out of eight Move 3 in my dataset. Authors maintain the effectiveness of the solutions they teach by placing part of the responsibility on readers. Readers are often asked to take an active role such as being persistent in practising the principles the author teaches in order to see positive outcomes. This step often comes after Step 4: Making claims about outcome of reading the book.

Examples:

15) Tapping potential is not a single solution to all of life's challenges. There are no scientific breakthroughs here; it cannot do the work for you. (Lodi, 2000)

16) They're simple. They're elegant. They're easy. And they're in your hands right now. (Moore, 2013)

\section{Step 6: Supporting author's claims of effectiveness (4/8)}

This step is optional and consists of personal observation, accounts of events, and other "evidence" to support the authors' claims. Examples 17 and 18 illustrate accounts of "successful" people. Authors include such accounts in the introduction chapters to persuade readers that the principles in the book are effective and that readers should read and apply them.

Examples:

17) Even though this is the first page you are reading, I will confess to you that it is the last thing I am writing as I put this book together. I really couldn't have done this introduction justice until the book was finished, because the writing of it has affected me in a meaningful way. To be candid, I usually feel tired and beat up after writing a book, but I don't now. I feel energized and razor sharp about the subject matter. (McGraw, 2012)

18) The successes of this world have simply followed the right recipe. After all, three-time Olympic gold medalist Wilma Rudolph was born with a crippling polio condition, and the multi-billion-dollar film industry was built by a 
handful of immigrants who came to this country with absolutely nothing. (Lodi, 2000)

\section{Step 7: Stating where the message originated $(3 / 8)$}

This is an optional step. Stating where the message of the book originated is a resource that authors can use to appraise the message, mainly to ascribe reliability to it. The purpose of convincing readers that the message is reliable is mainly to persuade them to read or buy the books.

Examples:

19) I listed those people in my life whom I admire and look up to and have enough intimate knowledge about to really know how they do what they do. These are people whom I have seen succeed, overcome, conquer, and contribute to this world. (McGraw, 2012)

20) I need not point out that the powerful principles contained herein are not my invention but are given to us by the greatest Teacher who ever lived and who still lives. This book teaches applied Christianity; a simple yet scientific system of practical techniques of successful living that works. (Peale, 1952)

\section{Step 8: Claiming uniqueness (3/8)}

One of the steps authors use to persuade readers to read their books, rather than those written by other authors, is to claim that their books are different from those written by others. Stine (1997, p. 28), an editor of self-improvement books, points out authors should include "a particular approach or slant that your have developed over the years" that "distinguishes your book from others" because "it will be competing in the same marketplace as other 'feel-good' products." This is an optional step. 
Examples:

21) If up until this point you've been doing everything "by the book" but your life still isn't where you want it, you've been reading the wrong book. It's time to read the right one. (McGraw, 2012)

22) Most books are written to entertain or inform. This book is written so that it might inspire. (Rohn, 2002)

Example 21 illustrates how the author constructs his book as "the right one" among "the wrong" ones. Example 22 demonstrates how the author contrasts the character of his book with other books.

\section{Step 9: Claiming accessibility (3/8)}

One of the ways that authors can persuade readers to read their books is to claim that they are easy to read. This optional step gives the impression that a selfimprovement book written in a simple and understandable manner is preferred. Stine (1997, pp. 97-98) reminds authors to keep their writing simple and plain and to minimise "technical or clinical jargon." Stine (1997, p. 97) reasons that "the more successful you are at keeping it [writing style] simple, the better your chances of reaching the vast audience that makes a book a bestseller."

Examples:

23) They're simple. They're elegant. They're easy. (Moore, 2013)

\section{Step 10: Claiming the power of the book/message (2/8)}

To persuade readers to read the book, authors sometimes claim that the book or message is powerful. This step is similar to Step 7: Stating where the message originated. While Step 7 is primarily about stating where the message originated and how it developed from its original idea, this step is about making claims that the message is powerful mainly because the author has put in effort into the writing process. This is an optional step. 
Examples:

24) To say that I'm proud of this book would be an understatement. It has been written from a place of passion, determination, and concern. (McGraw, 2012)

25) At this moment in time you hold in your hands a document that represents an awesome force, and I trust that you will be as serious about reading this book as I have been about writing it. (Rohn, 2002)

\section{Step 11: Encouraging readers to continue reading the book $(2 / 8)$}

This optional step focuses on persuading the readers who have begun reading the introduction chapter to read on. Authors express this purpose explicitly.

Examples:

26) Here we go. (McGraw, 2012)

27) It is human to put things off, It is divine to start things off.

W.H. Danforth (Lodi, 2000)

\section{Step 12: Challenging opposing worldview (1/8)}

Step 12 is only found in one book in my dataset. The author challenges an opposing worldview and presents his worldview as a better one to adopt. This constructs readers as in need of "fixing" in terms of having a "wrong" worldview and implies the need to read the book. Examples 28 and 29 illustrate how an author who is an advocate of negative thinking challenges the idea of positive thinking. This step is similar to Hyland's (2008) idea of how authors persuade their readers by anticipating potential disagreements.

Examples:

28) Don't be caught thinking something is going to work just because you think it's going to work. (Knight, 2013) 
29) One of our most lauded qualities is the ability to think fast. In an emergency, that's great. But it's also risky. When time permits, it's much better to be sure you're thinking clearly. How many times have we read or heard of someone who made a rash decision and now faces criminal charges, or lost his job, or broke his family apart by an unwise act? (Knight, 2013)

\section{Step 13: Identifying potential challenges in executing author's recommendation} $(1 / 8)$

There is one instance where the author anticipates difficulties in executing the solution that he recommends. This step encourages readers to continue reading if they experience such difficulties half way through the book. Like Step 12, this step is similar to how authors respond to readers' possible negative reaction to their claims. It responds to possible future challenges in terms of executing authors' advice, while Step 12 responds to readers' current worldview that is potentially in conflict with those that the authors teach.

Example:

30) Initially most people are a little reluctant, partially because it's unfamiliar territory, which always produces a touch of anxiety. (Goldsmith, 2010)

\section{Step 14: Using aphorisms (1/8)}

This step occurs only once in this dataset of introduction chapters. Example 31 is a quote, signalled by a person's name (see Section 5.1), included below the chapter heading. The quote is centred in terms of alignment and is separated from the body paragraphs. The author uses the quote to persuade readers that change should start with themselves. It is possible that the author is persuading readers to read the book and implicitly constructing his book as having the message that will change their lives. 
Example:

31) The best reformers the world has ever seen are those who begin on themselves. - George Bernard Shaw (Lodi, 2000)

\section{Move 4: Constructing credibility (5/8)}

This is an optional move (five out of eight books) in my dataset. The steps in this move show some of the ways self-improvement authors construct themselves as a credible source of advice.

\section{Step 1: Listing relevant experience (5/5)}

This is an obligatory step in Move 4. In the dataset, experiences that are relevant in constructing authors' credibility relate to authors' personal experience and observation, the number of self-improvement books written, invitations to speak on radio programmes, and being involved with teaching and coaching "successful" individuals and organisations.

Examples:

32) Given my profession and what I have dealt with every day for 35 years, I can unequivocally say I have seen the Good, the Bad, and the Ugly of life. It's in that "seeing" that I have gained what has, at times, been a painful wisdom that I seek to share in the following pages. (McGraw, 2012)

33) Throughout this book, I will speak largely as a coach, in coaching and basketball terms. (Knight, 2013) 


\section{Step 2: Hedging the scope of the message (4/5)}

It is likely that authors hedge the scope of their message to appear to be realistic about their claims. In other words, this is a resource that authors use to construct their identity as credible advice givers who are not irrationally idealistic.

Examples:

34) Tapping potential is not a single solution to all of life's challenges. (Lodi, 2000)

35) Let me be clear: I am not arguing for being a strict negativist, for walking around with a sour look, for always seeing the dark side, always expecting failure. That's not my intent at all. Quite the opposite. (Knight, 2013)

\section{Step 3: Referring to popularity $(1 / 5)$}

There is only one instance where the author refers to the popularity of the system he presents. I reason that the author would have to be significantly popular in order to include this step in the introduction chapter. To support this interpretation, the only occurrence of this step is in a classic self-improvement book.

Example:

36) Because so many have requested that these principles be put into book form, the better to be studied and practiced, I am publishing this new volume under the title, The Power of Positive Thinking. (Peale, 1952)

Example 36 illustrates how the author constructs the book as a result of readers' demand that implies his popularity. The example also illustrates how the author anticipates and counters readers who are sceptical about books that are published for financial gain. This interpretation is consistent with both reader and non-reader interview data. For example, when I asked Joanne, a regular reader of the genre, what she thought was the main purpose authors write these books, she said: 
I'm sure some of them are definitely motivated by money. And some of them are motivated by altruism and feel that they have some insights in life that they would like to share with people...I think it's probably a mixture of those things...It's hard to say but with the American ones [referring to those similar to The Choice is Yours], I just have this sort of feeling that it's got a lot to do with money. (June 6, 2013; Face-to-face interview)

When I asked Ivy, a non-reader of the genre, the same question, she said:

I'm sure they are just for the money. I don't think they want to help anybody. (March 11, 2013; Face-to-face interview)

Both reader and non-reader interview data suggests that some potential readers are suspicious that authors' primary goal is to genuinely help readers. Rather, they perceive the authors' primary interest to be making money. This step shows that authors counter this view by constructing the popularity of their message as the motivation for publishing their books.

\section{Move 5: Indicating the end of introduction chapter (3/8)}

This move is optional in my dataset. It occurs in two out of eight introduction chapters. Similar to the signalling functions of Move 1: Indicating the chapter and Move 2: Indicating the content of the section, Move 5 signals the end of the introduction chapter. This move is a structural move that mainly performs a textual function.

\section{Step 1: Including signature/name (3/3)}

The step is similar to ending a letter. Signature and name are found to be used to end the chapter.

Examples:

37) Karl Moore, May 2011 (Moore, 2013)

38) COACH BOB KNIGHT (Knight, 2013) 


\section{Step 2: Including date $(1 / 2)$}

There is one instance where the author includes a date beside his name to indicate the end of the chapter. Even though including a date is primarily serving a textual purpose, it might be serving an interpersonal purpose as well. Including a date beside the name at the end of the chapter gives letter-like layout to the introduction chapter making it appear to be a personal note from the author.

Example:

39) Karl Moore, May 2011 (Moore, 2013)

\section{Step 3: Providing website URL (1/2)}

This step occurs only once in the dataset. This step, while primarily performing a textual role, may have promotional elements. It is also possible that having a website where readers can read more about the author is how authors construct their credibility.

Example:

40) www.karlmoore.com (Moore, 2013)

This move analysis of introduction chapters shows that the minimal structure requires M1: Indicating the chapter and M3: Persuading readers to read the book. The step analysis shows that authors always persuade readers to read their books by presenting reasons to read the books, presenting the purpose of the books, and presenting the summary or parts of their message in the introduction chapters. Table 6 summarises the moves and steps that I identified in the introduction chapters. 
This page intentionally left blank 
Table 6: Moves and Steps in introduction chapters

\begin{tabular}{|c|c|c|}
\hline Moves/Steps & $\begin{array}{l}\text { Occurrence } \\
(\text { Total }=8)\end{array}$ & Typicality \\
\hline M1: Indicating the chapter & 8 & Obligatory \\
\hline S1: Using a heading & 8 & Obligatory \\
\hline S2: Using bigger font size & 8 & Obligatory \\
\hline S3: Using boldface & 6 & Optional \\
\hline S4: Using capital letters for every letter & 4 & Optional \\
\hline S5: Using different font style & 4 & Optional \\
\hline S6: Using centred formatting & 4 & Optional \\
\hline S7: Using capital letters for first letter of every word & 1 & Optional \\
\hline S8: Using underlining & 1 & Optional \\
\hline M2: Indicating content of the section & 5 & Optional \\
\hline S1: Using a heading & 5 & Obligatory \\
\hline S2: Using bigger font size & 5 & Obligatory \\
\hline S3: Using boldface & 4 & Optional \\
\hline S4: Using capital letters for first letter of every word & 4 & Optional \\
\hline S5: Using centred formatting & 3 & Optional \\
\hline S6: Using different font style & 3 & Optional \\
\hline S7: Using capital letters for every letter & 1 & Optional \\
\hline
\end{tabular}




\begin{tabular}{|c|c|c|}
\hline M3: Persuading readers to read the book & 8 & Obligatory \\
\hline S1: Listing potential problems & 8 & Obligatory \\
\hline S2: Stating the purpose of the book & 8 & Obligatory \\
\hline S3: Summarising/Presenting parts of the message of the book & 8 & Obligatory \\
\hline S4: Making claims about outcome of reading the book & 4 & Optional \\
\hline S5: Placing responsibility on readers & 5 & Optional \\
\hline S6: Supporting author's claims of effectiveness & 4 & Optional \\
\hline S7: Stating where the message originated & 3 & Optional \\
\hline S8: Claiming uniqueness & 3 & Optional \\
\hline S9: Claiming accessibility & 3 & Optional \\
\hline S10: Claiming power of the book/message & 2 & Optional \\
\hline S11: Encouraging readers to continue reading the book & 2 & Optional \\
\hline S12: Challenging opposing worldview & 1 & Optional \\
\hline S13: Identifying potential challenges in executing author's recommendation & 1 & Optional \\
\hline S14: Using aphorisms & 1 & Optional \\
\hline M4: Constructing credibility & 5 & Optional \\
\hline S1: Listing author's relevant experience & 5 & Obligatory \\
\hline S2: Hedging the scope of the message & 4 & Optional \\
\hline S3: Claiming popularity & 1 & Optional \\
\hline
\end{tabular}


S2: Including date

S3: Providing website URL

Optional

Optional 
To illustrate the moves and steps that I summarised in Table 6 in context, I provide an example of a full introduction chapter from my dataset in Table 7. The introduction chapter from The Power of Positive Thinking (Peale, 1952) was chosen because this book is often considered to be the classic of self-improvement books. In the process of selecting a full example, I also take into consideration the length of the chapter, in terms of the number of words.

Table 7: Example of full introduction chapter

\begin{tabular}{|c|c|c|}
\hline Data & Moves & Steps \\
\hline INTRODUCTION & $\begin{array}{l}\text { M1: Indicating } \\
\text { the chapter }\end{array}$ & $\begin{array}{l}\text { S1: Using a heading } \\
\text { S2: Using bigger font size } \\
\text { S3: Using boldface } \\
\text { S6: Using centred } \\
\text { formatting } \\
\text { S7: Using capital letters } \\
\text { for every word }\end{array}$ \\
\hline What This Book Can Do for You & $\begin{array}{l}\text { M2: Indicating } \\
\text { the content of } \\
\text { the section }\end{array}$ & $\begin{array}{l}\text { S1: Using a heading } \\
\text { S2: Using bigger font size } \\
\text { S3: Using boldface } \\
\text { S4: Using capital letters } \\
\text { for first letter of every } \\
\text { word } \\
\text { S5: Using centred } \\
\text { formatting }\end{array}$ \\
\hline $\begin{array}{l}\text { THIS BOOK is WRITTEN } \\
\text { [emphasis in original] to suggest } \\
\text { techniques and to give examples which } \\
\text { demonstrate that you do not need to be } \\
\text { defeated by anything, that you can have } \\
\text { peace of mind, improved health, and a } \\
\text { never-ceasing flow of energy. In short, } \\
\text { that your life can be full of joy and } \\
\text { satisfaction. }\end{array}$ & $\begin{array}{l}\text { M3: Persuading } \\
\text { readers to read } \\
\text { the book }\end{array}$ & $\begin{array}{l}\text { S2: Stating the purpose } \\
\text { of the book }\end{array}$ \\
\hline
\end{tabular}




\begin{tabular}{|c|c|}
\hline $\begin{array}{l}\text { Of this I have no doubt at all for I have } \\
\text { watched countless persons learn and } \\
\text { apply a system of simple procedures that } \\
\text { has brought about the foregoing benefits } \\
\text { in their lives. }\end{array}$ & $\begin{array}{l}\text { S6: Supporting author's } \\
\text { claims of effectiveness }\end{array}$ \\
\hline $\begin{array}{l}\text { These assertions, which may appear } \\
\text { extravagant, are based on bona-fide } \\
\text { demonstrations in actual human } \\
\text { experience. }\end{array}$ & $\begin{array}{l}\text { S7: Stating where the } \\
\text { message originated }\end{array}$ \\
\hline $\begin{array}{l}\text { Altogether too many people are } \\
\text { defeated by the everyday problems of } \\
\text { life. They go struggling, perhaps even } \\
\text { whining, through their days with a sense } \\
\text { of dull resentment at what they consider } \\
\text { the "bad breaks" life has given them. In a } \\
\text { sense there may be such a thing as "the } \\
\text { breaks" in this life, but there is also a } \\
\text { spirit and method by which we can } \\
\text { control and even determine those breaks. } \\
\text { It is a pity that people should let } \\
\text { themselves be defeated by the problems, } \\
\text { cares, and difficulties of human } \\
\text { existence, and it is also quite } \\
\text { unnecessary. }\end{array}$ & $\begin{array}{l}\text { S1: Listing potential } \\
\text { problems }\end{array}$ \\
\hline $\begin{array}{l}\text { In saying this I certainly do not } \\
\text { ignore or minimize the hardships and } \\
\text { tragedies of the world, but neither do I } \\
\text { allow them to dominate. }\end{array}$ & $\begin{array}{l}\text { S5: Placing responsibility } \\
\text { on readers }\end{array}$ \\
\hline $\begin{array}{l}\text { You can permit obstacles to control your } \\
\text { mind to the point where they are upper- } \\
\text { most and thus become the dominating } \\
\text { factors in your thought pattern. By } \\
\text { learning how to cast them from the }\end{array}$ & $\begin{array}{l}\text { S3: } \\
\text { Summarising/Presenting } \\
\text { parts of the message of } \\
\text { the book }\end{array}$ \\
\hline
\end{tabular}




\begin{tabular}{|c|c|}
\hline $\begin{array}{l}\text { mind, by refusing to become mentally } \\
\text { subservient to them, and by channeling } \\
\text { spiritual power through your thoughts, } \\
\text { you can rise above obstacles which } \\
\text { ordinarily might defeat you. By methods } \\
\text { I shall outline, obstacles are simply not } \\
\text { permitted to destroy your happiness and } \\
\text { well-being. You need be defeated only if } \\
\text { you are willing to be. This book teaches } \\
\text { you how to "will" not to be. }\end{array}$ & \\
\hline $\begin{array}{l}\text { The purpose of this book is a very } \\
\text { direct and simple one. It makes no } \\
\text { pretense to literary excellence nor does it } \\
\text { seek to demonstrate any unusual } \\
\text { scholarship on my part. This is simply a } \\
\text { practical, direct-action, personal } \\
\text { improvement manual. It is written with } \\
\text { the sole objective of helping the reader } \\
\text { achieve a happy, satisfying, and } \\
\text { worthwhile life. I thoroughly and } \\
\text { enthusiastically believe in certain } \\
\text { demonstrated and effective principles } \\
\text { which, when practiced, produce a } \\
\text { victorious life. My aim is to set them } \\
\text { forth in this volume }\end{array}$ & $\begin{array}{l}\text { S2: Stating the purpose } \\
\text { of the book }\end{array}$ \\
\hline $\begin{array}{l}\text { in a logical, simple, and understandable } \\
\text { manner }\end{array}$ & $\begin{array}{l}\text { S9: Claiming } \\
\text { accessibility }\end{array}$ \\
\hline $\begin{array}{l}\text { so that the reader, feeling a sense of } \\
\text { need, may learn a practical method by } \\
\text { which he can build for himself, with } \\
\text { God's help, the kind of life he deeply } \\
\text { desires. }\end{array}$ & $\begin{array}{l}\text { S2: Stating the purpose } \\
\text { of the book }\end{array}$ \\
\hline
\end{tabular}




\begin{tabular}{|c|c|}
\hline $\begin{array}{l}\text { If you read this book thoughtfully, } \\
\text { carefully absorbing its teachings, and if } \\
\text { you will sincerely and persistently } \\
\text { practice the principles and formulas set } \\
\text { forth herein, }\end{array}$ & $\begin{array}{l}\text { S5: Placing responsibility } \\
\text { on readers }\end{array}$ \\
\hline $\begin{array}{l}\text { you can experience an amazing } \\
\text { improvement within yourself. By using } \\
\text { the techniques outlined herewith you } \\
\text { can modify or change the circumstances } \\
\text { in which you now live, assuming control } \\
\text { over them rather than continuing to be } \\
\text { directed by them. Your relations with } \\
\text { other people will improve. You will } \\
\text { become a more popular, esteemed, and } \\
\text { well-liked individual. By mastering these } \\
\text { principles, you will enjoy a delightful } \\
\text { new sense of well-being. You may attain } \\
\text { a degree of health not hitherto known by } \\
\text { you and experience a new and keen } \\
\text { pleasure in living. You will become a } \\
\text { person of greater usefulness and will } \\
\text { wield an expanded influence. }\end{array}$ & $\begin{array}{l}\text { S4: Making claims about } \\
\text { outcome of reading the } \\
\text { book }\end{array}$ \\
\hline $\begin{array}{l}\text { How can I be so certain that the } \\
\text { practice of these principles will produce } \\
\text { such results? The answer is simply that } \\
\text { for many years in the Marble Collegiate } \\
\text { Church of New York City we have } \\
\text { taught a system of creative living based } \\
\text { on spiritual techniques, carefully noting } \\
\text { its operation in the lives of hundreds of } \\
\text { people. }\end{array}$ & $\begin{array}{l}\text { S7: Stating where the } \\
\text { message originated }\end{array}$ \\
\hline $\begin{array}{l}\text { It is no speculative series of extravagant } \\
\text { assertions that I make, for these }\end{array}$ & $\begin{array}{l}\text { S6: Supporting author's } \\
\text { claims of effectiveness }\end{array}$ \\
\hline
\end{tabular}




\begin{tabular}{|c|c|c|}
\hline $\begin{array}{l}\text { principles have worked so efficiently } \\
\text { over so long a period of time that they } \\
\text { are now firmly established as } \\
\text { documented and demonstrable truth. } \\
\text { The system outlined is a perfected and } \\
\text { amazing method of successful living. }\end{array}$ & & \\
\hline $\begin{array}{l}\text { In my writings, including several } \\
\text { books, in my regular weekly newspaper } \\
\text { column in nearly one hundred dailies, in } \\
\text { my national radio program over } \\
\text { seventeen years, in our magazine, } \\
\text { Guideposts, and in lectures in scores of } \\
\text { cities, I have taught these same scientific } \\
\text { yet simple principles of achievement, } \\
\text { health, and happiness. }\end{array}$ & $\begin{array}{l}\text { M4: } \\
\text { Constructing } \\
\text { author's } \\
\text { credibility }\end{array}$ & $\begin{array}{l}\text { S1: Listing author's } \\
\text { relevant experience }\end{array}$ \\
\hline $\begin{array}{l}\text { Hundreds have read, listened, and } \\
\text { practiced, and the results are invariably } \\
\text { the same: new life, new power, increased } \\
\text { efficiency, greater happiness. }\end{array}$ & $\begin{array}{l}\text { M3: Persuading } \\
\text { readers to read } \\
\text { the book }\end{array}$ & $\begin{array}{l}\text { S6: Supporting author's } \\
\text { claims of effectiveness }\end{array}$ \\
\hline $\begin{array}{l}\text { Because so many have requested that } \\
\text { these principles be put into book form, } \\
\text { the better to be studied and practiced, I } \\
\text { am publishing this new volume under } \\
\text { the title, The Power of Positive } \\
\text { Thinking. }\end{array}$ & $\begin{array}{l}\text { M4: } \\
\text { Constructing } \\
\text { author's } \\
\text { credibility }\end{array}$ & S3: Claiming popularity \\
\hline $\begin{array}{l}\text { I need not point out that the } \\
\text { powerful principles contained herein are } \\
\text { not my invention but are given to us by } \\
\text { the greatest Teacher who ever lived and } \\
\text { who still lives. This book teaches applied } \\
\text { Christianity; a simple yet scientific } \\
\text { system of practical techniques of } \\
\text { successful living that works. }\end{array}$ & $\begin{array}{l}\text { M3: Persuading } \\
\text { readers to read } \\
\text { the book }\end{array}$ & $\begin{array}{l}\text { S7: Stating where the } \\
\text { message originated }\end{array}$ \\
\hline
\end{tabular}




\begin{tabular}{|l|l|l|}
\hline - NORMAN VINCENT PEALE & $\begin{array}{l}\text { M5: Indicating } \\
\text { the end of }\end{array}$ & $\begin{array}{l}\text { S1: Including } \\
\text { signature/initial/name } \\
\text { introduction } \\
\text { chapter }\end{array}$ \\
\end{tabular}

From the book The Power of Positive Thinking. Copyright (C) 1952, 1956, 2012 by Prentice-Hall, Inc. Copyright renewed (C) 1980, 1984 by Norman Vincent Peale. Reprinted with permission from Simon \& Schuster Inc., New York. http://www.simonandschuster.com/

The first and by far the longest rhetorical move in this example is persuading readers to read the book. It is an obligatory move and it is realised by eight different steps. This suggests that the main purpose of the introduction chapter is a persuasive one, and this is confirmed by the analysis of the full dataset.

The three obligatory steps that authors use to achieve this purpose of persuading readers to read the book are listing problems that their imagined readers would encounter or are interested to find out more about, stating the purpose of the books they write, and summarising or presenting parts of the message of their books. These steps or strategies that authors use indicate how authors perceive their readers and what persuasion is perceived to be in self-improvement books.

A closer look at the three steps indicates that authors construct readers as people who have problems and are searching for advice, or as students who want to understand a particular problem. Stating the purpose of a book in the introduction chapter is very similar to stating the objective of a company. Both are ways to "sell" or present the company or book. Reading the purpose of a particular self-improvement book gives readers the opportunity to decide whether the book matches their needs. This is a crucial moment because it determines whether a particular reader is going to buy or continue reading the book. The third obligatory persuasion strategy is to summarise or present parts of authors' advice. This strategy gives readers a sense of what the advice may look like. It is a way of presenting what potential "buyers" might be interested in buying. It is very similar to the steps in conference abstracts, announcing present research and announcing principal findings, as strategies to introduce, or more specifically to occupy a niche, in conference papers (Samar et al., 2014). They explain that the main function of these steps is "to sell the article" rather than "to tell and give information" (p. 780). Similar to the purpose of conference abstracts that Samar et al. studied, the main purpose of 
introduction chapters in self-improvement books is to "sell" authors' advice rather than just providing information about their books.

Step 4: Making claims about outcome of reading the book, although not an obligatory step, sheds light on what authors view to be the need of their imagined readers. This step also contributes to the understanding of the values (e.g., desirable/undesirable) in selfimprovement. In Examples 13 and 14 (see Section 5.2), claiming that the book will help readers realise "where they would prefer to be" and "feel better" better about themselves indicates that authors construct their imagined readers as people who are not satisfied with their status quo, want to improve their lives, and are seeking for advice in that area. The types of improvement are related to maximising one's potential and being more successful, as illustrated in the examples.

Similar to the role of empirical data and references in academic writing, selfimprovement authors use accounts of successful stories and claim the popularity of their advice in Step 6: Supporting author's claims of effectiveness, as "evidence" for supporting the claim that their advice is effective. The preference in terms of strategy implies that the perception of evidence is culture specific. While empirical data and references are common persuasion strategies in academic writing, they are uncommon in selfimprovement books.

Using Step 8: Claiming uniqueness as a way to persuade readers implies that authors are aware that they have to compete with the abundance of self-improvement books in the market. This step also shows that authors anticipate their imagined readers to perceive their advice to be similar to other self-improvement books. This is consistent with reader and non-reader interview data. For example, when I asked Anne, a non-reader of the genre, what she thought was the reason people do not read this genre, she said:

I think maybe they think that the contents of the book, what's written in the book is nothing new. It's nothing they don't already know... Part of the reason I don't read them is because they are very predictable. They might find new ways to say things but I find them predictable. (November 27, 2013; Face-to-face interview)

Anne's comment indicates that she fits the imagined reader of self-improvement books. In the attempt to persuade readers like Anne to read the genre, authors would have to convince readers that their advice is not predictable and unique. 
The move analysis of the introduction chapters shows that the main purpose of these chapters is to "sell" authors' advice. I have also demonstrated that paying attention to steps sheds light on how authors perceive their imagined readers.

\subsection{Moves in body chapters}

Moving on to the next obligatory section in self-improvement books, the body chapters (see Section 5.1), I analysed the moves and steps in this section. Interview data suggests that readers perceived the body chapters to be the main section of self-improvement books.

Interview data also suggests that regular readers of self-improvement books do not necessarily read the chapters in a particular self-improvement book in the order they appear in the book. Some readers read the chapters selectively according to their current needs. For example, when I asked Gladys what she thought were the characteristics of self-improvement books, she stated that:

You can dip into them. You just look through and you don't have to start from the beginning and read the whole way through. I can just go....I want to know more about 'Commitment is a choice' and I'll just read that bit. (February 2, 2013; Faceto-face interview)

I interpret "that bit" in Gladys' comments as referring to a particular body chapter. Her comments also suggest that the main sections that readers read are body chapters. Due to the central role of the body chapters and because they are obligatory (see Section 5.1), I analysed how authors structure the internal organisation of individual body chapters.

The dataset for this analysis consists of 10 body chapters, each from a different book. With 10 body chapters, I was able to achieve a stable system of moves and steps. The body chapters are usually recognised and indicated by their location, after the introduction chapter and before the conclusion chapter, if there is one. To be consistent, I chose the first body chapters because they occurred after the introduction chapter. Although Gladys' comment may suggest that she perceived body chapters to have a 
coordinate relationship rather than a subordinate one, I do not have evidence to show that the order of body chapters in a particular book is completely flexible.

Because the analysis involved manually identifying the moves and steps, books in the electronic versions were selected to assist the coding process in NVivo10. Hardcopy books were not chosen because body chapters are relatively longer and scanning them would not be effective in terms of time management. At this point of my research, I discovered that about half of the books from the main dataset (see Appendix 1) were not published by a conventional publishing house. Knowing this, I included in this analysis a mixture of both books that were published by a conventional publishing house and those that were published in a non-conventional way. This explains why the books in this dataset were different from those for the analysis of introduction chapters, although the popularity and recency criteria were applied. Like the analysis of introduction chapters, the number of books for this analysis was determined by system stability (see Section 5.2). The books for this analysis were:

1. A Few Keys to All Success (Muncy, 2002) - non-conventional

2. How to Have a Beautiful Mind (de Bono, 2004) - conventional

3. Talent is Never Enough (Maxwell, 2007) - conventional

4. The Five Major Pieces to the Life Puzzle (Rohn, 2002) - non-conventional

5. The Power of Positive Thinking (Peale, 1952) - conventional

6. The 5 Love Languages (Chapman, 1992) - conventional

7. The 7 Habits of Highly Effective People (Covey, 1989) - conventional

8. The 18 Rules of Happiness (Moore, 2013) - non-conventional

9. You Can be Happy No Matter What (Carlson, 1997) - conventional

10. 5 Tools to Change Your World (Oldham, 2012) - non-conventional

To identify the moves and steps, I followed the same process I used to analyse the introduction chapters (see Section 5.2). The moves and steps are presented together with examples for illustrative purposes. 
This structural move signals the location of the section in relation to the book and indicates the content of the chapter. These headings are often signalled by formatting, which will be discussed later. This move performs a similar function to that of Move 1 in Introduction chapter.

\section{Step 1: Using a heading (10/10)}

Headings of body chapters were indicated by chapter numbers (e.g., Habit 1, Principle \#1, Tool 1) and/or the content of the chapter (e.g., The Principle of Thought, Responsibility strengthens your talent).

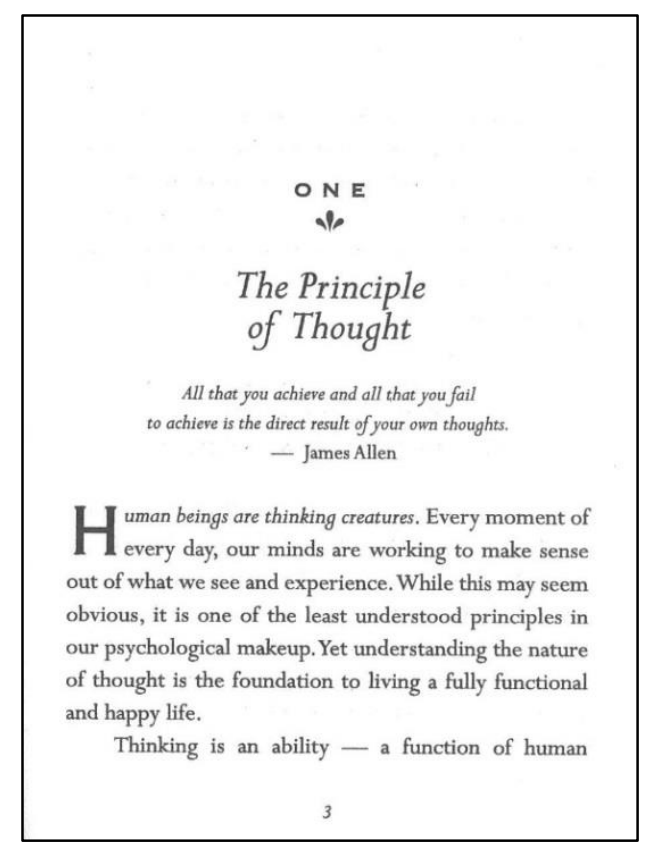

Figure 13: Heading

From the book You Can Be Happy No Matter What. Copyright ( 1992 by Richard Carlson, PhD. Reprinted with permission from New World Library, Novato CA. www.newworldlibrary.com

\section{Step 2: Using bigger font size (10/10)}

The heading "ONE: The Principle of Thought" has a bigger font size compared with the text in the paragraph (see Figure 13). 
Step 3: Using boldface (10/10)

The heading in Figure 13 is in boldface.

Step 4: Using centred formatting (9/10)

The heading in Figure 13 is centred formatted.

Step 5: Using capital letters for every lexical word (8/10)

The heading in Figure 13 is in capital letters.

Step 6: Using italics (4/10)

The heading in Figure 13 is in italics.

Move 2: Indicating content of the section (10/10)

This move is similar to Move 1 in its indicating function. While Move 1 indicates the location of the chapter in relation to the book, Move 2 indicates the content of a section.

Step 1: Using a sub-heading (10/10)

Figure 14 is an example of a subheading. The subheading reads "Having the option to act on our thoughts." 
chuckles and feels grateful that she no longer has to be victimized by her own thinking. She initiates a softer focus and dismisses her thoughts. She spends the drive enjoying her favorite music and her happiness.

HAVING THE OPTION

TO ACT ON OUR THOUGHTS

Most of us assume that if something comes to mind it does so for a reason; it must be representative of reality, worthy of our attention, and dealt with. If we understand the principle of thought, however, we know that this is a mental error. If something comes to mind, recognize it for what it is - a passing thought. This doesn't mean that we can't or shouldn't consider or act on the thought but it does provide the option. Thousands of thoughts pass through our minds each day; as the principle of thought goes, none is more important than the next, each of them is just a thought. Once we

Figure 14: Subheading

From the book You Can Be Happy No Matter What. Copyright (C) 1992 by Richard Carlson, PhD. Reprinted with permission from New World Library, Novato CA. www.newworldlibrary.com

Step 2: Using bigger font size (9/10)

The font size of the subheading in Figure 14 is bigger than that of the text in the paragraph.

\section{Step 3: Using boldface $(9 / 10)$}

The subheading in Figure 14 is in boldface.

Step 4: Using capital letters for every letter (8/10)

Refer to Figure 14. 
Step 5: Using different font style (6/10)

The font style of the subheading in Figure 14 is different from that of the text in the paragraph.

Step 6: Using centred formatting (5/10)

The subheading is centred formatted in Figure 14.

\section{Move 3: Presenting the problem (10/10)}

In Move 3 authors present potential problems that relate to the message they teach later in the chapter. Move 3 functions as the point of departure for other moves. It is important for authors to present the problems as convincingly as possible because if potential readers are not convinced of the relevance of the problems, it is likely that the readers would view the message or the solution to the problem as irrelevant. Authors elaborate the problems by providing explanations and support the legitimacy of the problems by using aphorisms and stories.

Step 1: Stating the problem $(10 / 10)$

Authors achieve Move 3: Presenting the problem by explicitly stating potential problems.

Example:

1) We live in a culture that overvalues talent and undervalues responsibility. (Maxwell, 2007) 


\section{Step 2: Explaining the problem (10/10)}

Authors explain an abstract problem in a tangible way. Example 2 illustrates how authors use specific examples to illustrate a particular problem (i.e., how individuals bring "into today the failures of yesterday").

Example:

2) I am amazed by how many individuals mess up every new day with yesterday. They insist on bringing into today the failures of yesterday and in so doing, they pollute a potentially wonderful day. "I can't believe you did it. I don't think I'll ever forget it. You can't possibly know how much you hurt me. I don't know how you can sit there so smugly after you treated me that way. You ought to be crawling on your knees, begging me for forgiveness. I don't know if I can ever forgive you." Those are not the words of love but of bitterness and resentment and revenge. [emphasis added] (Chapman, 1992)

\section{Step 3: Using aphorisms (2/10)}

Dolby (2005, p. 144) states that aphorisms are statements that say "what often was thought." I extend Dolby's definition to include quotes and proverbs. I propose that authors use aphorisms as a resource to construct the problems they pose as legitimate existing common problems because these sources are viewed as credible sources.

Example:

3) Founding Father Benjamin Franklin observed, "There is perhaps not one of our natural passions so hard to subdue as pride. Beat it down, stifle it, mortify it as much as one pleases, it is still alive. Even if I could conceive that I had completely overcome it, I should probably be proud of my humility." (Maxwell, 2007)

Example 3 illustrates how the author uses an aphorism, in this case a quote from Benjamin Franklin, to present pride as a problem. 
Move 4: Presenting the message (10/10)

After persuading readers of the necessity of addressing a particular problem, authors present their message. The message can be solutions to a particular problem or general principles that authors claim to have positive effects on improving one's life.

\section{Step 1: Stating the message (10/10)}

This step is usually a short statement that states the message. It is similar to a topic sentence.

Example:

4) If you desire success, make responsibility your choice. (Maxwell, 2007)

\section{Step 2: Explaining the message (10/10)}

Authors explain a message after they present the message. In Example 5, the author states the relationship between negative thoughts and negative feelings, followed by an explanation.

5) It's impossible to have jealous feelings without first having sad thoughts, to feel angry without having angry thoughts. And it's impossible to be depressed without having depressing thoughts. This seems obvious, but if it were better understood, we would all be happier and live in a happier world! (Carlson, 1997)

\section{Step 3: Explaining the terms (10/10)}

Part of presenting the message involves explaining the terms authors use in their books. 
Example:

6) Thinking is an ability - a function of human consciousness. No one knows exactly where thought comes from, but it can be said that thought comes from the same place as whatever it is that beats our heart - it comes from being alive. (Carlson, 1997)

\section{Step 4: Restating the message $(10 / 10)$}

This step is usually located at the end of Move 4: Presenting the message. This step is similar to how teachers end their lessons with a summary of what was taught.

7) The first step in making yourself the kind of person others can depend on is [being] dependable. The second is taking the focus off yourself and becoming aware that others are depending on you. Having the intention to be responsible isn't enough. Your actions need to come through. (Maxwell, 2007)

\section{Step 5: Soliciting agreement $(9 / 10)$}

Authors ask questions to solicit agreement from the readers.

8) What would happen to the emotional climate of a marriage if the husband and wife heard such words of affirmation regularly? (Chapman, 1992)

\section{Step 6: Supporting author's claims of effectiveness (9/10)}

Authors provide accounts of "successful" cases as evidence to support their claims. This step is typical in the body chapters but is optional in the introduction chapters. Because some reader interviewees and an author interviewee stated the role of these accounts in self-improvement books, I analysed them as a genre within a genre and present the analysis in Section 5.5. 


\section{Step 7: Using aphorisms (8/10)}

Besides using aphorisms to present a problem, authors also use aphorisms to support their message. The difference between this step and Step 3: Using aphorism in Move 3: Presenting the problem is that this step includes Bible verses as well as quotes and proverbs. Examples of a quote, a proverb and a Bible verse are as follows.

\section{Examples:}

9) In the words of Ghandi, "They cannot take away our self-respect if we do not give it to them." (Covey, 1989)

10) The manner in which we speak is exceedingly important. An ancient sage once said, "A soft answer turns away anger." (Chapman, 1992)

11) To help reduce this tension which seems to dominate our people everywhere, you can start by reducing your own pace. To do that you will need to slow down, quiet down. Do not fume. Do not fret. Practice being peaceful. Practice "the peace of God which passeth all understanding" (Philippians 4:7).

[emphasis added] Then note the quiet power sense that wells up within you. (Peale, 1952)

\section{Step 8: Using pull-quote (8/10)}

Monroe and Weaver (2005, p. 6) state that "pull-quotes are short phrases that summarise adjacent text." Drawing on Monroe and Weaver's explanation, I define pull-quotes as direct quotations of phrases or clauses from the primary text. I propose that self-improvement authors use pull-quotes to drawing readers' attention to the message. 
That mind-set served him well during the crisis of 9-11 in 2001. He had to make many tough decisions very quickly. And whether they were right or wrong, he stood by them. His tough-minded responsibility coupled with strong leadership served the people well during that difficult time.

President Abraham Lincoln

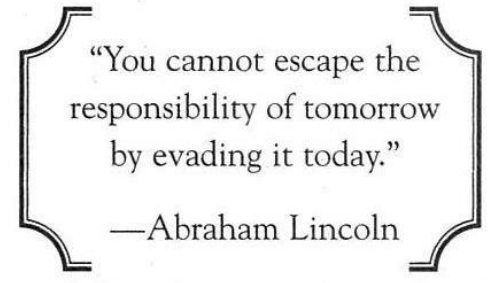
said, "You cannot escape the responsibility of tomorrow by evading it today." Easy decisions may make us look good, but making tough onesand taking ownership of them-makes us better.

Figure 15: Pull-quote

From the book Talent is Never Enough. Copyright (C) 2007 by John C. Maxwell. Reprinted with permission from Thomas Nelson, Nashville TN. http://www.thomasnelson.com/

The pull-quote in Figure 15 demonstrates a direct quotation from the primary text. As this example is taken from the chapter "Responsibility strengthens your talent," we see how the author uses the pull-quote to highlight his message related to responsibility. Figure 15 illustrates how authors use pull-quotes to draw to readers' attention to their message.

Move 5: Encouraging readers to apply the message (10/10)

After presenting the problem and the message that relates to the problem, authors encourage readers to apply the message in their lives. Interview data suggests that changing one's life starts with the mind, and taking practical actions follows. I propose that Move 5 is crucial because it encourages readers to move from changing the way they think to taking practical actions. The following steps show how authors achieve this intention. 
To encourage readers to apply the message, authors list the benefits of applying the message.

Example:

12) By releasing negative emotions, you'll not only enjoy much more freedom in your life - you'll also become more emotionally stable and less stressed too. (Moore, 2013)

\section{Step 2: Identifying potential challenges in applying the message (9/10)}

This step suggests that authors imagine readers to have excuses not to apply the message. Authors counter this by identifying potential challenges that prevent readers from applying what authors recommend.

\section{Example:}

13) It takes effort and, far from being a desultory affair, can take a lot of concentration; indeed a long session of listening closely to someone can be quite tiring. (Oldham, 2012)

Example 13 illustrates how the author, in discussing the importance of active listening, states that it requires effort and can be tiring.

\section{Step 3: Placing responsibility on readers $(9 / 10)$}

Authors place the responsibility to decide whether to apply the message on the readers. Example 14 demonstrates how authors realise this step in a direct manner.

14) If you want to be successful and to maximize your talent as a talent-plus person, you need to stop blaming others, take a good look in the mirror, and take responsibility for your own life. (Maxwell, 2007) 
Authors use this move at the end of body chapters to present a list of practical applications based on the message they teach. Authors usually present the list of practical applications in bullet points. Example 15 is an item from a list of practical applications at the end of the chapter.

15) Genuinely seek to find points of agreement in what the other person is saying. (de Bono, 2004)

The moves and steps analysis shows that all the moves that I identified are obligatory. The rhetorical moves that are obligatory are presenting the problem, presenting the message, encouraging readers to apply the message, and recommending practical application. I present a summary of the moves and steps in Table 8. Then, to illustrate the moves and steps in context, I include an almost complete body chapter in Table 9. Some parts of the texts from the chapter were removed to avoid infringing copyright issues. Moves and steps that occurred more than once, where plausible, were removed. This chapter was chosen because this book was a popular book based on Amazon's bestseller chart and was published by a conventional publisher. 
This page intentionally left blank 
Table 8: Moves and steps in body chapters

\begin{tabular}{|l|c|c|}
\hline Moves/Steps & Occurrence (Total = 10) & Typicality \\
\hline M1: Indicating the chapter & 10 & Obligatory \\
\hline S1: Using a heading & 10 & Obligatory \\
\hline S2: Using bigger font size & 10 & Obligatory \\
\hline S3: Using boldface & 10 & Obligatory \\
\hline S4: Using centred formatting & 9 & Typical \\
\hline S5: Using capital letters for the first letter of every lexical word & 8 & Optional \\
\hline S6: Using italics & 4 & Obligatory \\
\hline M2: Indicating content of the section & 10 & Obligatory \\
\hline S1: Using a sub-heading & 10 & Typical \\
\hline S2: Using bigger font size & 9 & Typical \\
\hline S3: Using boldface & 9 & Typical \\
\hline S4: Using capital letters for every letter & 8 & Optional \\
\hline S5: Using different font style & 6 & Optional \\
\hline S6: Using centred formatting & 5 & Obligatory \\
\hline M3: Presenting the problem & 10 & Obligatory \\
\hline S1: Stating the problem & 10 & Obligatory \\
\hline S2: Explaining the problem & 10 & Optional \\
\hline S3: Using aphorisms & 2 & 9 \\
\hline
\end{tabular}




\begin{tabular}{|c|c|c|}
\hline M4: Presenting the message & 10 & Obligatory \\
\hline S1: Stating the message & 10 & Obligatory \\
\hline S2: Explaining the message & 10 & Obligatory \\
\hline S3: Explaining the terms & 10 & Obligatory \\
\hline S4: Restating the message & 10 & Typical \\
\hline S5: Soliciting agreement & 9 & Typical \\
\hline S6: Supporting author's claims of effectiveness & 9 & Typical \\
\hline S7: Using aphorisms & 8 & Typical \\
\hline S8: Using pull-quote & 8 & Obligatory \\
\hline M5: Encouraging readers to apply the message & 10 & Obligatory \\
\hline S1: Listing reasons to apply the message & 10 & Typical \\
\hline S2: Identifying potential challenges in applying the message & 9 & Typical \\
\hline S3: Placing responsibility on readers & 9 & Obligatory \\
\hline M6: Recommending practical application & 10 & 9 \\
\hline
\end{tabular}


㕝 Table 9: Example of full body chapter

\begin{tabular}{|c|c|c|}
\hline Text & Moves & Steps \\
\hline Love Language \#1 & M1: Indicating the chapter & $\begin{array}{l}\text { S1: Using a heading } \\
\text { S2: Using bigger font size } \\
\text { S3: Using boldface } \\
\text { S4: Using centred formatting } \\
\text { S5: Using capital letters for the first } \\
\text { letter of every lexical word } \\
\text { S6: Using italics }\end{array}$ \\
\hline WORDS OF AFFIRMATION & $\begin{array}{l}\text { M2: Indicating content of the } \\
\text { section }\end{array}$ & $\begin{array}{l}\text { S1: Using a sub-heading } \\
\text { S2: Using bigger font size } \\
\text { S3: Using boldface } \\
\text { S4: Using capital letters for every } \\
\text { letter } \\
\text { S6: Using centred formatting }\end{array}$ \\
\hline $\begin{array}{l}\text { Mark Twain once said, "I can live for two months on a good } \\
\text { compliment." }\end{array}$ & M3: Presenting the problem & S3: Using aphorisms \\
\hline $\begin{array}{l}\text { If we take Twain literally, six compliments a year would have } \\
\text { kept his emotional love tank at the operational level. Your } \\
\text { spouse will probably need more. }\end{array}$ & & S1: Stating the problem \\
\hline
\end{tabular}




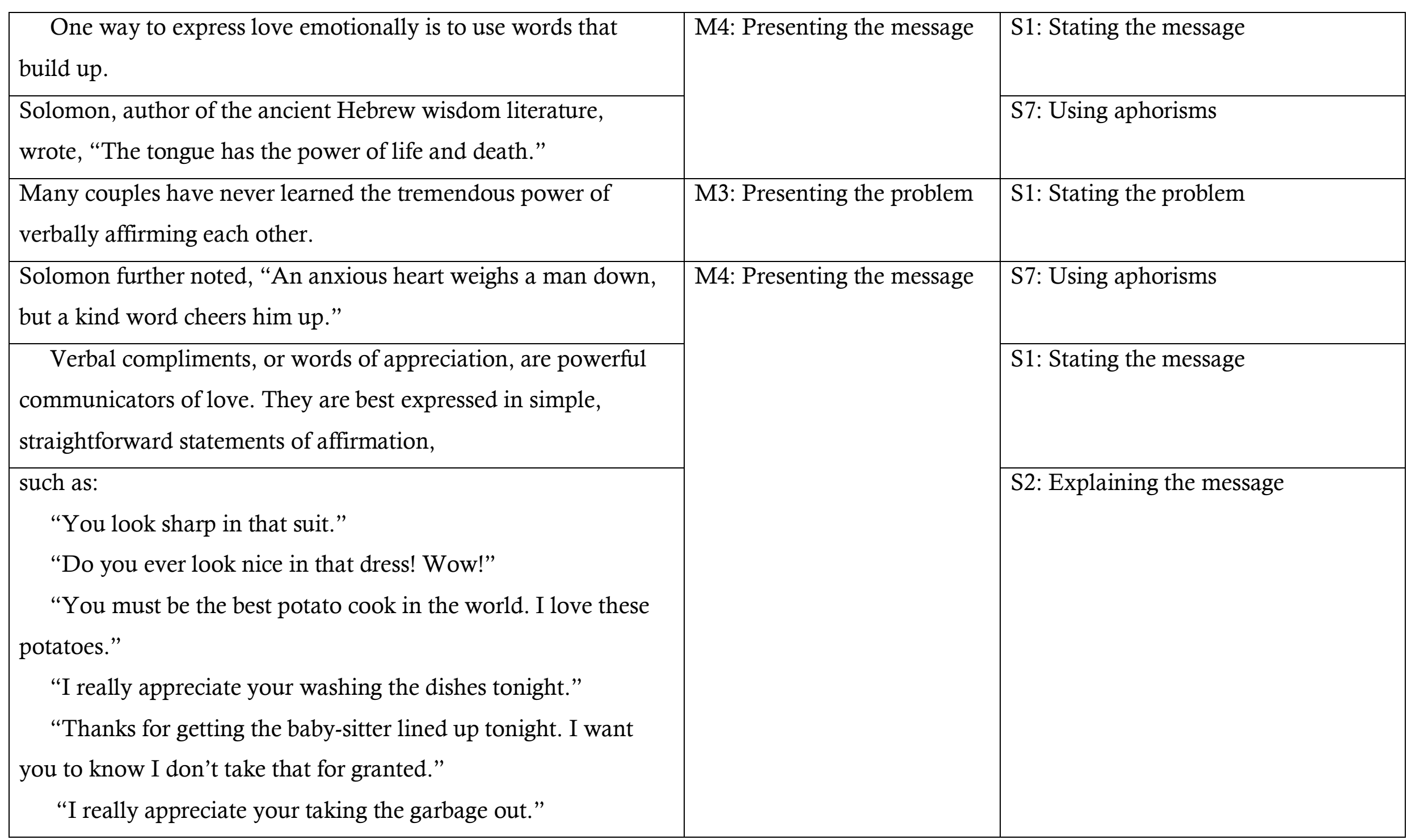


What would happen to the emotional climate of a marriage if the husband and wife heard such words of affirmation regularly?

Several years ago, I was sitting in my office with my door open. A lady walking down the hall said, "Have you got a minute?"

"Sure, come in."

She sat down and said, "Dr. Chapman, I've got a problem. I can't get my husband to paint our bedroom. I have been after him for nine months. I have tried everything I know, and I can't get him to paint it."

My first thought was, Lady, you are at the wrong place. I am not a paint contractor. But I said, "Tell me about it."

She said, "Well, last Saturday was a good example. You remember how pretty it was? Do you know what my husband did all day long? He washed and waxed the car."

"So what did you do?"

"I went out there and said, 'Bob, I don't understand you. Today would have been a perfect day to paint the bedroom, and here you are washing and waxing the car."”

"So did he paint the bedroom?" I inquired.
S5: Soliciting agreement

S6: Supporting author's claims of effectiveness 


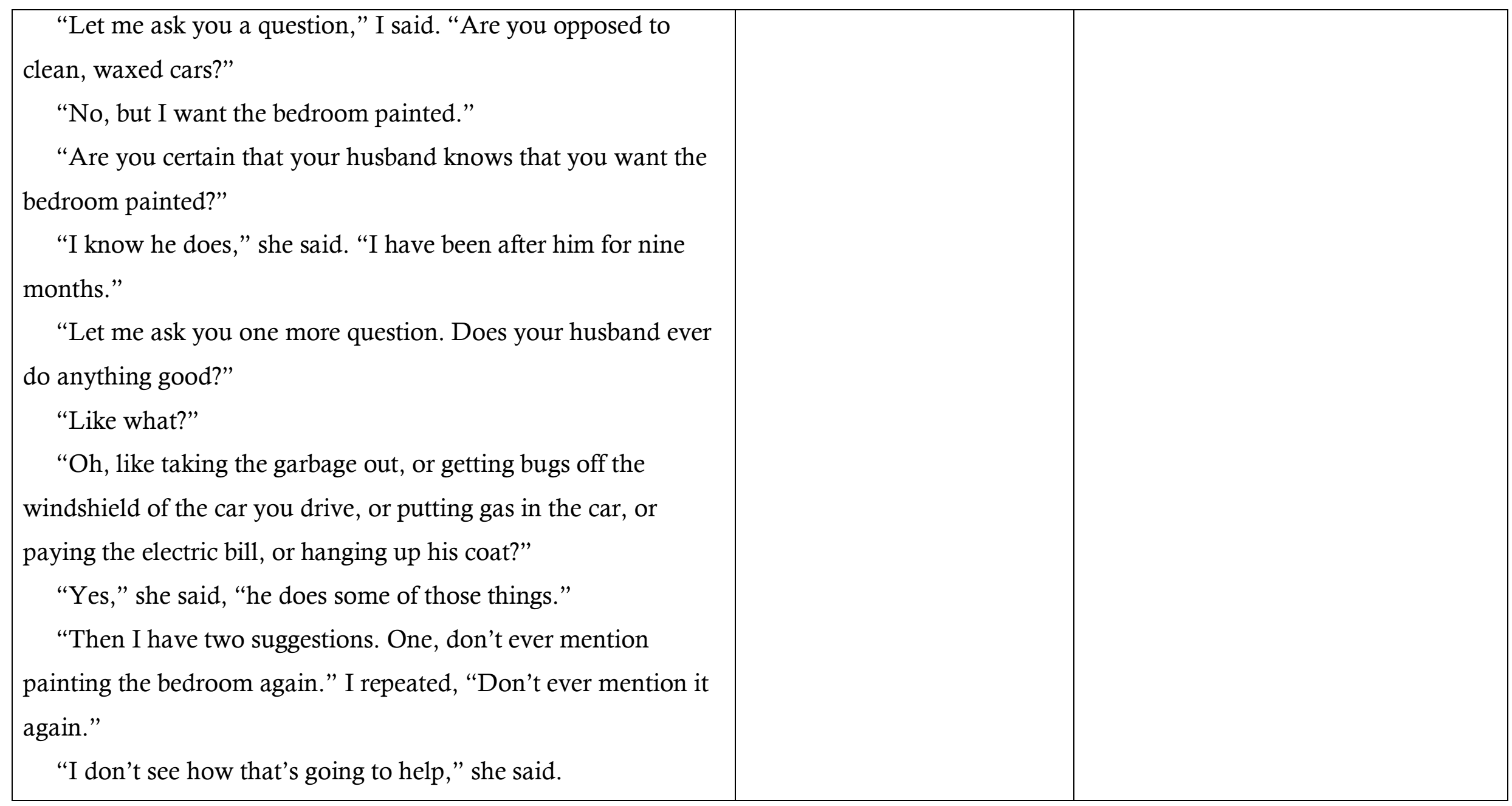




\begin{tabular}{|c|c|}
\hline $\begin{array}{c}\text { The object of love is not getting something you want } \\
\text { but doing something for the well-being of the one } \\
\text { you love. It is a fact, however, that when we receive } \\
\text { affirming words we are far more likely to be } \\
\text { motivated to reciprocate. }\end{array}$ & S8: Using pull-quotes \\
\hline $\begin{array}{l}\text { "Look, you just told me that he knows that you want the } \\
\text { bedroom painted. You don't have to tell him anymore. He } \\
\text { already knows. The second suggestion I have is that the next } \\
\text { time your husband does anything good, give him a verbal } \\
\text { compliment. If he takes the garbage out, say, 'Bob, I want you to } \\
\text { know that I really appreciate your taking the garbage out.' Don't } \\
\text { say, 'About time you took the garbage out. The flies were going } \\
\text { to carry it out for you.' If you see him paying the electric bill, put } \\
\text { your hand on his shoulder and say, 'Bob, I really appreciate your } \\
\text { paying the electric bill. I hear there are husbands who don't do } \\
\text { that, and I want you to know how much I appreciate it.' Every } \\
\text { time he does anything good, give him a verbal compliment." } \\
\text { "I don't see how that's going to get the bedroom painted." } \\
\text { I said, "You asked for my advice. You have it. It's free." }\end{array}$ & $\begin{array}{l}\text { S6: Supporting author's claims of } \\
\text { effectiveness }\end{array}$ \\
\hline
\end{tabular}




\begin{tabular}{|c|c|c|}
\hline $\begin{array}{l}\text { She wasn't very happy with me when she left. Three weeks } \\
\text { later, however, she came back to my office and said, "It } \\
\text { worked!" She had learned that verbal compliments are far greater } \\
\text { motivators than nagging words. } \\
\text { I am not suggesting verbal flattery in order to get your spouse to } \\
\text { do something you want. The object of love is not getting } \\
\text { something you want but doing something for the well-being of } \\
\text { the one you love. It is a fact, however, that when we receive } \\
\text { affirming words we are far more likely to be motivated to } \\
\text { reciprocate and do something our spouse desires. }\end{array}$ & & \\
\hline ENCOURAGING WORDS & $\begin{array}{l}\text { M2: Indicating content of the } \\
\text { section }\end{array}$ & $\begin{array}{l}\text { S1: Using a sub-heading } \\
\text { S2: Using bigger font size } \\
\text { S3: Using boldface } \\
\text { S4: Using capital letters for every } \\
\text { letter }\end{array}$ \\
\hline $\begin{array}{l}\text { Giving verbal compliments is only one way to express words of } \\
\text { affirmation to your spouse. Another dialect is encouraging } \\
\text { words. }\end{array}$ & M4: Presenting the message & S1: Stating the message \\
\hline The word encourage means "to inspire courage." & & S3: Explaining terms \\
\hline
\end{tabular}


All of us have areas in which we feel insecure. We lack courage, and that lack of courage often hinders us from accomplishing the positive things that we would like to do.

The latent potential within your spouse in his or her areas of insecurity may await your encouraging words.

\begin{tabular}{|l|l|}
\hline M3: Presenting the problem & S1: Stating the problem \\
\hline $\begin{array}{l}\text { M5: Encouraging readers to } \\
\text { apply the message }\end{array}$ & S3: Placing responsibility on readers \\
\hline
\end{tabular}

755 words omitted to fulfil copyright requirements.

Encouragement requires empathy and seeing the world from your spouse's perspective.

We must first learn what is important to our spouse. Only then can we give encouragement. With verbal encouragement, we are trying to communicate, "I know. I care. I am with you. How can I help?" We are trying to show that we believe in him and in his abilities. We are giving credit and praise.

Most of us have more potential than we will ever develop. What holds us back is often courage. A loving spouse can supply that all-important catalyst.

Of course, encouraging words may be difficult for you to speak. It may not be your primary love language. It may take great effort for you to learn this second language. That will be especially true if you have a pattern of critical and condemning words,

M5: Encouraging readers to apply the message
S1: Stating the message

S2: Explaining the message

S4: Restating the message

S2: Identifying potential challenges in applying the message 


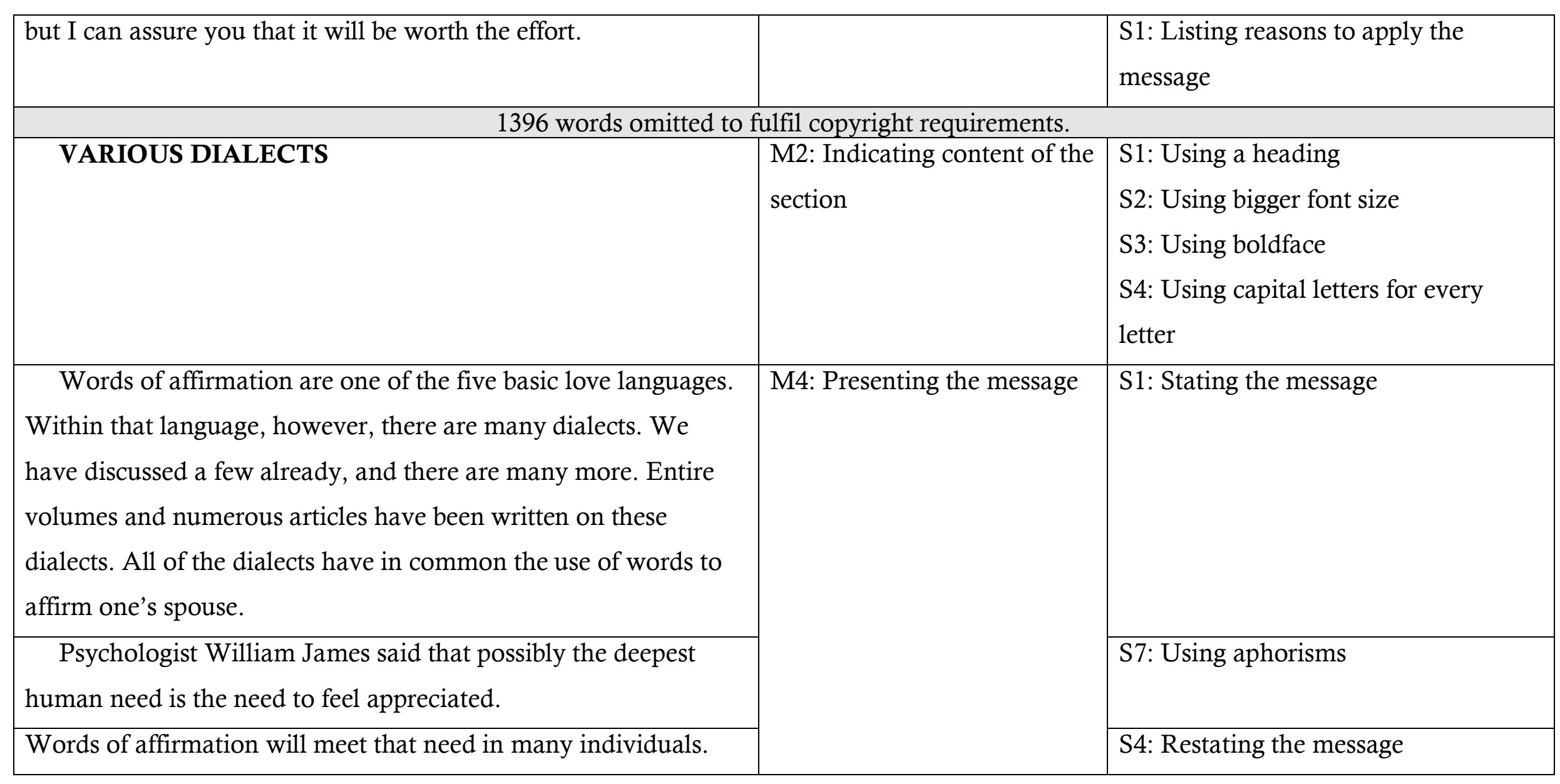


If you are not a man or woman of words, if it is not your primary love language but you think it may be the love language of your spouse, let me suggest that you keep a notebook titled "Words of Affirmation." When you read an article or book on love, record the words of affirmation you find. When you hear a lecture on love or you overhear a friend saying something positive about another person, write it down. In time, you will collect quite a list of words to use in communicating love to your spouse.

You may also want to try giving indirect words of affirmation, that is, saying positive things about your spouse when he or she is not present. Eventually, someone will tell your spouse, and you will get full credit for love. Tell your wife's mother how great your wife is. When her mother tells her what you said, it will be amplified, and you will get even more credit. Also affirm your spouse in front of others when he or she is present. When you are given public honor for an accomplishment, be sure to share the credit with your spouse. You may also try your hand at writing words of affirmation. Written words have the benefit of being read over and over again.

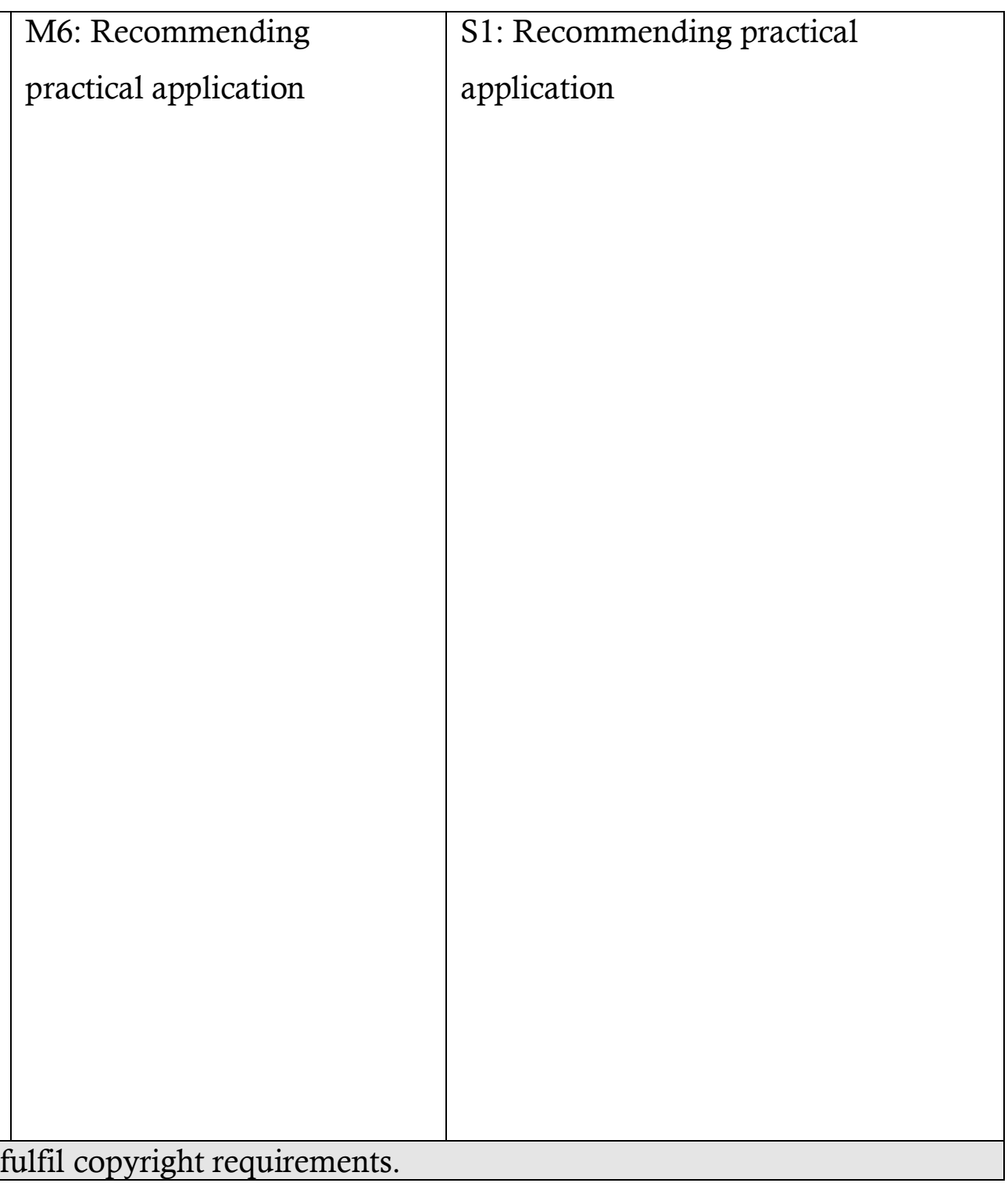




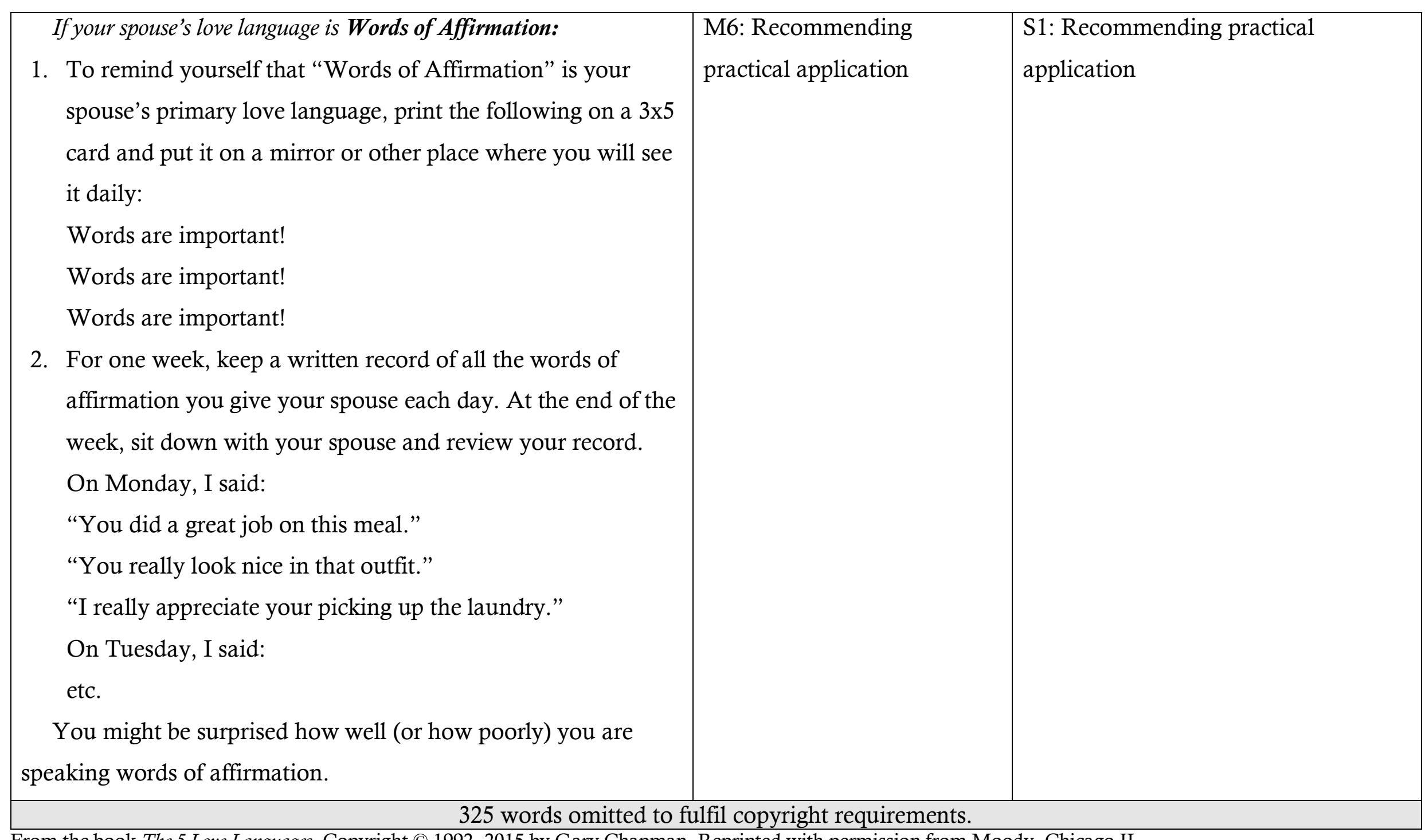

From the book The 5 Love Languages. Copyright (c) 1992, 2015 by Gary Chapman. Reprinted with permission from Moody, Chicago IL. 
This example illustrates how a body chapter begins by presenting a problem followed by presenting a message, and ends with a list of recommendations. However, it is not unusual to begin by presenting a message followed by a problem that relates to the message. As can be seen in this example, Move 3: Presenting the problem is often followed by a very long move, Move 4: Presenting the message. This implies that authors give a lot of attention to presenting their advice. Consistent with interview data, Move 4 indicates that the main purpose of the chapter is to give advice. Because body chapters are the most important section of self-improvement books, as discussed at the beginning of this section, the main purpose of body chapters is crucial in understanding the purpose of selfimprovement books as a genre.

My study identifies eight steps that authors use to present their message. This is always done by stating the message, explaining the message, explaining terms, and restating the message. Although Step 3: Explaining the terms can be found in research articles, it serves a different purpose in self-improvement books. In research article introductions in software engineering, for example, Anthony $(1999$, p. 43) states that definitions of important terms are included to "illustrate difficult concepts." In spiritual self-help books, a genre closely related to self-improvement books, Askehave $(2004$, p. 14) states that the purpose of explaining terms is to "alter people's thought patterns and the way they talk about and conceptualise things in order to promote change." She explains that the purpose of Step 3 is usually to redefine well-known words that authors want readers to reconsider.

Similar to spiritual self-help books, self-improvement authors explain the terms in their books to present an alternative worldview. Consider this example:

16) By "quality time," I mean giving someone your undivided attention. (Chapman, 1992)

The author explains the term quality time by introducing the idea that spending quality time is not just about giving someone attention but one that is undivided. Like the spiritual self-help book that Askehave (2004) studied, the terms that self-improvement authors explain are well-known words and authors use this step to present an alternative worldview (e.g., perception of quality time). To some extent, providing a more "correct" definition constructs authors as teachers. 
One of the typical steps that authors use to present their message is using aphorisms. This step is also used to realise Move 3: Presenting the problems. Firstly, this step shows what constitutes a credible source of advice in self-improvement books. The sources include activists (e.g., Martin Luther King), presidents of America (e.g., Abraham Lincoln), ancient philosophers (e.g., Aristotle), ancient texts (e.g., the Bible, ancient Hebrew wisdom literature), authors, business executives, cartoonists, chief judge, consultants, holocaust survivor, inventors (e.g., Thomas Edison), professors, psychiatrists, psychologists, television hosts (e.g., Oprah Winfrey), and trainers. This list shows that people who are influential, popular, and "successful"; have formal training in psychology and psychiatry; and historical figures are constructed as credible sources of advice. The following example shows how an author explicitly refers to a specific source as credible.

17) Some of the best advice you could follow on this subject came from President Theodore Roosevelt: "Do what you can with what you have, where you are." (Maxwell, 2007)

My study shows that authors of self-improvement books use aphorisms in a way similar to how writers distance themselves from a particular subject matter in research articles and present themselves as being objective by referring to what the literature says (Parkinson, 2013). Consider this example:

18) But thinking is different. William James, the father of American psychology, once said, "Thinking is the grand originator of our experience." (Carlson, 1997)

To provide some context for Example 18, the author is teaching that the ability to think is different from other human abilities. After discussing other human abilities the author states that thinking is different and includes a quote which allows the author to distance himself from his claim by including an external source.

Readers seem to recognise aphorisms as a feature of self-improvement books. For example, I asked Ruby, previously a regular reader of the genre, what she thought were the reasons people read this genre and after she provided the reasons, she said:

They have a whole lot of quotes and heigh-ho you got a self-help book. (March 17, 2013; Face-to-face interview) 
Ruby's comment suggests that some readers perceive self-improvement books to be a collection of aphorisms.

The analysis of moves in body chapters shows that the main purpose of body chapters in self-improvement books is to present a message. I have also illustrated how analysing the body chapter (i.e., the most crucial section of self-improvement books) can shed light on the purpose of self-improvement books as a genre. This section has also demonstrated how the analysis of steps contributes to the understanding of what is perceived as valuable and credible in this genre.

\subsection{Moves in about the author section}

The previous section discussed the moves and steps in the body chapters. This section investigates the moves and steps in about the author sections. The dataset of this analysis consisted of 20 about the author sections each from a different book. The books were selected based on popularity and recency, and sections that were longer than two pages were excluded because they were not prototypical of the section. In books that have two of this section, I selected the longer version. The 20 book titles were:

1. Attitudes are Contagious (Mannering \& Mannering, 2000)

2. Awaken the Giant (Robbins, 1992)

3. Break Free of Your Rut (Barrett, 2013)

4. Here's to Your Success (Keller, 2007)

5. How to Have a Beautiful Mind (de Bono, 2004)

6. Life Code (McGraw, 2012)

7. Live Your Dream (Chapman, 2002)

8. The Difference Maker (Maxwell, 2006)

9. The Encore Effect (Sanborn, 2008)

10. The Five Major Pieces to the Life Puzzle (Rohn, 2002)

11. The Gifts of Imperfection (Brown, 2010a)

12. The Magic is in the Extra Mile (DiAngi, 2002)

13. The Mindful Path to Self-Compassion (Germer, 2009)

14. The Seven Wonders that Will Change Your Life (Beck \& Ablow, 2011) 
15. The 7 Habits of Highly Effective People (Covey, 1989)

16. Voices in the Family (Gottlieb, 2007)

17. You Can be Happy No Matter What (Carlson, 1997)

18. Wisdom from Sam (Gottlieb, 2011)

19. 5 Tools to Change Your World (Oldham, 2012)

20. 7 Secrets to a Phenomenal L.I.F.E. (Partridge, 2012)

How I analysed the data was similar to the way I analysed the introduction chapters and body chapters (see Section 5.2). The moves and steps were coded using NVivo 10.

The moves and steps in about the author sections are presented with examples from my data for illustration:

\section{Move 1: Indicating the section (16/20)}

The about the author section is a typical section (see Section 5.1). This move is typical and it occurs in the introduction chapters and the body chapters as well. In about the author sections, it is realised by a heading, which is either the phrase about the author or the author's name.

\section{Step 1: Using a heading (16/16)}

Eleven headings are realised by the phrase, About the Author. See Figure 16 on next page. Five are realized by the author's name.

\section{Step 2: Using bigger font size (16/16)}

The font size of the heading "ABOUT THE AUTHOR" is bigger than that of the text in the paragraph. See Figure 16 on next page.

\section{Step 3: Using centred formatting (16/16)}

This is an obligatory step. The heading is centred. See Figure 16 on next page. 


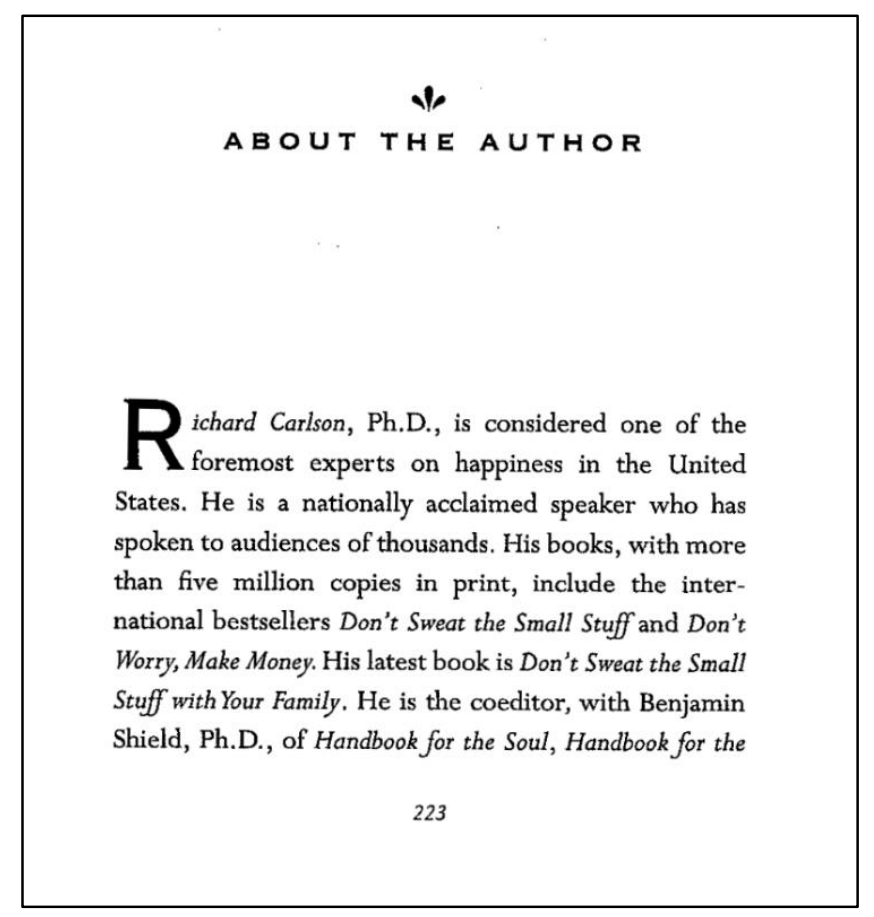

Figure 16: About the author

From the book You Can Be Happy No Matter What. Copyright (C) 1992 by Richard Carlson, PhD. Reprinted with permission from New World Library, Novato CA. www.newworldlibrary.com

\section{Step 4: Using capital letters for every letter (12/16)}

This is a typical resource that authors use to realise the heading. See Figure 16.

\section{Step 5: Using boldface (11/16)}

The heading as shown in Figure 16 is in boldface. This is an optional step.

\section{Move 2: Constructing credibility $(20 / 20)$}

This is an obligatory move. The overall communicative purpose of the about the author section is to establish credibility. I have identified 12 steps that are used to realise this move. This move is optional $(5 / 8)$ in the introduction chapters. 


\section{Step 1: Reference to areas of expertise $(16 / 20)$}

Authors sometimes list their areas of expertise as a way to establish credibility. Stiff and Mongeau (2003, p. 105) suggest that perception of credibility is dependent on, among other things, the perception of source expertise. Stiff and Mongeau (2003, p. 109) also suggest that an audience's judgement of a source's expertise may be topicdependent. In other words, the perception of source expertise is based on how wellinformed a self-improvement author is about the topic that he/she is trying to communicate. I have highlighted the words that indicate these areas.

Examples:

1) She is well known as a pioneer in the fields of personal and professional coaching. (Chapman, 2002)

2) ...is the leading authority in the field of creating thinking and the direct teaching of thinking as a skill. (de Bono, 2004)

3) ...is a clinical psychologist in private practice, specializing in mindfulness- and acceptance-based treatment. (Germer, 2009)

These examples show authors' areas of expertise signalled by noun phrases (pioneer, leading authority) and -ing verb (specializing).

\section{Step 2: Reference to being popular/highly sought after $(15 / 20)$}

Authors sometimes portray themselves as being popular and being highly sought after. This idea suggests that authors' advice is reliable, which makes them credible advice-givers. The authors are sometimes described as being popular by making references to the number of books which they have sold and having a wide variety of audience or readership. As Cherry (2011, p. 340) suggests that "'The International Bestseller' label implies that the book transcends the boundaries of culture." I think having a book published in a number of different languages also implies that the author is popular across cultures. This implies that the advice is relevant across cultures making the authors credible advice-givers. 


\section{Examples:}

4) ...he has taught millions of individuals and families and leaders in business, education, and government... (Covey, 1989)

5) He has become a sought after resource for personal and professional development. (DiAngi, 2002)

6) John C. Maxwell is an internationally recognized leadership expert, speaker, and author who has sold more than 12 million books. (Gottlieb, 2011; Maxwell, 2006)

7) ...which have been published in 15 languages and received worldwide attention. (Gottlieb, 2011)

\section{Step 3: Reference to previous works $(14 / 20)$}

Making reference to previous books and speaking engagements means that the author has experience writing books and giving advice. Having these experiences tells the readers that the author is experienced in what he/she is doing and therefore he/she is credible. Being invited to speak to crowds implies that the author's advice is desirable making him/her credible. Listing the books that an author has written may also give the readers an idea of the topics or areas which the author is expert in. This is different from making reference to areas of expertise in step 1. Reference to areas of expertise refers directly to the topics or areas in which the author is an expert. It is similar to listing one's experience in a resume.

Examples:

8) ...is the author of Letters to Sam and Learning from the Heart. (Gottlieb, 2011)

9) For more than 20 years, he has delivered his uplifting presentations to businesses, trade associations, and educational institutions. (Keller, 2007) 
Another way of establishing credibility is to describe an author as being endorsed and recognised by media or other sources that are perceived to be reliable. This can be awards given to the authors in recognition of their contribution. Media endorsement also refers to instances where an author is invited on radio or television. In this step an author could also be acknowledged by the newspapers, magazines or people with credentials as a highly sought after advice-giver.

Examples:

10)...he was the recipient of the Books for a Better Life Award in the Motivational Book category. (Gottlieb, 2011)

11) "Dr. Phil" (Phillip C. McGraw, Ph.D.) is the host of America's number-one daytime talk show. (McGraw, 2012)

12) A leading Austrian business journal chose him as one of the twenty visionaries alive today. (de Bono, 2004)

\section{Step 5: Reference to passion $(8 / 20)$}

To establish credibility, authors sometimes describe themselves as people who are passionate about the things they teach. They describe themselves as people who genuinely passionate about helping others. This contributes to their credibility. Examples:

13) He talks readily about his experiences, feelings, and reflections-including the fact that he is a quadriplegic. (Gottlieb, 2011)

14) Robbins' special passion is to make the world a better place to live by assisting individuals in captaining their destinies. (Robbins, 1992)

In Example 13, the author uses an adverb to refer to his passion and in Example 14, a noun phrase. They are underlined. 
Step 6: Reference to academic achievements/involvements $(8 / 20)$

Authors sometimes present themselves as academically qualified people. Some authors include their involvements in the academic environment. In my opinion, these contribute to the credibility of the authors. Such references may imply that the authors are aware of the difference between opinions and scientific findings. By doing this, authors present a professional image of themselves and thus construct their credibility.

Examples:

15) He holds an M.B.A. from Harvard and a doctorate from B.Y.U., where he was a professor of organizational behaviour and business management... (Covey, 1989)

16) Psychologist Daniel Gottlieb, Ph.D... (Gottlieb, 2011)

17) To date, Dennis has earned a Masters degree. (Mannering \& Mannering, 2000)

Example 15 shows how the author uses his academic position as a resource to construct credibility. In Examples 16 and 17, postgraduate degrees are used to construct a credible identity.

\section{Step 7: Reference to years of experience $(8 / 20)$}

Making reference to the number of years of experience of an author in a particular field, to me, implies that the author is highly experienced. This contributes to his/her credibility. Having a long history in the industry implies that the author's advice is still relevant today. That is why after many years, this person is still providing advice and insights. Spending a long time in the trade also means that the author's advice is refined over the years and this makes him/her more credible.

Examples:

19) Joyce has been combining and utilizing her life and educational experiences for more than 40 years to serve at the highest level she is capable of achieving. (Chapman, 2002) 
20) Jeff Keller has been speaking and writing about attitude and human potential for more than 20 years. (Keller, 2007)

21) Anthony Robbins has devoted more than half his life to helping people discover and develop their own unique qualities of greatness. (Robbins, 1992)

\section{Step 8: Positive attribution to the ideas/principles/lessons $(5 / 20)$}

Appraising the advice of an author is an indirect way to appraise the author. Appraising the advice can be done by attributing positive attribution to the advice such as its effectiveness. Making reference to the effectiveness of an author's advice directly points the readers to the credibility of the author. This means that the author's advice and insights are valuable. Good advice comes from good sources. Effective advice comes from credible advice-givers. To me, this is possibly one of the more direct ways to establish the credibility of an author.

Examples:

22) ... has helped small businesses all over the world dramatically improve their businesses and lives. (Partridge, 2012)

23) Dr. Gottlieb's approach is both fresh and effective. (Gottlieb, 2011)

24) ... also sought his help and became the most successful cricket team in history. (de Bono, 2004)

25) Ian's programmes are transformational and universal... (Oldham, 2012)

As illustrated in the examples above, the positive attributes of authors' advice are related to having the effectiveness to help readers regardless of their background improve their lives or be more successful.

\section{Step 9: Reference to affiliation $(5 / 20)$}

Authors sometimes mention their affiliation to established organisations and personalities to establish their credibility. They usually mention that they have coached the staff from prominent organisations and famous people such as wellknown sportsmen. This constructs credibility because it is reasonable to assume that 
prominent organisations do not invite people with little credibility to train their staff. Being invited by prominent organisations also implies that the author is reliable. Authors sometimes mention that they belong to a particular prominent charitable organisation or foundation, which gives the impression that they are good people who give their time for good causes. Affiliation with such organisations and foundations also implies that the author is part of the inner circle.

Examples:

26) The Australian national cricket team also sought his help...(de Bono, 2004)

27) Dr. Phil has carried his message from the senate chambers of Washington, D.C., to the suburbs and inner cities across America. (McGraw, 2012)

\section{Step 10: Reference to author's personal history of success $(3 / 20)$}

Referring to the authors' personal history of success implies that the authors are successful and we should emulate them. Since they are successful in their own ways, they are worth our attention. This step is different from appraising authors' advice because it is not about appraising the advice but giving an account of the authors' achievements.

Examples:

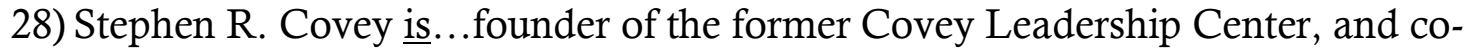
chairman of Franklin Covey Co. (Covey, 1989)

29) He started his first business at age 23 and has transformed it into a thriving multi-million dollar enterprise. (Partridge, 2012)

In terms of lexicogrammatical feature, Examples 28 and 29 show that authors use relational and material processes to refer to their personal success respectively. Eggins (2004) explains that relational processes cover "the many different ways in which being can be expressed in English clauses" (p. 239) and material processes are "usually concrete, tangible actions" (p. 215). Using the relational process, is, the author associates himself with a position that is likely to be viewed as being successful in the context of self-improvement. In Example 29, the author uses 
material process in the past tense, started and has transformed, to identify his success with his actions and to construct his prior experience as a history of achievements.

\section{Step 11: Appraisal from readers/seminar participants (1/20)}

Appraisal from a third party in this case, the readers and the participants of the author's workshops or seminars, is a way to establish the credibility of an author. This is an optional step in my dataset, found in only one book. In this source, feedback from workshop participants is included as part of the about the author section.

Examples:

33) “...truly inspirational and an amazing facilitator” (Oldham, 2012)

34) "I recommend the programme to anyone looking for improved performance" (Oldham, 2012)

35) "...met my expectations and more" (Oldham, 2012)

36) "Returned to work and home life uplifted, thoughtful" (Oldham, 2012)

\section{Step 12: Reference to affiliation with established authors $(1 / 20)$}

This step is found in one source, a first time author. Woodstock (2006, p. 332) states that authors rarely acknowledge their influential teachers because acknowledging influences would conflict with the author's claim to authority based on personal experience. This is probably why there is only one source in my dataset which mentions his affiliation with established authors.

Examples:

37) ... is an independent, and a certified coach with the John C. Maxwell team. (Partridge, 2012)

38) ... holds his own live multi day events which have featured some of America's top business trainers including Michael Gerber, Bob Burg, Dr. Joseph A. Michelli, and American legend Zig Ziglar. (Partridge, 2012) 
Woodstock (2006, p. 323) states that rapport between the author and the reader is crucial in this genre and she explains that distance between them is a liability. Therefore, it is not surprising to find elements of rapport building in the about the author section which is not typical in 20 academic textbooks that I checked informally. Eleven out of 20 sections in my dataset contain this move, which can be realised in a number of ways. I have identified four steps which can realise this move in my dataset.

\section{Step 1: Providing personal information/accounts (10/11)}

To build rapport, authors provide personal information such as place of residence, date of birth, place of birth, and author's spouse and children to portray himself/herself as a lay person to readers. Providing such information tells the readers that the author is a human being like the reader. It is likely that everyone has a place of residence, a date of birth and a place of birth. Example 40 is the only example in my dataset which contains the exact date of birth.

Dolby (2005, p. 123) proposes that personal accounts help authors to achieve a degree of intimacy with the readers. This implies personal accounts are a resource that authors use to build rapport and construct trust. Personal accounts can include telling the author's personal history and family life.

Examples:

39) Stephen, his wife, Sandra, and their family live in the Rocky Mountains of Utah. (Covey, 1989)

40) DENNIS MANNERING WAS BORN ON JANUARY 23, 1942 [emphasis in original] and grew up in the foothills of the Ozark Mountains in southwest Missouri. (Mannering \& Mannering, 2000)

41) In his "first life," Jeff was an attorney and practiced law for more than 10 years before he decided to pursue a full time career as a speaker and writer. (Keller, 2007) 
Providing contact details is a way to build rapport with readers. By doing this, the authors present themselves as being approachable. This may imply that these authors are willing to offer their time to respond to their readers. This is an optional step in my dataset, found in three out of 20 sources.

Examples:

42) Or contact us at: Attitude is Everything, Inc. P.O. Box 310, East Norwich, NY 11732-0310. Tel: 1-800-790-5333. E-mail: jeff@attitudeiseverything.com (Keller, 2007)

43) He can be reached at dan@enemieslist.net. Comments are welcome. (Barrett, 2013)

44) Contact Ian Oldham: ian@shiftinggears.co.nz (Oldham, 2012)

\section{Step 3: Personal message to readers $(1 / 11)$}

There is one instance in my dataset where the author includes a personal message to the readers. This step functions to build a relationship with the readers. The personal message functions almost like a good luck card to wish the readers all the best.

Example:

45) I wish for you a life of wealth, health, and happiness; a life in which you give to yourself the gift of patience, the virtue of reason, the value of knowledge, and the influence of faith in your own ability to dream about and to achieve worthy reward. (Rohn, 2002) 
This move includes promoting the book(s) an author writes and other products such as seminars and CDs. Some authors promote the books by attributing positive qualities to them. From my dataset, I have identified two steps that can achieve this move.

\section{Step 1: Providing URL/contact details for free online resources/other products/orders $(6 / 8)$}

Authors sometimes promote other products they sell by providing the URL or contact details so readers can contact them for further information. Other products can also mean products by other authors.

Examples:

46) For more information, visit www.marksanborn.com or call 800-650-3343. (Sanborn, 2008)

47) You can learn more about Brené and her research by visiting www.brenebrown.com or by visiting her blog at www.ordinarycourage.com. For a Gifts of Imperfection reading guide and a list of book recommendations, please visit her Web site. (Brown, 2010a)

\section{Step 2: Listing other products (2/8)}

This is an optional step. There are two instances where authors end the about the author section by listing products that may interest potential readers.

Examples:

48) His live presentations include:

- The encore Effect: How to Give a Remarkable Performance

- $\quad$ The Fred Factor: How to Make the Ordinary Extraordinary

- $\quad$ You Don't Need a Title to Be a Leader (Sanborn, 2008) 
49) For those individuals who want to use the step-by-step program presented in this book and become part of an international dream team to facilitate and coach, she offers a training and certification program. (Chapman, 2002)

\section{Step 3: Attributing positive qualities to the book (1/8)}

Attributing positive qualities to the book is a way to promote a book. In my dataset, there is only one instance of this step and it is done by describing the style of writing.

Example:

50) Here, in wonderfully readable, jargon-free prose, is Dr. Gottlieb's advice on... (Gottlieb, 2011)

\section{Step 4: Including name (1/8)}

This step is an optional one and it also occurs in three introduction chapters (see Section 5.2). Step 4 occurs only once in my dataset.

Example:

51) Jim Rohn (Rohn, 2002) (see Table 11 for context)

As can be seen in Table 10, constructing credibility is the only obligatory move, and indicating the section is the only typical move in the about the author sections in this dataset. In this analysis, all the structural moves were indicated by headings. This analysis shows that authors typically state their areas of expertise, refer to their popularity, and list the books they have written as resources to construct themselves as credible advice givers. Then, to illustrate the moves and steps in context, Table 11 shows an example of a full about the author section. 
Table 10: Moves and steps in about the author section

\begin{tabular}{|c|c|c|}
\hline Moves/Steps & Occurrence $($ Total $=20)$ & Typicality \\
\hline M1: Indicating the section & 16 & Typical \\
\hline S1: Using a heading & 16 & Obligatory \\
\hline S2: Using bigger font size & 16 & Obligatory \\
\hline S3: Using centred formatting & 16 & Obligatory \\
\hline S4: Using capital letters for every letter & 12 & Typical \\
\hline S5: Using boldface & 11 & Optional \\
\hline M2: Constructing credibility & 20 & Obligatory \\
\hline S1: Reference to areas of expertise & 16 & Typical \\
\hline S2: Reference to popularity/highly sought after & 15 & Typical \\
\hline S3: Reference to previous books & 14 & Typical \\
\hline S4: Reference to celebrity/media recognition/endorsement & 12 & Optional \\
\hline S5: Reference to passion & 8 & Optional \\
\hline S6: Reference to academic achievements/involvements & 8 & Optional \\
\hline S7: Reference to years of experience & 8 & Optional \\
\hline S8: Positive attribution to the ideas/principles/lessons & 5 & Optional \\
\hline S9: Reference to affiliation with prominent organisations/personalities & 5 & Optional \\
\hline S10: Reference to author's personal history of success & 3 & Optional \\
\hline S11: Appraisal from readers/seminar participants & 1 & Optional \\
\hline S12: Reference to affiliation with established authors & 1 & Optional \\
\hline
\end{tabular}




\begin{tabular}{|l|c|c|}
\hline M3: Building rapport & 11 & Optional \\
\hline S1: Providing personal information/accounts & 10 & Typical \\
\hline S2: Providing contact details & 3 & Optional \\
\hline S3: Personal message to readers & 8 & Optional \\
\hline M4: Indicating the end of about the author section & 6 & Optional \\
\hline S1: Providing URL/contact details for free online resources/other products/orders & 2 & Typical \\
\hline S2: Listing other products & 1 & Optional \\
\hline S3: Attributing positive qualities to the book & 1 & Optional \\
\hline S4: Including name & 1 \\
\hline
\end{tabular}




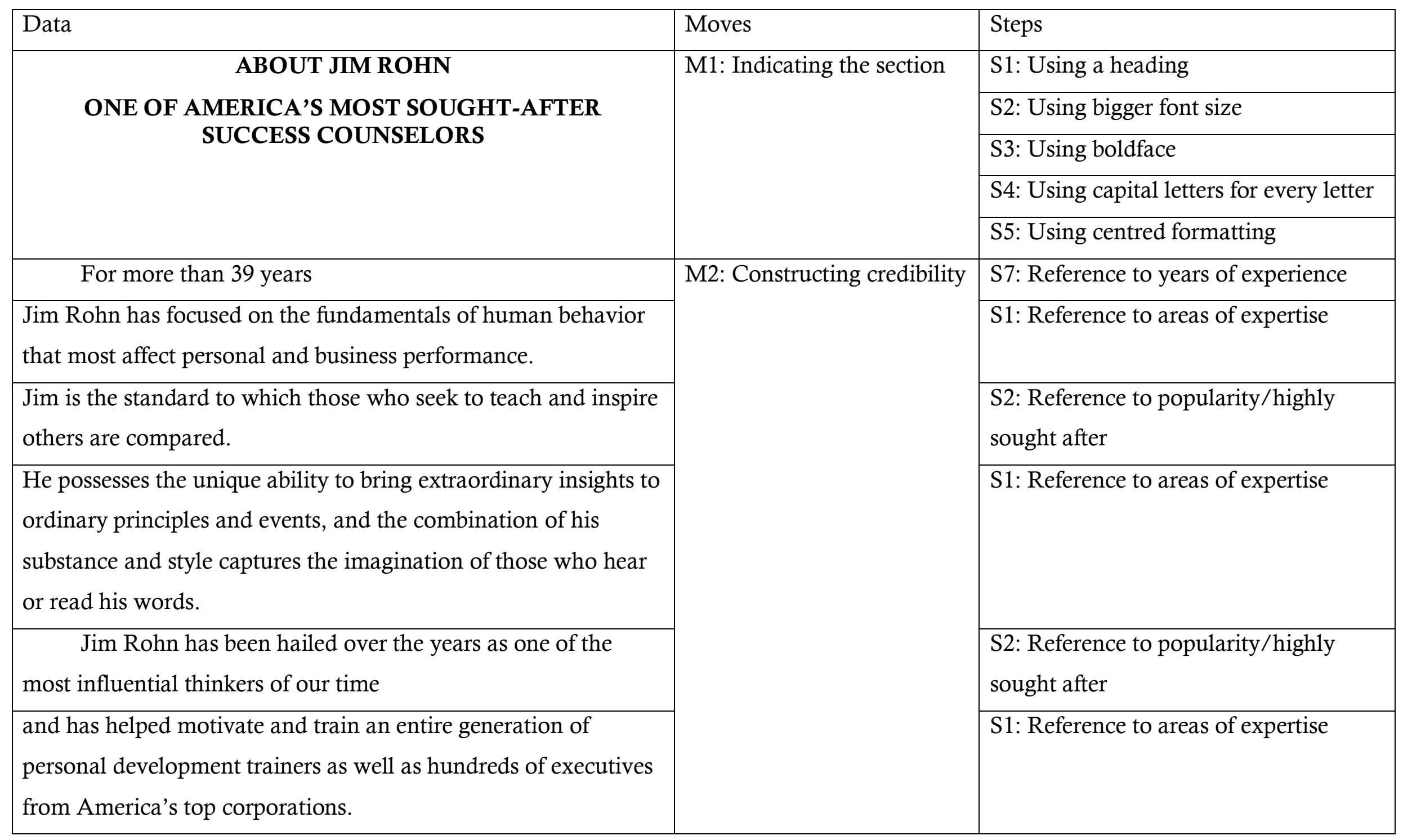




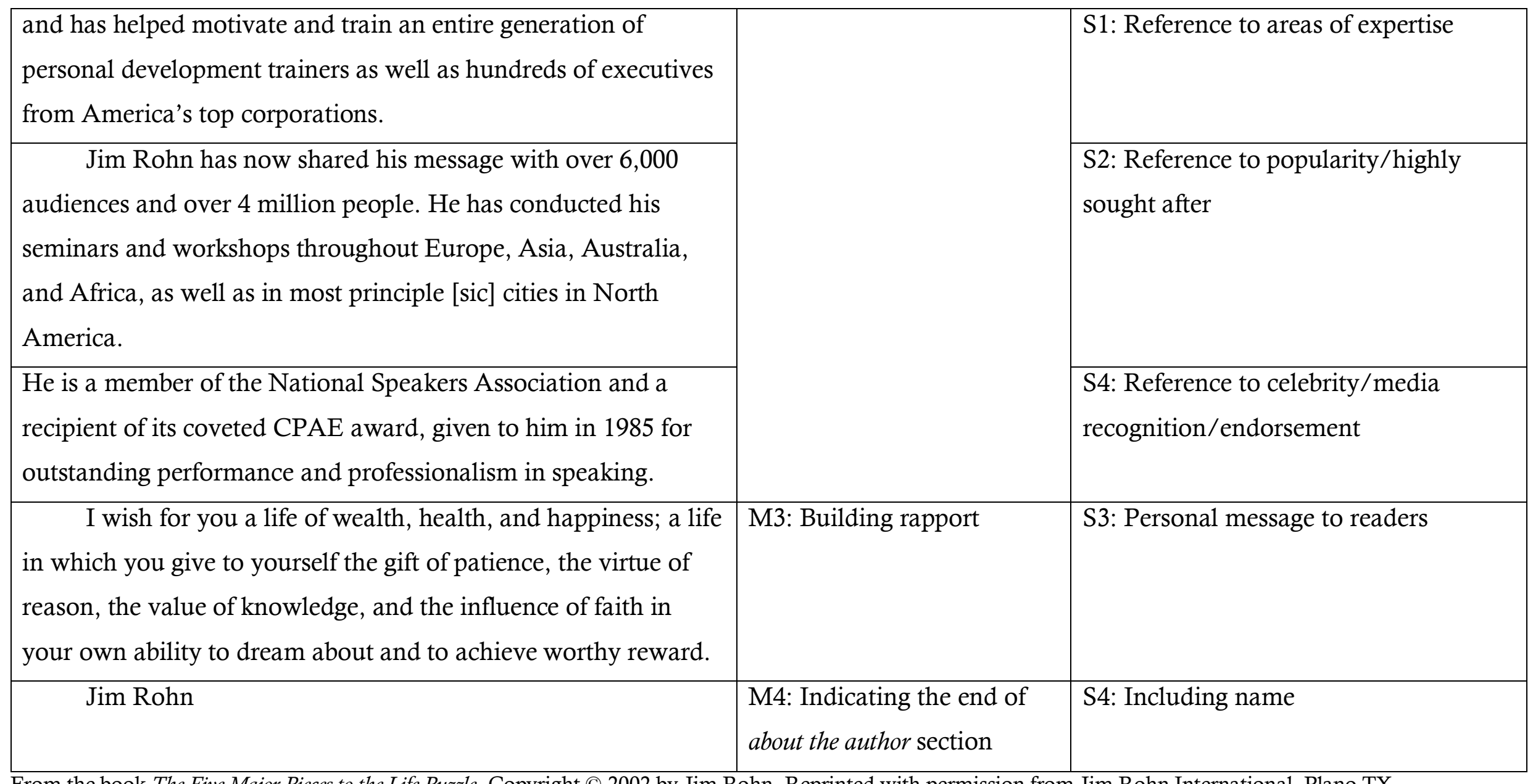

From the book The Five Major Pieces to the Life Puzzle. Copyright (c) 2002 by Jim Rohn. Reprinted with permission from Jim Rohn International, Plano TX. http://www.jimrohn.com/ 
The about the author section in Table 11 shows that the only obligatory move is Move 2: Constructing credibility. It is the longest move in this example and is realised by four different steps. This author constructs a credible persona by referring mainly to his areas of expertise and popularity. This is the only about the author section in my dataset where the author attempts to build rapport with the readers by including a personal message to the readers. By doing this, the author constructs himself as caring and supportive.

Besides being the most common strategy in this example, Step 1: Reference to areas of expertise is also the most commonly used strategy in this dataset (see Table 10). In selfimprovement books, authors construct themselves as an authoritative persona and competent in a relevant area by listing their areas of expertise. As Hyland (1998a, p. 233) explains, credibility relates to the readers' perception of the writer's "authority and competence." For example, an author who claims to have extraordinary insights is likely to be perceived as being competent in terms of sharing insights, but it is quite unlikely that the same author would be perceived as being competent in carpentry. Similar to a $\mathrm{CV}$, authors list what they are good at to present themselves as the best candidate for the task.

Paying attention to the same step also provides insights into the areas of expertise that are perceived to be relevant to the genre. Consider this example:

19) Brené spent the first seven years of her decade-long research journey studying how the universal experiences of shame and fear affect us and how practicing resilience in our everyday lives can change the way we live, love, parent, and work. (Brown, 2010a)

This example illustrates how the author constructs the study of the listed area as relevant to her attempt to construct a credible persona. This example also illustrate how readers are constructed as people who want to improve their family and work lives.

Unlike writers of research articles, who construct a credible persona by aligning themselves with expert members of the community (Hyland, 2010b), Woodstock (2006) states that self-improvement authors avoid associating themselves with the expert community because this results in creating a distance from readers. Her finding is consistent with mine. In the analysis of about the author section, Step 12: Reference to affiliation with established authors is an optional step and occurs in one out of 20 books. 
While expressing writers' passion and enthusiasm for a particular topic in research articles is unlikely to be considered as a way to construct credibility, this strategy appears to be acceptable and perhaps important in self-improvement books. Woodstock (2006, p. 332) explains that constructing the authors as having good intentions, such as sharing their wisdom and having genuine desires to help readers, presents the authors as being selfless. This characteristic, Woodstock explains, is crucial in constructing the authors as trustworthy people which adds to their credibility.

Although Woodstock (2006) claimed that authors of self-improvement books often use their personal success as a strategy to present themselves as credible advice givers, this strategy is not a dominant feature in the about the author sections that I analysed. Step 10: Reference to author's personal history of success is an optional step and can be found in only three out of 20 books. It is likely that presenting the authors' history of success distinguishes authors from their readers and this distinction is a liability in selfimprovement books because it creates an interpersonal distance between the author and reader. Rather than presenting the authors as "successful" figures, Woodstock (2006) explains that authors "gain authority" by "articulation of similarity with readers" (p. $323)$.

Although not typical, authors use Move 3: Building rapport to construct themselves as having common experience with the readers. This move is typically realised by Step 3: Providing personal information/account. Such information includes information about their spouses, children, and where they live. The idea of having a family, children, and a house seems to fit the ideals of middle- and upper- class Americans (Becker and Marecek, 2008, p. 1775). This value indicates that they may well be the target readers of selfimprovement books.

The moves and steps analysis shows that it is important for authors of self-improvement books to list their areas of expertise because the credibility of their advice will be judged based on the relevance of their expertise. Within this genre, a credible advice giver is perceived as one who is trustworthy and genuinely concerned for the readers. This means that it is crucial for authors to construct themselves as having something in common with their readers by presenting themselves as lay people. To construct themselves as having the ability to empathise with the challenges that readers are going through and to foster closeness with them, authors usually distance themselves from the role of expert. The 
effort that authors put in to write the about the author section, as demonstrated by the number of steps, shows that the main purpose of this section is to construct authors as credible advice givers.

Drawing on Woodward-Korn's (2005) idea of embedded genre or how micro-genres are embedded in a macro-genre (see Section 2.2.7), this thesis views self-improvement books as a macro-genre and stories as a micro-genre. In the next section, I provide an analysis of moves in stories in self-improvement books.

\subsection{Stories}

Author interview data suggests that stories could be a feature of self-improvement books. For example, when I asked John, a self-improvement book author, what he thought were crucial elements in this genre, he replied:

I think stories are key. People relate to stories. I have tried to read some self-help books and as soon as they get all preachy, I lose interest. I like to read about stories. So I think that is key. (July 13, 2013; E mail)

John said that "stories" are a crucial element in self-improvement books because he thought they are an effective tool to engage readers. As I was analysing the moves in the body chapters, I noticed that there were quite a number of accounts of sequences of events that could be construed as stories. Both findings from author interview data and my encounter with these accounts in the process of analysing the body chapters led me to examine them in my dataset. As a background to understanding these accounts, the following section reviews relevant literature.

\subsubsection{Stories and storytelling}

Stories are accounts of sequences of events, and they are a common and socially recognisable form of text. However, their labels seem to vary in the literature. Labov and Waletzky (1967), for example, call them narratives, while Bamberg and Georgakopoulou (2008) refer to them as stories. This study uses the term story as an umbrella term to 
include various types of stories (e.g., recount, anecdote) because I prefer to use a more everyday term to capture the broadest sense of the genre. Drawing on Labov (1997), I consider a story to minimally have a sequence of two events, having a very broad purpose of reporting the events. Following Polanyi (1989, p. 15), a conversational story is recognisable by how a particular talk moves from "the here and now" to a "storyworld" that is located in a different time and very often a different place. This implies that the end of a story is often observable when the time and place move from the "storyworld" to the present setting. This indicates that stories are often embedded in a broader discourse (e.g., casual conversation, counselling session). In the review of literature on narrative and stories that follows, I use the term story rather than other terms that are employed in the literature.

Research on stories is not a new area of study and has been a focus in various disciplines such as linguistics (Koven, 2012), psychology (McAdams, 2012) and sociology (Polletta, 2012). Narrative researchers have been interested in a number of ways of approaching stories. Approaches to what is commonly known as narrative analysis can generally be categorised into three broad categories: a) analysing stories at a textual or structural level (Labov, 1997), b) investigating the social action or function of telling stories (Holmes \& Marra, 2005), and c) utilising stories as a methodology or a means of inquiry (e.g., identity analysis) (Bamberg \& Georgakopoulou, 2008). Research that analyses spoken stories has focused on a number of contexts: casual conversation (Georgakopoulou, 2007), workplace (e.g., government departments, small businesses, blue-collar factory environments) (Holmes \& Marra, 2005), courtroom hearing (Harris, 2005), radio advice programmes (DeCapua \& Dunham, 1993), and TV talk shows (Thornborrow, 2000).

Drawing on genre theory, stories can be organised into various types that are recognisable by their social purpose. Following Thornbury and Slade (2006, p. 152), I use the term storytelling genres as an umbrella term that includes various story types rather than Martin and Rose's (2008, pp. 51-52) "types of stories," "story genre family" and "family of story genres" because Thornbury and Slade's term is the shortest term in the list. Thornbury and Slade (2006, p. 152) organise stories into four categories: narrative, anecdote, exemplum, and recount. Martin and Rose (2008, pp. 51-52) have five categories in their "types of stories" or "story genre family" where the fifth category is observation and the four other categories are similar, though not identical, to Thornbury and Slade's system in name and in context. I will discuss the similarities and differences between the 
two systems below. Table 12 shows a simplified version of the components of storytelling genres based on Thornbury and Slade (2006), and Martin and Rose (2008) where ${ }^{\wedge}$ means followed by, ( ) means optional, and the rest are obligatory components.

Table 12: Storytelling genres

\begin{tabular}{|l|l|l|l|}
\hline & Beginning & Middle & End \\
\hline Recount & $(\text { Abstract })^{\wedge}$ Orientation & $\wedge$ Record of events $\wedge$ (Reorientation $)$ & $($ Coda $)$ \\
\hline Anecdote & $(\text { Abstract })^{\wedge}$ Orientation & $\wedge$ Remarkable event $\wedge^{\wedge}$ Reaction & $($ Coda $)$ \\
\hline Exemplum & $(\text { Abstract })^{\wedge}$ Orientation & $\wedge$ Incident $\wedge$ Interpretation & $(\mathrm{Coda})$ \\
\hline Observation & $(\text { Abstract })^{\wedge}$ Orientation & $\wedge$ Record of events $\wedge$ Comment & $(\mathrm{Coda})$ \\
\hline Narrative & $($ Abstract $) \wedge$ Orientation & ${ }^{\wedge}$ Complication ${ }^{\wedge}$ Evaluation ${ }^{\wedge}$ Resolution & $($ Coda $)$ \\
\hline
\end{tabular}

Bamberg (2012, p. 122) states that it is necessary to analyse the forms of the types of stories and "what speakers do and accomplish" with them. Bamberg's statement complements Swales' (1990) idea that moves accomplish a particular intention. Incorporating the components of storytelling genres into Swales' (1990) idea of moves, I view these components (e.g., interpretation, reaction) as moves because each component serves a particular intention.

An orientation is obligatory in Thornbury and Slade's (2006) system, but it is not explicitly included in Martin and Rose (2008) system. Martin and Rose (2008, p. 52) state that the various storytelling genres "may" start with an orientation, implying that it is optional component. Also, Martin and Rose's (2008) system is slightly different from that of Thornbury and Slade (2006) because Martin and Rose do not seem to define or include the abstract in their system, even though Martin and Rose (2008, p. 9) briefly mention the influence of Labov's work (which has an abstract) has on their work on storytelling genres. It seems from Martin and Rose's examples that the abstract is not part of storytelling genres because this component is not present in any of their examples. Also, Martin and Rose (2008) do not seem to provide reasons for excluding the abstract from their system. My study includes the abstract and considers it to be an important component of a story because there are no good reasons to exclude it. Moreover, it is an established concept in the Labovian tradition of analysing stories. 
Studies from a genre perspective usually analyse the purposes and structures of stories. The following sections review the purposes and structures of the five storytelling genres listed in Table 2 above: recount, anecdote, exemplum, observation and narrative.

\subsubsection{Recount}

Thornbury and Slade (2006, p. 157) explain that a recount typically "tells the listener that something happened." A recount is very similar to what Polanyi $(1989$, p. 20) calls a report, which she explains is often told as a response to the listener's request for information.

As illustrated in Table 12, the obligatory components of a recount are an orientation (though not in Martin and Rose's system), and a record of events (Martin \& Rose, 2008; Thornbury \& Slade, 2006), and optionally, a recount starts with an abstract (Thornbury \& Slade, 2006). Thornbury and Slade (2006, p. 149) explain that the abstract is an optional component and it "announces the onset of" a storytelling genre and "encapsulates the point or theme" of a particular story. Labov (1997, p. 4) defines an abstract as "an initial clause in a narrative that reports the entire sequence of events." Drawing on both Thornbury and Slade, and Labov's definitions, the main function of an abstract is to present the purpose of telling a story or an overview of the plot in the story.

This is an example of an abstract from Thornbury and Slade (2006, p. 149):

1. A friend of mine told me this amazing story the other day.

The point in Example 1 would be this amazing story, and appraising the story as amazing seems to provide legitimacy for the speaker/writer to recount the story. In my study, an abstract indicates the beginning of a storytelling genre and can provide the purpose or theme of the story (Thornbury \& Slade, 2006) or an overview of the series of events (Labov, 1997).

Thornbury and Slade (2006, p. 149) state that the orientation "provides circumstantial information," and Labov and Waletzky (1967, p. 32) specify that this circumstantial information includes the characters and settings. Even though the orientation introduces the characters, these characters do not necessarily have to be given names. It seems there is little agreement in terms optionality of this component. According to Thornbury and 
Slade (2006), an orientation is obligatory and often occurs after the abstract in a recount, but Martin and Rose (2008) briefly mention that this component is optional but typical. Consider this example from Thornbury and Slade (2006, p. 149):

2. I went to a film, and ah, I'd just bought this new outfit and it was long silky, black pants that came up all in one...

The character in Example 2 is $I$, an unnamed character, and the setting is likely to be a cinema.

In a recount, the record of events always follows the orientation, and Thornbury and Slade (2006, p. 158) explain that listing the events is often a way of responding to a request for information. This is unlikely to be the case in self-improvement books because the readers are not present to request information when the authors are writing the stories. This is an example of record of events from Martin and Rose (2008, p. 55):

3. I went off to school in the morning and I was sitting in the classroom and there was only one room where all the children were assembled and there was a knock at the door, which the schoolmaster answered.

The events in Example 3 are marked by verbs (e.g., went off, was sitting, were assembled). Note that there were no out-of-the-ordinary events.

Thornbury and Slade (2006, p. 152) claim that a reorientation optionally follows the record of events but they do not provide any explanations or examples of reorientation. By contrast, Martin and Rose (2008, p. 54) explain that the reorientation "addresses events in hindsight." Consider this example from Martin and Rose (2008, p. 56):

4. I was taken from Cape Barren in October 1959 aged $12 \ldots$ I never saw my mum again.

Example 4 is a reorientation of a recount about a recollection of an Indigenous Tasmanian man who was removed from the island he grew up on when he was 12 years old. The reorientation brings the readers back to the initial setting and expresses a consequence of the event. Martin and Rose provide two recount examples but neither has a coda. Briefly, a coda signals the end of a particular storytelling genre. It seems to me that a reorientation is very similar to a coda because I never saw my mum again in Example 4 seems to indicate the end of the recount. Because Martin and Rose do not provide examples of recounts that 
have a coda, the difference between a reorientation and a coda is unclear. In my study, I have excluded the reorientation due to its ambiguity.

Thornbury and Slade (2006, p. 152) state that a recount optionally ends with a coda. Labov and Waletzky (1967, p. 39) and Thornbury and Slade (2006, p. 149) state that a coda is a functional device that connects the storytelling genre to the present moment or the context where the storytelling genre is embedded. The coda indicates the end of the story (Viney \& Bousfield, 1991, p. 758) and it can be a short summary of the record of events (Johnstone, 2001, p. 638). In my study, I view Example 4 to be a coda, in which case, I was taken from Cape Barren in October 1959 aged 12...I never saw my mum again would be a short summary of the record of events.

\subsubsection{Anecdote}

Thornbury and Slade (2006, p. 155), and Martin and Rose (2008, p. 56) state that the purpose of an anecdote is to share an emotional reaction. Thornbury and Slade (2006, p. 152) propose that an anecdote starts with an abstract (optional), followed by an orientation (obligatory), and then by the remarkable event (obligatory) and then the reaction (obligatory). Thornbury and Slade (2006, p. 155) explain that remarkable events are events that are out of the ordinary that speakers/writers use to convey an emotional reaction, and a reaction is the speaker's/writer's emotional response towards the events. Unlike record of events in recounts, remarkable events are unexpected events to the audience. Example 5 is a reaction from Martin and Rose (2008, p. 57):

5. I was so afraid and unhappy and didn't understand what was happening. The emotional response that the speaker expresses in Example 5 is feeling afraid, unhappy and confused. Unlike the overall purpose of a recount, that is to report a series of events, or "expository" as Thornbury and Slade (2006, p. 157) describe it, the overall purpose of an anecdote is to express an emotional response.

However, the term anecdote is not always used in the same sense as Thornbury and Slade (2006) and Martin and Rose (2008) use it. For example, Askehave (2004) studied spiritual self-help books and observes that parables are a prominent feature of this genre. Askehave (2004, p. 25) defines parables as: 
Small anecdotes [emphasis added] of real-life or fictitious events that serve to illustrate the point an author is trying to make and to ultimately encourage readers to make a particular decision or take a particular action.

Although Askehave uses the term anecdote she does not provide an explanation of the term. Askehave's (2004, p. 26) analysis shows that the purpose of telling what she calls "anecdotes" is to make claims: "we learn from our mistakes", "trust your instincts", and "respect and cherish your body." Because her claims do not seem to be related to expressing an emotional response, which is a key element in Martin and Rose, and Thornbury and Slade, her use of the term anecdote is inconsistent with that of Martin and Rose (2008) and Thornbury and Slade (2006). In my view, a parable, as defined by Askehave (2004), is very similar to Martin and Rose's and Thornbury and Slade's exemplum because of the "take-home" points they make.

\subsubsection{Exemplum}

The overall purpose of telling an exemplum is "to make a moral point" or to express "what is considered to be acceptable behaviour in the cultural context" (Thornbury \& Slade, 2006, p. 156). An exemplum (Martin \& Rose, 2008; Thornbury \& Slade, 2006) is very similar to what Polanyi $(1989$, p. 20$)$ calls a story, which aims to "make a point" or "transmit a message - often some sort of moral evaluation or implied critical judgement." For my study, I have decided to use the term exemplum for this sort of story so that I can reserve the term story for use as an umbrella term.

Based on Thornbury and Slade's (2006, p. 152) system, the structure of an exemplum is $($ Abstract $) \wedge$ Orientation ${ }^{\wedge}$ Incident $^{\wedge}$ Interpretation ${ }^{\wedge}$ (Coda). Thornbury and Slade (2006, p. 156) include incident and interpretation as obligatory components in this storytelling genre. Thornbury and Slade (2006, p. 156) explain that incident consists of events that serve as examples to illustrate a moral point, and interpretation refers to the speaker's/writer's moral judgement of the events. Similarly, Martin and Rose (2008, p.

62) state that the interpretation indicates what/who should be praised or condemned. Consider an example of interpretation from Martin and Rose (2008, p. 63). 
6. It was a kindly action from the natives.

In Example 6, the speaker expresses his/her moral judgement by appraising the natives' action as kindly.

As mentioned earlier in 2.4.2, Askehave (2004) studied one spiritual self-help book and identifies what she calls parables as a feature in the genre. As reported in 2.4.2, the points of these parables in Askehave's $(2004$, p. 26) data are "we learn from our mistakes," "trust your instincts," and "respect and cherish your body." In my opinion, Askehave's definition (refer 2.4.2) of a parable is unconventional because parables are often associated with religious messages. For example, the online Oxford Dictionaries define a parable as "a simple story used to illustrate a moral or spiritual lesson, as told by Jesus in the gospel" (Parable, 2015). Based on this definition, a parable is a story that can be found in the gospel and the message of the story could be a moral or spiritual one. Considering this definition, the points of the parables in Askehave's data do not appear to have a dominant spiritual or religious message. I would categorise Askehave's parables as exempla. I reserve the term parables for a subset of exempla in which the points or lessons have a religious orientation. As a subset of exempla, I view the religious oriented lessons to be conveying ways of behaving in a particular cultural context (i.e., religion).

\subsubsection{Observation}

Observations are a storytelling genre in Martin and Rose's (2008) system but are not found in Thornbury and Slade's (2006) system. Observations are very similar to anecdotes because the purpose of both is to convey a response towards the events. While the purpose of telling an anecdote is to convey an emotional response, Martin and Rose (2008, p. 67) state that the purpose of telling an observation is to comment on the "states of affairs." Although Martin and Rose (2008, p. 66) do not explicitly state that the record of events component and the comment component are obligatory, their examples imply that. Example 7 is a comment component from Martin and Rose (2008, p. 66).

7. That was terribly shameful for me, I will not say anymore.

In Example 7, the speaker comments on an event, "that," by describing it as "terribly shameful." Although it is possible that one might interpret describing an event as a "terribly shameful" one as an emotional response, to be conservative in my 
interpretation, the speaker was explicitly commenting on an event as opposed to expressing emotion in Example 5, "I was so afraid and unhappy." Hypothetically, I would interpret the clause, it was a frightful and unhappy event, as a comment rather than a reaction. Unlike in anecdotes, expressing the speaker's emotional response is not the main purpose in observations.

Drawing on Thornbury and Slade's system, I view the abstract and orientation to be the beginning of an observation, and the coda to be an optional component to end the genre.

\subsubsection{Narrative}

Narratives are recognised by the complication and resolution components (Labov \& Waletzky, 1967, p. 39; Martin \& Rose, 2008, p. 67; Thornbury \& Slade, 2006, p. 152). Thornbury and Slade (2006) propose the obligatory stages of narratives as Orientation ${ }^{\wedge}$ Complication ${ }^{\wedge}$ Evaluation ${ }^{\wedge}$ Resolution, they explain that the evaluation, the component that expresses the speaker's attitude towards the events (complication and resolution), can be found throughout a narrative. Labov and Waletzky (1967, p. 34) state that because narratives are used "to establish some point of personal interests," the evaluations are central, though optional, to draw listeners (or readers) to the particular points. These points, according to Martin and Rose (2008, p. 52), can vary: expressing emotional reaction, conveying a moral point, commenting on the state of affairs.

A complication is an issue that is resolved by a resolution. Johnstone (2001, p. 638) explains that resolutions usually release the tension contributed by the complications. Martin and Rose's (2008) view of a resolution is slightly different from that of Thornbury and Slade's (2006). While Martin and Rose (2008, p. 67) state that "the 'point' of a narrative is how the protagonists resolve a complication in their lives" (implying the agency of the protagonist), Thornbury and Slade (2006, p. 153) state that "the resolution does not necessarily involve the agency of the protagonist."

Example 8 on the next page is a complication followed by an evaluation and a resolution from Martin and Rose (2008, p. 69). 


\section{Complication:}

As I got older I noticed my skin colouring was different to that of my family. My Mother told me I was adopted from Australia and part Aboriginal.

\section{Evaluation:}

I felt quite lonely especially as I approached my teens. I got teased often about being Aboriginal and became very withdrawn and mixed up, I really did not know where I belonged.

Resolution:

I eventually got married to a New Zealander...my husband, boys and myself had the opportunity to go to Melbourne... I got in touch with my birth Mother and made arrangements to meet her...

The complication or issue in Example 8 is that $I$, the protagonist, found, as she got older, that she looked different from her family and later discovered she was an adopted child, which led her to want to get in touch with her biological mother. The complication is resolved by the resolution when she had the opportunity to travel to Melbourne and eventually met her biological mother.

Because the purpose of a narrative can vary and because a genre is primarily recognised by its social purpose, viewing narratives as a genre according to Martin and Rose's (2008) explanation might present a problem. Although later Rose and Martin (2012, p. 56) state that the purpose of a narrative is "resolving a complication," this seems to be the function of the resolution move rather than a narrative.

Because narratives cannot be identified by their purpose, Martin and Rose (2008) and Thornbury and Slade (2006) define narratives based on their complication-resolution structure. However, defining a genre based on its structure rather than its social purpose is problematic. To resolve this problem, my study views narratives as a text type rather than a genre. Paltridge (1996, p. 237) explains that text types are "groupings of texts which are similar in linguistic form, irrespective of genre." This implies that it is reasonable to define a narrative as a text type by its complication-resolution structure. To further support this point, narrative is often associated with structural characteristics and the term narrative structure is not uncommon in the literature (Benson, 2014; Leikin et al., 2014; Martin, 2014). Although the complication-resolution structure contributes to the unique characteristics of narratives, namely a problem-solution structure, this structure can 
realise the purpose of any of the storytelling genres. In other words, a story can be a narrative in terms of structure and any of the storytelling genres in terms of purpose.

Drawing on various systems of storytelling genres, the following section analyses the stories in self-improvement books by identifying their purposes and examines the narrative structure in these stories.

\subsubsection{Analysis of stories}

I initially identified the stories in my data based on what looked like a story to me intuitively, and I counted the number of such stories in the first body chapters of each of the books in a 20-book dataset (See Table 13). The books were chosen based on their popularity, which was based on Amazon's bestselling charts and recency. In this analysis, a recent book is operationalised as one that was published between 2005 and 2014. As mentioned in Section 5.2, The Power of Positive Thinking (Peale, 1952) was included because it is generally viewed as the classic of self-improvement books.

Table 13: Occurrence of stories

\begin{tabular}{|l|l|c|}
\hline & Book titles & Number of stories \\
\hline 1 & A Few Keys to All Success (Muncy, 2002) & 9 \\
\hline 2 & Talent is Never Enough (Maxwell, 2007) & 9 \\
\hline 3 & The Power of Negative Thinking (Knight, 2013) & 9 \\
\hline 4 & 5 Tools to Change Your World (Oldham, 2012) & 8 \\
\hline 5 & The Mindful Path to Self-Compassion (Germer, 2009) & 8 \\
\hline 6 & Quiet (Cain, 2012) & 7 \\
\hline 7 & Eight Facets of a Fulfilling Life (Pearson, 2012) & 7 \\
\hline 8 & Power of Positive Thinking (Peale, 1952) & 6 \\
\hline 9 & You Can be Happy No Matter What (Carlson, 1997) & 6 \\
\hline 10 & Awaken the Giant (Robbins, 1992) & 5 \\
\hline 11 & The 7 Habits of Highly Effective People (Covey, 1989) & 4 \\
\hline 12 & Becoming a Person of Influence (Maxwell \& Dornan, 2006) & 4 \\
\hline 13 & Break Free of Your Rut (Barrett, 2013) & 7 \\
\hline 14 & How Will You Measure Your Life (Christensen et al., 2012) & 9 \\
\hline
\end{tabular}




\begin{tabular}{|c|l|c|}
\hline 15 & The Shift (Dyer, 2010) & 3 \\
\hline 16 & How to Have a Beautiful Mind (de Bono, 2004) & 1 \\
\hline 17 & Life Code (McGraw, 2012) & 1 \\
\hline 18 & The Five Major Pieces to the Life Puzzle (Rohn, 2002) & 1 \\
\hline 19 & The Gift of Imperfection (Brown, 2010a) & 1 \\
\hline 20 & The 18 Rules of Happiness (Moore, 2013) & 0 \\
\hline
\end{tabular}

The counting as illustrated in Table 13 shows that there is at least one story in the first chapter of all but one of the books in the dataset. The only book that does not have a story in the first body chapter is The 18 Rules of Happiness (Moore, 2013). This book has 18 relatively short body chapters and the first body chapter has 349 word tokens. It is possible that the author did not include stories to keep the chapters concise.

For a closer examination of this feature, I selected all the stories I had identified from the first body chapters from the four books with the most stories as shown in Table 13. This selection resulted in a dataset of 36 stories. The purpose of collecting the stories from the chapters that are story-rich is to make sure the dataset is big enough to capture the possibility of a variety of storytelling genres. Although it is arguable that these four books may contain abnormally high number of stories that could misrepresent selfimprovement books, for the purpose of this analysis, frequency is less important because the main goal of this analysis is to study the characteristics and purpose(s) of the stories rather than the distribution of the various storytelling genres.

From the dataset I classified the stories into storytelling genres by identifying their purpose (e.g., to express emotional reaction, to make a moral point). After identifying the purpose and categorising their storytelling genres (e.g., anecdote, exemplum), I then examined whether the stories have a complication-resolution structure. I examined the components in each story and identified whether the components are obligatory (100\%), typical (more than $70 \%$ ), or optional (less than $70 \%$ ).

Table 14 shows the distribution of stories across the storytelling genres in the first body chapters from the four books with the highest number of stories:

1. A Few Keys to All Success (Muncy, 2002)

2. Talent is Never Enough (Maxwell, 2007) 
3. The Power of Negative Thinking (Knight, 2013)

4. 5 Tools to Change Your World (Oldham, 2012)

Table 14: Occurrences of storytelling genres

\begin{tabular}{|l|c|c|c|c|c|}
\hline & Few Keys & Talent is & The Power & 5 Tools & Total \\
\hline Exemplum & 9 & 9 & 9 & 9 & 36 \\
\hline Total & 9 & 9 & 9 & 9 & 36 \\
\hline
\end{tabular}

Table 14 shows that all the stories in this dataset belong to the storytelling genre exemplastories told to make a moral point. It should be noted that some of these exempla have a narrative complication-resolution structure and some do not. I discuss the narratives separately below. There are no recounts, anecdotes or observations in this dataset and this may imply that the purpose of these three storytelling genres does not serve the overall purpose of self-improvement books. Also, an informal check of the stories in the first body chapters from the books in Table 13 showed that they are exempla. The purposes of the three storytelling genres are:

a) Recount: to respond to a request for information (Thornbury \& Slade, 2006, p. 158)

b) Anecdote: to express an emotional reaction (Thornbury \& Slade, 2006, p. 155)

c) Observation: to comment on the states of affairs (Martin \& Rose, 2008, p. 66)

The absence of recounts in self-improvement books implies that self-improvement authors do not tell stories in response to readers' requests for information. The absence of anecdotes in this genre is an indication that self-improvement authors do not tell stories to share the authors' emotional reactions. The absence of observations implies that selfimprovement authors do not tell stories with the purpose of commenting on a state of affairs. The abundance of exemplums indicates that self-improvement authors use this storytelling genre to illustrate a "take-home" message that authors want their readers to learn, or in Thornbury and Slade's (2006, p. 156) words, "to make a moral point."

\subsubsection{Analysis of exemplums}

After identifying the stories, I examined the purpose of the stories and found that all the stories in this dataset are exemplums. The five moves that I identified in the exemplums are abstract, orientation, incidents, interpretation, and coda. This section categorises the 
moves according to their typicality: obligatory, typical, or optional, and provides an example of a typical exemplum from my dataset to illustrate the moves. Table 15 is an example of an exemplum with all five moves.

I chose this exemplum as an example because it is the shortest exemplum in my dataset. In this example, "the point or theme," as Thornbury and Slade (2006, p. 149) call it, is a take-home message that the author wants the readers to learn. The message is the claim that people around us influence how we think.

Table 15: Complete example of exemplum

\begin{tabular}{|c|c|}
\hline Data & Moves \\
\hline $\begin{array}{l}\text { The biggest influence on the way we think is the people we } \\
\text { are around. We all know what a big effect peer pressure can } \\
\text { have on children and teenagers. }\end{array}$ & M1: Abstract \\
\hline $\begin{array}{l}\text { Say a teenager has been a great student, never getting in trouble, } \\
\text { making good grades, showing respect for adults, and the like. }\end{array}$ & M2: Orientation \\
\hline $\begin{array}{l}\text { Then he suddenly changes. He starts smoking and drinking. His } \\
\text { grades drop. He starts using bad language and talking back to } \\
\text { his parents and teachers. }\end{array}$ & M3: Incidents \\
\hline $\begin{array}{l}\text { If you were to ask his parents what happened, most of the time } \\
\text { they would say that the young man "fell into a bad crowd." We } \\
\text { all know that teens are incredibly susceptible to taking on the } \\
\text { attitudes, beliefs, and behaviors of those around them. } \\
\text { When does that change? When do we stop being strongly } \\
\text { influenced by those around us? At twenty, thirty, or forty? Not } \\
\text { at all. We stop being influenced by those around us when we } \\
\text { die. Until then, we will be like the people we surround ourselves } \\
\text { with. }\end{array}$ & M4: Interpretation \\
\hline $\begin{array}{l}\text { For that reason, we must look very closely at the people } \\
\text { we choose to be around. Are they the type of people we want to } \\
\text { become? If not, then we must find a way to get around the } \\
\text { people who are. As corny as it sounds, you really can't soar with } \\
\text { the eagles when you are surrounded by turkeys. }\end{array}$ & M5: Coda \\
\hline
\end{tabular}

From the book A Few Keys to All Success. Copyright (C) 2002 by Jim Muncy. Reprinted with permission from Few Keys, Valdosta GA. 
The abstract is an optional component because it occurs in less than $70 \%$, that is, fewer than 18 out of 36 exempla. It usually presents the purpose of telling a particular story. See Table 15 for an example of the abstract.

\section{Move 2: Orientation (36/36)}

Based on my analysis, the orientation is an obligatory component because it occurs in all 36 exempla. The primary function of the orientation is to provide circumstantial information such as the characters and settings. In the example in Table 15, the character is not named. He is introduced as a teenager who was a great student and had other positive characteristics.

\section{Move 3: Incidents (36/36)}

The incidents are an obligatory component in this dataset. They are events that are told to illustrate a moral point. The clause, "Then he suddenly changes," implies that there are at least two states- before and after. Then the story goes on to give examples of incidents that occur in his new state, i.e., smoking, drinking, using bad language, talking back to his parents and teachers.

\section{Move 4: Interpretation (36/36)}

The interpretation is an obligatory component in this dataset. In the interpretation move, the author interprets the incidents and makes explicit what he wants his potential readers to learn. In this example the author claims that we will always be influenced by people around us. The interpretation move in this example uses questions to engage readers. I argue that authors attempt to engage readers in the interpretation move because this is where authors make explicit the lesson that they want readers to learn from the exemplum. 


\section{Move 5: Coda (31/36)}

The coda move is a typical move in this dataset because it occurs in more than $70 \%$ of the 36 stories. It usually indicates the end of a story and its primary function is to connect the storyworld to the present storytelling event or the present moment. In other words, it reveals the purpose and relevance of the incidents. In this example, the author presents his advice or makes the desirable way of behaving in a particular culture (the "be successful" culture) explicit, that is, to choose one's friends wisely.

Table 16 shows the frequency of moves in the 36 exempla for this analysis. The obligatory moves are the orientation, incidents and interpretation. The coda move is a typical move while the abstract move is optional.

Table 16: Moves in exempla

\begin{tabular}{|l|c|c|}
\hline Moves & Occurrences $($ Total = 36) & Typicality \\
\hline M1: Abstract & 20 & Optional \\
\hline M2: Orientation & 36 & Obligatory \\
\hline M3: Incidents & 36 & Obligatory \\
\hline M4: Interpretation & 36 & Obligatory \\
\hline M5: Coda & 31 & Typical \\
\hline
\end{tabular}

My analysis shows that the obligatory moves of the exempla in my dataset are consistent with Martin and Rose (2008) and Thornbury and Slade (2006). In other words, the moves in a minimal structure of an exemplum are the orientation, incidents, and interpretation.

As discussed in Section 5.5.1.5, because this study does not view narrative as a storytelling genre but as a structure, the next section explores narrative structure in the 36 exempla that I identified.

\subsubsection{Analysis of narrative structure}

Unlike storytelling genres, narratives in my study were identified based on their complication-resolution structure. I could not identify them based on their purpose (e.g., expressing emotional reaction, making a moral point) because the purpose of a narrative 
can vary and literature seems to describe them structurally. Because I identified narratives based on their complication-resolution structure, it will not be surprising that the complication and resolution moves are obligatory components of narratives in this study. Table 17 shows the distribution of narratives in four books with the highest number of stories.

Table 17: Occurrence of stories with complication-resolution structure

\begin{tabular}{|l|c|c|c|c|c|}
\hline & Few Keys & Talent is & The Power & 5 Tools & Total \\
\hline Narrative & 2 & 4 & 2 & 3 & 11 \\
\hline
\end{tabular}

Table 17 shows that not many exempla in my dataset have a complication-resolution structure. I was unable to make a strong case in terms of typicality of the moves because the number of stories with this structure in my study is not very high. Table 18 shows an example from my dataset of these stories that has all the moves (abstract, orientation, complication, resolution, evaluation, and coda). After the example, I discuss the moves that I have identified in the 11 stories with this structure.

Table 18: Complete example of story with complication-resolution structure

\begin{tabular}{|c|c|}
\hline Data & Moves \\
\hline $\begin{array}{l}\text { Your potential is really up to you. It doesn't matter what } \\
\text { others might think. It doesn't matter where you came from. It } \\
\text { doesn't even matter what you might have believed about } \\
\text { yourself at a previous time in your life. It's about what lies } \\
\text { within you and whether you can bring it out. }\end{array}$ & M1: Abstract \\
\hline $\begin{array}{l}\text { There's a story about a farm boy from Colorado who loved } \\
\text { to hike and rock climb. One day while climbing in the } \\
\text { mountains, he found an eagle's nest with an egg in it. He took } \\
\text { the egg from the nest, and when he got home, he put it under a } \\
\text { hen along with her other eggs. }\end{array}$ & M2: Orientation \\
\hline $\begin{array}{l}\text { Since he hatched among chicks, the eagle thought he was a } \\
\text { chicken. He learned chicken behavior from his "mother" and } \\
\text { scratched in the chicken yard along with his "siblings." He } \\
\text { didn't know any better. And when he sometimes felt strange }\end{array}$ & M3: Complication \\
\hline
\end{tabular}




\begin{tabular}{|l|l|}
\hline $\begin{array}{l}\text { stirrings within him, he didn't know what to do with them, so he } \\
\text { ignored them or suppressed them. }\end{array}$ & M4: Evaluation \\
\hline After all, if he was a chicken, he should behave like a chicken. & M3: Complication \\
chicken-yard eagle looked up and saw him. In that moment, he \\
realized he wanted to be like that eagle. He wanted to fly high. \\
$\begin{array}{l}\text { He wanted to go to the mountain peaks he saw in the distance. } \\
\text { He spread his wings, which were much larger and stronger than } \\
\text { those of his siblings. }\end{array}$
\end{tabular}

From the book Talent is Never Enough. Copyright (C 2007 by John C. Maxwell. Reprinted with permission from Thomas Nelson, Nashville TN. www.thomasnelson.com

\section{Move 1: Abstract (4/11)}

The abstract move is an optional move in this dataset. The abstract conveys the take-home message or lesson that authors want readers to learn. See Table 18 for an example of abstract in a story with a complication-resolution structure. 
The orientation move introduces the character(s) and the setting, and is an obligatory component in this dataset. See Table 18 for an example of this move. The characters in this move are a farm boy from Colorado who enjoyed hiking and rock climbing, and a baby eagle that grew up with chicken.

\section{Move 3: Complication (11/11)}

The complication move includes events that are usually problems or challenges. This move is an obligatory move, and it is one of the two identifying moves for stories with a complication-resolution structure. See Table 18 for an example of the complication move. In this example, the problem is a baby eagle that does not behave like an eagle because it grew up with the chickens.

\section{Move 4: Evaluation (11/11)}

The evaluation move is an obligatory move that expresses the authors' attitude towards the events (complication or resolution). Also, I view the evaluation move to be compatible with the interpretation move in an exempla because both moves express authors' attitude towards the story.

The evaluation move in this dataset is usually signalled by modal verbs and relational processes. See Table 18 for examples of the evaluation moves. I have included the two examples of evaluation moves here. Note that the modal verb and relational processes are underlined.

\section{Evaluation 1:}

After all, if he was a chicken, he should behave like a chicken. (Maxwell, 2007) The relational process, was, relates the baby eagle to a chicken. Because it is not an action, it could not be an event. The modal verb, should, is an extrinsic modality that is based on logical reasoning the baby eagle should behave like a chicken. This conveys the author's attitude towards how the baby eagle ought to behave - like a chicken. 


\section{Evaluation 2:}

Though he had never flown before, he possessed the instinct and the capabilities. (Maxwell, 2007)

Possessed in Evaluation 2 is a relational process. It ascribes qualities, the instinct and capabilities to fly, to the baby eagle. Having these qualities is not an action and I argue that it is unlikely to be an event. In this example, the author expresses his attitude or perception towards the baby eagle by ascribing to it these qualities.

\section{Move 5: Resolution (11/11)}

The resolution move is obligatory, and it is the second of the two identifying moves for stories with a complication-resolution structure. Refer to Table 18 for an example of the move. This move usually resolves the problems or challenges in the complication move. In this example, the baby eagle suddenly came to realise that it was an eagle and finally spread its wings, flew, and discovered its potential. Within the storytelling genre framework, the complication and resolution moves are compatible to the incidents moves in exempla.

\section{Move 6: Coda (7/11)}

The coda move is a typical move and it indicates the end of a narrative. Refer to Table 18 for an example of the coda move in context. The primary purpose of the coda move is to convey the message or point that the authors want readers to learn. The following are excerpts from all the four coda moves in this dataset.

\section{Coda 1:}

All they needed was the opportunity to view their situation in a new light and the courage to create the change; what happened is not especially common but it pays to be open to the unexpected. (Oldham, 2012) 


\section{Coda 2:}

Likewise, your viewpoint is a choice; a decision that you cannot avoid making. This is why a statement such as "They made me angry" is the language of a victim. (Oldham, 2012)

Coda 3:

We are where we are in life because of the way we think. (Muncy, 2002)

Coda 4:

Sheppard learned an important lesson. We can mess up the planting and no one will know the difference while the seed is in the ground. Inevitably though, the seed will grow and the truth will be revealed. We can fool others for a while. We can even fool ourselves. But we can't fool the law of the harvest. (Muncy, 2002)

\section{Coda 5:}

To reach your potential, you must first believe in your potential, and determine to live way beyond average. (Maxwell, 2007)

\section{Coda 6:}

Do you believe in your mission? Are you confident that you can accomplish great tasks? Do you expect to achieve your goals? These are necessary ingredients to lift your talent from potential to fruition. (Maxwell, 2007)

\section{Coda 7:}

Keep believing in yourself. It was a just reward for the students who had worked hard and believed in themselves. (Maxwell, 2007)

Note that all the coda moves in this dataset seem to be making a moral point or presenting the authors' advice. The advice relates to desirable ways of behaving, particularly ways of thinking, within self-improvement as a culture. In Coda 1, the author encourages the readers to change the way they think from being narrow minded to being open to the unexpected. In Coda 2, the author attempts to teach the readers that they have a choice to determine their viewpoint. I argue that it is related to encouraging potential readers to change the way they think. In Coda 3, the author implies that how readers think has an effect on their current situation. In Coda 4 , the author attempts to teach potential readers that their actions have consequences. In Coda 5 , the author encourages the readers to change from not believing in their potential to believing in their 
potential, and from being less determined to being more determined to live beyond average lives. In Coda 6 , believing in one's mission and being confident are necessary to be successful. Finally, in Coda 7, the author presents hard work and believing in oneself as desirable values.

A closer examination of the seven coda moves shows that authors use the personal pronoun you to direct the advice to the readers (see Codas 5, 6 and 7). Authors also use a less direct way in presenting the point by using the inclusive-we (see Codas 3 and 4). The analysis also shows that authors can present their message in an indirect way by using the third person pronoun they or presenting the message as a general statement using the relational process is/are in declarative clauses (see Coda 1, 2 and 6). As can be seen in Coda 6 , authors sometimes use questions as a resource to engage readers.

Table 19 shows that the obligatory moves in the narratives in this dataset are the orientation move, the complication move, the evaluation move, and the resolution move. The abstract move is optional and the coda move is typical.

Table 19: Moves in narratives

\begin{tabular}{|l|c|c|}
\hline Moves & Occurrences $($ Total = 11) & Typicality \\
\hline M1: Abstract & 4 & Optional \\
\hline M2: Orientation & 11 & Obligatory \\
\hline M3: Complication & 11 & Obligatory \\
\hline M4: Evaluation & 11 & Obligatory \\
\hline M5: Resolution & 11 & Obligatory \\
\hline M6: Coda & 7 & Typical \\
\hline
\end{tabular}

The analysis shows that the obligatory moves in this dataset are consistent with those of Martin and Rose (2008) and Thornbury and Slade (2006). This analysis concludes that authors use exempla, both with and without a narrative structure, to convey take-home lessons, and these lessons are related to encouraging readers to change the way they think.

The characteristics of the stories that I analysed are very similar to children's literature as Ewers (1992) describes. For example, Ewers, from a literary tradition, claims that stories in children's literature are didactic and they provide useful insights (p. 174) although he 
provides no evidence. Historically, these stories, Ewers claims, were intended to teach children "abstract concepts in the areas of religion, ethics, morals, and reasoning" (p. 175). Again, no evidence was provided to support this claim. Based on Ewers' claim, stories in self-improvement books serve a very similar purpose as those in children's literature. Ewers relates the stories in children's literature to stories in oral traditions which he claims were originally told to give advice. One of my interviewees made a similar claim. When I asked Grace, a regular reader of self-improvement books, what she thought the reason for writing this genre was, she said:

It's [writing self-improvement books] sort of a way we pass on achieved wisdom these days. Once upon a time, that [sharing experience] might have happened in a family or within the village. (March 1, 2013; Face-to-face interview)

This comment suggests that the purpose of telling stories in self-improvement books might be similar to sharing experience or stories in oral traditions.

Another common characteristic of stories in my dataset and children's literature, as Ewers (1992) claims, is the way storytellers engage their readers by addressing them directly. In the stories in my dataset, I have illustrated how authors of self-improvement books address their readers in the coda moves by using reader pronouns (i.e., you, inclusive-we). My analysis also shows that self-improvement authors use questions in the coda moves to engage readers.

Based on my analysis, stories in self-improvement books serve a very similar purpose as those used in sermons (i.e., to illustrate a point). Cheong (1999), for example, analysed the moves in sermons and one of the moves he identified was "illustration" (p. 53). Cheong explains that the purpose of the illustration move is to shed "light upon a sermon by the use of an example" and that this move could be a description of incidents that preachers use to help their audience "grasp" the point of their sermons (p. 53). The example of this move that Cheong provides is a story. Ewers (1992) also claims that preachers use stories "to embellish sermons" (p. 173). Although the stories in Cheong's data may well be to illustrate a spiritual lesson, my study does not view them as parables because, drawing on the definition of parable in the online Oxford Dictionaries (see Section 5.5.1.3), they are not stories that are found in the Bible. 
Although with no evidence provided, Ewers (1992) claims that storytellers are considered credible if their audience perceive them to be "open and sincere" and "deeply attached to society" (p. 176). His claim is consistent with how self-improvement authors construct themselves as credible advice givers by constructing themselves as trustworthy people and people who are genuinely concerned for their readers. This can be seen in how authors refer to their genuine intentions in Step 5 to achieve Move 2: Constructing credibility in the about the author section (see Section 5.4).

The purpose of telling stories in self-improvement books is explicitly expressed typically in the coda moves. Although these moves play an important role in presenting the point of the story, the interpretation move in exempla and the evaluation move in narratives also play a similar role. They guide readers to a desired understanding of the stories, one that is related to the advice authors give.

Drawing on the 36 stories that I analysed, stories play a crucial role in self-improvement books in illustrating authors' advice. Similar to stories in children's literature, the stories I analysed have a didactic character and authors use them to share their insights with regards to improving one's life. Because stories in my dataset are a resource that authors use to illustrate a point, reader engagement is necessary. This is evident in the use of reader pronouns in the coda moves. Although stories are an important resource for teaching, storytellers' credibility is part of storytelling. In the exempla that I analysed, the coda move, the interpretation move, and the evaluation move are important elements that authors use to direct readers to the take-home message.

\subsection{Summary of chapter}

The goals of this chapter are primarily to describe self-improvement books at a genre level by examining the sections in self-improvement books, and analysing the moves and steps in the introduction chapters, the body chapters, and the about the author sections. This chapter has also analysed the purpose of stories in these books by identifying the moves. My analysis shows that the main purposes of the introduction chapters, body chapters, about the author sections in self-improvement books are to "sell" authors' advice, to present a message, and to construct authors as credible advice givers. 
This chapter has demonstrated that the main purpose of self-improvement books is to teach readers how to improve their lives. Authors motivate their message by listing problems that their imagined readers may have. To persuade readers that the solutions they recommend are effective, they construct their message as being popular and include stories of people who are "successful" as a result of following the authors' advice. Like children's literature, self-improvement authors tell stories for pedagogical purposes. In self-improvement books, stories illustrate the message that readers can improve their lives. Although self-improvement authors have a different message from preachers, both use stories for illustrative purposes.

Constructing themselves as experts, authors of self-improvement books present their advice in the body chapters. Authors also construct their readers as people who have problems and are not satisfied with their status quo. Not only are readers constructed as people who want to improve their lives and feel better about themselves, but by doing so authors also present a particular worldview. It seems that feeling good about oneself and having a constant need for self-improvement are presented as desirable. Also, presenting themselves as experts, they redefine well-known words to introduce alternative worldviews. Using aphorisms, authors present these worldviews as consistent with other credible sources of advice (e.g., presidents of America, ancient philosophers, business executives). Aphorisms are also a resource that authors use to distance themselves from their claims, making their claims appear more objective.

To persuade readers that the authors' advice is worthy of their attention, it is necessary for authors to construct themselves as credible advice givers. Authors do this, besides presenting themselves as experts, by presenting themselves as trustworthy people who genuinely care for their readers. Authors also gain credibility by presenting themselves as lay people who are similar to the readers (i.e., middle- and upper- class Americans). They do this by writing about their families and where they live.

Consistent with both reader and non-reader interview data, my analysis also shows that authors are aware that their potential readers perceive the message across selfimprovement books to be predictable. My analysis shows that authors anticipate this perception by claiming the uniqueness of their message.

This chapter has demonstrated that analysing moves and steps not only contributes to the understanding of how the genre is structured but it also sheds light on the context of 
culture of this genre (e.g., what is viewed as desirable, interpersonal relationship between authors and readers). The analysis in this chapter has also demonstrated that while authors construct themselves as experts, they are careful to balance their identity by creating closeness with their readers. 


\section{Chapter 6: Register analysis}

In the previous chapter, I demonstrated how self-improvement books as a genre are structured in a particular way by analysing the moves and steps in main sections of the genre. This chapter examines self-improvement books at a register level and Halliday (1985) explains that register can be seen as the configuration of field, tenor and mode. To understand this configuration, this chapter analyses the lexicogrammatical features of self-improvement books focusing on Hyland's engagement system (i.e., personal pronouns, imperative clauses, questions), and the interpersonal relationship between authors and readers by analysing modal verbs. This chapter also explores the lexicogrammatical features of self-improvement book titles.

\subsection{Personal pronouns}

To explore the register of self-improvement books, following how Yeo and Ting (2014, p. 27) analyse personal pronouns in their data, I began my exploration by observing patterns in the word frequency list. I selected 20 self-improvement books (1,327,500 word tokens) from the main dataset of 40 books (see Appendix 1) and generated a word frequency list using Antconc concordancer software. Hence, all the books that I chose for this analysis were those in electronic version. The 20 books were:

1. A Few Keys to All Success (Muncy, 2002)

2. Awaken the Giant Within (Robbins, 1992)

3. Becoming a Person of Influence (Maxwell \& Dornan, 2006)

4. Break Free from Your Rut (Barrett, 2013)

5. How to Have a Beautiful Mind (de Bono, 2004)

6. How will You Measure Your Life? (Christensen, Allworth, \& Dillon, 2012)

7. Life Code (McGraw, 2012)

8. Quiet (Cain, 2012)

9. Talent is Never Enough (Maxwell, 2007) 
10. The Eight Facets of a Fulfilling Life (Pearson, 2012)

11. The Five Major Pieces to the Life Puzzle (Rohn, 2002)

12. The Gifts of Imperfection (Brown, 2010a)

13. The Mindful Path to Self-Compassion (Germer, 2009)

14. The Power of Negative Thinking (Knight, 2013)

15. The Power of Positive Thinking (Peale, 1952)

16. The Shift (Dyer, 2010)

17. The 7 Habits of Highly Effective People (Covey, 1989)

18. The 18 Rules of Happiness (Moore, 2013)

19. You Can be Happy No Matter What (Carlson, 1997)

20. 5 Tools to Change Your World (Oldham, 2012)

The words in this dataset are treated as lowercase to avoid Antconc from counting you and You as two word types. The number of word types refers to "the number of different word forms" and the number of word tokens refers to "the number of running words" (Biber et al., 1999, p. 52). Consider this example:

1) People who have nothing to hide, hide nothing. (McGraw, 2012)

There are six word types and eight word tokens in the above example: hide (2), nothing (2), have (1), people (1), to (1), who (1). The number of tokens of each word type is bracketed.

Table 20 shows the generated frequency list. Because you is the most frequent lexical word, I manually removed you that does not function as a personal pronoun (e.g., thank you) from my counting. This implies that the occurrences of you in Table 20 are those that function as personal pronouns. As Kuo (1999, p. 127) notes, imperative clauses contain an unspoken you. For example, the imperative clause change your life! actually means (you) change your life!. I did not include such instances in my counting because I would not be able to compare the frequency of you in my dataset with other genres in the literature as such instances are not typically included. 
Table 20: Most frequent words in 20 self-improvement books $(1,327,500$ word tokens)

\begin{tabular}{|l|l|l|}
\hline Rank & Word type & Frequency \\
\hline 1 & the & 56572 \\
3 & to & 43636 \\
4 & and & 35436 \\
5 & of & 33359 \\
6 & you & 28930 \\
7 & in & $\underline{23640}$ \\
8 & that & 20545 \\
9 & is & 16175 \\
10 & $\underline{\text { i }}$ & $\underline{18400}$ \\
11 & $\underline{\text { it }}$ & $\underline{14239}$ \\
12 & $\underline{\text { we }}$ & $\underline{12029}$ \\
13 & your & $\underline{10100}$ \\
14 & for & 9710 \\
15 & with & 8572 \\
\hline
\end{tabular}

Table 20 shows that personal pronouns are a prominent feature in the dataset. Five of the 15 most frequent words in the dataset are personal pronouns and you is the most frequent of them. I analysed the personal pronoun, you, and compared it to other genres. To explore the characteristics of you in self-improvement books, I compared the frequencies of you across genres.

\subsubsection{Comparing frequencies of you across genres}

As demonstrated in Section 6.1, you is the most frequent personal pronoun in the dataset. Focusing more closely on you, I compared the frequency of you across genres: job posting (Fu, 2012, p. 409), conversation, fiction, news, and academic (Biber et al., 1999, p. 334). See Table 21 for the comparison. 
Table 21: Comparison of you frequencies

\begin{tabular}{|l|l|}
\hline Genre & Frequency (per 10,000 word tokens) \\
\hline Conversation & 300 \\
Job posting (Job advertisement) & 193 \\
Self-improvement books & $\underline{178}$ \\
News & 20 \\
Fiction & 10 \\
Academic & 10 \\
\hline
\end{tabular}

The frequency of you in my dataset for the written genre of self-improvement books is very high compared to those of Biber et al.'s (1999) written genres (news, fiction, academic), though it is only about half the frequency of you in conversation. The comparison gives us an indication that even though self-improvement books are written texts, they are much more like conversations in terms of frequency of you than other written genres (news, fiction and academic). This observation is supported by Stine, an editor of self-improvement books. In her book, Writing Successful Self-Help and How-to Books (1997, p. 93), she advises self-improvement authors to write in a "conversational style" and to address readers, as frequently as possible, as you.

Job postings have an even higher frequency of you than self-improvement books and Fu (2012, p. 409) points out that the high occurrence of you gives us an indication that the genre has an "addressee-oriented character."

This pronoun is a resource that self-improvement authors use to engage potential readers, which is what Hyland (2005b) found was also the case in academic prose. Selfimprovement authors use you to construct closeness with readers and to explicitly acknowledge reader's presence in the text, as academic authors do Hyland (2010b).

Reader and non-reader interview data is consistent with this finding. When I asked Joanne (reader) if she thought there was a common message in self-improvement books and asked her to elaborate on that, she said:

One common message is that if you do this [advice], your life will be better. You will be richer, you will be happier, you will be more fulfilled if you read this book and do what I [authors] suggest. (June 6, 2013; Face-to-face interview) 
As an interviewee who regularly reads self-improvement books, Joanne noticed that the common message across this genre is related to how readers could better their lives and become richer, happier and more fulfilled. It seems from Joanne's comment that selfimprovement books have a reader-oriented character.

Ruby (non-reader) was able to identify a self-improvement book by looking at its cover. I asked her why she was able to do that and she said:

I think it directly addresses the reader. It's you. Get the job you deserve. bla bla bla. A self-help tool to create the relationship you need. They always go you, the rest of your life. (April 17, 2013; Face-to-face interview)

Based on Ruby's comments on self-improvement books, authors explicitly address readers by using the personal pronoun, you. Ruby also commented that the advice that self-improvement authors give is related to a reader's job, relationship and life. This implies that self-improvement books have a reader-oriented character.

Author interview data also reveals that self-improvement books have a reader-oriented character. When I asked Tim (author) what he thought was the most crucial element in self-improvement books, he said:

To me, it's making the decision to feed your mind with the right things. A self-help [self-improvement] book would convince you that's what you need to do and then it will give you the right things to put into your mind. Because once you change your thinking, you change your actions. (October 1, 2013; Skype interview)

Tim stated that the most crucial purpose of self-improvement books is to convince readers that they need to take heed of the authors' advice and to provide readers with the "right" worldview. Tim also mentioned that change, in terms of thinking and actions, revolves around readers. This interview data reveals that readers are the focus of the genre.

Both text analysis and interview data show that self-improvement books have a readeroriented character. 


\subsubsection{Grammatical positions of you}

Not only do self-improvement books have a reader-oriented character, they construct potential readers as active participants in the genre. I analysed the grammatical positions of you in a small dataset (26,900 word tokens), on the basis that you in subject position would imply a reader as active participant and you in object position would not. Fu (2012) explains that the subject shoulders the responsibility of a clause. These are some examples:

You (subject): If you know it but do not do it then you have not learnt it.

(Oldham, 2012)

You (object): For instance, if someone has wronged you in some way and...

(Oldham, 2012)

The small dataset consists of a total of four body chapters from two randomly selected self-improvement books (two chapters from each book) from the dataset (20 books, $1,327,500$ word tokens) that I used in Section 6.1. I chose the body chapters because, as I argued in Section 5.3, they are likely to be considered the main sections of selfimprovement books. I selected the four chapters by reading the contents page and then by randomly selecting two chapters from each book. Then, I manually classified instances of you as subject and as object, and coded them using NVivo 10, a qualitative data analysis software package. Table 22 presents the results of my analysis, and compares them with Fu's (2012) findings for job advertisements.

Table 22: Comparison of grammatical positions of you in self-improvement books and job advertisements

\begin{tabular}{|l|c|c|c|c|}
\hline & $\begin{array}{c}\text { Self-improvement books } \\
\text { (per 10,000 word tokens) }\end{array}$ & $\%$ & $\begin{array}{c}\text { Job advertisements } \\
\text { (per 10,000 word tokens) }\end{array}$ & $\%$ \\
\hline You (Subject) & 131 & 82 & 31 & 23 \\
\hline You (Object) & 28 & 18 & 105 & 77 \\
\hline Total & 159 & 100 & 136 & 100 \\
\hline
\end{tabular}

In this dataset, you occurs in the subject position 131 times per 10,000 word tokens (82\%) and in the object position 28 per 10,000 word tokens (18\%). My findings are contrary to Fu's (2012) findings in her dataset of 220 job advertisements (77,100 word tokens). She 
found that you occurred more frequently in the object position (105 per 10,000 word tokens, $77 \%$ ) than the subject position (31 per 10,000 word tokens, $23 \%$ ).

$\mathrm{Fu}$ (2012, p. 410) explains that because "the role of subject is to shoulder the responsibility of the clause, it is natural that the writer uses you to unfold the job responsibilities or job requirements" in job advertisements. Even though you-object is more prominent in Fu's data, she did not explain the significance of the phenomenon. The high occurrence of you-subject in self-improvement books implies that readers are constructed as active participants rather than passive recipients of the authors' advice. These readers are constructed as being capable of helping themselves by taking heed of the author's advice, hence the name of the genre - self-improvement. Being constructed as actors of the advice also implies that readers are responsible for improving their lives.

\subsubsection{Collocates of your}

In sections 6.1.1 and 6.1.2, the frequency of you and the grammatical positions of you show that self-improvement books have a reader-oriented character. Because the genre is reader-oriented, this section examines collocates of your. I propose that it is reasonable to regard your as referring to the addressee who is the potential reader of self-improvement books, and paying attention to the collocates of your allows us to explore what the authors are relating the readers to through the expression of your + noun.

In the same dataset of 20 self-improvement books (1,327,500 word tokens) that I used in 6.1.1, I generated a list of words that collocate with your using Antconc. I set the software to detect the immediate word on the right of your to investigate the items that your associates with. This setting allows me to include in the counting, for example, focus in:

There are two primary ways, then, to change your emotional state: by changing the way you use your physical body, or by changing your focus. (Robbins, 1992)

and exclude focus in:

The best way to show people your faith in them and motivate them is to focus your attention on their strengths. (Maxwell \& Dornan, 2006) 
Table 23 presents the raw data of the collocations of your generated by Antconc and shows the 15 most frequent collocates in the dataset.

Table 23: Collocates of your in 20 self-improvement books (1,327,500 word tokens)

\begin{tabular}{|l|l|l|}
\hline Rank & Word type & Frequency \\
\hline 1 & life & 832 \\
3 & own & 410 \\
4 & mind & 329 \\
5 & body & 179 \\
6 & children & 132 \\
7 & family & 131 \\
8 & talent & 110 \\
9 & brain & 92 \\
10 & thoughts & 84 \\
11 & attention & 82 \\
12 & job & 79 \\
13 & heart & 79 \\
14 & time & 71 \\
15 & personal & 71 \\
\hline
\end{tabular}

Table 2323 shows that your life is the most frequent collocation. Although the raw data in this table is useful, it poses two problems. The first problem is identifying whether a particular word type functions as a head noun. This has to be done manually, and a manual check showed that some occurrences of life, own, personal and best following your in Table 23 are not head nouns. For example, I manually removed the following instance of life because adventures, rather than life, is the head noun.

Just enjoy and embrace all your life adventures. (Moore, 2013)

Table 23 shows the frequencies after instances of the words that do not function as head nouns were removed. 
The second problem is that Antconc is unable to automatically combine the singular and plural forms of the same word (e.g., children and child) as one item. For example, to claim that body (179 word tokens) collocates more frequently with your compared to children (132 word tokens), based on the data in Table 23, is misleading. When children (132 word tokens) and child (70 word tokens) are combined, they total 202 word tokens. This combination shows that child/children (202 word tokens) collocates more frequently with your compared to body (179 word tokens) and bodies if it had occurred in the dataset, but it did not. For a more accurate interpretation of the collocations, I combined the frequencies of the singular and plural forms as one item and organised the combined frequencies in Table 24.

Table 24: Collocations of your after grouping

\begin{tabular}{|l|l|l|}
\hline Rank & Word type & Frequency \\
\hline 1 & life & 806 \\
2 & mind & 329 \\
4 & child/children & 202 \\
5 & body & 179 \\
6 & family & 131 \\
7 & goal/goals & 122 \\
8 & talent/talents & 117 \\
9 & friend/friends & 94 \\
10 & brain & 92 \\
11 & thoughts & 84 \\
12 & attention & 82 \\
13 & heart & 79 \\
14 & job & 79 \\
15 & time & 71 \\
\hline
\end{tabular}

Table 24 shows that life is the most frequent collocate of your in this dataset $(1,327,500$ word tokens) and its frequency is very high compared to other items. This indicates that the main domain of self-improvement books revolves around readers' lives. Interview 
data supports this finding. When I asked Lynn, a reader of the genre, to summarise the message in self-improvement books in a sentence, she stated:

You have the power to change your life. (February 21, 2013; Face-to-face interview)

Brenda, a non-reader, commented that even though she would not consider herself a reader of self-improvement books, she felt that there is a common message across the genre:

I think it's being in control of your own life and your own destiny. (February 21, 2013; Face-to-face interview)

When I asked Joanne (reader) to elaborate what she thought was the common message across self-improvement books, she stated that:

One common message is that if you do this [advice], your life will be better. You will be richer, you will be happier, you will be more fulfilled if you read this book and do what I suggest. (June 6, 2013; Face-to-face interview)

Joanne's comment suggests that some readers associate a better life with being richer and happier, and feeling more fulfilled.

Table 24 also includes a group of words that relate to thinking: mind (329), goals (122), brain (92), thoughts (84), and attention (82). Their frequencies total 709 occurrences, next after life, which suggests that thinking is also a dominant idea in self-improvement books. As discussed in Chapter 4, interview data suggests that the abundance of these nouns reflects the idea that one can improve one's life by changing the way one thinks. For example, I asked Tim, a self-improvement author, what he thought was the core message of self-improvement books and he said:

You are who you are and what you are because of what's going into your mind. You change who you are and you change what you are by changing what goes into your mind. (October 1, 2013; Skype interview)

His comment suggests that self-improvement authors believe that improving one's life starts with the mind. 
Interview data is consistent with text analysis in suggesting that the main area of interest in self-improvement books is related to readers' lives. Interview data also shows that readers and non-readers were able to identify self-improvement books by identifying the domain of the genre. Because the frequency of your + life is very high compared to your + other noun, I devote the next section (6.1.4) to discussing your + life.

\subsubsection{Verbs that connect with your life}

In previous sections, I demonstrated how word frequency lists point us to the readeroriented character of self-improvement books. I also showed, by examining grammatical positions of your, that authors construct potential readers of the genre as active participants rather than passive recipients of advice. The analysis in 6.1.3 shows that life is the most frequent collocate of your. Because readers' lives seem to be central in selfimprovement books, I investigated the verbs that collocate with your life.

I selected four books randomly from the 20-book dataset (see 6.1.1) to form a smaller dataset of 391,613 word tokens. I began the analysis by generating the concordance of your life using Antconc, followed by identifying and coding instances of your life (with life as head noun), using NVivo10, into three grammatical categories: your life as subject, your life as object, and your life in prepositional phrase. In this study, the position of your life in relation to the verb in the clause determines the role (subject/object) of your life. Your life is the subject when it occurs before the verb in a declarative clause. When your life occurs after the verb in the clause, it is the object. In an interrogative clause, I transposed the clause to its declarative mood and identified the grammatical position of your life in the resulting declarative clause. Consider these examples:

Subject:

1) Your life will be profoundly different. (Barrett, 2013)

Object:

2) The way you define your identity defines your life. (Robbins, 1992)

3) How do you approach your life in general? (McGraw, 2012) 
Prepositional phrase:

4) Imagine spending months of your life conquering something so simple that we all take for granted. (Muncy, 2002)

In Example 1, your life is the subject because it occurs before the verb, be. The declarative mood in Example 2 would be I approach my life... and because my life occurs after approach, I consider my life to be the object. In Example 3, your life is the object because it occurs after the verb, defines. Of your life in Example 4 is a prepositional phrase that modifies months.

Because the purpose of this analysis is to investigate a) what role your life is performing, and b) what is being performed on your life at clause level, the discussion focuses on the subject and object positions of your life. I did not analyse your life in prepositional phrases beyond its frequency because the purpose of this analysis is to examine the verbs that connect with your life.

The analysis of the smaller dataset (391,613 word tokens) reveals that your life is more common in the object position (102 occurrences) compared to the subject position (22 occurrences). There are 224 instances of your life in prepositional phrases. I compared the proportion of you (subject) and you (object) in Section 6.1.2 and decided to compare it to the proportion of your life (subject) and your life (object). It is arguable that they are not comparable because they are different datasets. However, because the four books were selected from the dataset I used in Section 6.1.2, it is reasonable to draw insights from such comparison though it is not sufficient for building a strong case.

Table 25: Comparing grammatical positions of your life and you

\begin{tabular}{|l|l|l|}
\hline & Subject position (\%) & $\begin{array}{l}\text { Object position } \\
(\%)\end{array}$ \\
\hline Your life & 18 & 82 \\
\hline You & 82 & 18 \\
\hline
\end{tabular}

The comparison in Table 25 shows that your life is predominantly in the object position while you is predominantly in the subject position. Also, while self-improvement authors construct readers as active participants in the text, they construct readers' lives as something that is being acted upon. 


\subsubsection{Your life in the subject position}

Nine of the 22 occurrences of your life in the subject position are followed by relational processes. Authors use your life + relational process to construct the ideal life that readers should desire and they often present this ideal state of life as something readers will achieve if they are committed to the authors' advice. For example:

5) If you can successfully make the Three Essential Mindset Shifts we cover in this course, you will never need to worry about being stuck in a rut again. Your life will be profoundly different. (Barrett, 2013)

In Example 5, we see that the ideal life that the author claims is one that is profoundly different, and the condition to achieve this is to "successfully" apply the author's advice or method, "Three Essential Mindset Shifts."

Besides relational processes, other verbs that follow your life in this small dataset include changes, ends, turns out, and takes on. Authors use your life in the subject position followed by simple present tense to present their claims related to readers' life as timeless truths (Haghverdi et al., 2013, p. 800). Consider this example:

6) Your life changes the moment you make a new, congruent, and committed decision. (Robbins, 1992)

This example shows that the author constructs the relationship between changes in one's life and the decision one makes as timeless truths and a "cause and effect" relationship.

There are two instances of your life in the subject position in the interrogative form. Authors use this as a resource to prompt readers to reflect. Consider this example.

7) So, is your life balanced? (Pearson, 2012)

Example 7 illustrates how the self-improvement author uses your life in the subject position in the interrogative form to prompt readers to reflect on whether their lives are balanced. This question comes after a few paragraphs that discuss the benefits of having a balanced life. Authors use such questions to explicitly relate the topic that they write about to the readers.

The analysis of your life in the subject position reveals that authors use this grammatical structure to construct the ideal life that readers should desire and their claims as timeless 
truths. In interrogative clauses, authors use your life in the subject position to prompt readers to reflect on the topic they discuss and explicitly relate the topic to the readers.

\subsubsection{Your life in the object position}

Examining your life in the object position and the verbs that govern it is useful to investigate what is acting on your life or what is happening to your life. There are 102 occurrences of your life in the object position in the smaller dataset (391,613 word token). As shown in Table 26, the analysis reveals that change is the most frequent verb (23 occurrences) that governs your life.

Table 26: Verbs that frequently govern your life

\begin{tabular}{|l|l|l|}
\hline Rank & Word type & Frequency \\
\hline 1 & change/changes/changed/are changing & 23 \\
3 & make & 9 \\
4 & live/have lived & 7 \\
5 & improve & 5 \\
6 & transform & 4 \\
7 & shape/shapes/shaped/shaping & 4 \\
8 & take & 2 \\
9 & run & 2 \\
10 & move & 2 \\
11 & limit & 2 \\
\hline
\end{tabular}

In the dataset, change + your life occurs 20 times, while changes + your life, changed + your life and are changing + your life each occur only once. See Example 8 for an example of change + your life from the dataset.

8) Change your values and you change your life. (Robbins, 1992) To develop the idea further, I decided to identify the agents that change your life. When I manually identified the subjects of the clauses, you as the subject occurs 64 times (62\%) and other forms of subject occur 40 times (38\%). Following Beauvais (1989, p. 25) I 
consider you to be the inferred subject in imperative clauses and therefore grouped such instances as having you as the agent. Example 9 shows you as the subject in a declarative form and 10) shows the inferred you in the imperative form:

You:

9) You are the resident expert on how you live your life and no one else has such an abiding interest in your wellbeing. (Oldham, 2012)

10) Master your time and your life. (Robbins, 1992)

Other forms of subject:

11) Remember that a truly committed decision is the force that changes your life. (Robbins, 1992)

Text analysis shows that change is the most frequent verb that governs your life in this dataset. The agent of the change is mainly you (the reader). Other agents include particular strategies, such as a truly committed decision in Example 11.

In an interview I asked Johnson, a self-improvement author, who his imagined readers were when he wrote a self-improvement book. This was his response:

Probably the broadest category is anybody who wants to improve their personal or professional life...The second category is the people who realise that success is dependent upon what they do and not what someone did for them. In other words, they are not waiting for the government to fix it; they are not waiting for the education to fix it or whatever. They realise that if something is going to change, they have to be the instigator of that change. (August 16, 2013; Skype interview)

His comment suggests that he views potential readers as agents for change. This complements text analysis that reveals that the readers, you, are frequently constructed as agents of change in terms of improving their lives.

Author interview data also reveals that change is a common theme in self-improvement books. This data supports the text analysis that reveals that authors construct potential readers as the agents of change and improvement. For example, I asked Tim, a selfimprovement author, what was the core message of self-improvement books and he said: 
You change who you are and you change what you are by changing what goes into your mind. (October 1, 2013; Skype interview)

Interview data with readers and non-readers also reveals a similar theme as text analysis and the author interview data. For example, Joanne, a reader of selfimprovement books, stated that this genre has an individualistic orientation, and when I asked her to elaborate on that point she said:

This [The Choice is Yours] is about self-determination and you will determine your life and it's all about you. You can decide to and you can decide not to. (June 6, 2013; Face-to-face interview)

When I asked Christina, a non-reader, to label the genre of The Choice is Yours (a self-improvement book) and comment on it, she said it is:

A self-help book. It can be about the way you think and the way you can change your thinking. They say you can better your life if you choose to do this and that. (March 25, 2013; Face-to-face interview)

Both text analysis and interview data reveal that the main social purpose of selfimprovement books is to help readers change or improve their lives and that authors construct readers as having the ability or having the responsibility to change their lives.

The analysis of your life in the subject/object position shows that one of the domains of advice in self-improvement books is related to changing, improving and transforming one's life. The analysis also shows self-improvement authors construct readers as the main agents of change. Text analysis and interview data suggest that the central message in self-improvement books is that individuals have the ability to change their lives. To explore the types of advice that authors give with regards to changing individuals' lives, I examined imperative clauses (i.e., the most unambiguous grammatical realisation of giving advice). 


\subsection{Directives in the imperative form}

Still at a register level, this section explores directives, one of the three most unambiguous aspects of engagement based on Hyland's system (see 2.4.2), focusing on those that are realised by imperative clauses. The purpose of this section is to explore the type of advice self-improvement authors give by categorising the verbs in the imperative clauses using Halliday's process types.

While research (Goodwin, 2006; Parry, 2013; Vine, 2009) tends to examine directives and imperative clauses as a means to explore the tenor aspect of a particular context, my study investigates the field aspect of the advice in self-improvement books. This section explores the type of advice that self-improvement authors offer in their books. To collect a sample of directives systematically, the study examined only directives that are in imperative form. I reasoned that the imperative form is the most straightforward form of directive and is unambiguously a directive. After collecting the imperatives, I categorised them according to Halliday's process types. This investigation sheds light on the experiential world of self-improvement books.

The analysis of directives in my study involves a subset of six self-improvement books from 40-book dataset (see Appendix 1). I chose the six books based on popularity by referring to bestseller charts. Because the verbs in the imperative clauses required manual identification, I also take into consideration the lengths of the books. I selected the books that are of reasonable and manageable lengths. The five books are:

1. Break Free of Your Rut (Barrett, 2013) - author interviewed

2. The Five Major Pieces to the Life Puzzle (Rohn, 2002) - popularity

3. The Gifts of Imperfection (Brown, 2010a) - popularity

4. The Shift (Dyer, 2010) - recency

5. 5 Tools to Change Your World (Oldham, 2012) - author interviewed

Then, I manually coded the verbs in the imperative clauses using qualitative data analysis software, NVivo 10. To explore this linguistic feature, I compared the frequency of imperative clauses in my dataset with other genres in Biber et al. (1999, p. 221). 
Table 27Table 27 shows the frequency of imperative clauses in the five books and Table 28 compares the frequency of imperative clauses in self-improvement books with Biber et al.'s genres (conversation, fiction, news, and academic). All decimals in the tables are rounded to the nearest whole number.

Table 27: Frequency of directive in the imperative form

\begin{tabular}{|l|c|c|c|}
\hline Books & $\begin{array}{c}\text { Imperative } \\
\text { (clauses) }\end{array}$ & $\begin{array}{c}\text { Book size } \\
\text { (word tokens) }\end{array}$ & $\begin{array}{c}\text { Imperatives per } \\
\text { 10,000 word tokens }\end{array}$ \\
\hline Break Free & 154 & 17,600 & 88 \\
5 Tools & 114 & 26,000 & 43 \\
The Shift & 46 & 27,900 & 16 \\
The Gifts & 54 & 46,400 & 12 \\
The Five Major & 32 & 33,400 & 10 \\
\hline Total & 400 & 151,300 & 34 (average) \\
\hline
\end{tabular}

Table 28: Frequency of imperative clauses in various genres

\begin{tabular}{|l|l|c|}
\hline Mode & Genre & Frequency (per 10,000 word tokens) \\
\hline Spoken & Conversation (Biber et al., 1999) & 100 \\
\hline Written & Self-improvement books & $\underline{34}$ \\
& Fiction (Biber et al., 1999) & 20 \\
& News (Biber et al., 1999) & 10 \\
& Academic (Biber et al., 1999) & 10 \\
\hline
\end{tabular}

In this dataset of 151,300 word tokens, I identified 400 imperative clauses (34 per 10,000 word tokens). Although the number of imperative clauses in the dataset varies, Table 28 shows that on average there are more imperative clauses in self-improvement books than any of Biber et al.'s three written genres. Because Biber et al.'s findings suggest that imperative clauses are relatively common in conversation (a spoken genre) I propose that this feature in self-improvement books contributes to a more spoken character of this genre compared to Biber et al.'s written genres.

To examine the character of the verbs in these imperative clauses, I categorised them into Halliday's six process types because this system provides a systematic way of examining 
the types of verbs with a functional approach. Biber et al.'s (1999, p. 383) semantic domain is also useful for categorising verbs, but they categorise words such as begin, continue, start, and stop as aspectual verbs, a category that characterises "the stage of progress pf some other event or activity" (p. 364). For example, In Biber et al.'s system, begin in Begin to reflect on your past achievements is categorised as an aspectual verb. In Halliday's system, reflect in this example determines the verb type. Halliday and Matthiessen (2004, p. 498) state that when the verbal group in the imperative form consists of the primary verbal group and the secondary verbal group, the latter realises the process type. They explain that the primary group "carries the mood" (i.e., declarative, interrogative, imperative) of a particular clause (e.g., she began to reflect, was she beginning to reflect, begin to reflect) and the secondary group is "always non-finite" (e.g., to reflect), "this being the realisation of its dependent status" (p. 498). In other words, Halliday and Matthiessen do not treat Biber et al.'s aspectual verbs as processes. In Halliday's system, begin, in the example, is the primary verbal group and to reflect is the secondary verbal group. Following Halliday and Matthiessen (2004), I categorised begin to reflect as a mental process.

Halliday's six process types are:
a) Material processes
b) Mental processes
c) Verbal processes
d) Behavioural processes
e) Existential processes
f) Relational processes

Briefly, material processes are related to physical actions which Eggins (2004, p. 215) describes as concrete and tangible. These processes can be identified by asking: What action did $\mathrm{x}$ do?

1) Now go out and find someone who knows what to do. (Barrett, 2013)

2) Spend time gathering the knowledge that success requires. (Rohn, 2002)

Mental processes are processes which are about thinking and feeling (Eggins, 2004, p. 225): 
3) Each time you are faced with making a decision, consider how it fits with the filters you want to nurture, whether it supports your future, or ties you to the past. (Oldham, 2012, p. 8)

4) Trust me, I've tried. (Brown, 2010a)

Verbal processes are verbal acts such as saying and talking:

5) As a general comment, wherever possible, speak for yourself. (Oldham, 2012, p. 11)

6) If you're not the writing type, make a mental note of changes or mention them to others who might be interested in your progress. (Germer, 2009, p. 241)

Relational processes include a variety of ways of which being can be expressed in English clauses (Eggins, 2004, p. 239). It also includes ways of expressing meanings of ownership and possession (Eggins, 2004, p. 247):

7) However, dip into the book, stimulate your thinking, have a bit of fun, reflect, and consider other viewpoints. (Oldham, 2012, p. viii)

8) Be patient with the practice. (Germer, 2009, p. 142)

Behavioural processes are "processes of physiological and psychological behaviour" (Eggins, 2004, p. 233). In my study, I regard reflexive and non-volitional processes as behavioural processes. As they are reflex and non-volitional, they cannot be voluntarily performed. As they cannot be voluntarily performed, they would be marked to have behavioural processes as directives. I did not find any behavioural processes in the imperative form in this dataset.

Briefly, existential processes "represent experience by positing that 'there was/is something"' (Eggins, 2004, p. 238). In such cases where there in there was/is refer to a location, the process is not an existential process. I propose that existential processes in the imperative form cannot occur, and they do not occur in the dataset. These are some examples in the declarative form:

9) There is a tendency for each of us to give ourselves licence to continue an undisciplined act. (Rohn, 2002, p. 28)

10) There are also occasions when we need to take a tough attitude toward our emotions. (Germer, 2009, p. 240) 
In this analysis, I excluded directives in imperative form which are in quotation marks. As I am interested in looking at directives that are addressed directly to the readers, I view those in quotation marks as not being explicitly directed to the readers. This means that directives in a dialogue are excluded from this analysis. These are some of the examples.

11) The master took one look at the single unused talent and said, "Take the one talent from him and give it to the one who now has ten." (Rohn, 2002, p. 49)

12) I remember saying out loud: "I need to talk to someone RIGHT NOW [emphasis in original]. Be brave, Brené!" (Brown, 2010a)

Table 27 shows that the occurrences of imperative clauses vary from 88 to 10 per 10,000 word tokens. It should be noted that the occurrences of imperative clauses in The Shift (Dyer, 2010), The Gifts of Imperfection (Brown, 2010a), and The Five Major Pieces to Life's Puzzle (Rohn, 2002) are similar to Biber et al.'s (1999, p. 221) finding. The differences in terms of frequencies in this dataset may imply that some authors are more direct than others in the way they present their advice. Author interview data, as discussed in 4.2.4, indicates that some authors prefer to suggest possible ideas rather than to prescribe a solution. For example, Barry expressed his reservation towards the idea of positive thinking, but when I asked him to elaborate on that idea, he said:

But a lot of those books are, you know, they contain helpful ideas and most people read them in an intelligent way. They take the bits that are useful to them and test them out and they don't take the bits that are not helpful to them. (July 30, 2013; Skype interview)

Even though Barry expressed his scepticism towards self-improvement books that have a positive thinking orientation, he appears to be comfortable with those that suggest possible ideas. His comments suggests that self-improvement books can have either a suggestive orientation or prescriptive orientation. The difference in terms of orientation may explain the different frequencies in each book as demonstrated in Table 27. 
Table 29 shows the frequency of process types in each of the six books. The process types are organised from the most frequent (mental processes) to the least frequent (verbal processes) in this subset. Because mental processes are the most frequent process type (see Table 29), the books in the table are arranged based on their percentage of mental processes, from the highest percentage to the lowest. 
Table 29: Distribution of process types in six self-improvement books

\begin{tabular}{|c|c|c|c|c|c|c|c|c|c|c|c|c|c|c|}
\hline \multirow{2}{*}{$\begin{array}{l}\text { Process } \\
\text { types }\end{array}$} & \multicolumn{2}{|l|}{5 tools } & \multicolumn{2}{|l|}{ The Shift } & \multicolumn{2}{|l|}{ Break Free } & \multicolumn{2}{|l|}{ The Path } & \multicolumn{2}{|c|}{ The Five Major } & \multicolumn{2}{|l|}{ The Gift } & \multicolumn{2}{|l|}{ Total } \\
\hline & Frequency & $(\%)$ & Frequency & $(\%)$ & Frequency & $(\%)$ & Frequency & $(\%)$ & Frequency & $(\%)$ & Frequency & $(\%)$ & Frequency & $(\%)$ \\
\hline Mental & 85 & 75 & 34 & 74 & 98 & 64 & 317 & 64 & 20 & 62 & 18 & 33 & 572 & 64 \\
\hline Material & 6 & 5 & 10 & 22 & 46 & 30 & 145 & 29 & 7 & 22 & 33 & 61 & 247 & 27 \\
\hline Relational & 14 & 12 & 2 & 4 & 5 & 3 & 12 & 2 & 5 & 16 & 3 & 6 & 41 & 5 \\
\hline Verbal & 9 & 8 & 0 & 0 & 5 & 3 & 23 & 5 & 0 & 0 & 0 & 0 & 37 & 4 \\
\hline Total & 114 & 100 & 46 & 100 & 154 & 100 & 497 & 100 & 32 & 100 & 54 & 100 & 897 & 100 \\
\hline
\end{tabular}


In Table 29, the process types are arranged from the most frequent to the least frequent, and the books are arranged based on the overall distribution of process types. Table 29 shows that overall mental processes are the most common followed by material processes. Relational and verbal processes are scarce in my dataset. Based on Table 29, it is reasonable to conclude that these books advocate that change and improvement start by changing how we think, except for The Gift of Imperfection (Brown, 2010a). The distribution of process types in this book is different from the other five books. Material processes $(33,61 \%)$ are three times more frequent than mental processes $(18,33 \%)$ in this book.

The marked difference might be due to the difference in terms of the author's view of selfimprovement. This difference may also indicate that the author perceives material actions to be more important than thoughts.

Findings from the reader and non-reader interview data suggest that changing the way readers think is central in improving their lives might be the case. When I asked Jane, a regular reader of self-improvement books, to compare The Choice is Yours (selfimprovement book) and Live Longer, Look Younger (how-to book), she said:

This [The Choice is Yours] is to do with your emotional, mental state. (March 19, 2013; Face-to-face interview)

When I asked Dennis, a non-reader of self-improvement books, what he thought were the reasons people read the genre, he said:

They think they can improve their life, improve their mind, change their attitude to life, become more positive, become a better person, probably achieve goals, they want to make progress in life. This kind of books may help them do that. (February 21, 2013; Face-to-face interview)

Both Jane's and Dennis' comments suggest that the advice in self-improvement books is primarily related to the mind. This may suggest the prominence of thinking related nouns that collocate with your in the genre (see Table 24 in Section 6.1.3).

In an interview, Johnson, a self-improvement author, mentioned that people get better by changing and growing. Following that statement, I asked him where he thought change took place or started, and he responded: 
It's inside. It starts in your mind. I mean, all change starts with the mind. You change the way you start to think. From changing the way you think, you start to change the way you act. Then when you change the way you act, you have a whole different world. (August 16, 2013; Skype interview)

Change in the way people act, according to Johnson, starts with the mind (mental processes) followed by actions (material processes). From the interview data, it seems that mental processes are central in changing one's life and that this might be a possible explanation of the high occurrence of mental processes (64\%) followed by material processes $(27 \%)$ among the directives in the imperative form.

Some of the most common directives in the imperative form in my dataset are consider, remember and imagine. These are examples from my dataset.

13) Consider yourself like a captain on rough seas, always needing to make a course correction. (Germer, 2009, p. 210)

14) Remember that there is always more than one solution to whatever is happening (actually there are many). (Oldham, 2012, p. 57)

15) If we did all that, just imagine what an incredible effect this would have on our future! (Rohn, 2002, p. 39)

Material processes are rather common directives in my dataset. This suggests that authors believe that thinking alone is not sufficient to change one's life. Readers are advised to take actions. These are the examples.

16) Set up things in your environment to remind you of your compelling vision. (Barrett, 2013)

17) Make a list of the work that inspires you. (Brown, 2010a)

Unlike other research that examines directives in the imperative form to explore interpersonal relationships between the speaker/writer and the listener/reader, my study examines the same grammatical feature to explore the field, in a Hallidayan sense, of selfimprovement books. This systematic exploration reveals that most self-improvement books advocate that improving one's life starts in the mind, followed by executing material actions. 


\subsection{Functions of questions}

In the previous section, I analysed directives to explore the type of advice authors give, focusing on the most unambiguous type - imperative form. The present section presents the analysis of questions, another of the most unambiguous aspects of engagement in Hyland's system (see Section 2.4.2.2). The purpose of this section is to explore the functions of questions in self-improvement books.

In the literature, Manning (2012), for example, suggests that questions are sometimes used to challenge opposing ideas. In the same paper, Manning observes that questions can function effectively to put forward a suggestion without intimidating the audience. This study examined how questions function as an engagement resource by analysing the purposes they realise. To analyse the questions, I built a dataset of five books selected from the main dataset of 40 self-improvement books (see Appendix 1). Because the analysis involved identifying the functions of questions manually, I viewed five books to be a manageable number. Books that were particularly long, based on the number of pages, were not considered in the selection process. This is because by having shorter books, I was able to analyse more books. I reasoned that having more books in a dataset contributes to a more representative dataset, compared with a dataset with the same number of word tokens but with a smaller number of books. Hardcopy books were not selected for this analysis because the coding was done electronically using NVivo10. Priority was given to books that were written by authors that I interviewed. The other two criteria for the selection was popularity (based on Amazon's bestseller chart) and recency. The five books are:

1. Break Free of Your Rut (Barrett, 2013) - author interviewed

2. The Five Major Pieces to the Life Puzzle (Rohn, 2002) - popularity

3. The Gift of Imperfection (Brown, 2010a) - popularity

4. The 18 Rules of Happiness (Moore, 2013) - recency

5. 5 Tools to Change Your World (Oldham, 2012) - author interviewed

The questions that I included in this analysis were those that end with a question mark. Hyland (2002c) in his analysis of questions in academic writing excluded questions that are found in quotations. However, I think it is not sensible to exclude questions based solely on formatting. I wanted to look at questions that are directed explicitly from the author to the readership. In my study, quotation marks warrant careful attention because 
some of these questions may or may not be included in the analysis. I am not interested in looking at questions that are part of a conversation within a story in self-improvement books because such questions are not directed by the author to the reader. For example:

1) If a friend or colleague would ask, "Are you excited about that television interview?" I'd shrug it off and say, "I'm not sure. It's not that big of a deal." (Brown, 2010a)

2) Today merely says, "Here I am. What are you going to do with me?" (Rohn, 2002)

There are a few instances where clauses that end with a question mark are disregarded as questions in this analysis. They are declarative clauses with embedded interrogative clauses. These interrogative clauses function as the object of the declarative clauses. Biber et al. (1999) call these interrogative clauses "dependent interrogative clauses" or "indirect questions" (p. 193). The following are examples from my dataset.

3) The big question is what would we do? (Rohn, 2002)

4) The question is what did we do with its opportunity? (Rohn, 2002)

I excluded such instances because Examples 3 and 4 can be written as:

5) The big question is "what would we do?."

6) The question is "what did we do with its opportunity?."

To examine the frequency of questions in self-improvement books, I counted the questions in the five self-improvement books and present them in Table 30.

I compare in Table 31 the frequency of questions in this genre with that of Hyland's (2002c, p. 534) dataset of various academic genres (textbooks, research articles, student reports) and Biber et al.'s (1999) genres (conversation, fiction, news, academic). It should be noted that not all questions that Hyland (2002c) and Biber et al. (1999) regard as questions were included in my counting as explained earlier. This implies that the frequency of questions in my dataset would have been higher if I did not exclude a certain type of questions. Note that the decimals are rounded to the nearest whole number. 
W Table 30: Number of questions per 10,000 words in five self-improvement books

\begin{tabular}{|l|c|c|c|c|c|c|}
\hline & Break Free & The 18 Rules & $\begin{array}{l}\text { The Five } \\
\text { Major }\end{array}$ & The Gift & Tools & Overall \\
\hline Total number of questions & 165 & 82 & 95 & 90 & 47 & 479 \\
\hline Total number of word tokens in books & 17,600 & 13,500 & 33,400 & 46,400 & 26,000 & 136,900 \\
\hline Number of questions per 10,000 word tokens & 94 & 61 & 28 & 19 & 18 & 35 \\
\hline
\end{tabular}


I compare in Table 31 the frequency of questions in this genre with that of Hyland's (2002c, p. 534) dataset of various academic genres (textbooks, research articles, student reports) and Biber et al.'s (1999) genres (conversation, fiction, news, academic). It should be noted that not all questions that Hyland (2002c) and Biber et al. (1999) regard as questions were included in my counting, as explained earlier. This implies that the frequency of questions in my dataset would have been higher if I did not exclude a certain type of questions. Note that the decimals are rounded to the nearest whole number.

Table 31: Number of questions per 10,000 words in various genres

\begin{tabular}{|l|c|c|}
\hline Books/genres & \multicolumn{2}{|c|}{ Number of questions per 10,000 word tokens } \\
\hline Break Free from Your Rut & 94 & 35 (average) \\
The 18 Rules of Happiness & 61 & \\
The Five Major Pieces & 28 & \\
The Gift of Imperfection & 19 & \\
5 Tools to Change Your World & 18 & 7 (average) \\
\hline Textbooks (Hyland (2002c) & 13 & \\
Research articles (Hyland (2002c) & 6 & \\
Student reports (Hyland (2002c) & 4 & \\
\hline Conversation (Biber et al., 1999) & 235 \\
Fiction (Biber et al., 1999) & 70 & \\
News (Biber et al., 1999) & 5 \\
Academic (Biber et al., 1999) & 5 & \\
\hline
\end{tabular}

The number of questions ranges from 94 questions per 10,000 words to 18 questions per 10,000 words. The average number of questions in the five self-improvement books is 35 questions per 10,000 words. This is approximately seven times more frequent than in Hyland's (2002c, p. 534) corpus of academic written text (7 questions per 10,000 words). The comparison shows that the number of questions per 10,000 in my dataset of selfimprovement books is about seven times more than those in research articles, student reports, news, and in the academic register. Although the number of questions varies across the five books, the lowest frequency (18 per 10,000 words) in my dataset is higher 
than the other written genres except fiction. The comparison indicates that questions are a feature of self-improvement books.

To further examine the questions in self-improvement books, I analysed the functions of questions in the genre. The functions that I identified are:
a) Prompting readers
b) Reinforcing a point
c) Soliciting agreement
d) Introducing new ideas/instructions/solutions
e) Explaining an idea
f) Anticipating potential questions
g) Announcing next step
h) Recommending solutions

\section{a) Prompting readers}

In my dataset, questions are sometimes used as prompts to assist readers to respond to a particular task assigned by the author. The readers might be prompted to write a list of items, to reflect on a particular topic, or to make decisions based on the author's advice. Example 7 includes a listing task followed by prompts to assist the completion of the task.

7) On a sheet of paper, attempt to write down your current life situation in paragraph form. What are your thoughts? The feelings you experience most often? Things in your life that bother you? That you love? (Barrett, 2013)

Example 7 includes questions that prompt readers to reflect, and they define the topic for reflection. The directive in Example 8 can be read as an imperative: reflect every day. The directive is followed by a list of prompt questions.

8) We must never allow a day to pass without finding the answers to a list of important questions such as: What is going on in our industry? What new challenges are currently facing our government? Our community? Our neighborhood? What are the new breakthroughs, the new opportunities, the new 
tools and techniques that have recently come to light? Who are the new personalities that are influencing world and local opinion? (Rohn, 2002)

In Example 8, the author attempts to prompt the readers to reflect on a list of areas such as industry, government, community and neighbourhood. Then the author provides specific aspects of the areas that he wants his readers to reflect on, such as new breakthroughs, new opportunities and new influential personalities within the list of areas. Notice that these questions in Examples 7 and 8 define the experiential boundary. Note also that these questions tend to congregate in clusters.

Example 9 shows that questions in self-improvement books can be asked to prompt readers to respond by making decisions based on the advice given by the author. This is the only instance of a question used to prompt readers to make decisions in my dataset.

9) A choice to escape the rut, to change your life, to live in the full realization that our time really is short.

It's now or never. The end.

What will you choose? (Barrett, 2013)

Example 9 is taken from the end of the book. The author ended the book with a question. He was listing the items that one could do and concluded that it is now or never and ended by prompting the readers to make a choice.

\section{b) Reinforcing a point}

Questions can be used rhetorically to reinforce an idea. Such questions usually attempt to deepen readers' understanding of a particular idea or lesson by elaborating it. Consider Examples 10 and 11.

10) Accountability: reward success and punish failure.

It's just human nature. How likely would you be to have perfect attendance at work if your boss never saw you, couldn't tell if you were there or not, and paid you the same no matter what you did? (Barrett, 2013)

Example 10 is from a chapter about "how to use habits to change your life." The author suggests six "traits" (the author's word) for effective behaviour change and habit creation. 
One of the traits is "accountability." "Accountability: reward success and punish failure" is the subheading of the chapter. I interpret the question in Example 10 as reinforcing the necessity of accountability for behaviour change and habit formation. The question also elaborates the idea of accountability.

11) What stops us from recognizing our inherent gifts and talents is a poor attitude about ourselves. Why are we so quick to see the value in others and yet so reluctant to see it in ourselves? Why are we always ready to applaud someone else's accomplishment and yet so shy about recognizing our own? (Rohn, 2002)

In Example 11, the two questions function to reinforce the idea. I have underlined the idea which the questions are attempting to reinforce. Both questions reinforce the idea that a poor attitude stops readers from recognising their talents.

\section{c) Soliciting agreement}

As persuading readers to take on the authors' ideas is central in self-improvement books, questions used to solicit agreement are noticeable in this genre. Such questions are utilised rhetorically to persuade readers to agree with the authors' ideas or recommendations. Consider Examples 12 and 13:

12) Taking the time to read and digest all the information in this book will make the entire process more effective. And that's the point, right? (Barrett, 2013)

The question in Example 12 is an explicit attempt to persuade readers to agree that it is important to take time to "digest" the book.

Example 13 contains a list of questions that persuade readers to agree that committing oneself to take action without procrastination makes a difference.

13) Imagine how different our world would be if we made a commitment right now to put into action all that we currently are, wherever we currently are, and with whatever we currently have. What if we all gave 100 percent to our jobs, our families and our communities? What if, starting right now, we began to read the books, replace errors with disciplines and associate with people who have stimulating ideas? What if, starting right now, we converted our dreams into plans 
and our plans into refined activities that would lead toward the achievement of our goals? What an incredible difference we could make! (Rohn, 2002)

\section{d) Introducing new ideas/instructions/solutions}

Questions can be a useful resource to introduce a new idea or lesson in self-improvement books. These questions prepare readers to anticipate a new idea or lesson. Consider Examples 14 and 15. I have underlined the clauses where new ideas are introduced:

14) What's the solution, then? The solution is gradual change. Changing gradually leaves you with enough willpower to deal with your everyday life while still addressing the deeper problems that are causing you frustration. (Barrett, 2013)

15) Now, we may have to work hard at the daily discipline part of the equation, but reaching out with our talents to embrace success and its rewards is very easy to do. But if it is so easy, why don't more of us do it? Because while it is easy to do the things that success and happiness require, it is also easy not to do them. (Rohn, 2002)

The question in 14) informs readers that the author is about to introduce a lesson about a solution. The question in 15) seeks to prepare readers for the explanation as to why most people do not reach out to achieve success even though it is easy. In my dataset, the sentences following such questions are often in the declarative mood and the main verbs are relational processes. The relational processes are in boldface. Examples 16 and 17 illustrate this observation. I have underlined the introduced ideas and the relational processes are in bold print. Note also that they are usually in declarative form in present tense, presenting the ideas as timeless truths (Haghverdi et al., 2013, p. 800) and authoritative ideas (Cumming, 2013, p. 136).

16) Why is that? Why, when we want to change, is it so difficult to break our old patterns and build new ones? As previously mentioned, humans are creatures of habit. We are constantly building habits and routines into our everyday life. (Barrett, 2013)

17) If this is true, why don't more people take time to ponder the future? The answer is simple: They are so caught up in the current moment that it doesn't seem to matter. (Rohn, 2002) 


\section{e) Explaining an idea}

Questions can be utilised to explain an idea or concept. Brown (1995) states that questions can be used to disambiguate the intended meaning of the author. Consider Examples 18 and 19:

18) Revise your habits. Are they:

- Concrete (an actual thing you can do)

- Actionable (a positive action, not something you shouldn't do)

- Measurable (Can you easily tell if you did it or not? Is it objective?) (Barrett, 2013)

In Example 18, the questions are utilised to explain the concept of measurable. In other words, the author is saying that if something is measurable, you can tell whether a particular task is completed and it can be observed objectively.

19) Another important way to measure our results is to take a closer look at what we have become. What sort of people have we attracted into our lives? Are we wellrespected by our co-workers and neighbors? (Rohn, 2002)

In Example 19, the questions explain the idea of "what we have become." These questions explain to the readers that the discussion is about "what we have become" in terms of relationships with people.

\section{f) Anticipating potential questions}

Questions sometimes appear as taking the reader's voice. They can potentially function to anticipate disagreement from the reader. Such questions indicate that the author is aware of opposing ideas. On the other hand, these questions potentially construct readers as being curious. Such questions are projected as if addressed by the reader to the author. These questions usually have a more casual tone. I propose that such questions create a dialogic effect, and that they explicitly involve readers in the discourse, making it more interactive. Similarly, Thompson (2001) notices similar instances in academic writing. These are some examples from my dataset. The advice clauses are in boldface and the explanations for the anticipated questions from the readers are underlined. 
20) I suggest reading one chapter a week. Why such a slow pace? For one, most chapter have those "Homework Assignments" that help you incorporate that chapter's information into your life. Leaving a week between chapters also gives you time to practice implementing each chapter's lessons. (Barrett, 2013)

21) All of us become careless on occasion, and the wrong people, the wrong opportunity, or the wrong thoughts can find their way into our lives. The key is to learn to recognize the effect and to take the necessary steps to minimize or eliminate the source. Why take such drastic action? Because the negative influence is too powerful and too threatening. (Rohn, 2002)

Examples 20 and 21 show that the authors provide explanations to a curious reader or for potential disagreements immediately after a question is asked. Given the context, we are able to construe that these questions are in the reader's voice. In Example 20, "Why such a slow pace?" refers to the reading process which involves the reader, rather than the author. In Example 21, the implied participants of making drastic actions are the readers rather than the author. In my dataset, all instances of questions that function to anticipate a potential disagreement as if asked by readers are why questions.

Bova (2011, p. 781) notes that children's why questions trigger the beginning of argumentative discussion in family dinner conversations. Scott (2002, pp. 317-318) in her study of linguistic features of disagreement in spoken discourse, discovers that asking questions is a way to disagree. Her examples contain mainly why questions. I propose that asking why questions constructs the readers as wanting further explanation and this gives the authors the privilege to further explain an idea in order to counter a potential disagreement. Scott (2002, p. 317) categorises such why questions as personally oriented and impersonally oriented, and explains that the former challenges the integrity of the interlocutor and the latter challenges the viewpoint of the interlocutor. In my dataset, all questions that function to anticipate disagreement are impersonally oriented, where the author's recommendation is challenged rather than the author himself/herself. In Example 20, the recommendation that readers should read the book at a slow pace is challenged. In Example 21, the recommendation that readers should take drastic changes is challenged. All of these challenge the recommendation of the author rather than the integrity of the author. 
There is only one instance where a question is asked in the author's voice to resolve a potential confusion or counter a potential disagreement. Note the author's use of the first person singular pronoun in Example 22:

22) Why am I still purchasing these things? Didn't I just say that self-help is bad? It's true: self-help as mental pornography is damaging to your vision of what you could be. You should never again buy into anything that promises to "change your life" or "attract what you want."..."Self-help" like that is dangerous, but quality education is critical. (Barrett, 2013)

In the earlier chapters, the author was advising readers that reading self-help books is not beneficial because they make you feel good without suggesting useful practical advice. In the paragraph before Example 22, the author says that he buys self-help materials to build his web design business. In anticipation of potential disagreements, the author explains that the self-help materials that he bought are educational rather than making one "feelgood."

\section{g) Announcing next step}

Questions in self-improvement books are sometimes asked for procedural purposes. They are similar to instructions given by teachers. There are not many of these questions in my dataset. From my current dataset of five books, they are found only in one book. These are some examples:

23) Let's get started, shall we? (Barrett, 2013)

24) Ready for your homework assignment for today? (Barrett, 2013)

Questions such as Examples 23 and 24 carry interactive and engaging elements similar to a teacher-student interaction. They have a sense of invitation. This is evident in the tag question in Example 23, shall we. In Example 24, the question seems to signal to the readers that the author is about to assign them some tasks as homework. They are rhetorical questions where answers to the questions are not expected if they are in the spoken form. 


\section{h) Recommending solutions}

I have identified two questions in my dataset that function to recommend solutions. They are both found in the same book. I have underlined the advice in the examples.

25) But does all of that pent-up anger and resentment really serve anything? Rather than fighting it internally, wouldn't it be much better just to accept what is first and then change what you want, if you still want to? (Moore, 2013)

26) Once you've applied the rules in this book, you'll automatically find yourself being a happier, jollier person - naturally! But why not give it all a little helping hand? (Moore, 2013)

I read the advice in Example 25 as accept a particular situation and in Example 26, to apply the rules.

Table 32 shows the distribution of questions according to their functions. As most questions are multifunctional, following Holmes and Chiles (2010, p. 188), only the primary functions are counted for quantitative analysis. This is an example of a multifunctional question from my dataset.

27) So, what do YOU dream of?

Would you like to explore the ancient castles of England? Would you like to act in a local theater production? (Moore, 2013)

The underlined question in Example 27 is a subheading within a chapter, Have a dream. I see the underlined subheading question as mainly to prompt readers to reflect. Simultaneously, this question can be analysed as reinforcing the idea of the chapter. However, because the question is used as a subheading, its main function is unlikely to be reinforcing an idea. 
Table 32: Distribution of question functions in five self-improvement books

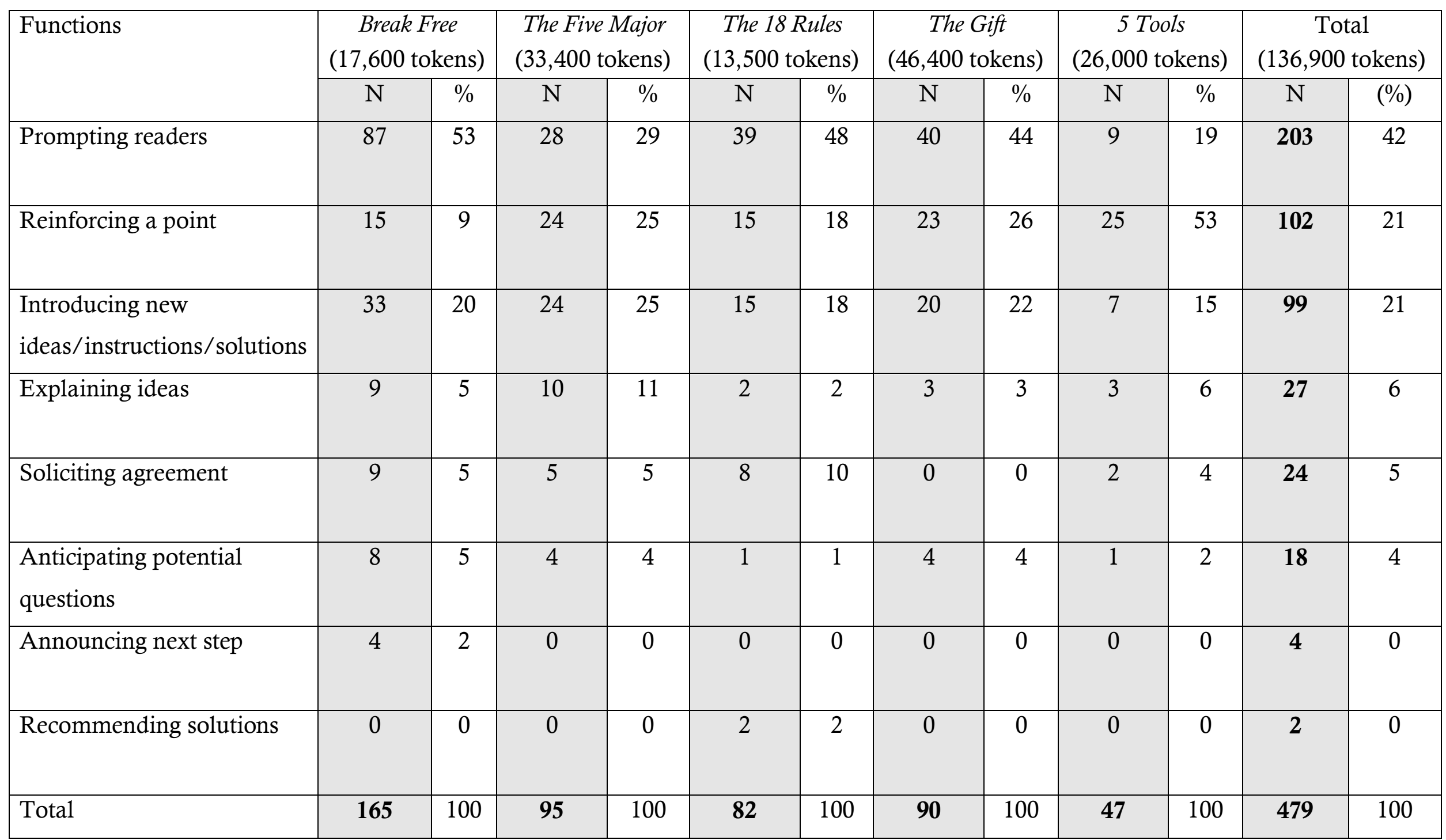


Based on Table 32, the overall most common function of questions in the five selfimprovement books is to prompt readers. Such questions are relatively less common in 5 Tools to Change Your World but this book has a significantly higher frequency of questions that are used to reinforce a point compared to other books in this dataset.

To explore a lexicogrammatical aspect of the questions analysed, I paid attention to pronouns which $\mathrm{Fu}$ (2012, p. 401) refers to as reader-inclusive pronouns (i.e., pronouns that include the readers). They are personal pronouns such as second person pronouns, inclusive-we, inclusive-us and inclusive-our. Considering the percentage in Table 33, the percentage of questions with reader-inclusive pronouns seems to vary across selfimprovement books.

Table 33: Frequency of questions with reader pronoun

\begin{tabular}{|l|c|c|c|}
\hline Books & $\begin{array}{c}\text { Total number } \\
\text { of } \\
\text { questions with } \\
\text { reader- } \\
\text { inclusive } \\
\text { pronoun }\end{array}$ & $\begin{array}{c}\text { Total number } \\
\text { of questions }\end{array}$ & $\begin{array}{r}\text { Percentage of } \\
\text { questions with } \\
\text { reader-inclusive } \\
\text { pronoun }\end{array}$ \\
\hline $\begin{array}{l}\text { The } 18 \text { Rules } \\
(13,500 \text { words) }\end{array}$ & 63 & 82 & $77 \%$ \\
\hline $\begin{array}{l}\text { The Five Major Pieces } \\
(33,400 \text { words) }\end{array}$ & 65 & 95 & $58 \%$ \\
\hline $\begin{array}{l}5 \text { Tools } \\
(26,000 \text { words) }\end{array}$ & 26 & 47 & $48 \%$ \\
\hline $\begin{array}{l}\text { Break Free from Your Rut } \\
(17,600 \text { words) }\end{array}$ & $\mathbf{2 7 5}$ & $\mathbf{4 7 9}$ & $\mathbf{5 7 \%}$ \\
\hline $\begin{array}{l}\text { The Gift of Imperfection } \\
(46,400 \text { words) }\end{array}$ & 41 & 90 & $46 \%$ \\
\hline Total & & & \\
\hline
\end{tabular}

Overall, 57\% (275 out of 479 questions) of the questions in my dataset contains at least one reader-inclusive pronoun. It is reasonable to conclude that authors include reader- 
inclusive pronouns in questions to engage readers in a more explicit way. Examples 28 and 29 are questions with reader-inclusive pronouns:

28) Now, if you do not know where you are going, how can you get there? (Oldham, 2012)

29) How will we know if we've succeeded or failed? (Barrett, 2013)

The analysis shows that questions are a linguistic feature of self-improvement books. Because a question demands a response, this feature may contribute to the engaging character of self-improvement books. This, however, is not to claim that selfimprovement books are more engaging compared to other genres, because it is likely that the linguistic realisations of engagement in various genres are not necessarily the same. The analysis also shows that most authors frequently use questions to prompt readers except the author of 5 Tools to Change Your World, who uses questions predominantly to reinforce his message. The analyses of personal pronouns, imperative clauses, and questions indicate that self-improvement authors use these linguistic resources to engage their readers. The prominence of these features indicates that making the readers' presence visible and addressing them in the text are central to the genre. The next section explores the interpersonal relationship between the author and reader.

\subsection{Modality}

Register analysis has indicated that, at the ideational dimension, self-improvement books are a reader-oriented genre. To explore the interpersonal dimension at a register level, namely the author-reader relationship, following Bruce (2008, p. 25), I analysed how authors use modality to construct this relationship.

Modality has been used to examine interpersonal relationships between the speaker/writer and the listener/reader (Biber, 2006; Charteris-Black, 2014; Cheng \& Cheng, 2014; Patrona, 2005; Strauss \& Feiz, 2014). There are a number of systems that discuss modality, and Biber et al.'s (1999, p. 485) system states that modality can have two types of meaning: intrinsic and extrinsic. Scholars such as Charteris-Black (2014) and Palmer (1990) categorise modality into epistemic and deontic. 
Biber et al. (1999, p. 485) categorise modality into three major categories based on their predominant meanings:

a) Permission/possibility/ability

b) Obligation/necessity

c) Volition (or intention)/prediction

Biber et al. (1999, p. 485) relate intrinsic modality to "actions and events that humans (or other agents) directly control: meanings relating to permission, obligation, or volition (or intention)." They relate extrinsic modality to "the logical status of events or states, usually relating to assessments of likelihood: possibility, necessity, or prediction" (p. 485). Even though they mention ability, it is categorised as neither intrinsic nor extrinsic modality. Biber says, "we thought it [ability] didn't fit in either [intrinsic or extrinsic modality], and so treated it [ability] as a separate category" (personal communication, 18 April, 2014). Biber et al.'s (1999) system of modality is summarised in Table 34. Even though Biber et al. (1999, p. 485) imply that intrinsic and extrinsic modality are parallel to deontic and epistemic modality, I will use intrinsic and extrinsic modality in my writing when I refer to Biber et al.'s work. Where works that I review use the terms deontic and epistemic modality, such terms are retained.

Table 34: Modality according to Biber et al. (1999)

\begin{tabular}{|l|l|l|}
\hline Intrinsic modality (deontic) & Extrinsic modality (epistemic) & \\
\hline Permission & Possibility & Ability \\
\hline Obligation & Necessity & \\
\hline Volition (or intention) & Prediction & \\
\hline
\end{tabular}

To illustrate these categories, consider the following examples from Biber et al. (1999). Because Biber et al. approach modality from a form-driven orientation, the examples are organised according to their form rather than intrinsic vs. extrinsic modality. 
Permission:

1. You can read my book. (p. 492)

In Example 1, the speaker is allowing the listener to read his/her book, hence, expressing can expresses permission. Also, the act of giving permission in this example is one that is directly controlled by a human, the speaker, making can intrinsic modality.

Obligation:

2. This is the sort of case in which judges must exercise the discretionary power described a moment ago. (p. 495)

This example shows that judges are obliged to use "the discretionary power" in certain cases. This implies that judges are obligated to exercise this power because they are to comply with an agent (i.e., the judicial system).

Volition (or intention):

3. I won't be here early enough to show you before school. (p. 496)

Example 3 shows that the speaker, $I$, as the agent, is making a choice. It is an action that is directly controlled by the speaker.

Possibility:

4. The two processes may well be independent. (p. 492)

May in Example 4 illustrates extrinsic modality because the two processes, based on an assessment of likelihood, are independent. In other words, the dependency of the two processes are based on a set of logical reasoning rather than being directly controlled by humans or other active agents.

Necessity:

5. Your feet must feel wet now. (p. 495)

Rather than marking personal obligation, must, in this example, marks logical necessity. Logically, it is necessary that the listener's feet feel wet. 
Prediction:

6. It won't be that difficult to do. (p. 496)

Example 6 illustrates extrinsic modality because the difficulty of the task is mostly likely predicted on the basis of logical reasoning (i.e., one that is not directly controlled by humans).

Ability:

7. I can hear what she is saying to somebody. (p. 492)

Can in this example refers to having auditory ability. This category is neither intrinsic or extrinsic because this ability is not volitional and it is not based on logical reasoning.

Other scholars such as Charteris-Black (2014) and Palmer (1990) categorise modality into epistemic and deontic modality. Palmer (1990, p. 6) states that epistemic modality is related to "judgement about the truth of the proposition." Charteris-Black (2014, p. 113) extends Palmer's definition by including aspects of accuracy and certainty. CharterisBlack relates epistemic modality to a speaker's judgement towards the truth of a proposition and his/her level of commitment. Halliday (1970, p. 349) states that epistemic modality "is the speaker's assessment of probability and predictability. It is external to the content, being a part of the attitude taken up by the speaker: his attitude, in this case, towards his own speech role as 'declarer'." These definitions of epistemic modality are somewhat different to Biber et al.'s (1999, p. 485) definition of extrinsic modality which is not related to the speaker's commitment towards a proposition.

Patrona (2005) pays attention to modality to explore how experts construct their identity in expert talk in Greek television studio discussion programmes. Patrona (2005, p. 234) examines the linguistic resources that these experts use to "encode their commitment to the truth and reliability of information" they present in the programmes. Patrona analyses modality in the following grammatical units: modal verbs (e.g., must), adverbs (e.g., perhaps) and modal constructions (e.g., this is a fact). I focus here only on modal verbs, the most unambiguous form of modality. The system that Patrona uses has three levels of modality: absent, high, and low. Patrona (2005, p. 240) states that the absence of modality and high modality relate to high truth value of a proposition, and low modality 
relates to low truth value of a proposition. The following examples are excerpts from Patrona's data:

8. When there is freedom, there is transparency, there is information. (absence of modality)

9. So the issue is that the Prime Minister must be reinforced in his effort (high modality)

10. The problem may lie in many stages of the reproductive stages. (low modality)

Example 8 illustrates how the absence of modality constructs transparency and information as unquestionably criteria for freedom. Example 9 demonstrates how high modality constructs the speaker as an expert, expressing the necessity of the Prime Minister to reinforce his effort. In Example 10, low modality constructs "the problem" as possibly occurring in various reproductive stages.

Patrona's (2005, p. 253) analysis shows that debates are characterised by their use of high modality as opposed to low modality in informational discussions. Table 35 compares high and low modality elements in the two genres.

Table 35: Number of high and low modality elements per 180 turns

\begin{tabular}{|l|c|c|}
\hline & High modality elements & Low modality elements \\
\hline Debates & 90 & 17 \\
\hline Informational discussions & 28 & 130 \\
\hline
\end{tabular}

Patrona (2005, p. 254) explains that the two genres have different "communicative function," and she states that the main purpose of a debate is to persuade or to argue, while the main purpose of informational discussion is to inform. Patrona (2005, p. 249) reasons that experts, in debates, use high modality and unmitigated statements to stress the reliability of their propositions. According to Patrona (2005, p. 256), low modality is common in informational discussions because experts tend to avoid confrontation and construct their statements as personal opinion. Patrona's (2005) paper as a whole concludes that depending on the communicative goals (e.g., to argue, to discuss, to persuade), experts use different choices of modality to construct their expert identity.

A review of literature shows that modality has been used to explore interpersonal meaning. Also, literature has categorised modality as high and low. Because modality is not the main part of my study, a smaller dataset was built based on six first body chapters 
from six different self-improvement books from the 40-book dataset. The books were chosen based on their popularity based on Amazon's bestseller chart, recency, and availability of author for interview. The six books are:

1. Break Free of Your Rut (Barrett, 2013) - author interviewed

2. Life Code (McGraw, 2012) - popularity

3. The Eight Facets of a Fulfilling Life (Pearson, 2012) - recency

4. The Power of Negative Thinking (Knight, 2013) - recency

5. The 18 Rules of Happiness (Moore, 2013) - recency

6. 5 Tools to Change Your World (Oldham, 2012) - author interviewed

I have selected books that were published recently (2012-2013). The first body chapters from six books were selected to make sure the analysis was manageable because the analysis was done manually. To systematically collect a sample of linguistic elements that signal modality and focusing on the most unambiguous form of such elements, the analysis identified all the modal verbs (i.e., can, could, may, might, must, shall, should, will, would) in the selected chapters and categorised them according to Biber et al.'s (1999) modality system: extrinsic, intrinsic, and ability. Examples 1, 2, and 3 are examples of extrinsic, intrinsic, and ability from my dataset respectively:

1) Understand your actions, for they will become habits. (Pearson, 2012) - extrinsic

2) I'11 tell you right now, one goal of this book is for you to stop being victimized and start being "victim-wise!" (McGraw, 2012) - intrinsic

3) I can't change what happened in the past, and neither can you. (McGraw, 2012) ability

Example 1 demonstrates the author's prediction, based on logical reasoning, of the outcomes of actions. In Example 2, will, illustrates the author's intention to tell (i.e., a volitional action) the goal of his book to his reader. Can't and can in Example 3 refer to the inability to change the past.

Biber et al. (1999, p. 492) acknowledge that some modal verbs can be ambiguous in terms of modality type. In such cases, I categorise the modal verbs according to their predominant function. In the coding process, I excluded modal verbs in statements that are not explicitly directed to the readers. For example: 
4) A senior manager told me that he had always thought that he could delay making decisions. He would say to others or to himself, "I will make a decision next month," until one day, in a blinding flash of the intensely obvious, he realised that he had just made a decision. (Oldham, 2012)

To explore the distribution of modality in the dataset, I organise the frequency of modality types in the six chapters collectively in Table 36. The distribution shows that there are more instances of extrinsic modality than intrinsic modality and ability.

Table 36: Collective frequency of modal verbs

\begin{tabular}{|l|l|c|c|}
\hline Modality & Frequency & $\mathbf{( \% )}$ \\
\hline Extrinsic & Possibility & 153 & 47 \\
\cline { 2 - 4 } & Prediction & 80 & 24 \\
\cline { 2 - 4 } & Necessity & 30 & 9 \\
\cline { 2 - 4 } & Total & $\mathbf{2 6 3}$ & $\mathbf{8 0}$ \\
\hline Intrinsic & Volition (or intention) & 38 & 12 \\
\cline { 2 - 4 } & Permission & 1 & 0 \\
\cline { 2 - 4 } & Obligation & 0 & 0 \\
\cline { 2 - 4 } & Total & $\mathbf{4 0}$ & $\mathbf{1 2}$ \\
\hline Ability & Ability & $\mathbf{2 6}$ & 8 \\
\cline { 2 - 4 } & Total & $\mathbf{3 2 9}$ & $\mathbf{1 0 0}$ \\
\hline Total & & &
\end{tabular}

Almost half of the modal verbs I identified in this dataset are extrinsic modality possibility. To explore whether this distribution pattern is similar across the six chapters, Table 37 compares the frequency of each modality type across the six chapters. 
Table 37: Frequency of modal verbs in individual chapters

\begin{tabular}{|c|c|c|c|c|c|c|c|c|c|c|c|c|c|c|c|}
\hline \multicolumn{2}{|l|}{ Modality } & \multicolumn{2}{|c|}{ Life Code } & \multicolumn{2}{|c|}{ Eight Facets } & \multicolumn{2}{|c|}{5 Tools } & \multicolumn{2}{|c|}{ The Power } & \multicolumn{2}{|c|}{ Break Free } & \multicolumn{2}{|c|}{18 Rules } & \multicolumn{2}{|c|}{ Total } \\
\hline \multirow[t]{4}{*}{ Extrinsic } & Possibility & 56 & 47 & 33 & 48 & 32 & 50 & 21 & 40 & 7 & 50 & 4 & 40 & 153 & 47 \\
\hline & Prediction & 34 & 29 & 19 & 28 & 10 & 16 & 12 & 23 & 1 & 7 & 4 & 40 & 80 & 24 \\
\hline & Necessity & 14 & 12 & 1 & 1 & 4 & 6 & 10 & 19 & 1 & 7 & 0 & 0 & 30 & 9 \\
\hline & Total & 104 & 87 & 53 & 77 & 46 & 72 & 43 & 82 & 9 & 64 & 8 & 80 & 263 & 80 \\
\hline \multirow[t]{4}{*}{ Intrinsic } & Volition & 8 & 7 & 8 & 12 & 13 & 20 & 5 & 10 & 3 & 21 & 1 & 10 & 38 & 12 \\
\hline & Permission & 1 & 1 & 0 & 0 & 0 & 0 & 0 & 0 & 0 & 0 & 0 & 0 & 1 & 0 \\
\hline & Obligation & 0 & 0 & 0 & 0 & 0 & 0 & 0 & 0 & 0 & 0 & 0 & 0 & 0 & 0 \\
\hline & Total & 9 & 8 & 8 & 12 & 13 & 20 & 5 & 10 & 3 & 21 & 1 & 10 & 39 & 12 \\
\hline \multirow[t]{2}{*}{ Ability } & Ability & 6 & 5 & 8 & 12 & 5 & 8 & 4 & 8 & 2 & 14 & 1 & 10 & 26 & 8 \\
\hline & Total & 6 & 5 & 8 & 12 & 5 & 8 & 4 & 8 & 2 & 14 & 1 & 10 & 26 & 8 \\
\hline \multicolumn{2}{|l|}{ Total } & 119 & 100 & 69 & 100 & 64 & 100 & 52 & 100 & 14 & 100 & 10 & 100 & 328 & 100 \\
\hline
\end{tabular}


Table 37 shows that extrinsic modality (80\%) in the six selected chapters is considerably more frequent compared intrinsic modality (12\%) and ability (8\%). The table also shows that the distribution of modality types across the six chapters is similar to the collective distribution. In other words, the ratios of modality types in individual books are reasonably consistent across the six books.

Expressing possibility is the most common modality in self-improvement books. Authors regularly present their message as possibilities and options to avoid being demanding and "talking down" to their readers. Presenting authors' advice as possibilities and options is less face-threatening and less confrontational, constructing a more equal power authorreader relationship, than as objective authoritative instructions. For example:

5) I say "player" because so much of life is a competition. You may wish it wasn't, but it is. (McGraw, 2012)

In Example 5, the author avoids being authoritative by using may to construct some readers as possibly wishing life is not similar to a competition.

Collectively, prediction is the second most common modality in self-improvement books. Patrona (2005, p. 246) states that predictions are common in political discourse in Greek television studio discussion programmes, and explains that politicians often use prediction "as a means for commenting on future developments." Similar to Patrona's finding, I propose that self-improvement authors construct themselves as experts by using prediction to comment on the positive outcomes in readers' lives as a result of applying the authors' advice and the consequences of not applying the authors' advice.

For example:

6) Prepare your team to prepare and execute properly, to curtail its mistakes, and the most painful aftermaths of losing will be minimized — but never avoided. (Knight, 2013)

Example 6 shows how the author predicts the outcome of preparing a team well results in a less "painful aftermaths." The author uses his experience as a coach to illustrate how his readers can reduce "painful aftermaths" if they are well prepared. Such predictions construct the authors as having the expertise to predict the outcomes. 
Permissions occur infrequently in the dataset and obligations are not found. Interview data suggests that authors rarely use permissions and do not use obligation to avoid dictating what readers are obliged to do. For example, when I asked Barry whether authors achieve "guruship" before or after they write a book, he said:

I have a problem with authority... For me, I'm not a guru. I'm not a psychologist. I'm not like a success coach or anything. I'm just a person who is writing about stuff that is in my life and I'm systematising it and saying this works for me, it might work for you and if it does, that's awesome. For me it's not, I'm not trying to set myself up as a position of authority. I'm just trying to share information with people. (July 30, 2013; Skype interview)

Barry's comment suggests that some authors avoid appearing to be in a position of authority, and this could be the explanation to why permission is rare and obligations do not occur in self-improvement books.

This is the only instance of permission in this dataset:

7) If you think I'm just a cynic; if you're not interested in getting real and acknowledging that there are some truly bad people out there, committing to protecting yourself and your loved ones, and preserving what you earned and value and seek in life; if you want to be average; if you want to sit in the middle of the bell curve and "receive" rather than "create" what comes your way and hope that nobody takes it away from you - then you can stop reading right now, because this book is not for you. (McGraw, 2012)

Example 7 is a conditional statement. In short, the author is allowing or giving permission to the readers to stop reading the book if they are not keen on improving their lives. It is similar to school teachers who dismiss their students who are not interested in the lessons they teach.

The analysis of modality shows that rather than prescribing advice to the readers, selfimprovement authors use possibility to construct their advice as options and possibilities. This constructs the relationship between authors and readers as a more equal power relationship. The absence of obligation modality and almost no instance of permission modality also indicate that authors do not demand that readers perform a particular action. The analysis also shows that authors use prediction to comment on the outcome of 
applying or not applying their advice. The use of prediction constructs the authors as experts.

My analysis also shows how authors use modal verbs to manage their relationship with their potential readers. It seems on one hand authors want to present themselves as an authoritative source of advice, and on the other hand, they seem to avoid being perceived as trying to impose their ideas on the readers. Although authors construct this interpersonal relationship in the text, it is likely that the book title is the first part of the text that readers encounter. The next section explores the lexicogrammatical features of self-improvement book titles.

\subsection{Lexicogrammar of self-improvement book titles}

In analysing self-improvement books as a genre, I propose that examining the titles of the genre is a crucial part of describing the characteristics of the genre. As mentioned earlier, analysing the titles is important because they are probably one of the first things that potential readers encounter, and from which they decide whether to read on. The following paragraphs review relevant terms and studies in the literature for this exploration.

While APA $6^{\text {th }}$ edition (2010, p. 185) makes a distinction between titles and subtitles, a survey of the literature shows that some researchers (Haggan, 2004; Hartley, 2007; Soler, 2007) do not make a distinction between the two and consider subtitles as part of the title. As titles and subtitles are commonly separated by a colon (x:y), Hartley (2007, p. 558), for example, refers to $\mathrm{x}: \mathrm{y}$ as a colonic sentence rather than a title: subtitle pattern. Following APA $6^{\text {th }}$ edition, in $\mathrm{x}: \mathrm{y}, \mathrm{I}$ analyse $\mathrm{x}$ as a head title and $\mathrm{y}$ as a subtitle. In my study, I call x:y a title and in cases where there is no subtitle, a title consists of only the head title. In other words, a title could be $x$ :y or $x$. In cases where there are a title and a subtitle, I describe them as complex titles. For example, in the title, Focus: The Hidden Driver of Excellence, the head title is Focus, the subtitle is The Hidden Driver of Excellence, and they are separated by a colon. 
Research on academic article titles has analysed the length of titles in terms of the number of words (Haggan, 2004; Soler, 2007), grammatical structure (Haggan, 2004; Hartley, 2007; Soler, 2007), perception towards conference based on forms of titles (Hartley, 2007), and structural differences between disciplines (Haggan, 2004; Soler, 2007). Haggan (2004) and Soler (2007) categorise grammatical structures of titles as fullsentence, compound, and noun phrase. However, Haggan does not explain what she means by full-sentence, though the examples she provides indicate that full-sentence refers to an independent finite-clause. Haggan (2004, p. 301) describes a compound structure as having "a colon, a full stop or a dash." These are examples of compound structures from Haggan (2004):

1. Genome sequencing and informatics: New tools for biochemical discoveries ( $\mathrm{p}$. 302)

2. To Witness Spectacles of Pain: The Hypermorality of George Bataille (p. 304)

3. Noun incorporation. New evidence from Athapaskan (p. 306)

Although Haggan (2004) identifies compound structure with a dash, she does not provide any examples. In my study, I refer to Haggan's examples as complex titles (head title + subtitle).

Haggan (2004) compares research article titles from three disciplines: science, linguistics and literature. She notices a significant difference among the three disciplines in terms of grammatical structure and communicative purpose. In her corpus, full-sentence titles are rare across the three disciplines. Haggan (2004) observes that the science titles, on one end of the continuum, aim to present discovered facts, and the literature titles, on the other end, aim to appeal to the reader's aesthetic senses. Haggan (2004, p. 301) notices that linguistics titles fall between the two ends of the continuum and she reasons that linguists consider themselves as scientists but they also have a "fascination for language." Haggan's (2004, p. 301) analysis shows that more than $90 \%$ of the titles in the three disciplines are noun phrases.

In the same study, Haggan's (2004) corpus shows that $60.8 \%$ of the literature titles $(\mathrm{N}=237), 21.5 \%$ of the titles in science $(\mathrm{N}=307)$, and $4 \%$ of the titles in linguistics $(\mathrm{N}=207)$ have subtitles. Her analysis shows that it is most common to have subtitles in literature. Hagan notices that the science head titles are usually areas that potential readers are likely to be familiar with (e.g., sub-area of a field) and the subtitles are usually 
the focus of the researcher's work which the researcher constructs as breaking news. In literature, Haggan notices that a significant number of head titles are quotations from the studied work. In the field of linguistics, Haggan's analysis shows that head titles are commonly known sub-area and the subtitles are commonly the research contribution. This is an example of linguistics title which Haggan provides:

4. Noun incorporation. New evidence from Athapaskan. (p. 306)

Haggan notices that about two thirds of the science and linguistics titles with only head titles are complex noun phrases. In her study, the most common post-modifying prepositional phrase in science titles is of-phrase, and in linguistics, of-phrase and inphrase are equally frequent.

Drawing on the literature, my thesis examines the lengths of titles, head title and subtitles of self-improvement books, exploring the lexicogrammar of the head titles, and comparing the findings with historical biographies. In my study, a title refers to a unit which consists of a head title and subtitle (if there is a subtitle). The example below shows a title with the head title in bold face and the subtitle underlined.

Focus: The Hidden Driver of Excellence (Goleman, 2013)

\subsubsection{Lengths of titles, head titles and subtitles}

This section describes the length, in terms of number of words, of book title, head title and subtitle of self-improvement books. In my study, the number of words refers to the number of orthographic words. Following Biber et al. (1999, p. 54), an orthographic word refers to word forms that are separated by spaces. I generated the mean, median, mode and standard deviation using an online statistics calculator (http://easycalculation.com/statistics/statistics.php).

The dataset that I use in this section consists of the titles of 110 self-improvement books. Based on the criteria of self-improvement books that I developed (see Section 3.3), I selected 110 books from the online bookstore, www.amazon.com, under the self-help section. For this dataset, I did not select the books from bestseller charts because the charts do not provide a large enough number of books. 
Table 38 shows the frequencies of titles, head titles, and subtitles of self-improvement books and I will describe the length of head titles based on the statistics in Table 39.

Table 38: Frequencies of occurrence of lengths of titles, head titles and subtitles of selfimprovement books

\begin{tabular}{|l|c|c|c|}
\hline \multirow{2}{*}{$\begin{array}{l}\text { (worgth } \\
\text { (words }\end{array}$} & \multicolumn{3}{|c|}{ Frequencies } \\
\hline 1 & Title & Head title & Subtitle \\
\hline 2 & 0 & 15 & 0 \\
\hline 3 & 0 & 22 & 0 \\
\hline 4 & 2 & 28 & 0 \\
\hline 5 & 0 & 14 & 9 \\
\hline 6 & 2 & 9 & 11 \\
\hline 7 & 7 & 11 & 16 \\
\hline 8 & 7 & 7 & 14 \\
\hline 9 & 6 & 3 & 12 \\
\hline 10 & 11 & 0 & 10 \\
\hline 11 & 14 & 0 & 8 \\
\hline 12 & 6 & 0 & 6 \\
\hline 13 & 16 & 0 & 5 \\
\hline 14 & 9 & 1 & 3 \\
\hline 15 & 9 & 0 & 2 \\
\hline 16 & 6 & 0 & 2 \\
\hline 17 & 4 & 0 & 3 \\
\hline 18 & 5 & 0 & 1 \\
\hline 19 & 1 & 0 & 0 \\
\hline 20 & 4 & 0 & 0 \\
\hline Total & 110 & 110 & $\mathbf{1 0 2}$ \\
\hline
\end{tabular}

Table 38, for example, shows that none of the books have a title of one word and none have a subtitle of one word, but 15 books have a head title of one word. This means that those 15 books all have a subtitle as well as a head title. 
Table 39: Length of titles (self-improvement books)

\begin{tabular}{|c|c|c|c|c|c|c|}
\hline & Total & $\begin{array}{c}\text { Range } \\
\text { (words) }\end{array}$ & Mean & Median & Mode & $\begin{array}{c}\text { Standard } \\
\text { deviation }\end{array}$ \\
\hline Title & 110 & $3-20$ & 11.35 & 11.5 & 12 & 3.706 \\
\hline
\end{tabular}

In the dataset of 110 self-improvement books, the most common title length is 12 words (see Table 39). In the same dataset, the length of titles ranges from three words to 20 words. Examples 1 and 2 are examples of the shortest (three word tokens) and longest (20 word tokens) titles respectively.

1) First things first (Cover et al., 1994)

2) From panic to power: Techniques to calm your anxieties, conquer your fear, and put you in control of your life (Bassett, 1995)

The title in Example 1 has a head title only, while the title in Example 2 has a head title and a subtitle.

The similarity of the mean (11.35), median (11.5) and mode (12) shows that there is a strong central tendency in the dataset. This implies that the most common title length tends to be the average title length in the dataset. Statistical analysis shows that the average length variation from the mean is not very high $(\mathrm{SD}=3.706)$.

To analyse the length of head titles, I removed the subtitles from the titles to build a dataset of 110 head titles and generated the mean, median, mode and standard deviation using the same online calculator.

Table 40: Length of head titles (self-improvement books)

\begin{tabular}{|c|c|c|c|c|c|c|}
\hline & Total & Range (words) & Mean & Median & Mode & $\begin{array}{c}\text { Standard } \\
\text { deviation }\end{array}$ \\
\hline Head title & 110 & $1-13$ & 3.6 & 3 & 3 & 2.094 \\
\hline
\end{tabular}

The analysis shows that the most common length of self-improvement book head titles is three words. The analysis also shows that the average length of these head titles is 3.6 words and they are predominantly at the lower end of the range (Median $=3$ ). In other words, a 13-word long head title is not typical and it occurs only once in my dataset. 
Similar to the titles, the similarity of the mean, median and mode of the head title length shows that there is a strong central tendency.

For the analysis of the length of subtitles of self-improvement books, I built a dataset of subtitles by removing the head titles from the existing dataset of 110 self-improvement book titles. This results in a dataset of 102 subtitles because eight self-improvement books in my dataset do not have subtitles. Table 41 presents the analysis of subtitle length of self-improvement book.

Table 41: Length of subtitles of self-improvement books

\begin{tabular}{|c|c|c|c|c|c|c|}
\hline & Total & Range (words) & Mean & Median & Mode & $\begin{array}{c}\text { Standard } \\
\text { deviation }\end{array}$ \\
\hline Subtitle & 102 & $4-17$ & 8.23 & 8 & 6 & 3.162 \\
\hline
\end{tabular}

Table 41 shows that the most common length of self-improvement book subtitles is six words. This indicates that the subtitles $($ Mode $=6)$ of self-improvement books are generally double the length of the head titles (Mode $=3$ ). Note that the distribution of length of subtitles of self-improvement books is slightly different from those of the titles and the head titles because it does not have such a strong central tendency.

To make a comparison with another non-fiction genre, I chose the comparison genre on the basis of popularity with readers. To establish popularity, I asked Wellington City Library what the most popular non-fiction was. The librarian replied that there are two ways of looking at popularity. One is the biggest section, which means the library has responded to public demand by buying a lot of items to meet the demand. There may not be many long reserve waiting lists, because the library buys either extra copies or additional similar titles to meet this more sustained demand. The second approach to popularity is to look at individual topics or items and assess average turnover rates per copy, as an expression of demand. According to the librarian, the second approach is rarely used to calculate overall popularity but is used to assess viability of individual items. Taking the first approach, the most popular genre is historical biography.

I built a comparative dataset of 110 historical biography titles by selecting the first 110 titles in subcategory, "historical," under the larger category, "biographies and memoirs" in the online bookstore, www.amazon.com. In analysing historical biographies, I applied 
the same procedure as for self-improvement books, and the analysis shows that 23 books (20.9\%) from the historical biography dataset do not have subtitles.

Table 42: Frequencies of occurrence of lengths of titles, head titles and subtitles of historical biographies

\begin{tabular}{|l|c|c|c|}
\hline \multirow{2}{*}{$\begin{array}{l}\text { Length } \\
\text { (words) }\end{array}$} & \multicolumn{3}{|c|}{ Frequencies } \\
\cline { 2 - 4 } & Title & Head title & Subtitle \\
\hline 2 & 4 & 24 & 1 \\
\hline 3 & 6 & 38 & 12 \\
\hline 4 & 6 & 19 & 13 \\
\hline 5 & 12 & 14 & 16 \\
\hline 6 & 19 & 6 & 13 \\
\hline 7 & 11 & 4 & 10 \\
\hline 8 & 14 & 5 & 6 \\
\hline 9 & 6 & 0 & 9 \\
\hline 10 & 7 & 0 & 3 \\
\hline 11 & 9 & 0 & 2 \\
\hline 12 & 6 & 0 & 1 \\
\hline 13 & 5 & 0 & 1 \\
\hline 14 & 1 & 0 & 0 \\
\hline 15 & 2 & 0 & 0 \\
\hline 16 & 1 & 0 & 0 \\
\hline Total & 110 & $\mathbf{1 1 0}$ & $\mathbf{8 7}$ \\
\hline
\end{tabular}

Table 43: Length of titles of historical biographies

\begin{tabular}{|c|c|c|c|c|c|c|}
\hline & Total & $\begin{array}{c}\text { Range } \\
\text { (words) }\end{array}$ & Mean & Median & Mode & $\begin{array}{c}\text { Standard } \\
\text { deviation }\end{array}$ \\
\hline Title & 110 & $1-16$ & 6.72 & 6 & 5 & 3.307 \\
\hline
\end{tabular}


Examples 3) and 4) are examples of the shortest and longest titles respectively.

3) Churchill (Johnson, 2009)

4) Roger Williams and the creation of the American soul: Church, state, and the birth of liberty (Barry, 2012)

Table 44: Length of head titles of historical biographies

\begin{tabular}{|c|c|c|c|c|c|c|}
\hline & Total & $\begin{array}{c}\text { Range } \\
\text { (words) }\end{array}$ & Mean & Median & Mode & $\begin{array}{c}\text { Standard } \\
\text { deviation }\end{array}$ \\
\hline Head title & 110 & $1-7$ & 2.75 & 2 & 2 & 1.605 \\
\hline
\end{tabular}

Table 45: Length of subtitles of historical biographies

\begin{tabular}{|c|c|c|c|c|c|c|}
\hline & Total & $\begin{array}{c}\text { Range } \\
\text { (words) }\end{array}$ & Mean & Median & Mode & $\begin{array}{c}\text { Standard } \\
\text { deviation }\end{array}$ \\
\hline Subtitle & 87 & $1-12$ & 5.02 & 5 & 4 & 2.387 \\
\hline
\end{tabular}

The historical biographies analysis shows that the most common length of the titles is five words. The most common length of the head titles is two words and the most common length of subtitles is four words. In historical biographies, the most common length of subtitles (mode $=4$ ) is twice the most common length of the head title (mode $=2$ ). The analysis also reveals that the head title lengths are the most consistent $(\mathrm{SD}=1.605)$ compared to the lengths of the titles and subtitles, but this is largely because they are shorter than those of self-improvement books.

Comparatively, self-improvement books have longer titles, head titles and subtitles than historical biographies and the range of self-improvement book titles, head titles and subtitles is wider.

Table 46 on next page shows that the most common title length in self-improvement books is more than twice the most common title length in historical biographies. However, the difference between the most common head title lengths of selfimprovement books and historical biographies is small. 
Table 46: Comparing self-improvement books and historical biographies

\begin{tabular}{|l|l|c|c|c|c|c|c|}
\hline \multirow{2}{*}{ Title } & Genre & Total & $\begin{array}{c}\text { Range } \\
\text { (words) }\end{array}$ & Mean & Median & Mode & $\begin{array}{c}\text { Standard } \\
\text { deviation }\end{array}$ \\
\cline { 2 - 8 } & $\begin{array}{l}\text { Self-improvement } \\
\text { Historical } \\
\text { biographies }\end{array}$ & 110 & $3-20$ & 11.35 & 11.5 & 12 & 3.706 \\
\hline Head title & Self-improvement & 110 & $3-13$ & 3.6 & 3 & 3 & 2.094 \\
\cline { 2 - 8 } & $\begin{array}{l}\text { Historical } \\
\text { biographies }\end{array}$ & 110 & $1-7$ & 2.75 & 2 & 2 & 1.605 \\
\hline Subtitle & Self-improvement & 102 & $4-17$ & 8.23 & 8 & 6 & 3.162 \\
\cline { 2 - 8 } & $\begin{array}{l}\text { Historical } \\
\text { biographies }\end{array}$ & 87 & $1-12$ & 5.02 & 5 & 4 & 2.387 \\
\hline
\end{tabular}

The comparative study also shows that it is more likely for self-improvement books $(102 / 110,92.7 \%)$ to have subtitles compared to historical biographies $(87 / 110,79.1 \%)$. The analysis also shows that self-improvement books $($ Mean $=8.23)$ tend to have longer subtitles compared to historical biographies (Mean $=5.02)$.

Stine (1997, p. 20), an editor of self-improvement books, advises self-improvement authors that titles are a very important element of the genre because they are likely the first thing readers notice and serve as advertisements for the books. Stine (1997, p. 25) recommends that authors keep the head title as "short and readable" as possible, preferably below six words. She explains that besides having "more punch," short head titles "are also easier to remember" (p. 25). Stine (1997, pp. 27-28) suggests that an effective subtitle of a self-improvement book should inform readers the "key benefits or a unique approach" of the book because it "will be competing in the same marketplace as other 'feel-good' products." Stine's recommendation to self-improvement authors gives us an indication of why the length of head title (Mean = 3.6) in self-improvement books are relatively short compared to the subtitle (Mean $=8.23$ ). Drawing from Stine's reasoning, I propose that the subtitle lengths of self-improvement books are generally longer because authors attempt to provide potential readers with as much information as possible in the subtitles as a way of promoting their books among other competing books. 
To explore further the characteristics of self-improvement book titles, I compared the complex titles (titles with both head titles and subtitles) of self-improvement books with Haggan's (2004) corpus that consists of journal article titles (science, literature and linguistics). The mean length of complex titles in my dataset is 11.7 words. Table 47 presents the comparison of my dataset and Haggan's corpus.

Table 47: Mean lengths of complex titles of self-improvement books and journal articles

\begin{tabular}{|l|c|}
\hline & $\begin{array}{c}\text { Mean length } \\
\text { (words/complex title) }\end{array}$ \\
\hline Science (Haggan) & 16.6 \\
Literature (Haggan) & 13.6 \\
Self-improvement & $\underline{11.7}$ \\
Linguistics (Haggan) & 9.9 \\
\hline
\end{tabular}

From Table 47, the mean length of complex titles of self-improvement books (11.7) is lower than those of science (16.6) and literature (13.6) but higher than linguistics (9.9).

Haggan (2004) also compares the number of complex titles across the three disciplines. Table 48 presents the comparison of the occurrence of complex titles in self-improvement books and the three disciplines.

Table 48: Distribution of complex titles

\begin{tabular}{|l|c|c|c|}
\hline Genre & Total number of titles & No of complex titles & $(\%)$ \\
\hline Self-improvement & $\underline{110}$ & $\underline{102}$ & $\underline{93}$ \\
Literature (Haggan) & 237 & 144 & 61 \\
Linguistics (Haggan) & 207 & 63 & 30 \\
Science (Haggan) & 307 & 66 & 22 \\
\hline
\end{tabular}

While literature has the most complex titles among the three disciplines, Table 48 shows that the occurrence of complex titles in self-improvement books is comparatively very high. I reason that the resource that self-improvement authors and academic authors use to persuade readers to read their work is different because what is deemed as valuable is different between the two broad contexts. I propose that unlike researchers who use journal article titles to present the focus of their research as precisely and explicitly as 
possible (Haggan, 2004, p. 312), self-improvement authors use titles to provide readers with as much information as possible, making complex titles more common in selfimprovement books.

\subsubsection{Lexicogrammar of titles}

This section examines the field of head titles in self-improvement books by generating a word frequency list followed by examining lexical words that occur frequently. The dataset for this analysis consists of 110 head titles of self-improvement books. This is the same dataset as the one in 6.3.1. As well as paying attention to the field of the head titles, this section also examines the grammatical features of the head titles and compares them with historical biographies.

\subsubsection{The field of titles}

I generated a word frequency list of the titles, using Antconc, to investigate the field of the titles. I treated all words as lowercase in the analysis to avoid Antconc from identifying your and Your as two word types. Following Mautner (2009), I use high frequency lexical words as an indicator to what should be given attention in terms of the field of the genre. To decide the cut-off point of the word frequency list, I stopped at rank 14 because it has the third most frequent lexical word, success (10 word tokens), and comparatively, the frequency of this word is relatively low compared to the most frequent lexical word, life (48 word tokens). This implies that lexical words that have lower frequency than success have little importance in exploring the dominant field in titles. Table 49 on next page shows the word frequency list. 
Table 49: Word frequency list of self-improvement book titles

\begin{tabular}{|l|c|c|}
\hline Rank & Word type & Frequency \\
\hline 1 & the & 79 \\
\hline 2 & to & 58 \\
\hline 3 & your & 50 \\
\hline 4 & life & 48 \\
\hline 5 & and & 39 \\
\hline 6 & of & 39 \\
\hline 7 & you & 32 \\
\hline 8 & a & 28 \\
\hline 9 & how & 23 \\
\hline 10 & for & 16 \\
\hline 11 & change & 15 \\
\hline 12 & in & 14 \\
\hline 13 & what & 12 \\
\hline 14 & success & 10 \\
\hline
\end{tabular}

Table 49 shows that your is the most frequent personal pronoun and life is the most frequent lexical word. The three most frequent lexical words in this dataset are life (48 word tokens), change (15 word tokens) and success (10 word tokens). A closer look at the pronoun your shows that it collocates mostly frequently with life (23), followed by potential (2). Other words (e.g., dreams, fear, success, talent, thinking, world, etc.) that collocate with your occur only once. Your + life occurs 23 times in the dataset with four occurrences in the head title and 19 occurrences in the subtitles.

\subsubsection{Your life in titles}

In analysing instances of your life that have life as the head noun, I removed one occurrence of your + life from my counting, as shown in Example 5 on next page, because life is not the head noun.

5) The life you were born to live: A guide to finding your life purpose (Millman, 1993) 
As can be seen, purpose rather than life is the head noun in this subtitle.

The analysis after removing that occurrence of your + life shows that 19 out of the 23 occurrences of your + life are in the object position and none in the subject position. There is no instance of your + life in the subject position in the subtitles. Change (7) is the most common verb that governs your + life. Other verbs include take control of (2), transform (2), creating (1), dominate (1), finding (1), fuel (1), improving (1), measure (1), take back (1), and taking (1). The followings are examples of change your life, each from a head title, a subtitle, and a title without a subtitle.

6) Change your questions, change your life: 10 powerful tools for life and work (Adams, 2009)

7) Learned optimism: How to change your mind and your life (Seligman, 1990)

8) One word that will change your life (Britton et al., 2012)

Based on the verbs that govern your + life in the titles, self-improvement authors seem to construct potential readers as people who seek to change their lives. It seems to me also that authors construct the idea of changing one's life as central in the genre and a necessary one. Interview data shows that some interviewees viewed the central message of self-improvement books to be about changing one's life. For example, at the end of the interview I asked Lynn, an interviewee who reads self-improvement books on a regular basis, to summarise the message of self-improvement books in one sentence, she said:

You have the power to change your life. (February 21, 2013; Face-to-face interview)

Lynn identified that the core message of self-improvement books is that readers have the ability to change their lives. I propose that the high frequency of your + life in the dataset is because it is related to the core message of the genre.

Based on the analysis of titles, self-improvement authors seem to construct the ways to change one's life as simple tasks such as changing the way one asks questions (see Example 6), or changing the way one thinks (see Example 7). One of the titles that has your life reads One Word That Will Change Your Life. We are not certain whether one word literally refers to an orthographic word or whether it is a piece of advice from the author. Regardless of the possibility, it seems to me that the author uses one to construct the means to change one's life as simplistic and attainable. Interview data is consistent with 
this interpretation. For example, Robert, a non-regular reader of self-improvement, expressed his scepticism towards this genre during the interview, and when I asked him what the reason was, he said:

I think they make things look too easy. It's like you do this and do that and you get success. I think there is no easy way to success. I think it's hard work, perseverance, and a little bit of luck along the way. (February 28, 2013; Face-to-face interview)

Interviewees such as Robert identified the simplistic approach to changing one's life in self-improvement books.

When I asked John, a self-improvement author, where he got his ideas for writing a selfimprovement book, he said:

Normally, what I write now is based off emotions connected to my work. So if I have a bad customer service experience, I will write about it and what they should have done. I try to turn the simple things into lessons anyone can grasp and benefit from. (July 31, 2013; E-mail)

John, for example, mentioned that he turns his reflection into lessons that "anyone can grasp." Self-improvement authors, such as John, seem to imply that accessibility is central in presenting their message. Non-reader and author interview data suggests my interpretation that self-improvement authors construct the ways of changing one's life as simplistic and attainable.

Self-improvement books also seem to advocate that the mind plays an important role in changing or transforming people's lives. These are some examples:

9) How Successful People Think: Change your thinking, change your life (Maxwell, 2009)

10) 8 Habits of Love: Overcome fear and transform your life (Bacon, 2012)

11) Emotional Freedom: Liberate yourself from negative emotions and transform your life (Orloff, 2009)

12) Finding Your Element: How to discover your talents and passion and transform your life (Robinson, 2013)

As illustrated in Examples 9, 10, 11, and 12, changing one's mind, overcoming fear, liberating oneself from negative emotions, and discovering one's talents and passion are 
related to the mind or human perception. Interviews with self-improvement authors and readers of the genre suggest this interpretation. For example, when I asked Johnson, a self-improvement author, what were his thoughts on how change in life happened, he said:

It's inside. It starts in your mind. I mean, all change starts with the mind. You change the way you start to think. From changing the way you think, you start to change the way you act. Then when you change the way you act, you have a whole different world. (August 16, 2013; Skype interview)

Johnson's comments suggest that changing one's life starts with the mind. His response is parallel with my observation that self-improvement books advocate that how one thinks is crucial in changing one's life.

At the end of an interview with Gladys, a regular reader of the genre, I asked her if she had any final thoughts about the genre. She pointed to The Choice is Yours and commented:

It's probably related to changing your way of thinking. (February 19, 2013; Face-to-face interview)

Both author and reader interview data supports findings from text analysis that in helping readers to change their lives, self-improvement authors recommend that change starts in the mind.

\subsubsection{Grammatical structure of head titles}

Moving on to the grammatical aspects of titles, I analysed the grammatical structures of head titles in self-improvement books and compared them with those of historical biographies. Head titles were chosen because all the titles in my dataset have a head title. The dataset of head titles of self-improvement books (110 books) and historical biographies (110 books) is the same as the dataset in 6.5.1. I used Biber et al.'s (1999) grammar system to categorise the grammatical structure of head titles of both genres. I used Nvivo 10 to code the structures that I identified. The examples below illustrate the grammatical structures in Table 50. 
Noun phrase:

The 6 most important decisions you'll ever make (Covey, 2009)

Imperative clause:

Never give up! (Meyer, 2008)

Ing-clause:

Becoming a person of influence (Maxwell \& Dornan, 2006)

Declarative clause:

Talent is never enough (Maxwell, 2007)

Non-finite wh-clause:

How to stop worrying and start living (Carnegie, 1944)

Adjective phrase:

Happier (Ben-Shahar, 2007)

Finite wh-clause:

Who moved my cheese? (Johnson, 1998)

Prepositional phrase:

From panic to power (Bassett, 1995)

Ambiguous:

Change (Lee, 2013)

In Table 50 on next page, I arranged the grammatical categories from the most common category to the least common one. Table 50 shows that noun phrases are the most common grammatical structure in the dataset of head titles of self-improvement books. The next most common grammatical structures are imperative clauses (13.6\%) and ingclauses $(9.1 \%)$. 
Table 50: Grammatical structures of self-improvement book head titles

\begin{tabular}{|l|c|}
\hline Grammatical structure & Frequency \\
\hline Noun phrase & 65 \\
\hline Imperative clause & 15 \\
\hline Ing-clause & 10 \\
\hline Declarative clause & 7 \\
\hline Non-finite wh-clause & 5 \\
\hline Adjective phrase & 4 \\
\hline Finite wh-clause & 2 \\
\hline Prepositional phrase & 1 \\
\hline Ambiguous & 1 \\
\hline Total & $\mathbf{1 1 0}$ \\
\hline
\end{tabular}

While noun phrases in the head titles provide information about the topics that selfimprovement authors write about, the imperative clauses indicate the direct advice-giving purpose of the genre. There are not many ing-clauses in the dataset, but they seem to construct the action as continuous. For example, in Becoming a person of influence, the verb, becoming, constructs the process of changing into a person of influence as a dynamic, ongoing process.

As a comparative dataset, I identified the grammatical structures of 110 head titles of historical biographies and coded them using Nvivo 10. Table 51 shows the findings of the grammatical analysis and presents them according to their frequencies.

Table 51: Grammatical structure of historical biography head titles

\begin{tabular}{|l|c|}
\hline Grammatical structure & Frequency \\
\hline Noun phrase & 106 \\
\hline Declarative clause & 1 \\
\hline Non-finite wh-clause & 1 \\
\hline Adjective phrase & 1 \\
\hline Finite wh-clause & 1 \\
\hline Total & $\mathbf{1 1 0}$ \\
\hline
\end{tabular}


The analysis shows that almost all the head titles of historical biographies are noun phrase (106). Unsurprisingly, 60 out of the 106 noun phrases (57\%) in this dataset are names of people. This is an example of noun phrase that is a person's name:

13) Thomas Jefferson (Meacham, 2013)

This is an example of non-names noun phrase:

14) Giant in the shadows (Emerson, 2012)

There are only one each of declarative clause, finite nominal clause, adjective phrase, and finite wh-clause in the dataset:

15)I invented the modern age (Snow, 2013)

16) Where white men fear to tread (Means \& Wolf, 1995)

17) Not in your lifetime (Summers, 1980)

18) Who was Abraham Lincoln? (Pascal \& Harrison, 2008)

Table 52 compares the frequencies of grammatical structures of self-improvement book head titles and historical biography head titles. The comparison gives us an indication of whether the grammatical features that I identified in the head titles of self-improvement books are typical of the genre or similar across genres.

Table 52: Grammatical comparison of head titles of self-improvement book and historical biography

\begin{tabular}{|l|c|c|}
\hline \multirow{2}{*}{ Grammatical structure } & \multicolumn{2}{|c|}{ Frequency } \\
\cline { 2 - 3 } & Self-improvement & Historical biography \\
\hline Noun phrase & 65 & 106 \\
\hline Imperative clause & 15 & 0 \\
\hline Ing-clause & 10 & 0 \\
\hline Declarative clause & 7 & 1 \\
\hline Non-finite wh-clause & 5 & 1 \\
\hline Adjective phrase & 4 & 1 \\
\hline Finite wh-clause & 2 & 1 \\
\hline Prepositional phrase & 1 & 0 \\
\hline Ambiguous & 1 & $\mathbf{1 1 0}$ \\
\hline Total & $\mathbf{1 1 0}$ & 0 \\
\hline
\end{tabular}


Overall, the grammatical structures of head titles in self-improvement books are more diverse compared to those of historical biographies. The comparison shows that even though noun phrases are a common feature of self-improvement book head title, almost all head titles of historical biography are noun phrases. While 15 self-improvement book head titles are realised by imperative clauses and 10 by ing-clauses, these structures are not found in the head titles of historical biography. Finite clauses are more common in self-improvement head titles than in historical biography head titles. This might reflect the dynamic and action focused characteristic of self-improvement books. I propose that the imperative clause indicates that this genre is about advice-giving, and the ing-clause constructs the dynamic and ongoing nature of self-improvement.

\subsection{Summary of chapter}

At a register level, personal pronouns are a linguistic feature of self-improvement books, and the second person pronoun, you, is very frequent in this genre compared to other written genres. This implies that self-improvement books have a reader-oriented character based on the frequency of the pronoun, you. The abundance of your + life, and change being the most common verb that governs your life indicate that the social purpose of selfimprovement books is to help readers improve their lives. This is consistent with interview data (see Section 4.2.2). In terms of improving one's life, readers are constructed as the main agents of change who are capable of and hence responsible for improving their lives. In other words, rather than passive recipients of advice, readers are constructed as active participants in the process of improving their lives. This can be seen in the abundance of the pronoun, you, in the subject position (see Section 6.1.2). Also, the pronoun, you, is often the subject in clauses where your life in the object position is governed by the verb, change (see Section 6.1.4.2).

There is evidence from register analysis that the main communicative purpose of the authors is to provide advice for helping readers improve their lives. The direct, as opposed to indirect, advice giving character of this genre is indicated by the abundance of imperative clauses in the genre and its head titles. This grammatical structure is not found in any of the comparative data, historical biography head titles. The analysis of 
directive in the imperative form shows that readers are recommended to change the way they think in order to improve their lives. Also, the process of improving one's life is constructed as a realistic and achievable goal. Further exploration shows that selfimprovement is constructed as a dynamic and ongoing process. This is evident in the use of ing-clauses in head titles of self-improvement books. To "sell" their advice effectively, authors provide as much information about their advice as possible to the readers in their book titles.

Because advice-giving is central in this genre, it is important for authors to engage their readers with their message. My analysis shows that authors use reader pronouns, imperative clauses, and questions to engage readers. As a form of engagement, these features make the readers' presence visible in the text. More specifically, authors use questions primarily to prompt readers to reflect on a particular topic. Other functions of questions include reinforcing a point, soliciting agreement, and introducing new ideas.

This chapter also demonstrates that authors present themselves as experts, predicting the benefits/consequences of following/ignoring their advice. While authors construct themselves as teachers and credible advice-givers, they do not always present their advice in an authoritative way. As interpersonal distance between authors and readers is a liability in this genre (see Section 5.4), authors usually use possibility in terms of modality types to present their advice as options. This complicated interpersonal relationship is consistent with findings from interview data. Although it is important to appear as authoritative advice-givers, authors seem to avoid imposing their advice on readers.

In the next chapter, I will discuss the findings of text analyses from Chapters 5 and 6 drawing on the literature (Chapter 2) and interview data (Chapter 4). 


\section{Chapter 7: Discussion}

As mentioned in Section 2.6, the main purpose of this thesis is to explore the characteristics of self-improvement books. This exploration draws on three principal data sources, namely, interview data, self-improvement books, and the ideology literature. At a genre level, I demonstrated how self-improvement books are structured in Chapter 5, by analysing the typicality of sections in the genre. Focusing on the obligatory substantive sections, I analysed the moves and steps in introduction chapters, body chapters, and about the author sections. Because stories are a feature of self-improvement books, this thesis has also examined the purpose of telling stories and how they are structured. Moving on to the register level as presented in Chapter 6, I focused on reader pronouns, imperative clauses, and questions as resources that authors use to engage readers. In the same chapter, I also explored the interpersonal aspect of self-improvement books or the author-reader relationship by analysing modal verbs. Also in that chapter, I focused on the lexicogrammar of self-improvement book titles. To inform the genre and register analyses, my thesis draws on the literature in Chapter 2, and findings from author, reader, and non-reader interview data as presented in Chapter 4.

This chapter presents a discussion of the findings presented in the chapters mentioned above, drawing also on the ideology literature I reviewed in Section 2.5. As my thesis draws on the idea that a genre is socially recognised, I draw on interview data from multiple perspectives including non-readers' in discussing my findings. As genres are primarily recognisable by the purpose they serve, this chapter starts by discussing the advice-giving purpose of self-improvement books. To understand the advice that authors give, this chapter then discusses the areas of improvement that authors address in the genre and how they construct individuals as being responsible for improving their lives. The chapter then moves on to discuss recommendations that authors give and strategies they use to persuade their readers to "buy" their recommendations. In light of the discussions stated above, this chapter ends with a discussion of author-reader relationship. 


\subsection{The purpose of self-improvement books}

The core of genre studies, regardless of their traditions, is the idea that a genre is recognisable by the purpose it serves and the action it performs. As discussed in Section 2.2.1, social purpose and social action refer to a socially recognisable purpose/action that a particular genre serves/performs. Communicative purpose refers to speakers' or writers' intention that is communication driven. Following Askehave and Swales (2001), private intentions are author intentions that are not prototypical.

In order to claim that a particular purpose is a social purpose, it has to be socially recognisable. In this thesis, a socially recognisable purpose is operationalised as one that is recognisable to authors, readers, and non-readers of the genre. There is evidence from my interview data that interviewees from the three categories mentioned that the purpose of the genre was to help readers change their lives (see Sections 4.1.3 and 4.2.2). For example, when I asked Peter, an author of the genre, to describe the processes involved in designing his book cover, he said he consulted a professional illustrator and wanted to present the tools he teaches as strategies for changing one's life. Peter said:

I spent three months trying to figure out what to put on the cover... What's the point of learning the tools or learning anything if you cannot do something different with it? You're not learning for the sake of learning. You're learning because you want to change your life. So I wanted something that has a sense of changing your life. (June 24, 2013; Face-to-face interview)

Peter's comment shows that he considered the tools to be for the purpose of changing one's life. He suggested that the main purpose of reading his book should be to change one's life rather than to learn the strategies he teaches.

This purpose is also evident in reader interview data. For example, when I asked Jane, a reader, whether she thought there were any similarities between a self-improvement book and a how-to book, she said:

They are both giving ideas of how you can live your life differently and according to someone's opinion, better. You pick things out of it that will help you live a better life. (March 19, 2013; Face-to-face interview) 
Jane's response suggests that the purpose of self-improvement books is to help readers live better lives.

From the non-reader interview, when I asked Robert, whether he thought about the popularity of this genre, he said:

I'm sure if you go to bookstores you can find a whole section on these books...like change your life now, inspirational quotes for men. (February 28, 2013; Face-toface interview)

The main purpose of the genre that Robert seemed to be able to recognise is that it is about changing readers' lives.

As mentioned at the beginning of this section, this thesis views social action as a particular action that a genre performs. The social action that self-improvement books perform is to advise readers how they can improve their lives. As discussed in Section 2.2.1, social actions refer to socially recognisable goals of a particular genre and private intentions refer to authors' goals that are not socially recognisable. Figure 17 illustrates the difference between social action and an author's private intention in terms of perceptions of a genre's purpose.

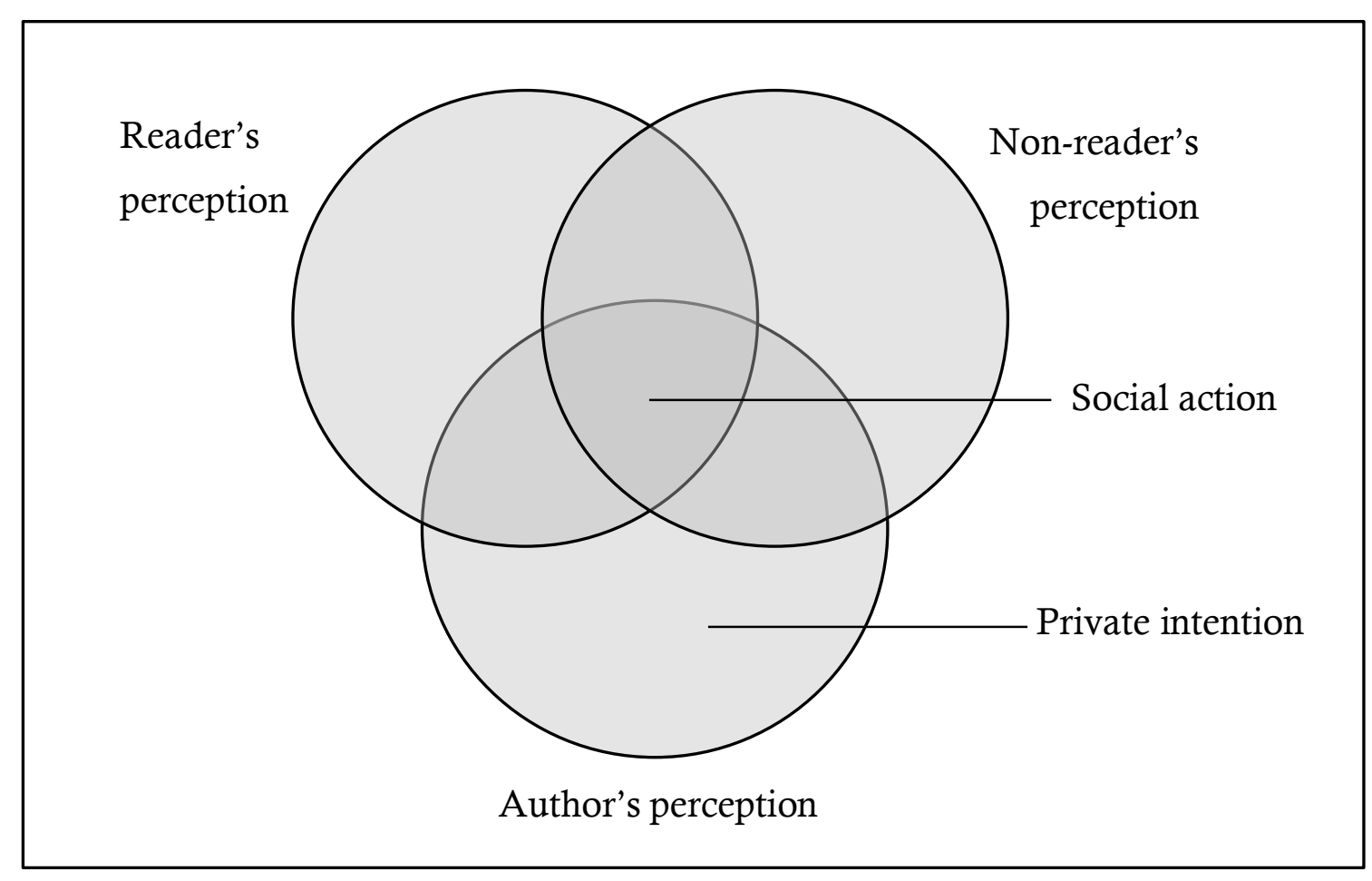

Figure 17: Social action vs. private intention 
In Figure 17, three circles represent the perception of the purpose of self-improvement books from three categories of participants in my study (i.e., author, reader, non-reader). The area where the three circles overlap represents the social action of the genre because it is socially recognisable. For example, interview data from all three categories of participants (i.e., authors, readers, and non-readers) are consistent in saying that the purpose of self-improvement books is to help readers improve their lives. This indicates that this purpose is socially recognisable.

Private intentions as presented in Figure 17 are authors' goals that are not recognisable by both readers and non-readers. To illustrate this idea, when I asked Peter, a selfimprovement author, what his purpose was for writing a self-improvement book, as discussed in Section 4.1.3, he said:

That's really easy. I was with a colleague and we were running workshops and we were trying to think how we could grow the business. He said the one thing that would validate the work we do is by publishing a book. (June 24, 2013; Face-to-face interview)

Peter stated that his goals for publishing a book were to validate his credibility as a workshop speaker. Based on interview data, readers and non-readers, and in fact other authors, did not mention these goals as the purpose of self-improvement books. In other words, these goals are Peter's private intentions.

Because Peter's goals are potentially not socially recognised, they are not purposes that can be used to identify self-improvement books as a genre. This, however, does not mean that private intentions are irrelevant to genre studies because they are able to provide insights into purposes that are not prototypical of a genre, thus providing a richer understanding of the studied genre. Interview data and text analyses show that the social purpose of self-improvement books is to help readers improve their lives.

Both genre and register analyses also show that the communicative purpose of selfimprovement books is to provide advice for helping readers change or improve their lives. At a genre level, this purpose can be seen in the moves in body chapters, arguably the most substantive section of the genre. The obligatory moves in body chapters are presenting the problem, presenting the message, encouraging readers to apply the message, and recommending practical applications. The problems that authors present motivate their 
message and recommendations. Without presenting the problems, it seems unnecessary to present the message. After authors present their message, they encourage readers to apply their message. These moves imply that presenting the message or more specifically advising readers how they can change their lives is central in this genre.

This purpose can be seen, at a register level, in the abundance of your + life in the genre (see Section 6.1.3), and further exploration reveals that this collocation in the object position is most frequently governed by the verb, change (see Section 6.1.4.2). This is an example from my data:

1) You can change your life, and you can start right now simply by developing a new sense of urgency. (Rohn, 2002)

Also, the analysis of book titles shows that your (50 occurrences) is the most frequent pronoun and the third most frequent word in the 110 book titles after the (79 occurrences) and to (58 occurrences) (see Section 6.5.2.1). Life is the word that collocates most frequently (23 occurrences) with your (see Section 6.5.2.2). Example 2 shows a book title with the verb, change, governing your + life in the subtitle:

2) Loving what is: Four questions that will change your life. (Katie, 2003)

A comparison of imperative clauses in self-improvement books and other written genres (i.e., fiction, news, academic) shows that such clauses occur more frequently in selfimprovement books (see Section 6.2). The abundance of imperative clauses, the most explicit form of directives, in self-improvement books also indicates the advice-giving character of the genre. Consider this example:

3) Think about what's right for you, make a plan, and stick to it. (Barrett, 2013) Both move analysis and register analysis indicate that the purpose of this genre is giving advice to readers to help them improve or change their lives. The social purpose (i.e., helping readers to improve their lives) motivates the communicative purpose (i.e., providing advice). To unpack what your life means in the genre, the next section discusses the areas of improvement that authors write about. 


\subsection{Areas of improvement in self-improvement books}

At a register level, among the words that frequently collocate with your are life, mind, children, body, family, goals, and job (see Section 6.1.3). Life is the most frequent word that collocates with your. This implies that the advice that self-improvement book authors provide are primarily related to improving readers' lives, and the list of words suggest that the idea of becoming happier and more fulfilled in life is related to aspects such as mind, health, family, personal goals, and jobs.

Interview data is consistent with this finding. For example, when I asked Ruby, a regular reader of self-improvement books, what she thought the common message of this genre was, she said:

They say a lot about accepting yourself and then tell you the self is actually not good enough... And they sound the same. Whether it's business or relationship, they all sounded the same. (April 17, 2013; Face-to-face interview)

Ruby perceived the main topics that self-improvement authors write about are the constant need to improve and the areas that one should improve are your career and relationships.

The three aspects of life (happiness, relationship, and career advancement) that are prevalent in self-improvement books reflect the American Dream and American individualism. The main aspects of the American Dream are related to economic and social advancement, making sure one's children have better lives and better education, and freedom to pursue one's happiness (Bergsma, 2008; Cullen, 2003). Another related ideology is American individualism. The main idea of this ideology is that individuals have the ability to pursue their goals and they should be given the rights to achieve them (Becker \& Marecek, 2008; Jones et al., 2011).

Drawing on ideas from literature that discusses the American Dream and American individualism, aspects of these ideologies (e.g., upward mobility, the pursuit of happiness) are present in self-improvement books and it seems reasonable to conclude that these are the ideologies underlying the genre. Consistent with these aspects, improving one's life, self-improvement books say, is synonymous to being happier, having better relationships and being more successful in one's career. I discuss this in the next section. 


\subsection{The self in self-improvement books}

Self-improvement books are a reader-oriented genre, and the name of the genre suggests this orientation. In other words, the self or the individual is responsible for improving her/himself, and at the register level, this is evident in the abundance of the pronoun, you, and that this pronoun is predominantly in the subject position, where authors construct readers as active participants in the text.

Reader interview data suggests that authors of self-improvement books usually place the responsibility for improving oneself on the individual. For example, when I asked Lynn, a regular reader of the genre, what she thought the common message across selfimprovement books was, she said:

I think you have a choice, you have the power, or the power is in your hand. The power is in your choice. (February 21, 2013; Face-to-face interview)

Lynn viewed the overarching message of self-improvement books as that individuals are responsible in improving their lives, and she reasoned that authors of self-improvement books perceive readers to be individuals who have the power to make individual decisions. Because authors construct individuals as having the power to decide to improve their lives, the individuals are to blame for not acting on the ability they have.

The idea that individuals are responsible for their improvements can also be related to the American Dream, American individualism, neoliberalism, and New Age ideology. As discussed in Sections 2.9.2 and 2.9.3, the American Dream and American individualism view individuals as being responsible for improving their lives. In other words, individuals are to blame themselves if they are not happy, not having good relationships, and not making progress in their careers. This might be an explanation to the prominence of you-subject and your life in the object position. Unlike the Puritans who believed that their lives or destiny were predestined by God, and consistent with the idea of self-made men and women, individuals are constructed as being capable of changing their future through hard work and self-reliance.

The idea of individuals being responsible for improving themselves is central in neoliberalism. For example, in a neoliberal government, the government places public responsibility such as healthcare on citizens or individuals and the government expects the individuals to be responsible and pay for their healthcare (see Section 2.9.4). This 
implies that individuals would have to accumulate wealth in order to afford, for example, healthcare services. Also, individuals should constantly strive to improve themselves to be better than others in order to survive in a neoliberal system and that individuals are responsible for their personal self-improvement. Johnson, a self-improvement author, in describing his imagined readers, said that:

Probably the broadest category is anybody who wants to improve their personal or professional life...The second category is the people who realise that success is dependent upon what they do and not what someone did for them. In other words, they are not waiting for the government to fix it; they are not waiting for the education to fix it or whatever. They realise that if something is going to change, they have to be the instigator of that change. (August 16, 2013; Skype interview)

It seems from Johnson's comment that rather than relying on the government, individuals are responsible for changing their lives because they are viewed as the instigator of the change they want to see.

The idea that individuals are responsible for improving themselves is consistent with reader interview data. For example, when I asked Tracy, a non-regular reader of selfimprovement books, what she thought the common message across self-improvement books was, she said:

I think in the times I have kind of picked them up and read through them, it's all about like picking yourself up by the bootstraps. (February 15, 2013; Face-to-face interview)

Interview data suggests that self-improvement books promote self-responsibility and that improvement is individual driven.

While self-improvement in neoliberalism is predominantly survival driven, selfimprovement within New Age ideology is driven by how New Agers view human beings. New Agers believe that human beings are divine and are the source of self-improvement (Askehave, 2004, p. 11), and individuals are responsible for improving themselves. Also, New Agers view human beings as both helpers and opponents in their lives, unlike the general Christian concept "where an Almighty God is called upon to bring changes in people's lives" (Askehave, 2004, p. 12). This implies that individuals, New Agers believe, 
are to be responsible for both the "good" and "bad" things that happen in their lives. Askehave (2004, p. 12) explains that within this ideology individuals are to be blamed for their unhappiness or illness and they are to "take control" and "do something about it." This results in the necessity of having New Age tools such as meditation, visualisation, and affirmation, to help human beings improve their lives (p. 12). Most relevant to my study is the idea that individuals are responsible for improving themselves.

While I do not have sufficient evidence to support a claim that New Age ideology is an underlying ideology in self-improvement books, neither do I have evidence to reject this possibility. New Age tools such as affirmation are found in my dataset, although there are not sufficient instances of them to claim that self-improvement books promote New Age ideology. According to Askehave (2004, p. 29), affirmations are short sentences that are being verbalised believing they will come true, such as "my life is perfect" and "I am a great researcher." In my analysis of sections in self-improvement books, there is one instance where the author presents a list of self-affirmation statements after the contents page and the author explicitly instructing the readers to read the statements to themselves. This is an example of an affirmation from the list:

4) It is my choice! Nobody can choose it for me (Glenn, 2008).

This example also illustrates the claim by self-improvement books that individuals are responsible for improving themselves. The idea of choice in the above example also implies that the self has the freedom to choose and make decisions, and this idea is related to the idea of freedom in American individualism.

In self-improvement books, the idea that individuals have the freedom to choose and determine their destiny implies that these individuals may need guidance and advice in improving their status. Interview data suggests that some readers and non-readers view the purpose of self-improvement books as to provide guidance and advice in terms of the direction individuals can take to improve their lives. For example, when I asked Tina, a non-reader of self-improvement books, what she thought the reason was that people read these books, she said:

Help them to think about where they want their life to go. (February 5, 2013; Faceto-face interview) 
Both reader and non-reader interview data suggests that participants in my study perceived that individuals were constructed as having freedom to pursue what they want in their lives in self-improvement books. This idea is consistent with American individualism (see Section 2.5.3).

Both reader and non-reader interview data also suggest that some readers and nonreaders of the genre perceived the idea of seeking advice from a book to be an individualistic approach to solving problems. For example, when I asked Anne whether she agreed that self-improvement books are an American-related genre, she said:

It's definitely embraced by Americans because they are very entrepreneurial and independent and they want to take their problems and fix them themselves instead of going to someone else. So a book is a way to empower yourself, make yourself a better person and fix what's wrong with your life. For some cultures, it is more common to take your problems to your family and talk about it. But for Americans, I think you try to figure things out independently. (February 20, 2013; Face-to-face interview)

Also, interview data suggests that participants perceive that the idea of being independent is present in the genre. This idea of independence is related to the idea of self-reliance and self-determination in American individualism.

In summary, text analysis shows that the pronoun, you, is the most common subject that changes your life because individuals are responsible for changing their lives in this genre. Findings from both text analysis and interview data indicate that the underlying ideologies of self-improvement books are the American Dream, American individualism, neoliberalism, and New Age ideology.

\subsection{Authors' recommendations}

The sections above demonstrate that the social purpose of self-improvement books is to help readers improve their lives and the improvements involve being happier, building better relationships and having more successful careers. Also, these books suggest that 
people are individually responsible for these improvements. This section discusses authors' recommendations for achieving these dreams.

Perhaps the most important function of imperative clauses in self-improvement books is to instruct readers, in an explicit way, what they could do to improve their lives. My study used Halliday's process types to investigate the characteristics of imperative clauses in the genre and found that mental processes are the most frequent category followed by material processes (see Section 6.2). The three most common verbs in the imperative clauses are consider, remember, and imagine (see Section 6.2). Also, nouns related to thinking (i.e., mind, goals, brain, thoughts, attention) frequently collocate with your (see Section 6.1.3). These analyses show that in this genre, improving one's life starts with the mind, hence the name "positive thinking."

Author interview data shows that authors view that changing how one thinks is central to self-improvement (see Sections 4.1.2). For example, when I asked Matt, an author, what he thought was the starting point of change, he said:

We probably all agree that change takes place with a commitment to change... We should be willing to change. (September 12, 2013; Skype interview)

Matt's comment suggests that authors view change starts with having a "right" mental attitude (i.e., commitment and willingness to change). His comment also suggests that authors view some readers as not willing to change. This implies a need to convince some readers of the necessity of being willing to change.

It is likely that readers are not willing to change because they do not see the need to change. To address this issue, in the introduction chapters, authors list problems that readers may have (obligatory step) to help readers see the need to change (see Section 5.2). When readers identify with the problems, the chances of readers being willing to change is likely to be higher. Other strategies that authors use include Step 4: Making claims about outcome of reading the book and Step 6: Supporting author's claims of effectiveness in the introduction chapters. The former provides the benefits/consequences of following/ignoring authors' advice and the latter provides "evidence" to support those claims. They serve as reasons for readers to be willing to change. It is also possible that some authors view that having a "wrong" worldview prevents readers from being willing 
to change. This is evident in Step 12: Challenging opposing worldview in the introduction chapter.

There are instances where readers' comments suggest that they view authors' advice as related to changing how readers think or adopting a new worldview. Before I ended an interview with Lynn, a regular reader of the genre, I asked her if she had more comments, she said:

These books challenge me to see things in a new light. It challenges me to try on a new hat and see if it fits. And if it fits, to keep wearing the hat. (February 21, 2013; Face-to-face interview)

It seems from this comment that self-improvement books challenge readers to change their worldviews that are in conflict with those that the books present. Step 5: Explaining the term (obligatory step) in body chapters shows how authors redefine well-known words as a means to present an alternative worldview (see Section 5.3).

\subsection{Persuasion}

In order to "sell" the message that individuals are responsible for improving themselves and that authors' advice is valuable, authors use various strategies to persuade readers. Drawing on various research studies (Connor \& Lauer, 1988; Hyland, 2008; Roitman, 2014; Virtanen \& Halmari, 2005), this study views presenting a credible persona and attempts to engage readers as components of persuasion. Drawing on text analyses and interview data, the following sections discuss the resources that authors use to present a credible persona and engage readers.

\subsubsection{Constructing a credible persona}

Move analysis of the about the author sections shows that the main communicative purpose of the section is to construct the authors' credibility (see Section 5.4). Because the about the author section is obligatory in self-improvement books, this status indicates the importance of authors' credibility in "selling" their message. Paying attention to the 
resources that authors use to construct a credible persona may shed light on the values and norms of self-improvement as a culture.

Stiff and Mongeau (2003, p. 109) state that the perceived credibility of writers is related to audiences' judgements of how well-informed the writers are on the topic they write about. Applying this idea to self-improvement authors, it is important for these authors to claim familiarity with their areas of expertise. One of the steps that self-improvement authors use to construct a credible persona is stating their areas of expertise. Move analysis of the about the author sections also shows that authors construct a popular persona by referring to groups of people (e.g., families, leaders in business, leaders in education) who have consulted them. Also, authors refer to their popularity by stating the number of copies they have sold, and that their books have been translated into a number of languages. Providing such information is authors' attempt to give readers the impression that their advice is highly sought after and relevant across cultures. Information about bestselling status of authors' previous books sometimes appears on the front book cover. For example:

1) New York Times Best-selling author of The 21 Irrefutable Laws of Leadership. (Maxwell, 2006).

Move analysis also indicates that authors often refer to their years of experience in writing self-improvement books and conducting seminars. For example, "For more than 20 years, he has delivered his uplifting presentations to businesses, trade associations, and educational institutions" (Keller, 2007, p. 253). Authors construct these experiences as being relevant to their areas of expertise. Also, authors refer to their experience being invited as guests on talk shows as a resource to construct a credible persona.

To present a credible persona, authors construct themselves as being passionate about helping their readers to improve themselves, and that they are genuinely concerned for their readers. Some authors refer to their academic achievements and/or involvement. It seems members of the self-improvement culture view having a qualification from a university as contributing to an author's credibility. This potentially contributes to the reliability of their advice. 
The move analysis of the about the author sections also indicates that authors refer to the origin of their message. Authors often construct their advice as a result of their personal experience and observations. For example:

2) His experiences in life and constant quest for principles that produce real results, prepared him to share these principles with people from all walks of life. (DiAngi, 2002, p. 204)

This example illustrates that members of the self-improvement culture value advice that results from personal experience and observation. Following Connor and Lauer's (1988, p. 146) model of persuasion, the author's life experience would relate to rational appeals and the author's quest for principles would relate to affective appeals (see Section 2.4). Consistent with this finding, interview data suggests that authors' life experience is a valuable aspect of credibility. For example, when I asked Joanne, a regular reader of selfimprovement books, what she thought made a credible author, she said:

Sometimes people have useful things from their life experience... You can get really useful insights. (June 6, 2013; Face-to-face interview)

Joanne's comment suggests that authors' life experience can be insightful. This implies that as well as academic qualifications, life experience is valued within self-improvement culture and authors draw on their life experience as a source of credibility. My analyses confirm Grodin's (1991, p. 412) finding that personal experience is necessary to construct competent authorship of self-improvement books.

While writers of research articles align themselves with expert members of the community (Hyland, 2010b), authors of self-improvement books, Woodstock (2006) states, avoid associating themselves with the expert community. Woodstock explains that aligning themselves with other established authors creates an interpersonal distance from readers. Consistent with Woodstock's study, only one author used Step 12: Reference to affiliation with established authors for constructing a credible persona in the about the author section.

To construct closeness with readers, authors present themselves as trustworthy people who genuinely care for their readers. As discussed in Section 5.4, this strategy is evident in Step 5: Reference to genuine intentions as a strategy for constructing credibility in the about the author sections. There is evidence from both reader and non-reader interview 
data that suggests authors are sometimes perceived to be genuine people. For example, when I asked Katrina, a regular reader of the genre, what she thought the reason for authors writing this genre was, she said:

Because they are trying to help other people. They might have gone through problems and they want to share their experience. (February 22, 2013; Face-to-face interview)

It seems authors are sometimes viewed as people who want to help their readers by sharing their experience.

From the non-reader interview data, Tina, a sceptic of self-improvement books, also seems to perceive authors as people who are genuinely helpful. When I asked Tina what she thought the reason for writing this genre was, she said:

[chuckle] The first comment that popped into my head was they want to make money. Sometimes they genuinely want to help people. (February 5, 2013; Face-toface interview)

Another way to construct a credible persona is by including appraisal from readers or seminar participants. This strategy is rarely (one out of 20 books) found in the about the author sections (see Section 5.4). Alternatively, some self-improvement books have a section that has a list of praise from other experienced authors. The praise from others section is a typical section (17 out of 20 books) in my dataset. This shows that while authors avoid aligning themselves with experienced authors in the about the author sections, being endorsed by experienced authors seem necessary for constructing a credible persona and authors go as far as devoting a section specifically for this purpose. Because being endorsed by experienced authors and distancing themselves from these experts are equally important though conflicting, authors manage these aspects by systematically presenting the endorsed persona in the praise from others sections (see Section 5.1) and exclude it in the about the author sections.

In constructing a credible persona, authors present themselves as experts by using predictive modality (see Section 6.4). Authors use this modality to predict the outcomes of acting on or dismissing their recommendations. Consider this example:

3) Stop feeling sorry for yourself - and you will be happy. (Moore, 2013) 
This example illustrates how authors use the predictive modality, will, to predict a positive outcome of following their advice. Presenting authors as having the ability to predict constructs them as experts.

\subsubsection{Engaging readers}

To explore the resources that self-improvement authors use to engage their readers, this research has studied reader pronouns, directives in the imperative form, and questions. These are the most unambiguous form of engagement resources based on Hyland's (2005b) system of engagement. My study also shows that authors use aphorisms and pullquotes, and tell stories as ways to engage readers.

\subsubsection{Reader pronouns}

The pronoun, you, is a feature of self-improvement books. The word frequency list generated from 20 self-improvement books shows that the pronoun, you, is the most frequent pronoun (see Section 6.1). A comparison of this pronoun in other written genres (i.e., job posting, news, fiction, academic) shows that the frequency of you in selfimprovement books is very similar to that of job postings and is relatively higher compared to those of news, fiction, and academic prose (see Section 6.1.1).

Drawing on the literature on reader pronouns (see Section 2.4.2.1), these pronouns (e.g., you, your, inclusive-we), Hyland (2005b) states, are the most explicit way to address readers. In an advice book for writing self-improvement books, Stine (1997, p. 93) recommends authors to use you to address their readers and she explains that using this pronoun contributes to a conversational style. Even though the frequency of you in selfimprovement books is about half the frequency of that in Biber et al.'s (1999, p. 334) conversation, it is much more like conversations in terms of frequency of you compared to other written genres (see Section 6.1.1). Reader pronouns, Hyland (2005b, p. 182) explains, are "the most explicit way" to bring readers into a text and "the clearest way" to acknowledge readers' presence.

Using the pronoun, you, is also a strategy to attract readers' attention (see Section 2.4.2.1). Stine (1997, p. 97), an editor of self-improvement books, explains that people 
tend to respond to you even though they may not be certain whether they are being addressed. This is how Stine (1997, p. 97) explains the importance of using you to beginner authors:

Have you ever been someplace where there were several people and suddenly someone yelled, "Hey, you!" Did you turn and look, just to be sure, even though you were sure the call wasn't meant for you? If so, then you know the power of addressing "you."

Although Stine's claim was not substantiated with empirical data, it is reasonable to regard her claim as insight from an expert member of the community of writers of the genre (i.e., editor of self-improvement books). Her claim suggests that using the pronoun to attract readers' attention is important in this genre.

Woodstock (2006) states that one of the ways self-improvement authors gain credibility is by constructing closeness by means of articulating similarities with the readers. It is likely that using you to address readers is a resource that authors use to construct closeness with their readers. Although calling people by their real names is probably the most personal way of addressing people (Emihovich, 1981), it is unlikely or even impossible for authors to address readers in that way. It is likely that the next most personal way to address people is using you. More than making readers visible in a text and acknowledging readers' presence, using you for addressing readers can be a way to foster closeness and perhaps a means for rapport building. However, to make a stronger claim would demand paying attention to the sentence structure where the pronoun is used and the lexical words around the pronoun. Nevertheless, it seems reasonable to claim that using you is a more personal way to address readers compared to using the noun, readers.

\subsubsection{Directives in the imperative form}

Another resource that authors use to engage readers is directives in the imperative form. As discussed in Section 2.4.2.2, a directive is an attempt to get a person do something. Similar to reader pronouns, directives make readers' presence visible in the text because they imply an audience. Because directives entail a response of some sort, they construct readers as active participants. In self-improvement books, directives are the most explicit way to instruct readers to do something in order to improve their lives. 
This is a feature in self-improvement books because, as a genre, they have the most imperative clauses compared to Biber et al's (1999) written genres (i.e., academic, fiction, news). Biber et al. explain that imperative clauses are rare in the written genres that they examined because these genres are less interactive compared to conversations. This implies that self-improvement books as a written genre are more interactive compared to Biber et al.'s written genres. These clauses make the dialogic aspect of the genre more visible.

As discussed above, because authors rely on interpersonal closeness as a way to construct a credible persona, authors use imperative clauses as a resource for that purpose. Biber et al. (1999, p. 222) explain that the use of directives in the imperative form or directives that do not "use softening devices" often indicates an informal situation and intimate relationship between participants (i.e., authors and readers). This seems to fit Stine's (1997, p. 94) claim that using an informal or conversational writing style can help readers sense that authors "are a comfortable presence they can trust."

\subsubsection{Questions}

Questions are another resource that authors use in their attempts to engage readers. Similar to directives in the imperative form, questions demand a response from readers, although not necessarily an answer, making them active participants of the genre.

The main function of asking questions in my dataset is to prompt readers to reflect (see Section 6.3). Interview data is consistent with my findings. For example, when I asked Tina, a non-reader of self-improvement books, what she thought the reason was that people read these books, she said:

These books give them questions that they can ask about their lives. (February 5, 2013; Face-to-face interview)

Tina's comment suggests that self-improvement authors use questions to prompt readers to think about their lives. This implies that being engaged with the genre is similar to reflecting on questions that self-improvement authors ask.

Self-improvement authors also ask questions to introduce new ideas (see Section 6.3). In research articles, Hyland (2005b, p. 185) states that questions arouse interest and 
encourage readers to explore an unresolved issue with the writer as an equal, a conversational partner. Similar to researchers, it can be said that self-improvement authors arouse readers' interest and curiosity by introducing new ideas with questions. Consider this example:

4) What is a compelling vision? What does it look like? Simply put, a compelling vision is a story - a descriptive, detailed account of the future you are working towards. (Barrett, 2013)

This example illustrates how authors use questions to construct readers as curious audience. These questions can also be viewed as questions that readers ask. Similar to directives, questions can make the dialogical aspect of self-improvement books more visible.

Unlike Strong and Baron (2004) who found that 33 percent of the suggestions veteran teachers give are in a form of questions, self-improvement books rarely use questions in their suggestions. My analysis shows that almost none (two out of 479 questions) of the questions I analysed are used for recommending solutions. Rather than using questions for this purpose, self-improvement authors use imperative clauses, which are more direct.

\subsubsection{Aphorisms and pull-quotes}

Aphorisms and pull-quotes are typical features in body chapters that authors use to engage readers in presenting their message, or as part of Hyland's (2005b, p. 176) definition of engagement, to focus readers' attention. In an interview with Jane, a regular reader of the genre, for example, I asked her to describe her experience reading selfimprovement books. She said:

I like aphorism, little statements. Often when I read a self-help book, I will take away a message that I really like and I will stick it on my fridge. (March 19, 2013; Face-to-face interview)

Jane's comment suggests that aphorisms are an important feature of self-improvement books because they are concise and are probably the core of authors' message. This feature also appears to be crucial in terms of presenting a message because they seem to be what readers take away from their reading. 
Pull-quotes are recognisable by their formatting and they can be aphorisms or statements that authors want to highlight in their books. Aphorisms play an important role in presenting the message, and pull-quotes make them visually obvious. They usually have a bigger font size compared to that of paragraphs and are placed in boxes (see Section 5.3). While aphorisms are used to focus readers' attention, they also contribute to authors' credibility. They distance authors from their claims making them appear to be objective.

\subsubsection{Stories}

Another strategy that authors use to engage readers is telling stories. Viewing stories from authors' perspective, author interview data suggests that the purpose of telling stories is to sustain readers' interest and attention. As presented in Section 5.5, when I asked John, a self-improvement book author, what he thought were crucial elements in selfimprovement books, he replied:

I think stories are key. People relate to stories. I have tried to read some self-help books and as soon as they get all preachy, I lose interest. I like to read about stories. So I think that is key. (July 13, 2013; Email)

Besides sustaining readers' interest, John claimed that people generally relate to stories. His comment suggests that readers seem to disengage when authors appear to be authoritative or "preachy" in their writing, and apparently stories are used to avoid this.

Moving on to readers' perspectives, interview data suggests that some readers are able to identify stories as a feature of self-improvement books. For example, after Ruby, a regular reader of the genre, described people who read the genre, without being prompted she said:

You have snappy little anecdotes, personal anecdotes, inspirational stories of I was lost but now I'm found, or I was in my garden and my son said something to me. At that point, I realised my life was...you know. (April 17, 2013: Face-to-face interview)

Ruby's comment also suggests that not only are readers aware of this feature, they seem to recognise that some stories in self-improvement books have a complication-resolution 
structure. This is consistent with the analysis of stories in Section 5.5.2. My analysis shows that all the stories that I analysed were exempla because they are told to convey a point and some of them (11 out of 36 exempla) have a narrative structure (i.e., complication-resolution structure). It seems from Ruby's comment that exempla with or without narrative structures can be inspiring as long as they convey a point (e.g., now I'm found, I realised my life was...).

Stine (1997), an editor of self-improvement books, recommends that it is necessary to make sure the stories are "clearly embodying the points you wish to make" (p. 111) and my analysis shows that the point is most explicitly presented in the coda move. This implies that the coda move is central in stories in self-improvement books. Stine (1997) also recommends authors to specifically "share stories of those who have benefited" from their message and she explains that when readers "read about people like themselves who have experienced healing and growth, readers become eager to see whether your approach will produce the same results in their own lives" (p. 111). Again, regarding Stine's claim as an insider's perspective, it seems to explain why all the stories I analysed are exempla.

Although the coda moves play an important role in conveying the point, they are not obligatory (31 out of 36 exempla) in the stories I analysed. To understand why this move is not obligatory, move analysis of body chapters shows that stories are a resource that authors use to support their claims of effectiveness (see Section 5.3). Such stories are found in Step 6: Supporting author's claim of effectiveness, a typical step in Move 4: Presenting the message. Because Step 1: Stating the message and Step 2: Explaining the message are placed before authors present the "evidence" for their claims, the point of the stories would have been announced before. This arrangement makes the coda move less necessary in terms of the role it plays.

The analysis of coda moves in Section 5.5.2.2 shows that authors use a number of resources to present their point in these moves ranging from direct ways to indirect ways. In a most direct way, authors use the personal pronoun, you, to present their message to readers. The inclusive-we is used for a less direct effect and perhaps to construct solidarity with readers. For presenting the point in an indirect way, authors use the third person pronoun, they. For the same effect, authors also use relational process, is/are, in declarative clauses to present their message as general statements and finally questions. 
Also, reader pronouns and questions in Hyland's (2005b) system of engagement are present in the coda moves, but directives in the imperative form are not found in any of the coda moves that I analysed. As John commented, because stories are used because they appear to be less "preachy," using directives in the imperative form would defeat the purpose of telling stories. The variety of resources authors use in the coda moves, ranging from direct to indirect ways, implies that authors constantly struggle between presenting themselves as authority figures and striving to construct an equal power relationship with readers.

\subsection{Author-reader relationship}

As stated above, the author-reader relationship in self-improvement books is a complicated one because while it is important for authors to construct themselves as authority figures, they also construct readers as being equally powerful to them.

An analysis of modal verbs (see Section 6.4) shows that authors use predominantly possibility modality (47\%) to present their advice as options and results as possible outcomes. Consider this example from my data:

1) There are strategies which can help you to transform your life. (Pearson, 2012) Example 1 shows how can is used to present the strategies as possible ways to transform one's life. Using possibility modality, the advice or strategies are presented as options and alternatives rather than the only solution that readers are obliged to accept for life transformation. As discussed in Section 4.1.4, some authors prefer to present their advice as options rather than prescriptions because they perceive their readers as "fully functioning adults." This is an example that I discussed in Section 4.1.4. In describing how Peter viewed his role as a self-improvement author, he said:

I viewed myself not as a self-help author in a normal sense. My basic approach is to treat people as fully functioning adults. I just like to think of it as giving you some tools and say here they are. You may find it useful but it's not telling you what to do, when to do...I think a peer, a friend or a confidant in some ways. (June 24, 2013; Face-to-face interview) 
Peter's comment suggests that presenting advice as options rather than absolutes is a way to construct an equal power relationship (i.e., peer, friend, confidant) with the readers. In Peter's comment itself, he used may, a possibility modality, to construct the "tools" as being possibly useful to readers. This suggests that Peter anticipated readers who find his advice not useful and implies that readers are constructed as having autonomy to decide whether a piece of advice is useful or not. As discussed in Section 7.5.2.1, my observation supports Woodstock's (2006) claim that fostering closeness with the readers is a way to gain credibility.

The idea of closeness is evident in the author interview data. One author explicitly described a reader-author relationship as a close one because he wanted to be approachable. When I asked Barry to describe his relationship with his readers, he said:

It's pretty close I guess. I want people to feel I'm approachable. I'm really trying to build a community of people who I can talk to and I can learn from. (July 30, 2013; Skype interview)

Based on Barry's comment, it seems constructing closeness and appearing to be approachable are viewed as important characteristics of self-improvement authors. The expression "I can talk to and I can learn from" suggests that an equal power relationship is desirable.

Similar to how veteran teachers express their suggestions in mentoring conversations predominantly (38\%) as possibility (Strong \& Baron, 2004), self-improvement authors seem to construct their advice in that way. Strong and Baron (2004, p. 53) suggest that veteran teachers, as mentors, use indirect ways such as possibility in presenting their advice to encourage beginning teachers to be "reflective practitioners" and to develop trust between the mentor and beginning teachers. Although some author interviewees avoid being perceived as mentors, trust seems to be an important element. Peter's comment expresses this idea most explicitly. As a follow up question to his comment that he did not view himself as "a self-help author in a normal sense," I asked him how he would label himself. He said:

I think a peer. I'd like to call what I'm doing peer based discussion. I don't like the word mentoring. (June 24, 2013; Face-to-face interview) 
Peter's considered himself to be a peer and a confidant to his readers. These roles suggest the importance of being trustworthy as authors. It seems from author interview data that authors want to appear to have an equal power relationship with their readers and be trustworthy people. Similar to Strong and Baron (2004, p. 53), it seems authors use possibility modality in presenting their advice as a means to foster trust. The idea of trust is also evident in Barry's comment that he wanted to be approachable.

From a modality perspective, the absence of obligation modality and almost no occurrence of permission modality in my data (see Section 6.4) suggest that authors do not present themselves as demanding authority figures or "preachy" (see Section 7.5.2.5). In other words, the lack of intrinsic modality implies that authors rarely demand their readers to subscribe to their advice. The high occurrence of extrinsic modality suggests that authors present their advice as necessary or relevant based on logical reasoning. The analysis of modality shows that rather than imposing authors' ideas on their readers, advice is presented as commonly agreed ideas, constructing the author-reader relationship as equal power relationship.

Although using imperative clauses may come across as being authoritarian and demanding, these clauses do not always behave that way. As Downes (1977, p. 78) points out, "sleep well" is an imperative clause that functions as a wish rather than a command. Downes' example demonstrates that imperative clauses do not necessarily imply an authority figure. In another study, Swales et al. (1998) compared imperative clauses in research articles from ten disciplines and their analysis shows that such clauses are found in "the main body of the texts where argumentation takes place, and never occur in the closing section," and they explain that these clauses help readers navigate through an argument. Again, Swales et al.'s explanation does not necessary imply an unequal power relationship between authors and readers. The examples above show that imperative clauses are not a very good indicator for investigating equal/unequal power relationships.

However, imperative clauses are a good indicator for directness. In other words they are typically the most unambiguous form to, as Biber et al. (1999, p. 218) describe, "urge the addressee to do something (or not to do something)." This explanation suggests that selfimprovement authors use these clauses for keeping their advice concise. As discussed in 
Section 4.1.5, Barry's (a self-improvement author) comment captures this idea well when he explained the reason for writing a short book:

That is part of the reason the book that I wrote was very short and very to the point. There is no extra crap in it. It's just like do these 10 things. (July 30, 2013; Skype interview)

As discussed in Section 4.1.5, Barry's comment suggests that presenting advice in a concise way, possibly using imperative clauses, is a feature of the genre. In terms of understanding author-reader relationship, the prominence of imperative clauses in this genre may suggest that authors construct themselves like teachers who want to present what they teach in an unambiguous way. Also, imperative clauses, Biber et al. (1999, p. 218) explain, "are used in contexts where the addressee is apparent." Similar to how teachers teach or address their students in a classroom, self-improvement authors aim to teach their apparent addressees in a same way. There is evidence from author interview data that some authors perceived themselves as teachers (see Section 4.1.4).

My analysis of the functions of questions (see Section 6.3) supports this interpretation. Authors use questions to introduce a new topic and this is similar to a function of questions that Flowerdew and Miller (1997) identified in lectures. This implies that, like lectures, self-improvement books have a teaching purpose. Move analysis of the body chapters (see Section 5.3) also points in the same direction. The obligatory moves in the chapters show that authors always present a problem, then provide a solution to a problem, and encourage readers to apply practical applications they recommend.

However, as well as having something to offer to the students, self-improvement authors such as Tim view themselves as teachers who are constantly learning from their students. For example, when I asked Tim what he thought his role was as a self-improvement author, he said:

My responsibility is to communicate the truth. I view myself as a teacher...I'm a student. I'm a consultant learner. When I go teach something, I get excited what I'm going to learn from people. (October 1, 2013; Skype interview)

Being open to learning new ideas from others' experiences implies that such authors do not necessarily view their advice as the ultimate advice. This implies that these authors welcome disagreement and potential challenges from their readers. This may explain 
why authors use modal verbs to present their message or advice as possibilities (see Section 6.4).

\subsection{Summary of chapter}

My thesis shows that the social purpose of self-improvement books, as a genre, is to help readers improve their lives. The communicative purpose of the genre or what authors attempt to accomplish can be grouped into one of two categories: social action and private intention. Drawing on interview data, social action, one that is socially recognised, is to give advice related to improving one's life and private intention, one that is not socially recognised, is writing a book to gain credibility.

Consistent with the American Dream and American individualism, the quality of one's life in self-improvement books is associated with happiness, fulfilling relationships, and successful careers. Similar to the idea of self-made men and women in these ideologies, this genre places the responsibility of improving one's life on individuals. Also, in neoliberal governments, individuals would have to constantly strive to improve themselves to accumulate wealth so that they can afford healthcare services, for example. The idea that individuals are responsible for improving themselves is a familiar concept in New Age ideology. Because New Agers believe that human beings are divine, they are responsible for the "good" and "bad" things that happen to them. Again, this implies individuals play an active role in improving their status quo. The explanations above show that self-improvement books participate in, draw on, and reinforce the American Dream, American individualism, neoliberalism, and New Age ideology.

In order for improvement to take place, authors recommend readers to change the way they think and then to take actions. To persuade readers to "buy" their advice, it is necessary for authors to construct themselves as credible advice givers. For this purpose, authors draw on aphorisms, their experience as advice givers, and claims of sincere intentions. Authors also foster trust and closeness with the readers, presenting themselves as friends and confidants. As engagement is an aspect of persuasion, authors engage their readers by addressing them using the pronoun, you, using imperative clauses, asking 
questions, and telling stories. To draw readers' attention to key ideas in self-improvement books, authors use pull-quotes to highlight these ideas.

My discussion has shown that rather than being authoritative figures, the author-reader relationship is likened to a mentor-mentee relationship. Like mentors, authors present their advice mainly as possibilities and use questions to prompt their readers. As discussed in this chapter, this way of giving advice is likely to foster trust among the readers. Besides mentors, authors also present themselves as teachers in the way they present their message in a concise and direct way using imperative clauses, and questions to explain their message.

In summary, the core message in self-improvement books is you can change your life. In this genre, improvement is not only possible, but also within readers' ability and hence, responsibility to improve. In the final chapter, I present contributions of this thesis, the limitations, and recommendations for future research. 


\section{Chapter 8: Conclusion}

In analysing self-improvement books as a genre, this thesis has drawn eclectically on three main traditions of genre studies (i.e., English for Specific Purposes, Rhetorical Genre Studies, and Systemic Functional Linguistics). Drawing on these traditions, my thesis has identified the social purpose, social action, and communicative purpose of the genre, including authors' private intentions, as discussed in Chapter 7. To identify these elements, I have identified the obligatory substantive sections (i.e., the introduction chapters, the body chapters, and the about the author section) in self-improvement books and analysed the moves and steps in these sections. These analyses were both situated and driven by an understanding of the context of self-improvement books which included the purposes for writing and reading this genre. This understanding was achieved by means of interviewing authors, readers, and non-readers of the genre, and reviewing literature relevant to the context of the genre (e.g., American Dream, American individualism, neoliberalism). To explore the building blocks of the genre, this thesis employed the concept of register. The register analysis in this thesis has focused on personal pronouns, directives in the imperative form, questions, and modal verbs. At a register level, this research also explored lexicogrammatical features of self-improvement book titles.

As mentioned in Chapter 1, this study was motivated by the desire to understand the characteristics of self-improvement books as potential ESL teaching material because from my past teaching experience, students seemed to engage with the topics that this genre discusses. Going beyond the topics, this thesis has explored linguistic resources that authors use to engage their readers. As self-improvement books have not been studied as a genre, this thesis contributes to the understanding of the genre by presenting a detailed description of its characteristics. In this final chapter, I summarise the findings of this research and discuss the methodological, theoretical, and practical contributions of this thesis. In this chapter, I also discuss the limitations of the study and make recommendations for future research. 


\subsection{Findings summary}

This study has investigated the social purpose of self-improvement books as a genre and identified the linguistic features of the genre. This thesis draws on text analyses and interview data to answer the research questions of this study:

RQ1: What are the characteristics of self-improvement books as a genre?

RQ2: Why do authors write self-improvement books?

RQ3: Why do readers of self-improvement books read this genre?

RQ4: Why do non-readers of self-improvement books not read this genre?

\subsubsection{Findings summary for RQ1}

Genre and register analyses, and interview data show that the main purpose of selfimprovement books as a genre is giving advice to help readers improve their lives, or more specifically in areas related to happiness, relationships, and career. The obligatory substantive sections in self-improvement books (i.e., introduction chapters, body chapters, about the author sections) show that authors "sell" their advice by persuading readers to read the books with the purpose of presenting their message in the body chapters. The most common way of persuading the readers is by listing problems that readers potentially experience. As persuasion is central in "selling" authors' message, authors devote a section (i.e., about the author section) specifically to construct a credible persona. Stories are also a feature of self-improvement books and they are told to illustrate authors' messages.

At a register level, the abundance of the pronoun you suggests that self-improvement books are a reader-oriented genre and the abundance of the same pronoun in the subject position reflects how individuals are constructed as being responsible for improving their lives. Register analysis also shows that your life is the most frequent collocation, indicating the domain of the genre. In terms of engagement, authors frequently use reader pronouns, directives in the imperative form, and questions. The analysis of modal verbs shows that possibility modality is the most common modality type in this genre. This feature suggests that authors present their advice mainly as options. Compared to titles of historical biographies, those of self-improvement books are characterised by imperatives and ing-clauses. 


\subsubsection{Findings summary for RQ2}

For convenience, I repeat the second research question here: Why do authors write selfimprovement books?

Authors write self-improvement books because they want to share their experience. More specifically, they want to share how they have overcome particular obstacles in life and this can be a result of their research or reflection. The purpose of sharing these experiences is primarily, authors claimed, to help their readers improve their lives. Consistent with how Bergsma (2008, p. 342) describes the feel-good industry as a profitable one, some authors write these books for financial gain. Although not typical in my data, one author wrote a book to construct a credible persona with the purpose of boosting his business in organising professional development seminars for corporate companies.

\subsubsection{Findings summary for RQ3 and RQ4}

RQ3: Why do readers of self-improvement books read this genre?

RQ4: Why do non-readers of self-improvement books not read this genre?

Readers read self-improvement books primarily because they want to change or improve their lives. However, some of them might be sceptical about the advice they get from these books because they found the advice to be repetitive. This explains why authors have to convince their readers that the messages in their books are unique. There is also evidence that, to anticipate readers who are sceptical, authors attempt to solicit agreement in their writing and provide "evidence" to support their claims of effectiveness.

Some people do not read this genre because they are not comfortable with the individualistic approach to improving oneself in the genre. Another reason for not reading is the perception that authors are not genuinely interested to help readers but are mainly interested in financial gain. Anticipating this perception, authors had to convince readers in the about the author sections that their intentions for writing were genuine. 


\subsection{Methodological contributions}

This section presents three methodological contributions of my thesis. Genre analysis studies usually recruit only users of the genre as informants, but I recruited non-readers of the genre as informants as well. A second methodological contribution is the procedure I used to recruit interview participants, and a third is how I identified whether interview participants were readers or non-readers of the genre.

\subsubsection{Non-readers of self-improvement books as informants}

This study draws on interview data as a means to triangulate findings from text analysis. Genre analysis studies usually draw on or at least acknowledge the role of ethnographic data in informing text analysis. As Bhatia (2014, p. 180) states, "linguistic perspective alone will only allow one to see part of the elephant." Bhatia (2014, pp. 180-181) states that analysing a genre involves understanding institutional constraints, cultures, relationships between participants of the genre, and their contributions to the process of genre construction.

To understand these aspects, Swales (1990, p. 130) states that having "specialist informants" in a study is useful as a source of "information and insight" and they form part of the ethnographic observation. For example, Yang (2015) studies calls for papers as a genre and his study draws on semi-structured interviews. His specialist informants were six scholars who have experience organising international academic conferences related to applied linguistics (p. 44). These scholars were selected for the interview because they are the immediate users/producers of the genres or part of what Swales (1990, p. 58) calls "expert members" of the "discourse community."

Besides being interview participants, specialist informants are sometimes involved to resolve discrepancies. For example, Martín and León Pérez (2014) compare the moves and steps in the introduction section of research articles in the fields of health sciences and humanities/social sciences. In their study, two researchers identified the moves and steps independently and then they compared the similarities and differences in their analysis. Where there were differences, the researchers discussed and in cases where they could not reach an agreement, they consulted a specialist informant. The specialist informants in their study were selected based on the field. For example, a specialist 
informant from the health sciences would be consulted if they could not come to an agreement on the analysis of a research article from the health sciences. Martín and León Pérez's study is an example of how specialist informants are involved in resolving discrepancies. Similar to Yang's (2015) study, the specialist informants in Martín and León Pérez (2014) were expert members of the community who use the genre in a direct way.

In my study, the specialist informants are self-improvement authors and readers of selfimprovement books. I consider these two groups of participants to be the expert members or immediate users of the genre. The authors "produce" the genre and the readers "consume the genre. However, unlike other studies, I included non-readers of selfimprovement books as my interview participants. This category of interview participants claimed not to have read a self-improvement book or to have had little experience with the genre. I propose that including non-readers of the genre contributes to a "360 degree" understanding of the genre.

For example, author interview data suggests that the communicative purpose of selfimprovement books is presenting advice (see Section 4.2.3). Reader interview data is consistent with author interview data in this regard (see Section 4.1.2). These two groups of participants allow the study to make claims regarding the communicative purpose of the genre. In order to make claims regarding the social purpose of the genre, I propose that the non-reader interview data is crucial. Viewing a genre to have a socially recognised purpose, that is a purpose that society beyond the "expert members" can recognise, the contribution of non-reader interview data is necessary. In my study, consistency between non-reader interview, and author and reader interview data (see Section 4.1.2) allows me to make a stronger claim that the social purpose of selfimprovement books is to help readers improve their lives.

\subsubsection{Recruitment of interview participants}

An effective research design is usually one that is informed by relevant literature.

Literature suggests that some Americans are "annoyed and embarrassed" that selfimprovement books are popular in America (Dolby, 2005, p. 56). This implies that some potential interview participants may not admit they read self-improvement books. This 
poses a problem in recruiting interview participants who read the genre. Literature also shows that females are more likely than males to have a positive attitude towards the genre (Bergsma, 2008, p. 347). This may imply that recruiting male readers of the genre is likely to be more challenging. Anticipating these potential challenges, the recruitment process in my study demonstrates how I addressed them.

I designed an advertisement and had copies of it posted on noticeboards in all public libraries in Wellington City. The advertisement did not state that the study was a selfimprovement book related research. See Appendix 4 for a copy of the advertisement. I designed the advertisement to appear as "neutral" as possible. The advertisement was designed to appear to be looking for people who enjoy reading and the researcher would like to talk about what they read. The way I designed the advertisement makes at least two methodological contributions.

Firstly, the advertisement appearing to be looking for people who enjoy reading potentially helped me to recruit people who read something but not self-improvement books. I refer to this category as non-readers. The purpose of recruiting non-readers of self-improvement books is to understand why people (who read other genres) do not read this genre. It is unlikely that having participants who do not read any genre will be useful for my purpose.

Secondly, presenting the interviewer as wanting to interview participants about the books they read enabled me to recruit participants who may not have participated in the study if they knew the study was about self-improvement books. For example, when I asked Laurence, a non-reader of self-improvement books, about his reading experience, he answered that he liked poetry and history. When I started asking questions that were related to self-improvement books, he said:

Is this research about self-help books? [laugh]... I wouldn't have said yes if you told me earlier this was going to be about self-help books. (February 19, 2013; Face-toface interview)

Laurence's comment implies that presenting the study as a general reading research is an effective way to recruit participants who may not be interested to talk about selfimprovement books. Towards the end of the interview session with, I asked Laurence if he had anything to add. He said: 
Personally, I was a little disappointed on the four examples that you had offer because they are so much out of my experience. That's probably why I have less to say. (February 19, 2013; Face-to-face interview)

Laurence commented that the four books of different genres that I showed him as part of the interview protocol were limited and that he had little to offer in terms of answering my interview questions. Nevertheless, the recording of the interview session provided useful data for the study.

\subsubsection{Identifying readers/non-readers of self-improvement books}

Rather than explicitly asking interview participants whether they read self-improvement books, my study used a more naturalistic approach. Using the term self-improvement book itself is problematic because participants potentially have various ideas of what a selfimprovement book is. In the interview session, I showed the participants four books, each from a different genre: novel, current issue, how-to, and self-improvement. After showing them the books, I asked them to name the genres of the books. Using the term they used, I asked them to talk about their experience reading each genre. I used how they talk about their experience reading self-improvement books as a guide to help me categorise them as readers or non-readers of the genre.

\subsection{Theoretical contributions}

In Section 8.1, I presented the methodological contributions of this thesis in terms of including non-readers of the genre as informants, the way I recruited interview participants, and how I identify whether the participants were readers or non-readers of the genre. Moving on to the theoretical contributions, my thesis proposes that narratives are best viewed as a text type rather than a genre. While narratives are recognised by their complication-resolution structure, stories refer to accounts of sequences of events that may or may not have a complication-resolution structure. The next theoretical contribution is extending Hyland's system of engagement, and my study shows that stories are a resource for engagement in self-improvement books. Although analysing steps in a genre is useful in exploring strategies that writers/speakers use to realise moves, 
particularly within the ESP tradition, my study suggests that the analysis of steps can also indicate what is valuable in a particular culture. Finally, my thesis shows that grammatical realisations of a verb are constrained by process type.

\subsubsection{Are narratives a genre?}

Narrative is a common term in the literature but its definition varies. In the Labovian tradition of narrative analysis, Labov and Waletzky (1967) examine the formal aspects and functional aspects of the simplest form of narrative which they claim is the oral version of personal experience.

Labov and Waletzky (1967, p. 13) explain that the most basic function of a narrative is for "recapitulating experience" but their analysis shows that narratives that serve this function alone are "abnormal." Labov and Waletzky (1967, p. 13) call them "empty or pointless narrative." While focusing on formal aspects of what they call a narrative, Labov and Waletzky (1967, p. 13) state that the function of telling a narrative depends on the "stimulus" that necessitates the narrative. They define a narrative as "any sequence of clauses which contains at least one temporal juncture" (p. 28). Labov and Waletzky's definition implies that narratives are identified primarily by their formal characteristics or structure rather than their functions. Based on their explanation that the function of a narrative varies according to the "stimulus" or social context, it seems reasonable that identifying a narrative based on its structure would be a realistic way. This is not to criticise Labov and Waletzky's work because the purpose of their analysis is to identify the most basic form of narratives rather than to define them as a genre.

From the Systemic Functional Linguistics approach, scholars such as Martin and Rose (2008) examine narratives as a genre and within this tradition, a genre is recognisable by its social purpose. In other words, narratives, within SFL, should be recognisable by their social purpose. See Section 2.4.5 for a discussion of narratives. This is somewhat complicated because while claiming that narratives as a genre are recognisable by their social purpose, Martin and Rose (2008, p. 52) state that the purpose of telling a narrative varies (expressing emotional reaction, conveying a moral point, commenting on the state of affairs). This implies that it would be impossible to identify narratives first and 
foremost by their purpose because these purposes are realised by specific genres (i.e., anecdote, exemplum, observation).

My study proposes the reconsideration of narratives as a genre because the social purpose of a narrative is not always the same and may vary from one narrative to another. The status of narratives as a genre is questionable because identifying a genre based on its structural pattern first and foremost would be inconsistent with the idea that genres are recognisable by their social purpose. However, this is not to say that texts of the same genre do not have similar structural patterns. The idea that narratives are identified by their complication-resolution structure may imply that the term narrative should be used to describe stories of particular storytelling genres (e.g., anecdote, exemplum) that have that particular structure. Christie (1999, p. 761), for example, uses the term "narrative structure" to refer to the orientation-complication-resolution structure. I propose that the term narrative should be used to describe a genre rather than to name a genre. It would be reasonable to say, for example, This exemplum has a narrative structure rather than This is a narrative.

\subsubsection{Extending Hyland's system of engagement - stories}

My study extends Hyland's (2005b) system of engagement to include stories as a resource. Hyland's (2005b, p. 177) system based on text analysis of published research articles and interviews with academics, consists of five categories: reader pronouns, directives, questions, shared knowledge, and personal asides (see Section 2.6.2). Hyland's system is particularly useful for analysing the resources that authors use in their attempt to engage readers, and my study analysed the most unambiguous categories (reader pronouns, directives and questions) in self-improvement books.

Because Hyland's system is one that is derived from an academic context, it can be extended for analysing engagement in other settings. However, my study shows that selfimprovement book authors also use stories as a resource to engage their readers. Interview data suggests that stories seem to be a common resource that authors use and are recognisable as a feature in the genre. For example, after Ruby, a participant who was a regular reader of the genre, explained the reason she stopped reading self-improvement books, she described the characteristics of the genre without being prompted: 
You have snappy little anecdotes, personal anecdotes, inspirational stories of I was lost and now I'm found. Or I was in my garden and my son said something to me. At that point, I realised my life was...you know. (April 17, 2013; Face-to-face interview)

Ruby's comment suggests that the stories in self-improvement books are "inspirational," and I interpret her way of using inspirational to carry meanings of interpersonal engagement. Author interview data also suggests that authors use stories to engage readers (see Section 5.5). While conveying or illustrating a message, stories function as a resource to engage readers within the context of self-improvement book.

\subsubsection{Analysing steps to understand a culture}

Analysing steps in genre analysis within the ESP tradition is an established methodology. ESP genre analysts identify the steps that realise a particular move in a particular genre and present the steps as a resource that learners could use to realise a particular move.

In the analysis of the moves and steps in the about the author section, for example, among the steps that self-improvement authors use to realise the establishing credibility move are reference to areas of expertise, reference to popularity, reference to previous books, and reference to passion. Besides providing novice authors with resources they could use to establish credibility, these steps indicate what the culture views as valuable and shed light on the underlying ideologies of self-improvement books. To illustrate this claim, consider the steps that Ding (2007) identifies in her dataset of application essays to medical and dental schools. Ding's (2007, p. 378) analysis shows that the steps that applicants use to establish credentials are listing academic achievements, reviewing research experiences related to medicine/dentistry, and discussing professional experiences in clinical settings. A comparison between the two genres indicates that steps that self-improvement authors use and those that the applicants of medical and dental schools use are different. To illustrate this point, it would be inappropriate and perhaps unacceptable for applicants to refer to their popularity, for example, as a means to construct a credible persona. The differences in terms of the steps they use to realise a particular move indicate that what is desirable or viewed as valuable is genre specific. 
My study has extended the purpose of analysing the steps of a particular genre from teaching applications to understanding the cultural and ideological aspects of a genre. This implies that move and step analysis can be a useful research tool or means of triangulation for researchers who analyse ideology. While corpus linguistics is gaining popularity among critical discourse analysts to make their research more empirical, move analysis has not been used for the same purpose, to my knowledge. I propose that incorporating move analysis in critical discourse analysis (CDA) is an innovation that CDA researchers can consider as a potential tool.

\subsubsection{Behavioural process and existential process}

My study analysed directives in the imperative form and categorised them according to Halliday's process types (e.g., material, mental, verbal) (see Section 6.2). My analysis did not find any behavioural processes and existential processes in the imperative form. Behavioural processes are processes of physiological and psychological behaviour (Eggins, 2004, p. 233), and these processes are always reflexes and non-volitional. In other words they cannot be performed voluntarily. Existential processes "represent experience by positing that 'there was/is something"' (Eggins, 2004, p. 238). When there in there was/is refers to a location, the process is not an existential process.

My study shows that behavioural processes do not occur in the imperative form because they cannot be voluntarily performed. This shows that one cannot be instructed to perform a behavioural process in a meaningful way. For example, if a doctor asks a patient to breathe, it is unlikely that the doctor is referring to non-volitional breathing. Existential processes also do not occur in imperative form in my study, and it seems likely that they cannot occur in that form.

Thus, as a theoretical contribution, my study has extended our understanding of how verbs behave grammatically in terms of their process types and their occurrence in imperative forms. 


\subsection{Practical applications}

Sections 8.1 and 8.2 have respectively presented the methodological and theoretical contributions of my study. This section moves on to present three practical applications of the study. The findings of this study serve as a resource for new self-improvement authors and propose the possibility of using texts from self-improvement books as potential teaching material in a language classroom.

\subsubsection{A resource for new self-improvement book authors}

My study has analysed textual features of self-improvement books as a genre. This includes identifying the sections in self-improvement books (e.g., contents page, introduction chapter, body chapter, about the author section), analysing how chapters are typically structured by identifying the moves and steps, analysing the lexicogrammatical realisations of self-improvement book titles, and analysing the resources that authors typically use to engage their readers.

A self-improvement author was in the process of rewriting one of the books he wrote and recently consulted me regarding the title of his new book. We discussed the typical lexicogrammatical features of self-improvement book titles (see Section 6.3) and explored the relationship between the lexicogrammatical features and the underlying ideologies. The same author consulted me on another occasion regarding the resources that selfimprovement book authors typically use to engage readers. He has since commented that the pragmatic functions of questions (see Section 6.4) have been useful to him in his writing.

\subsubsection{Language teaching applications}

The initial motivation for studying self-improvement books was to understand why this genre seemed to have a positive engaging effect on my secondary school students. I also observed that materials from self-improvement books seemed to promote active participation in the ESL classroom, and the positive effect that this genre has on lower English proficiency learners seemed to be more noticeable. As mentioned in Section 1.1, 
some parents commented on how these texts have benefited their children in terms of personal development and interpersonal relationship. These observations initiated my interest to explore this genre. This section discusses the potential that self-improvement books have as teaching material in an ESL classroom.

\subsubsection{Engaging and reader-oriented}

The idea that engagement is a characteristic of effective language teaching materials is a well-established one. Tomlinson (2010) concludes in his study that an engaging learning experience is one that stimulates the mind and emotion, and one that is meaningful and memorable, and McGrath (2013, p. 5) states that content that is engaging is more likely to stimulate communicative interaction. From my observation as a teacher, although not part of my study, self-improvement books seem to have that effect on my students.

Register analysis shows that the abundance of reader pronouns might contribute to explaining why self-improvement books have an engaging effect on students. This feature, Hyland (2010a) explains, is the most explicit way to foster closeness with the readers and is a way to acknowledge readers' presence explicitly. The abundance of the pronoun you and the collocation your life indicates that self-improvement books are a reader-oriented genre. In other words, the content of the genre is mainly about improving your life rather life improvement as a general topic.

Other features such as questions, directives and stories in the genre may also contribute to a positive engaging effect among learners. I propose that questions and directives are features that contribute a more observable dialogic character, in the Bakhtinian sense, to the genre. This is because questions and directives construct an actively participating audience. When a question is asked or when a directive is given, there is an assumption that they are directed to the immediate reader. These engaging elements in selfimprovement books may imply that it is worth considering using this genre as ESL teaching material. 


\subsubsection{Authentic material}

Another aspect that makes self-improvement books a potential teaching material is their authenticity. Nunan (1988, p. 99) explains that authentic material is "produced for purposes other than to teach language," and Joy (2011, p. 12) explains that authentic material is beneficial to learners because it exposes learners to naturally occurring language. On the other hand, Joy (2011, p. 12) points out that authentic materials may sometimes require simplification if the language is "unreasonably" complex. The benefit of using self-improvement books as teaching material is not only because it is authentic but also because interview data suggests that readers find the language simple. This genre is particularly useful for learners of lower English proficiency. From my teaching experience, texts that are linguistically manageable often come with topics that appear to be "childish" to secondary school students. On the other hand, topics that are likely to engage and stimulate this group of learners are often linguistically challenging. Selfimprovement books might be an ideal teaching material because they have topics that are often stimulating, based on my observation, and the language is reasonably comprehensible. However, text analysis that examines the complexity of the language would be necessary in order to present this claim more convincingly.

\subsubsection{Opportunities for critical reflection}

While helping learners of English language improve their language skills, generally speaking, is a common goal of most English language teachers, I do not view that as the only goal. I view language education as part of education and human development more broadly. For example, Weare (2002, p. 107) states that the goal of education is "to help learners become reflective and appropriately critical, self-motivated, self-directed and selfdisciplined, and responsible for their own behaviour and learning." Consistent with Weare's view of education, it seems to me that language education should be viewed as a means to promote these characteristics.

In some ways, the topics that self-improvement books discuss seem to promote the values that Weare (2002) mentions. While not suggesting that the advice that self-improvement authors recommend is the "gospel," it might be worthwhile considering the topics the 
genre discusses as prompts in classroom discussion. Such topics may promote useful discussion that promote reflective and critical thinking among learners.

The reader-oriented character of self-improvement books has the potential to help learners relate better to the topics they discuss and serve as a platform for learners to draw on their experience and evaluate the advice in self-improvement books. This implies that self-improvement books may be a useful tool to teach critical reading skills where learners are taught to not just comprehend a particular text but to evaluate, and potentially challenge, the ideas the text presents.

\subsubsection{Teaching material evaluation}

Although engagement is an important criterion for material evaluation (McGrath, 2013; Rubdy, 2003) and a systematic evaluation in selecting materials for language teaching is an important process of curriculum design (Nation \& Macalister, 2009, p. 159), most evaluations tend to use perspective based methodologies. They include using checklists, questionnaires, and interviews. Studies that use discourse analysis methodologies to evaluate course materials are rare.

These are examples of studies that use discourse analysis methodologies to evaluate textbooks. Kearsey and Turner (1999) use genre analysis to examine the moves in a biology textbook to explore how information is presented. Focusing on register, Hyland (1994) examines hedging devices (e.g., modal verbs, lexical verbs) in English for Academic Purpose (EAP) and EST (English for Science and Technology) textbooks. Analysing the ideology in textbooks, Oteiza (2003) examines how history is presented in two Chilean textbooks by analysing grammatical and lexical choices. However, none to my knowledge has examined engagement elements in textbooks using discourse analysis methodologies.

My study proposes that as well as using perspective based methodologies to examine the engagement elements in textbooks, researchers can evaluate such materials more systematically by analysing reader pronouns, directives, and questions. 


\subsection{Limitations and future research}

As with any research, this study has its limitations that provide room for future research. The limitations in this study are mainly methodological. To enhance the study, this section recommends potential future research.

The present study did not consider the role of editors. The need to consider the role of editors in the process of writing self-improvement books was suggested by an interview with an author. When I asked John, an author of the genre, how he viewed himself as a self-improvement author, he replied in his email:

I write from the heart and I am not a perfect writer. You don't have to be. There are people who are awesome at editing and helping you organize your material. The key is to just put your thoughts to paper and fix it up later. (July 13, 2013; Email)

John's comment suggests that editors may have a role in shaping self-improvement books into the characteristics of the genre.

The text analysis in my study draws on interview data and the literature. Future research can draw on relevant ethnographic observations such as data from life coaching sessions and motivation seminars. These data would be useful to better understand selfimprovement at a cultural level.

Future research can explore the presence of self-improvement discourse in various contexts. For example, Erjavec and Volćić (2009) investigated self-improvement discourse in a Slovene president's speeches. Future research can examine other contexts such as political speeches in other countries and graduation speeches. Because authors repeatedly referred to themselves as teachers in the interview data, future research can compare self-improvement literature with classroom teaching discourse.

To investigate my initial motivation to study the genre as potential teaching material in a language classroom, future research can include classroom observation, and learner's and teacher's feedback. Learner's and teacher's perspective of the genre and their experience using the genre in classroom can inform practitioners how self-improvement books can/cannot be as a potential teaching material.

My study did not attempt to study how self-improvement books may have evolved over time. Due to the synchronic focus of my study, the dataset of self-improvement books 
that I collected was based mainly on current bestseller charts. Future study can explore the diachronics of the genre, focusing on how the genre may have evolved and how that relates to societal influences and values.

\subsection{Closing remarks}

My study has described the characteristics of self-improvement books as a genre, and has linked language and social context by focusing on how social purpose is instantiated in text (i.e., self-improvement books). At the ideological level, my study has shown that selfimprovement books are situated within certain ideologies (e.g., the American dream, neoliberalism), and that move and step analysis can be a useful tool in understanding the underlying worldview of a particular genre. My study has also shown that paying attention to lexicogrammatical features is useful in supporting studies in discourse analysis that focus on macro analysis of language.

At a personal level, this study has led me to reflect on the purpose of self-improvement and personal development. The initial motivation for embarking on the $\mathrm{PhD}$ journey was in some ways driven by self-improvement, personal development, upward mobility, selfmade man (in my case), and believing in your dream, but this very journey has led me to a new journey: discovering the ultimate purpose of your life. 


\section{Appendices}

\section{Appendix 1: List of books in the main dataset}

\begin{tabular}{|c|c|c|}
\hline No & Book titles & $\begin{array}{l}\text { Hardcopy }(\mathrm{H}) \\
\text { Softcopy }(\mathrm{S})\end{array}$ \\
\hline 1 & 5 Tools to Change Your World (Oldham, 2012) & $\mathrm{H} / \mathrm{S}$ \\
\hline 2 & 7 Secrets of a Phenomenal L.I.F.E. (Partridge, 2012) & $\mathrm{H} / \mathrm{S}$ \\
\hline 3 & 100 Ways to Boost Your Self-Confidence (Goldsmith, 2010) & $\mathrm{H}$ \\
\hline 4 & A few keys to All Success (Muncy, 2002) & $\mathrm{H} / \mathrm{S}$ \\
\hline 5 & A Kick in the Attitudes! (Glenn, 2008) & $\mathrm{H}$ \\
\hline 6 & Attitudes are Contagious (Mannering \& Mannering, 2000) & $\mathrm{H}$ \\
\hline 7 & Awaken the Giant (Robbins, 1992) & S \\
\hline 8 & Becoming a People of Power (Maxwell, 2006) & S \\
\hline 9 & Break Free of Your Rut (Barrett, 2013) & S \\
\hline 10 & Building Your Legacy (Fritz, 2003) & $\mathrm{H}$ \\
\hline 11 & Fuel (Beavis, 2009) & $\mathrm{H}$ \\
\hline 12 & Here's to Your Success (Keller, 2007) & $\mathrm{H}$ \\
\hline 13 & How to Have a Beautiful Mind (de Bono, 2004) & $\mathrm{H}$ \\
\hline 14 & How Will You Measure Your Life? (Christensen et al., 2012) & $\mathrm{H} / \mathrm{S}$ \\
\hline 15 & Leadership and Self-Deception (The Arbinger Institute, 2000) & $\mathrm{H}$ \\
\hline 16 & Life Code (McGraw, 2012) & S \\
\hline 17 & Life Lifters (Ziglar, 2003) & $\mathrm{H}$ \\
\hline 18 & Live Your Dream (Chapman, 2002) & S \\
\hline 19 & Quiet (Cain, 2012) & $\mathrm{S}$ \\
\hline 20 & Talent is Never Enough (Maxwell, 2007) & $\mathrm{H} / \mathrm{S}$ \\
\hline 21 & Tapping Potential (Lodi, 2000) & $\mathrm{H}$ \\
\hline 22 & The 5 Love Languages (Chapman, 1992) & S \\
\hline 23 & The 7 Habits of Highly Effective People (Covey, 1989) & $\mathrm{H} / \mathrm{S}$ \\
\hline 24 & The 18 Rules of Happiness (Moore, 2013) & $\mathrm{S}$ \\
\hline 25 & The Difference Maker (Maxwell, 2006) & $\mathrm{H}$ \\
\hline 26 & The Eight Facets of a Fulfilling Life (Pearson, 2012) & $\mathrm{H} / \mathrm{S}$ \\
\hline
\end{tabular}




\begin{tabular}{|l|l|l|}
\hline 27 & The Encore Effect (Sanborn, 2008) & $\mathrm{H}$ \\
\hline 28 & The Five Major Pieces to the Life Puzzle (Rohn, 2002) & $\mathrm{S}$ \\
\hline 29 & The Gifts of Imperfection (Brown, 2010a) & $\mathrm{S}$ \\
\hline 30 & The Magic is in the Extra Mile (DiAngi, 2002) & $\mathrm{H}$ \\
\hline 31 & The Mindful Path to Self-Compassion (Germer, 2009) & $\mathrm{S}$ \\
\hline 32 & The Power of Focus (Canfield et al., 2001) & $\mathrm{H}$ \\
\hline 33 & The Power of Negative Thinking (Knight, 2013) & $\mathrm{S}$ \\
\hline 34 & The Power of Positive Thinking (Peale, 1952) & $\mathrm{H} / \mathrm{S}$ \\
\hline 35 & The Seven Wonders That Will Change Your Life (Beck \& Ablow, 2011) & $\mathrm{H} / \mathrm{S}$ \\
\hline 36 & The Shift (Dyer, 2010) & $\mathrm{S}$ \\
\hline 37 & The Wisdom of Sam (Gottlieb, 2011) & $\mathrm{H}$ \\
\hline 38 & Voices in the Family (Gottlieb, 2007) & $\mathrm{H}$ \\
\hline 39 & Wisdom from Sam (Gottlieb, 2011) & $\mathrm{H}$ \\
\hline 40 & You Can be Happy No Matter What (Carlson, 1997) & $\mathrm{H} / \mathrm{S}$ \\
\hline
\end{tabular}




\section{Appendix 2: Examples of interview questions (author)}

1. How long have you been writing?

2. How did you get started?

3. Where do you get your ideas for writing books from?

4. How would you view/describe your potential readers?

5. How would you view yourself as an author?

6. How do you decide which topic to write on?

7. Who writes the about the author section? The author, the publisher or a collaboration?

8. What is the purpose of having the about the author section?

9. How do you decide what goes into the about the author section?

10. What is the purpose of mentioning where an author lives?

11. Who decides what goes on the book cover such as the graphics?

12. Do people achieve guruship before or after a self-help/self-improvement book is produced?

13. What do you think are the crucial elements in a self-help/self-improvement book?

14. I notice that change, life and dream are the main themes in self-improvement books. How would you describe this journey? Or in your opinion, what is the most important aspects in changing our lives or achieving our dreams? 


\section{Appendix 3: Examples of interview questions (reader/non-reader)}

1. In your opinion, why do people read this kind of books?

2. In your opinion, why do people not read this kind of books?

3. In your opinion, why do authors write this kind of books?

4. In your opinion, what are the characteristics of this kind of books?

5. Could you name me a few authors of this kind of books?

6. Do you have friends who read this kind of books?
a) How would you describe them?
b) Why do you think they read this kind of books?

7. Do you have friends who don't read this kind of books?
a) How would you describe them?
b) Why do you think they do not read this kind of books? 


\section{Do you enjoy reading?}

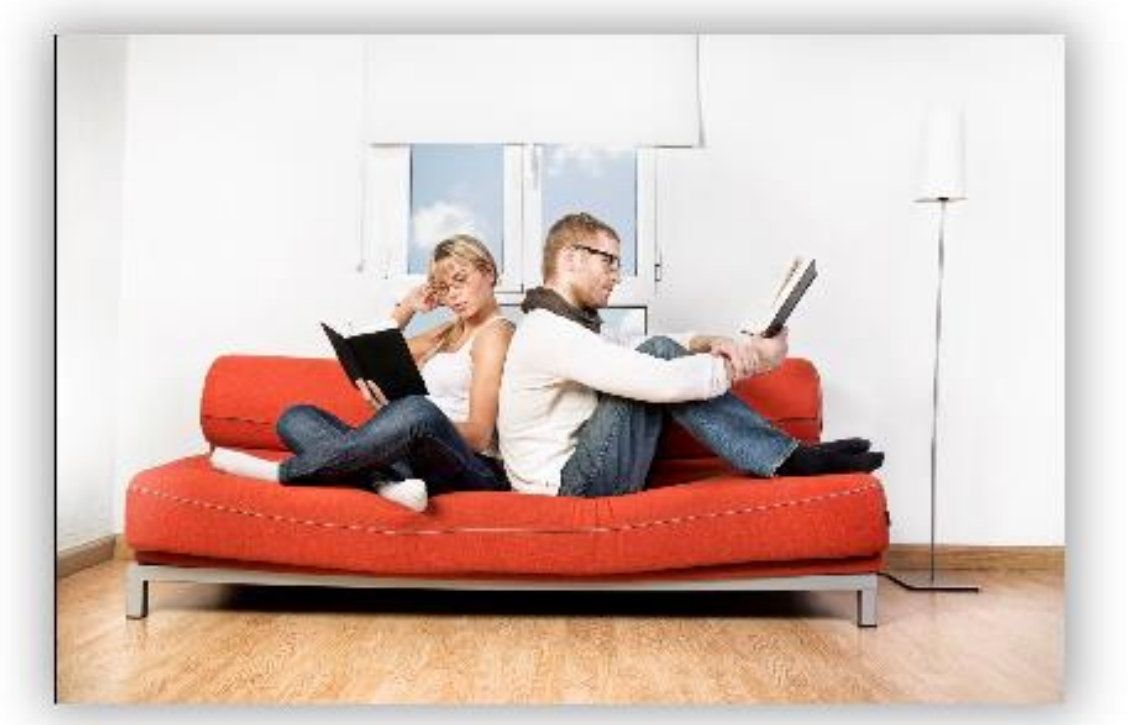

As part of my PhD research project, I would like to talk to you about what you read. We can arrange a time and place that suits you, and we would need no more than an hour. Be part of this research and contact me for more information.

\section{jeremy.koay@vuw.ac.nz}

Jeremy Koay

$\mathrm{PhD}$ researcher

School of Linguistics and Applied Language Studies

Victoria University of Wellington

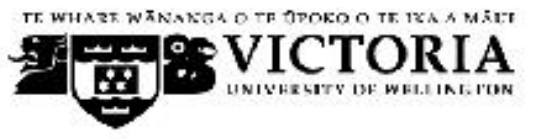

This research has been approved by Victoria University Human Ethics Committee.

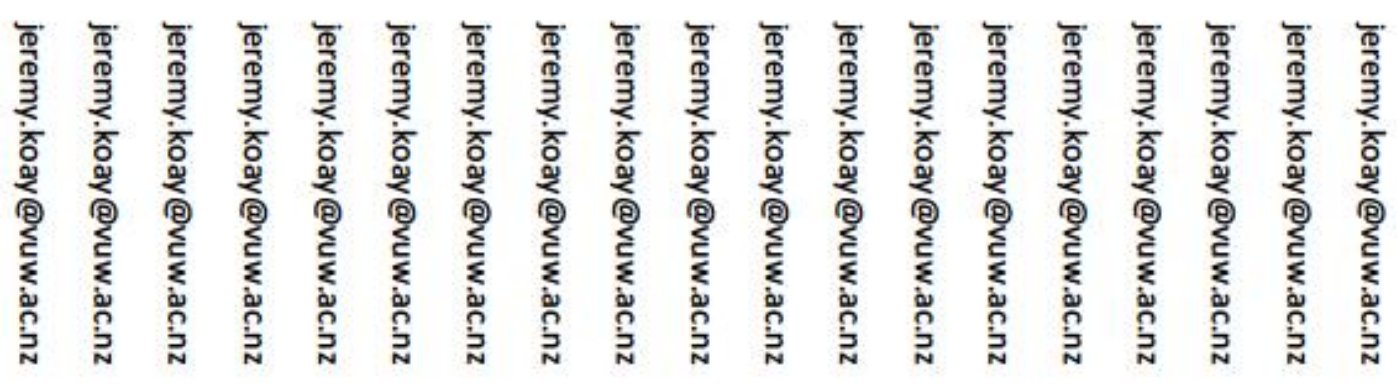




\section{Appendix 5: Ethics approval memorandum}

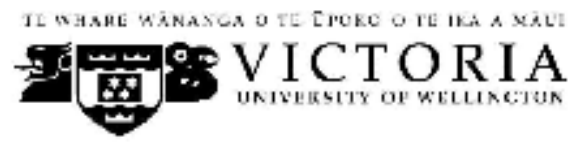

\section{MEMORANDUM}

\begin{tabular}{l|l}
\hline TO & Koay Dong Liang \\
\hline COPY TO & $\begin{array}{l}\text { Jean Parkinson } \\
\text { Elaine Vine }\end{array}$ \\
\hline FROM & Dr Allison Kirkman, Convener, Human Ethics Committee \\
\hline DATE & 5 November 2012 \\
\hline PAGES & 1 \\
\hline \multicolumn{2}{|l}{} \\
\hline SUBJECT & $\begin{array}{l}\text { Ethics Approval: 19496 } \\
\text { Self-help books: a genre analysis }\end{array}$ \\
\hline
\end{tabular}

Thank you for your application for ethical approval, which has now been considered by the Standing Committee of the Human Ethics Committee.

Your application has been approved from the above date and this approval continues until 30 November 2014. If your data collection is not completed by this date you should apply to the Human Ethics Committee for an extension to this approval.

Best wishes with the research

Allison Kirkman

Human Ethics Committee 


\section{Appendix 6: Information sheets and letter of consent}

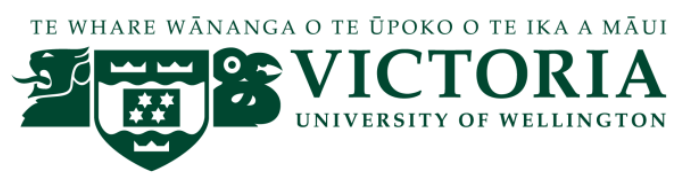

Self-Help Books: A Genre Analysis

INFORMATION SHEET (author)

- This is a $\mathrm{PhD}$ project investigating self-help books as a genre. Victoria University of Wellington requires that research involving human participants is given ethical approval by its Human Ethics Committee. This project has been given such approval.

- You are invited to participate in a semi-structured interview about your experience in writing these books.

- The interview will take no longer than one hour at a mutually agreed time and venue.

- The data you provide will be kept securely (password protected computer) and analysed in the School of Linguistics and Applied Language Studies. The data will be kept for up to five years before being destroyed. Your identity will remain confidential as agreed in the LETTER OF CONSENT.

- Supervisors of the research will have access to the data.

- The data may contribute to conference presentations, research publications and a thesis which will be publicly available.

- You retain the right, however, to withdraw any data provided, up to two months from the date on which you provide such data.

- You may request, by so indicating on the consent form, a summary report of the project, which will be sent to you at the end of the project.

\section{CONTACT DETAILS}

Researcher:

KOAY Dong Liang (Jeremy)

jeremy.koay@vuw.ac.nz

Supervisors:

Dr Jean Parkinson

jean.parkinson@vuw.ac.nz

Dr Elaine Vine

elaine.vine@vuw.ac.nz
School of Linguistics and Applied Language Studies Victoria University of Wellington PO Box 600, Wellington 6140

New Zealand Phone: +64 44635600 


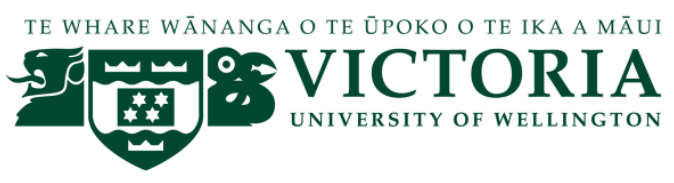

Self-Help Books: A Genre Analysis

INFORMATION SHEET

- This is a $\mathrm{PhD}$ project investigating self-help books as a genre. Victoria University of Wellington requires that research involving human participants is given ethical approval by its Human Ethics Committee. This project has been given such approval.

- The session that you will participate involves a semi-structured interview about your experience with self-help books.

- You may also be invited to participate in a voluntary follow-up in-depth interview.

- The interviews will take no longer than one hour each at a mutually agreed time and venue.

- The data you provide will be kept securely (password protected computer) and analysed in the School of Linguistics and Applied Language Studies. The data will be kept for up to five years before being destroyed. Your identity will remain confidential as agreed in the LETTER OF CONSENT.

- Supervisors of the research will have access to the data.

- The data may contribute to conference presentations, research publications and a thesis which will be publicly available.

- You retain the right, however, to withdraw any data provided, up to two months from the date on which you provide such data.

- You may request, by so indicating on the consent form, a summary report of the project, which will be sent to you when it has been completed.

\section{CONTACT DETAILS}

Researcher:

KOAY Dong Liang (Jeremy)

jeremy.koay@vuw.ac.nz

Supervisors:

Dr Jean Parkinson

jean.parkinson@vuw.ac.nz

Dr Elaine Vine

elaine.vine@vuw.ac.nz
School of Linguistics and Applied Language Studies

Victoria University of Wellington PO Box 600, Wellington 6140

New Zealand

Phone: +64 44635600 
School of Linguistics and Applied Language Studies

PO Box $600 \quad$ Tel: 4635600

Wellington $6140 \quad$ Fax: 4635604

email: jeremy.koay@vuw.ac.nz_ jean.parkinson@vuw.ac.nz elaine.vine@vuw.ac.nz

Self-Help Books: A Genre Analysis

LETTER OF CONSENT

NAME (please print clearly):

I understand the procedure of this research as set out in the INFORMATION SHEET.

I have had an opportunity to ask questions and have had them answered to my satisfaction.

I understand that the data I provide will be stored securely (password protected computer) and analysed in the School of Linguistics and Applied Language Studies at Victoria University of Wellington. Supervisors of this research will have access to the data I provide.

I understand that my identity will remain confidential and pseudonyms will be used.

I understand that within a period of two months after I have given you information, I may withdraw myself or any data or information I have provided from this project, without having to give reasons.

I agree to take part in this research.

Signed:

Date:

Please tick here if you wish to receive a copy of a written summary of the study at the end of the project, and give below an e-mail address to which this summary can be sent:

E mail address to which report can be sent: 


\section{Appendix 7: Copyright permissions letter}

School of Linguistics and Applied Language Studies

PO Box 600

Wellington 6140

NEW ZEALAND

15 January 2015

Dear

My name is Jeremy Koay. I am a Doctoral student at Victoria University of Wellington, New Zealand, and am writing a thesis on self-improvement books for a $\mathrm{PhD}$ in Applied Linguistics. A print copy of this thesis when completed will be deposited in the University Library, and a digital copy will also be made available online via the University's digital repository ResearchArchive. This is a not-for-profit research repository for scholarly work which is intended to make research undertaken in the University available to as wide an audience as possible.

I am writing to request permission for the following work, for which I believe you hold the copyright, to be included in my thesis:

My thesis examines self-improvement books as a genre from a linguistics perspective and I would like to use the above sections as examples in my thesis.

I am seeking from you a non-exclusive licence for an indefinite period to include these materials in the print and electronic copies of my thesis. The materials will be fully and correctly referenced.

If you agree, I should be very grateful if you would sign the form below and return a copy to me. If you do not agree, or if you do not hold the copyright in this work, would you please notify me of this. I can most quickly be reached by email at jeremy.koay@vuw.ac.nz.

Thank you for your assistance. I look forward to hearing from you.

Yours sincerely,

Jeremy Koay

I ........................................ agree to grant you a non-exclusive licence for an indefinite period to include the above materials, for which I am the copyright owner, in the print and digital copies of your thesis.

Signature:

Date: 


\section{References}

Abdollahzadeh, E. (2011). Poring over the findings: Interpersonal authorial engagement in applied linguistics papers. Journal of Pragmatics, 43(1), 288-297.

Adams, J. T. (1931). The epic of America. New York: Little, Brown.

Ainsworth-Vaughn, N. (1994). Is that a rhetorical question? Ambiguity and power in medical discourse. Journal of Linguistic Anthropology, 4(2), 194-214.

Allen, C. (1991). Louise Rosenblatt and theories of reader-response. In J. Clifford (Ed.), The experience of reading: Louise Rosenblatt and reader-response theory (pp. 15-22). Portsmouth: Boynton/Cook.

Anthony, L. (1999). Writing research article introductions in software engineering: how accurate is a standard model? Professional Communication, IEEE Transactions on, 42(1), 38-46. doi: 10.1109/47.749366

APA. (2010). Publication manual of the American Psychological Association. Washington, DC: American Psychological Association.

Askehave, I. (2004). If language is a game - These are the rules: A search into the rhetoric of the spiritual self-help book If life is a game - These are the rules. Discourse \& Society, 15(1), 5-31.

Askehave, I., \& Swales, J. (2001). Genre identification and communicative purpose: A problem and a possible solution. Applied Linguistics, 22(2), 195-212.

Asselin, M. (2000). Reader response in literature and reading instruction. Teacher Librarian, 27(4), 62-63.

Bamberg, M. (2012). Narrative practice and identity navigation. In J. A. Holstein \& J. F. Gubrium (Eds.), Varieties of narrative analysis (pp. 99-124). Los Angeles: Sage. 
Bamberg, M., \& Georgakopoulou, A. (2008). Small stories as a new perspective in narrative and identity analysis. Text \& Talk, 28(3), 377-396. doi: 10.1515/TEXT.2008.018

Basturkmen, H. (1999). A content analysis of ELT textbook blurbs: Reflections of theoryin-use. RELC Journal, 30(1), 18-38. doi: 10.1177/003368829903000102

Bawarshi, A. S., \& Reiff, M. J. (2010). Genre: An introduction to history, theory, research, and pedagogy. Indiana: Parlor Press.

Bax, S. (2011). Discourse and genre: Analysing language in context. Basingstoke: Palgrave Macmillan.

Bazerman, C. (1997). The concept of concepts. Readerly/Writerly Texts, 4(2), 9-20.

Beauvais, P. J. (1989). A speech act theory of metadiscourse. Written Communication, 6(1), 11-30. doi: 10.1177/0741088389006001002

Becker, D., \& Marecek, J. (2008). Dreaming the American Dream: Individualism and positive psychology. Social and Personality Psychology Compass, 2(5), 1767-1780. doi: 10.1111/j.1751-9004.2008.00139.x

Benson, P. (2014). Narrative inquiry in applied linguistics research. Annual Review of Applied Linguistics, 34, 154-170. doi: doi:10.1017/S0267190514000099

Bergsma, A. (2008). Do self-help books help? Journal of Happiness Studies, 9(3), 341-360.

Bhatia, V. K. (1983). Simplification vs. easification: The case of legal texts. Applied Linguistics, 4(1), 42-54.

Bhatia, V. K. (1993). Analysing genre: Language use in professional setting. London: Longman.

Bhatia, V. K. (1997). The power and politics of genre. World Englishes, 16(3), 359-371. 
Bhatia, V. K. (2008). Genre analysis, ESP and professional practice. English for Specific Purposes, 27(2), 161-174.

Bhatia, V. K. (2014). Worlds of written discourse: A genre-based view (2nd ed.). New York: Bloomsbury.

Biber, D. (2006). Stance in spoken and written university registers. Journal of English for Academic Purposes, 5(2), 97-116.

Biber, D., \& Conrad, S. (2009). Register, genre, and style. Cambridge: Cambridge University Press.

Biber, D., Johansson, S., Leech, G., Conrad, S., \& Finegan, E. (1999). Longman grammar of spoken and written English. Essex: Longman.

Borg, E. (2003). Key concepts in ELT: Discourse community. ELT Journal, 57(4), 398400.

Bova, A. (2011). Functions of "why" questions asked by children in family conversations. Procedia - Social and Behavioral Sciences, 30(0), 776-782. doi: http://dx.doi.org/10.1016/j.sbspro.2011.10.151

Brown, P. (1995). Politeness strategies and the attribution of intentions: The case of Tzeltal irony. In E. Goody (Ed.), Social intelligence and interaction (pp. 153-174). Cambridge: Cambridge University Press.

Brown, P. (2010b). Questions and their responses in Tzeltal. Journal of Pragmatics, 42(10), 2627-2648.

Bruce, I. (2008). Academic writing and genre: A systematic analysis. New York: Continuum.

Carlisle, A. (2000). Reading logs: An application of reader-response theory in ELT. ELT Journal, 54(1), 12-19. 
Chang, C.-F., \& Kuo, C.-H. (2011). A corpus-based approach to online materials development for writing research articles. English for Specific Purposes, 30(3), 222234. doi: http://dx.doi.org/10.1016/j.esp.2011.04.001

Charteris-Black, J. (2014). Analysing political speeches: Rhetoric, discourse and metaphor. New York: Palgrave Macmillan.

Cheng, W., \& Cheng, L. (2014). Epistemic modality in court judgments: A corpus-driven comparison of civil cases in Hong Kong and Scotland. English for Specific Purposes, $33(1), 15-26$.

Cheong, E.-Y. (1999). Analysis of sermons delivered by Korean, Filipino and American pastors: The view of genre analysis. RELC Journal, 30(2), 44-60. doi: $10.1177 / 003368829903000203$

Cherry, S. (2011). A critical study of self-help and self-improvement practices. New York: The Edwin Mellen Press.

Cheung, M. (2008). 'Click here': The impact of new media on the encoding of persuasive messages in direct marketing. Discourse Studies, 10(2), 161-189. doi: $10.1177 / 1461445607087007$

Choi, J. M., Vavuris, T. J., \& Ono, M. (2012). Educating the "education president". In L. Esposito \& L. L. Finley (Eds.), Grading the 44th president: A report card on Barack Obama's first term as a progressive leader (pp. 41-57). Santa Barbara, California: ABCCLIO.

Christie, F. (1984). Children writing: Study guide. Geelong, Vic: Deakin University Press.

Christie, F. (1999). Genre theory and ESL teaching: A systemic functional perspective. TESOL Quarterly, 33(4), 759-763.

Connor, U., \& Lauer, J. (1988). Cross-cultural variation in persuasive student writing. In A. C. Purves (Ed.), Writing across languages and cultures (pp. 138-159). Newbury Park, CA: Sage. 
Connor, U., \& Mauranen, A. (1999). Linguistic analysis of grant proposals: European Union research grants. English for Specific Purposes, 18(1), 47-62. doi: http://dx.doi.org/10.1016/S0889-4906(97)00026-4

Coutinho, M. A., \& Miranda, F. (2009). To describe genres: Problems and strategies. In C. Bazerman, A. Bonini \& D. Figueiredo (Eds.), Genre in a changing world (pp. 3555). Indiana: Parlor Press.

Coyle, K., \& Grodin, D. (1993). Self-help books and the construction of reading: Readers and reading in textual representation. Text \& Performance Quarterly, 13(1), 61.

Craven, A., \& Potter, J. (2010). Directives: Entitlement and contingency in action. Discourse Studies, 12(4), 419-442. doi: 10.1177/1461445610370126

Crawford Camiciottoli, B. (2008). Interaction in academic lectures vs. written text materials: The case of questions. Journal of Pragmatics, 40(7), 1216-1231. doi: http://dx.doi.org/10.1016/j.pragma.2007.08.007

Cullen, J. (2003). The American dream: A short history of an idea that shaped a nation. Oxford: Oxford University Press.

Cumming, A. (2013). Multiple dimensions of academic language and literacy development. Language Learning, 63, 130-152. doi: 10.1111/j.14679922.2012.00741.x

Dafouz-Milne, E. (2008). The pragmatic role of textual and interpersonal metadiscourse markers in the construction and attainment of persuasion: A cross-linguistic study of newspaper discourse. Journal of Pragmatics, 40(1), 95-113.

DeCapua, A., \& Dunham, J. F. (1993). Strategies in the discourse of advice. Journal of Pragmatics, 20(6), 519-531.

Ding, H. (2007). Genre analysis of personal statements: Analysis of moves in application essays to medical and dental schools. English for Specific Purposes, 26(3), 368-392. 
Dolby, S. K. (2005). Self-help books: Why Americans keep reading them. Illinois: University of Illinois Press.

dos Santos, V. B. M. P. (2002). Genre analysis of business letters of negotiation. English for Specific Purposes, 21(2), 167-199.

Downes, W. (1977). The imperative and pragmatics. Journal of Linguistics, 13(1), 77-97. doi: $10.2307 / 4175378$

Eggins, S. (2004). An introduction to systemic functional linguistics (2nd ed.). London: Continuum International Publishing Group.

Eggins, S., \& Martin, J. R. (1997). Genres and registers of discourse. In T. A. Van Dijk (Ed.), Discourse as structure and process. London: Sage.

Emihovich, C. A. (1981). The intimacy of address: Friendship markers in children's social play. Language in Society, 10(2), 189-199. doi: 10.2307/4167212

Erjavec, K., \& Volćić, Z. (2009). A Slovene president's self-help discourse: Making Slovenes more positive. Critical Discourse Studies, 6(2), 97-110.

Ervin-Tripp, S. (1976). Is Sybil there? The structure of some American English directives. Language in Society, 5(1), 25-66. doi: 10.2307/4166849

Ewers, H.-H. (1992). Children's literature and the traditional art of storytelling. Poetics Today, 13(1), 169-178. doi: 10.2307/1772796

Flowerdew, J., \& Dudley-Evans, T. (2002). Genre analysis of editorial letters to international journal contributors. Applied Linguistics, 23(4), 463-489. doi: 10.1093/applin/23.4.463

Flowerdew, J., \& Miller, L. (1997). The teaching of academic listening comprehension and the question of authenticity. English for Specific Purposes, 16(1), 27-46. 
Flowerdew, J., \& Wan, A. (2006). Genre analysis of tax computation letters: How and why tax accountants write the way they do. English for Specific Purposes, 25(2), 133 153.

Foreword. (2015). Oxford Dictionaries. Retrieved from http://www.oxforddictionaries.com/definition/english/foreword.

Frank, J. (1989). On conversational involvement by mail: The use of questions in direct sales letters. Text, 9(2), 231-259.

Freed, A. F. (1994). The form and function of questions in informal dyadic conversation. Journal of Pragmatics, 21(6), 621-644. doi: http://dx.doi.org/10.1016/0378$\underline{2166(94) 90101-5}$

Freedman, A., \& Medway, P. (1994). New views of genre and their implications for education. In A. Freedman \& P. Medway (Eds.), Learning and teaching genre (pp. 122). Portsmouth, NH: Boynton/Cook.

$\mathrm{Fu}, \mathrm{X}$. (2012). The use of interactional metadiscourse in job postings. Discourse Studies, 14(4), 399-417.

Georgakopoulou, A. (2007). Small stories, interaction and identities. Amsterdam: John Benjamins.

Gerring, J. (1997). Ideology: A definitional analysis. Political Research Quarterly, 50(4), 957-994. doi: 10.2307/448995

Goodwin, M. H. (2006). Participation, affect, and trajectory in family directive/response sequences. Text \& Talk, 26(4/5), 515-543. doi: 10.1515/TEXT.2006.021

Grodin, D. (1991). The interpreting audience: The therapeutics of self-help book reading. Critical Studies in Mass Communication, 8(4), 404-420. 
Haggan, M. (2004). Research paper titles in literature, linguistics and science: dimensions of attraction. Journal of Pragmatics, 36(2), 293-317. doi: http://dx.doi.org/10.1016/S0378-2166(03)00090-0

Haghverdi, H. R., Biriya, R., \& Alippur, M. (2013). A disciplinary study of colligation: Hard versus soft sciences. International Research Journal of Applied and Basic Sciences, 4(4), 79-805.

Halleck, G. B., \& Connor, U. M. (2006). Rhetorical moves in TESOL conference proposals. Journal of English for Academic Purposes, 5(1), 70-86. doi: http://dx.doi.org/10.1016/j.jeap.2005.08.001

Halliday, M. A. K. (1970). Functional diversity in language as seen from a consideration of modality and mood in English. Foundations of Language, 6(3), 322-361. doi: $10.2307 / 25000463$

Halliday, M. A. K. (1985). Spoken and written language. Oxford: Oxford University Press.

Halliday, M. A. K., \& Matthiessen, C. M. I. M. (2004). An introduction to functional grammar (3rd ed.). London: Hodder Arnold.

Harris, S. (2005). Telling stories and giving evidence: The hybridisation of narrative and non-narrative modes of discourse in a sexual assault trial. In J. Thornborrow \& J. Coates (Eds.), The sociolinguistics of narrative (pp. 215-237). Amsterdam: John Benjamins.

Hartley, J. (2007). Planning that title: Practices and preferences for titles with colons in academic articles. Library \& Information Science Research, 29(4), 553-568. doi: http://dx.doi.org/10.1016/j.lisr.2007.05.002

Hasan, R. (1994). Situation and the definition of genres. In A. Grimshaw (Ed.), What's going on here? Complementary studies of professional talk (pp. 127-172). New Jersey: Ablex. 
Henry, A., \& Roseberry, R. L. (1998). An evaluation of a genre-based approach to the teaching of EAP/ESP writing. TESOL Quarterly, 32(1), 147-156. doi: $10.2307 / 3587913$

Hight, A. J. (2011). The American dream: Illusion of individualism and self-help in Oprah's book club. (Masters), Northeastern University, Boston.

Hirvela, A. (1996). Reader-response theory and ELT. ELT Journal, 50(2), 127-134.

Holmes, J., \& Chiles, T. (2010). "Is that right?" Questions and questioning as control device in the workplace. In A. Freed \& S. Ehrlich (Eds.), "Why do you ask?" The function of questions in institutional discourse (pp. 187-210). Oxford: Oxford University Press.

Holmes, J., \& Marra, M. (2005). Narrative and the construction of prefessional identity in the workplace. In J. Thornborrow \& J. Coates (Eds.), The sociolinguistics of narrative (pp. 193-213). Amsterdam: John Benjamins.

Holmes, R. (1997). Genre analysis, and the social sciences: An investigation of the structure of research article discussion sections in three disciplines. English for Specific Purposes, 16(4), 321-337.

Hopkins, A., \& Dudley-Evans, T. (1988). A genre-based investigation of the discussion sections in articles and dissertations. English for Specific Purposes, 7(2), 113-121. doi: http://dx.doi.org/10.1016/0889-4906(88)90029-4

Hudson, T. (1990). The discourse of advice giving in English: I wouldn't feed until spring no matter what you do. Language \& Communication, 10(4), 285-297. doi: http://dx.doi.org/10.1016/0271-5309(90)90014-3

Hyland, K. (1994). Hedging in academic writing and EAF textbooks. English for Specific Purposes, 13(3), 239-256. doi: http://dx.doi.org/10.1016/0889-4906(94)90004-3

Hyland, K. (1998a). Exploring corporate rhetoric: Metadiscourse in the CEO's letter. Journal of Business Communication, 35(2), 224-245. 
Hyland, K. (1998b). Persuasion and context: The pragmatics of academic metadiscourse. Journal of Pragmatics, 30(4), 437-455.

Hyland, K. (2002a). Directives: Argument and engagement in academic writing. Applied Linguistics, 23(2), 215-239.

Hyland, K. (2002b). Genre: Language, context, and literacy. Annual Review of Applied Linguistics, 22, 113-135.

Hyland, K. (2002c). What do they mean? Questions in academic writing. Text, 22(4), 529-557.

Hyland, K. (2003). Self-citation and self-reference: Credibility and promotion in academic publication. Journal of the American Society for Information Science and Technology, 54(3), 251-259. doi: 10.1002/asi.10204

Hyland, K. (2004a). Disciplinary interactions: Metadiscourse in L2 postgraduate writing. Journal of Second Language Writing, 13(2), 133-151. doi: http://dx.doi.org/10.1016/j.jslw.2004.02.001

Hyland, K. (2004b). Graduates' gratitude: the generic structure of dissertation acknowledgements. English for Specific Purposes, 23(3), 303-324. doi: http://dx.doi.org/10.1016/S0889-4906(03)00051-6

Hyland, K. (2005a). Metadiscourse: Exploring interaction in writing. London: Continuum.

Hyland, K. (2005b). Stance and engagement: A model of interaction in academic discourse. Discourse Studies, 7(2), 173-193.

Hyland, K. (2008). Persuasion, interaction and the construction of knowledge: representing self and others in research writing. International Journal of English Studies, 8(2), 1-23.

Hyland, K. (2010a). Community and individuality: Performing identity in applied linguistics. Written Communication, 27(2), 159-188. 
Hyland, K. (2010b). Constructing proximity: Relating to readers in popular and professional science. Journal of English for Academic Purposes, 9(2), 116-127.

Hyon, S. (1996). Genre in Three Traditions: Implications for ESL. TESOL Quarterly, 30(4), 693-722.

Jessop, B. (2002). Liberalism, neoliberalism, and urban governance: A state-theoretical perspective. Antipode, 34(3), 452-472.

Johnstone, B. (2001). Discourse analysis and narrative. In D. Schiffrin, D. Tannen \& H. E. Hamilton (Eds.), The handbook of discourse analysis (pp. 635-649). Massachusetts: Blackwell.

Joy, J. J. L. (2011). The duality of authenticity in ELT. Journal of Language \& Linguistics Studies, 7(2), 7-23.

Kamler, B., \& Thomson, P. (2008). The failure of dissertation advice books: Toward alternative pedagogies for doctoral writing. Educational Researcher, 37(8), 507-514.

Kanoksilapatham, B. (2005). Rhetorical structure of biochemistry research articles. English for Specific Purposes, 24(3), 269-292. doi: http://dx.doi.org/10.1016/j.esp.2004.08.003

Kanoksilapatham, B. (2007). Introduction to move analysis. In D. Biber, U. Connor \& T. A. Upton (Eds.), Discourse on the move: Using corpus analysis to describe discourse structure (pp. 23-41). Amsterdam: John Benjamins.

Kearsey, J., \& Turner, S. (1999). Evaluating textbooks: The role of genre analysis. Research in Science and Technological Education, 17(1), 35-43.

King, M. L., Jr. (1963). I have a dream. Retrieved from http://www.archives.gov/press/exhibits/dream-speech.pdf.

Koven, M. (2012). Speaker roles in personal narratives. In J. A. Holstein \& J. F. Gubrium (Eds.), Varieties of narrative analysis (pp. 151-180). Los Angeles: Sage. 
Kwan, B. S. C. (2006). The schematic structure of literature reviews in doctoral theses of applied linguistics. English for Specific Purposes, 25(1), 30-55. doi:

http://dx.doi.org/10.1016/j.esp.2005.06.001

Labov, W. (1997). Some further steps in narrative analysis. Journal of narrative and life history, 7, 395-415.

Labov, W., \& Waletzky, J. (1967). Narrative analysis: Oral versions of personal experience. In J. Helme (Ed.), Essays on the verbal and visual arts: Proceedings of the American Ethnological Society (pp. 12-44). Seattle: University of Washington Press.

Labrador, B., Ramón, N., Alaiz-Moretón, H., \& Sanjurjo-González, H. (2014).

Rhetorical structure and persuasive language in the subgenre of online advertisements. English for Specific Purposes, 34(0), 38-47. doi:

http://dx.doi.org/10.1016/j.esp.2013.10.002

Lassen, I. (2006). Is the press release a genre? A study of form and content. Discourse Studies, 8(4), 503-530.

Leikin, M., Ibrahim, R., \& Eghbaria, H. (2014). The influence of diglossia in Arabic on narrative ability: evidence from analysis of the linguistic and narrative structure of discourse among pre-school children. Reading and Writing, 27(4), 733-747. doi: $10.1007 / \mathrm{s} 11145-013-9462-3$

Li, L. J., \& Ge, G. C. (2009). Genre analysis: Structural and linguistic evolution of the English-medium medical research article (1985-2004). English for Specific Purposes, 28(2), 93-104.

Li, Y. (2009). A social and pragmatic analysis of the second person deixis you. Asian Social Science, 5(12), 130-133.

Lichterman, P. (1992). Self-help reading as a thin culture. Media, Culture \& Society, 14(3), 421-447.

Maingueneau, D. (2002). Analysis of an academic genre. Discourse Studies, 4(3), 319-341. 
Manning, T. (2012). The art of successful persuasion: Seven skills you need to get your point across effectively. Industrial and Commercial Training, 44(3), 150-158.

Marley, C. (2002). Popping the question: Questions and modality in written dating advertisements. Discourse Studies, 4(1), 75-98. doi: $10.1177 / 14614456020040010401$

Martin, J. R. (1984). Language, register and genre. In F. Christie (Ed.), Children writing: A reader (pp. 21-29). Geelong, Vic: Deakin University Press.

Martin, J. R. (1992). English text: System and structure. Amsterdam: Benjamins.

Martin, J. R. (1997). Analysing genre: Functional parameters. In F. Christie \& J. R. Martin (Eds.), Genre and institutions: Social processes in the workplace and school (pp. 339). London: Cassell.

Martin, J. R. (2009). Genre and language learning: A social semiotic perspective. Linguistics and Education, 20(1), 10-21. doi: http://dx.doi.org/10.1016/j.linged.2009.01.003

Martin, J. R. (2014). Evolving systemic functional linguistics: Beyond the clause. Functional Linguistics, 1(3), 2-24.

Martin, J. R., \& Rose, D. (2008). Genre relations: Mapping culture. London: Equinox.

Martín, P., \& León Pérez, I. K. (2014). Convincing peers of the value of one's research: A genre analysis of rhetorical promotion in academic texts. English for Specific Purposes, 34(0), 1-13. doi: http://dx.doi.org/10.1016/j.esp.2013.09.002

Mautner, G. (2009). Corpora and critical discourse analysis. In P. Baker (Ed.), Contemporary corpus linguistics (pp. 32-46). London: Continuum.

Mayes, P. (2003). Language, social structure, and culture: A genre analysis of cooking classes in Japan and America. Amsterdam: John Benjamins. 
McAdams, D. P. (2012). Exploring psychological themes through life-narrative accounts. In J. A. Holstein \& J. F. Gubrium (Eds.), Varieties of narrative analysis (pp. 15-32). Los Angeles: Sage.

McGee, M. (2005). Self-help Inc: Makeover culture in American life. Oxford: Oxford University Press.

McGrath, I. (2013). Teaching materials and the roles of EFL/ESL teachers: Practice and theory. New York: Bloomsbury.

McGrath, L., \& Kuteeva, M. (2012). Stance and engagement in pure mathematics research articles: Linking discourse features to disciplinary practices. English for Specific Purposes, 31(3), 161-173. doi: http://dx.doi.org/10.1016/j.esp.2011.11.002

McKay, S., \& Bonner, F. (2002). Evaluating illness in women's magazines. Journal of Language and Social Psychology, 21(1), 53-67.

Miller, C. R. (1984). Genre as social action. Quarterly Journal of Speech, 70, 151-167.

Miller, D. (1967). Individualism: Personal achievement and the open society. Austin: University of Texas Press.

Monroe, M. C., \& Weaver, L. (2005). Enhancing natural resource programs: Designing effective brochures. University of Florida, EDIS publication, 1436.

Morrow, P. R. (2006). Telling about problems and giving advice in an Internet discussion forum: Some discourse features. Discourse Studies, 8(4), 531-548.

Muntigl, P., \& Gruber, H. (2005). Introduction: Approaches to genre. Folia Linguistica, $39(1 / 2), 1-18$.

Nation, P., \& Macalister, J. (2009). Language curriculum design. New York: Taylor and Francis. 
Neiderhiser, J. A., Kelley, P., Kennedy, K. M., Swales, J. M., \& Vergaro, C. (2014). 'Notice the similarities between the two Sets ...': Imperative usage in a corpus of upper-level student papers. Applied Linguistics. doi: 10.1093/applin/amu017

Nugent, W. (2010). Progressivism: A very short introduction. Oxford: Oxford University Press.

Nunan, D. (1988). The learner-centered curriculum. Cambridge: Cambridge University Press.

Nunan, D. (2008). Exploring genre and register in contemporary English. English Today: The International Review of the English Language, 24(2), 56-61.

Oteiza, T. (2003). How contemporary history is presented in Chilean middle school textbooks. Discourse \& Society, 14(5), 639-660. doi: 10.1177/09579265030145005

Ozturk, I. (2007). The textual organisation of research article introductions in applied linguistics: Variability within a single discipline. English for Specific Purposes, 26(1), 25-38. doi: http://dx.doi.org/10.1016/j.esp.2005.12.003

Palmer, F. (1990). Modality and the English modals (2nd ed.). London: Longman.

Paltridge, B. (1996). Genre, text type, and the language learning classroom. ELT Journal, 50(3), 237-243. doi: 10.1093/elt/50.3.237

Paltridge, B. (1997). Genre, frames, and writing in research settings. Amsterdam: John Benjamins Publishing.

Parable. (2015). Oxford Dictionaries. Retrieved from http://www.oxforddictionaries.com/definition/english/parable.

Parkinson, J. (2013). Adopting academic values: Student use of that-complement clauses in academic writing. System, 41(2), 428-442. doi: http://dx.doi.org/10.1016/j.system.2013.03.002 
Parry, R. (2013). Giving reasons for doing something now or at some other time. Research on Language \& Social Interaction, 46(2), 105-124. doi: $10.1080 / 08351813.2012 .754653$

Patrona, M. (2005). Speaking authoritatively: On the modality and factuality of expert talk in Greek television studio discussion programs. Text, 25(2), 233-267.

Philip, B. (2009). Analysing the politics of self-help books on depression. Journal of sociology, 45(2), 151-168.

Polanyi, L. (1989). Telling the American story: A structural and cultural analysis of conversational storytelling. Cambridge: The MIT Press.

Polletta, F. (2012). Analyzing popular beliefs about storytelling. In J. A. Holstein \& J. F. Gubrium (Eds.), Varieties of narrative analysis (pp. 229-250). Los Angeles: Sage.

Posteguillo, S. (1999). The schematic structure of computer science research articles. English for Specific Purposes, 18(2), 139-160. doi: http://dx.doi.org/10.1016/S08894906(98)00001-5

Pradl, G. M. (1991). Reading literature in a democracy: The challenge of Louise Rosenblatt. In J. Clifford (Ed.), The experience of reading: Louise Rosenblatt and reader-response theory (pp. 23-46). Portsmouth: Boynton/Cook Publishers.

Preface. (2015). Oxford Dictionaries. Retrieved from http://www.oxforddictionaries.com/definition/english/preface.

Rauen, F. J. (2009). Relevance and genre: Theoretical and conceptual interfaces. In C. Bazerman, A. Bonini \& D. Figueiredo (Eds.), Genre in a changing world (pp. 56-76). Indiana: Parlor Press.

Rimke, H. M. (2000). Governing citizens through self-help literature. Cultural Studies, 14(1), 61-78. 
Rodgers, D. T. (1982). In search of progressivism. Reviews in American History, 10(4), 113132.

Roitman, M. (2014). Presidential candidates' ethos of credibility: The case of the presidential pronoun I in the 2012 Hollande-Sarkozy debate. Discourse \& Society, 25(6), 741-765. doi: 10.1177/0957926514536835

Rosch, E. (1973). On the internal structure of perceptual and semantic categories. In T. Moore (Ed.), Cognitive development and the acquisition of language (pp. 111-144). New York: Academic Press.

Rose, D., \& Martin, J. R. (2012). Learning to write, reading to learn: Genre, knowledge and pedagogy in the Sydney school. Bristol: Equinox.

Rosenblatt, L. M. (1982). The literary transaction: Evocation and response. Theory into Practice, 21(4), 268-277.

Rubdy, R. (2003). Selection of materials. In B. Tomlinson (Ed.), Developing materials for language teaching (pp. 37-57). New York: Continuum.

Ruiying, Y., \& Allison, D. (2003). Research articles in applied linguistics: Moving from results to conclusions. English for Specific Purposes, 22(4), 365-385. doi: http://dx.doi.org/10.1016/S0889-4906(02)00026-1

Sadeghi, V., \& Samuel, M. (2013). Genre analysis of the letters of appeal. Discourse Studies, 15(2), 229-245. doi: 10.1177/1461445612471467

Samar, R. G., Talebzadeh, H., Kiany, G. R., \& Akbari, R. (2014). Moves and steps to sell a paper: A cross-cultural genre analysis of applied linguistics conference abstracts. Text \& Talk, 34(6), 759-785. doi: 10.1515/text-2014-0023

Samraj, B. (2002). Introductions in research articles: Variations across disciplines. English for Specific Purposes, 21(1), 1-17. doi: http://dx.doi.org/10.1016/S08894906(00)00023-5 
Samraj, B. (2005). An exploration of a genre set: Research article abstracts and introductions in two disciplines. English for Specific Purposes, 24(2), 141-156. doi: http://dx.doi.org/10.1016/j.esp.2002.10.001

Samraj, B. (2008). A discourse analysis of master's theses across disciplines with a focus on introductions. Journal of English for Academic Purposes, 7(1), 55-67.

Scott, S. (2002). Linguistic feature variation within disagreements: An empirical investigation. Text, 22(2), 301.

Self-improvement. (2015). Oxford Dictionaries. Retrieved from http://www.oxforddictionaries.com/definition/english/self-improvement.

Shamsudin, S., \& Ebrahimi, S. J. (2013). Analysis of the moves of engineering lecture introductions. Procedia-Social and Behavioral Sciences, 70(0), 1303-1311. doi: http://dx.doi.org/10.1016/j.sbspro.2013.01.191

Shi, H., \& Wannaruk, A. (2014). Rhetorical structure of research articles in agricultural science. English Language Teaching, 7(8), 1-13.

Silverman, D. (2001). Interpreting qualitative data: Methods for analysing talk, text and interaction (2nd ed.). London: Sage.

Soler-Monreal, C., Carbonell-Olivares, M., \& Gil-Salom, L. (2011). A contrastive study of the rhetorical organisation of English and Spanish $\mathrm{PhD}$ thesis introductions. English for Specific Purposes, 30(1), 4-17. doi: http://dx.doi.org/10.1016/j.esp.2010.04.005

Soler, V. (2007). Writing titles in science: An exploratory study. English for Specific Purposes, 26(1), 90-102. doi: http://dx.doi.org/10.1016/j.esp.2006.08.001

Spence, J. T. (1985). Achievement American style: The rewards and costs of individualism. American Psychologist, 40(12), 1285-1295. doi: http://dx.doi.org/10.1037/0003-066X.40.12.1285 
Stiff, J. B., \& Mongeau, P. A. (2003). Persuasive communication. New York: The Guilford Press.

Stine, J. M. (1997). Writing successful self-help and how-to books. New York: John Wiley \& Sons, Inc.

Strauss, S., \& Feiz, P. (2014). Discourse analysis: Putting our worlds into words. New York: Routledge.

Strong, M., \& Baron, W. (2004). An analysis of mentoring conversations with beginning teachers: Suggestions and responses. Teaching and Teacher Education, 20(1), 47-57. doi: http://dx.doi.org/10.1016/j.tate.2003.09.005

Swain, M., Kinnear, P., \& Steinman, L. (2011). Sociocultural theory in second language education: An introduction through narratives. Buffalo: Multilingual Matters.

Swales, J. M. (1990). Genre analysis: English in academic and research settings. Cambridge: Cambridge University Press.

Swales, J. M. (1998). Other floors, other voices: A textography of a small university building. Mahwah, NJ: Lawrence Erlbaum Associates.

Swales, J. M. (2004). Research genres: Explorations and applications. Cambridge: Cambridge University Press.

Swales, J. M. (2009). Worlds of genre: Metaphors of genre. In C. Bazerman, A. Bonini \& D. Figueiredo (Eds.), Genre in a changing world (pp. 3-16). Indiana: Parlor Press.

Swales, J. M., Ahmad, U. K., Chang, Y.-Y., Chavez, D., Dressen, D. F., \& Seymour, R. (1998). Consider this: The role of imperatives in scholarly writing. Applied Linguistics, 19(1), 97-121. doi: 10.1093/applin/19.1.97

Taboada, M. (2011). Stages in an online review genre. Text \& Talk, 31(2), 247-269. doi: 10.1515/TEXT.2011.011 
Tardy, C. M. (2011). Genre analysis. In K. Hyland \& B. Paltridge (Eds.), Continuum companion to discourse analysis (pp. 54-68). London: Continuum International Publishing Group.

Tessuto, G. (2015). Generic structure and rhetorical moves in English-language empirical law research articles: Sites of interdisciplinary and interdiscursive cross-over.

English for Specific Purposes, 37(0), 13-26. doi:

http://dx.doi.org/10.1016/j.esp.2014.06.002

Thompson, G. (2001). Interaction in academic writing: learning to argue with the reader. Applied Linguistics, 22(1), 58-78. doi: 10.1093/applin/22.1.58

Thornborrow, J. (2000). The construction of conflicting accounts in public participation TV. Language in Society, 29, 357-377.

Thornbury, S., \& Slade, D. (2006). Conversation: From description to pedagogy. Cambridge: Cambridge University Press.

Tomlinson, B. (2010). Engaged to learn: Ways of engaging ESL learners. Advances in Language and Literary Studies, 1(1), 29-55.

Upton, T. A., \& Cohen, M. A. (2009). An approach to corpus-based discourse analysis: The move analysis as example. Discourse Studies, 11(5), 585-605. doi: $10.1177 / 1461445609341006$

US. (1776). Declaration of independence. Retrieved from http://www.archives.gov/exhibits/charters/declaration transcript.html.

van Dijk, T. A. (2009). Critical discourse studies: A sociocognitive approach. In R. Wodak \& M. Meyer (Eds.), Methods of critical discourse analysis (2nd ed., pp. 62-86). Los Angeles: Sage.

van Dijk, T. A. (2011). Discourse and ideology. In T. A. van Dijk (Ed.), Discourse studies: A multidisciplinary introduction (2nd ed., pp. 379-407). Los Angeles: Sage. 
Ventola, E. (2005). Revisiting service encounter genre: Some reflections. Folia Linguistica, $39(1 / 2), 19-43$.

Vine, B. (2009). Directives at work: Exploring the contextual complexity of workplace directives. Journal of Pragmatics, 41(7), 1395-1405. doi: http://dx.doi.org/10.1016/j.pragma.2009.03.001

Viney, L. L., \& Bousfield, L. (1991). Narrative analysis: A method of psychosocial research for AIDS-affected people. Social Science \& Medicine, 32(7), 757-765. doi: http://dx.doi.org/10.1016/0277-9536(91)90301-R

Virtanen, T., \& Halmari, H. (2005). Persuasion across genres: Emerging perspectives. In H. Halmari \& T. Virtanen (Eds.), Persuasion across genres: A linguistic approach (pp. 3-24). Amsterdam: John Benjamins.

Weare, K. (2002). The contribution of education to health promotion. In R. Bunton \& G. Macdonald (Eds.), Health promotion: Disciplines, diversity, and development (2nd ed., pp. 102-126). New York: Routledge.

West, C. (1990). Not just "doctors' orders": Directive-response sequences in patients' visits to women and men physicians. Discourse \& Society, 1(1), 85-112. doi: $10.1177 / 0957926590001001005$

Wilson, D. M., \& Cash, T. F. (2000). Who reads self-help books?: Development and validation of the Self-Help Reading Attitudes Survey. Personality and Individual Differences, 29(1), 119-129.

Wittgenstein, L. (1958). Philosophical investigations. Oxford: Basil Blackwell.

Woodstock, L. (2005). Vying constructions of reality: Religion, science, and "positive thinking" in self-help literature. Journal of Media \& Religion, 4(3), 155-178.

Woodstock, L. (2006). All about me, I mean, you: The trouble with narrative authority in self-help literature. Communication Review, 9(4), 321-346. 
Woodward-Kron, R. (2005). The role of genre and embedded genres in tertiary students' writing. Prospect, 20(3), 24-41.

Xiao, R., \& Cao, Y. (2013). Native and non-native English abstracts in contrast: A multidimensional move analysis. Belgian Journal of Linguistics, 27(1), 111-134. doi: $10.1075 / b j 1.27 .06 x i a$

Yang, W. (2015). "Call for papers": Analysis of the schematic structure and lexicogrammar of CFPs for academic conferences. English for Specific Purposes, 37(0), 3951. doi: http://dx.doi.org/10.1016/j.esp.2014.06.006

Yeo, J. Y., \& Ting, S. H. (2014). Personal pronouns for student engagement in arts and science lecture introductions. English for Specific Purposes, 34(0), 26-37. doi: http://dx.doi.org/10.1016/j.esp.2013.11.001

Young, D. (2008). Radical neoliberalism in British Columbia: Remaking rural geographies. Canadian Journal of Sociology, 33(1).

Zhou, S. (2012). Advertorials: A genre-based analysis of an emerging hybridized genre. Discourse \& Communication, 6(3), 323-346. doi: 10.1177/1750481312446265

Zhu, Y. (2000). Structural moves reflected in English and Chinese sales letters. Discourse Studies, 2(4), 473-496. 


\section{Primary Sources}

Adams, M. (2009). Change your questions, change your life: 10 powerful tools for life and work. San Francisco, CA: Berrett-Koehler.

Bacon, E. (2012). 8 habits of love: Overcome fear and transform your life. New York: Hachette Book Group.

Barrett, D. (2013). Break free of your rut: 10 steps to discovering and breaking the patterns that dominate your life. Glastonbury, CT: Eternal Suffering Society.

Barry, J. (2012). Roger Williams and the creation of the American soul: Church, state, and the birth of liberty. New York: Penguin Group.

Bassett, L. (1995). From panic to power: Proven techniques to calm your anxieties, conquer your fears, and put you in control of your life. New York: HarperCollins.

Beavis, W. (2009). Fuel: The energy you need to succeed. Irvine, CA: Powerborn.

Beck, G., \& Ablow, K. (2011). The seven wonders that will change your life. New York: Threshold Editions - Mercury Radio Arts.

Ben-Shahar, T. (2007). Happier: Learn the secrets to daily joy and lasting fulfillment. New York: McGraw-Hill.

Bennett, A. (2009). How to live on 24 hours a day. Bel Air, CA: Merchant Books.

Brewer, S. (2012). Live longer, look younger. London: Connections.

Britton, D., Page, J., \& Gordon, J. (2012). One word that will change your life. Hoboken, NJ: John Wiley \& Sons.

Brown, B. (2010a). The gifts of imperfection: Let go of who you think you're supposed to be and embrace who you are. Center City, MN: Hazelden. 
Cain, S. (2012). Quiet: The power of introverts in a world that can't stop talking. New York: Random House.

Canfield, J., Hansen, M. V., \& Hewitt, L. (2001). The power of focus. London: Vermilion.

Carlson, R. (1997). You can be happy no matter what: Five principles for keeping life perspective. Novato, CA: New World Library.

Carnegie, D. (1936). How to win friends and influence people. New York: Simon \& Schuster

Carnegie, D. (1944). How to stop worrying and start living. New York: Simon \& Schuster.

Chapman, G. (1992). The 5 love languages: The secret to love that lasts. Chicago, IL: Northfield.

Chapman, J. (2002). Live your dream. Franklin Lakes, NJ: New Page Books.

Christensen, C., Allworth, J., \& Dillon, K. (2012). How will you measure your life?: Finding fulfilment using lessons from some of the world's greatest businesses. London: HarperCollins.

Cover, S. R., Merrill, A. R., \& Merrill, R. R. (1994). First things first. New York: Fireside.

Covey, S. (1989). The 7 habits of highly effective people. New York: Simon and Schuster.

Covey, S. (2009). The 6 most important decisions you'll ever make: A guide for teens. New York: Fireside.

de Bono, E. (2004). How to have a beautiful mind. London: Vermilion.

DiAngi, L. (2002). The magic is in the extra mile. Erie, PA: Larry DiAngi Productions.

Dyer, W. (2010). The shift: Taking your life from ambition to meaning. New York: Hay House. 
Emerson, J. (2012). Giant in the shadows. Springfield, IL: Southern Illinois University.

Fritz, R. (2003). Building your legacy: One decision at a time. Naperville, IL: Inside Advantage.

Germer, C. K. (2009). The mindful path to self-compassion: Freeing yourselffrom destructive thoughts and emotions. New York: The Guilford Press.

Glenn, S. (2008). A kick in the attitudes!: 13 kick'n lessons to re-energize your attitude for personal $\&$ professional success. New Jersey: John Wiley \& Sons.

Goldsmith, B. (2010). 100 ways to boost your self-confidence: Believe in yourself and others will too. Pompton Plains, NJ: Career Press.

Goleman, D. (2013). Focus: The hidden driver of excellence. New York: HarperCollins.

Gottlieb, D. (2007). Voices in the family: A therapist talks about listening, openness and healing. New York: Sterling Publishing.

Gottlieb, D. (2011). The Wisdom of Sam: Observations on life from an uncommon child. New York: Hay House.

Hamilton, M. B. (1987). The elements of the concept of ideology. Political Studies, 35, 1838.

Hosseini, K. (2003). The kite runner. New York: Riverhead Books.

Johnson, P. (2009). Churchill. New York: Penguin Group.

Johnson, S. (1998). Who moved my cheese?: An amazing way to deal with change in your work and in your life. New York: Penguin Putnam.

Jones, J., Wood, P. H., Borstelmann, T., May, E. T., \& Ruiz, V. L. (2011). Created equal: $A$ history of the United States (3rd ed.). New York: Prentice Hall. 
Jones, P. (2011). How to do everything and be happy: your easy-peasy guide to creating happiness. Great Britain: SoundHaven \& Authors Online Ltd.

Katie, B. (2003). Loving what is: Four questions that can change your life. New York: Three Rivers Press.

Keller, J. (2007). Here's to your success. East Norwich, NY: Attitude is Everything, Inc.

Knight, B. (2013). The power of negative thinking: An unconventional approach to achieving positive results. New York: Houghton Mifflin Harcourt.

Lee, I. (2013). Change: Realizing your greatest potential. Sedona, AZ: BEST Life Media.

Lodi, K. (2000). Tapping potential: Achieving what you want with the abilities you already have. Los Angeles, CA: The Catalyst Group.

Mannering, D., \& Mannering, W. (2000). Attitudes are contagious: Are yours worth catching? Green Bay, WI: Options Unlimited.

Maxwell, J. (2009). How successful people think: Change your thinking, change your life. New York: Center Street.

Maxwell, J. C. (2006). The difference maker: Making your attitude your greatest asset. Nashville: Thomas Nelson.

Maxwell, J. C. (2007). Talent is never enough: Discover the choices that will take you beyond your talent. Nashville: Thomas Nelson.

Maxwell, J. C. (2008). The choice is yours. Nashville: Countryman.

Maxwell, J. C., \& Dornan, J. (2006). Becoming a person of influence: How to positively impact the lives of others. Nashville: Thomas Nelson.

McGraw, P. (2012). Life code: The new rules for winning in the real world. Los Angeles: Bird Street Books. 
Meacham, J. (2013). Thomas Jefferson: The art of power. New York: The Random House.

Means, R., \& Wolf, M. (1995). Where white men fear to tread: The autobiography of Russell Means. New York: Martin's Press.

Meyer, J. (2008). Never give up!: Relentless determination to overcome life's challenges. New York: Hachette Book Group.

Millman, D. (1993). The life you were born to live: A guide to finding your life purpose. Novato, CA: New World Library.

Moore, K. (2013). The 18 rules of happiness. London: Inspire3.

Muncy, J. (2002). A few keys to all success: Discovering the best person I can be. Unknown: Few Keys.

Oldham, I. (2012). 5 tools to change your world: Taking control of what you experience. Bloomington, IN: Trafford.

Orloff, J. (2009). Emotional freedom: Liberate yourself from negative emotions and transform your life. New York: Random House.

Partridge, H. (2012). 7 secrets of a phenomenal L.I.F.E. Shippensburg: PA: Sound Wisdom.

Pascal, J., \& Harrison, N. (2008). Who was Abraham Lincoln? New York: Grosset \& Dunlap.

Peale, N. V. (1952). The power of positive thinking: A practical guide to mastering the problems of everyday living. New York: Simon \& Schuster.

Pearson, P. (2012). The eight facets of a fulfiling life. Sydney: Ignis Global.

Renowden, G. (2007). Hot topic: Global warming and the future of New Zealand. Auckland: AUT Media. 
Robbins, A. (1992). Awaken the giant: How to take immediate control of your mental, emotional, physical and financial destiny! New York: Free Press.

Robinson, K. (2013). Finding your element: How to discover your talents and passions and transform your life. New York: Penguin Group.

Rohn, J. (2002). The five major pieces to the life puzzle. Southlake, TX: Jim Rohn International.

Sanborn, M. (2008). The encore effect: How to achieve remarkable performance in anything you do. New York: Random House.

Seligman, M. (1990). Learned optimism: How to change your mind and your life. New York: Vintage Books.

Snow, R. (2013). I invented the modern age: The rise of Henry Ford. New York: Simon \& Schuster.

Summers, A. (1980). Not in your lifetime: The defining book on the J.F.K. assassination. New York: Open Road Integrated Media.

The Arbinger Institute. (2000). Leadership and self-deception: Getting out of the box. San Francisco, CA: Meridien Marketing.

Ziglar, Z. (2003). Life lifters: Moments of inspiration for living life better. Nashville: B \& H. 